ROBERTO EIKI OSHIRO

ESTUDO DA SIMILARIDADE IMPERFEITA EM ESTRUTURAS SUJEITAS A CARREGAMENTOS DE IMPACTO 

ROBERTO EIKI OSHIRO

\section{ESTUDO DA SIMILARIDADE IMPERFEITA EM ESTRUTURAS SUJEITAS A CARREGAMENTOS DE IMPACTO}

Tese apresentada à Escola Politécnica da Universidade de São Paulo para obtenção do título de Doutor em Engenharia 

ROBERTO EIKI OSHIRO

\section{ESTUDO DA SIMILARIDADE IMPERFEITA EM ESTRUTURAS}

SUJEITAS A CARREGAMENTOS DE IMPACTO

Tese apresentada à Escola Politécnica da Universidade de São Paulo para obtenção do título de Doutor em Engenharia

Área de concentração:

Engenharia Mecânica

Orientador: Prof. Dr.

Marcilio Alves 
FICHA CATALOGRÁFICA

Oshiro, Roberto Eiki

Estudo de similaridade imperfeita em estruturas sujeitas a carregamento de impacto / R.E. Oshiro. -- São Paulo, 2010. $110 \mathrm{p}$.

Tese (Doutorado) - Escola Politécnica da Universidade de São Paulo. Departamento de Engenharia Mecatrônica e de Sistemas Mecânicos.

1. Estruturas (Impacto; Modelos) I. Universidade de São Paulo. Escola Politécnica. Departamento de Engenharia Mecatrônica e de Sistemas Mecânicos II. t. 


\section{AGRADECIMENTOS}

Ao professor Marcilio Alves, pela orientação e pelo constante estímulo transmitido durante todo o trabalho.

Aos amigos do GMSIE e a todos que colaboraram direta ou indiretamente, na execução deste trabalho. 



\section{RESUMO}

As leis usuais de redução de escala não produzem bons resultados em estruturas sujeitas a cargas de impacto, gerando uma semelhança imperfeita entre modelo e protótipo. Neste trabalho, utiliza-se a técnica de similaridade não direta através da alteração da velocidade inicial do corpo de impacto, gerando uma resposta do modelo idêntica ao do protótipo. Três fatores que contribuem para a resposta não similar da estrutura em escala são estudados nessa tese: taxa de deformação e modelo com parâmetros geométricos e de material distorcidos em relação ao protótipo. Além disso, mostra-se como a técnica proposta pode ser usada para correção das distorções através da mudança da massa de impacto. Considerandose todos esses elementos, um procedimento abrangente e simples que gera um modelo com comportamento similar ao do protótipo é criado. Para corroborar as hipóteses levantadas durante a tese e estudar o método de correção, três problemas analíticos e dois problemas numéricos são explorados. Em todas as análises, os resultados mostram uma melhora significativa na semelhança entre modelo e protótipo após a aplicação do método de correção apresentado. Ao longo do trabalho, as vantagens e limitações das técnicas desenvolvidas e as principais diferenças em relação a trabalhos anteriores são detidamente discutidas.

Palavras-chave: Impacto. Similaridade. Escala. Estrutura. 



\begin{abstract}
Current scaling laws are not capable of predicting the structural impact response of prototypes from the behavior of the corresponding scaled models. Here, the nondirect similitude technique is employed by changing the initial impact velocity loading so that model and prototype behave the same. Three main factors that contribute to the non-similar response of a scaled structure are investigated: strain rate, model geometry and material parameters distorted in relation to the prototype. Moreover, it is shown how the proposed technique can be applied to alter the impact mass instead of its velocity. By considering all these aspects, it is then created a comprehensive and simple procedure that generates models similar to a given prototype. Three analytical and two numerical problems are used to present the main features of the technique. In all the cases analyzed, after the correction is applied, it was possible to accurately predict the behavior of the structure under analysis by the response of the model. Throughout this work, limitations and advantages of the method are emphasized bearing in mind other published works.
\end{abstract}

Keywords: Impact. Similarity. Scale. Estructure. 



\section{LISTA DE ILUSTRAÇÕES}

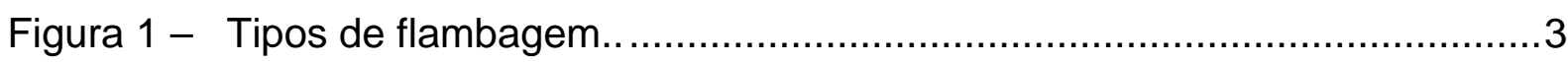

Figura 2 - Identificação das regiões para os diferentes modos de flambagem de um tubo sujeito a um impacto axial. ...................................................... 4

Figura 3 - Simulação de impacto entre dois veículos. …….................................

Figura 4 - Estruturas testadas por Booth, Collier e Miles (1983). .........................10

Figura 5 - Modelos escalonados testados sob impacto: ensaio de queda livre para espécimes de aço "eggbox" e placas guias

Figura 6 - Resultados do estudo realizado por Drazetic et al. (1994) com espécimes apresentando distorção na geometria e nas propriedades materiais

Figura 7 - Evolução do ângulo de rotação da barra em função do tempo adimensional no modelo de Calladine

Figura 8 - Resultados numéricos do escalonamento de tubos de aço impactados à $40 \mathrm{~m} / \mathrm{s}$ na direção axial..

Figura 9 - Comparação da resposta do protótipo com o modelo na simulação de um arco para disparo de flechas com geometria e material distorcidos. 15

Figura 10 - Curva tensão x deformação para aço doce em várias taxas de deformação uniaxial

Figura 11 - Modelo de Calladine.

Figura 12 - Ângulo de rotação em função do tempo adimensional para o modelo de Calladine em diversas escalas.

Figura 13 - Histórico da taxa de deformação para o modelo de Calladine em diversas escalas.

Figura 14 - Ângulo final de rotação como função da energia de impacto para o modelo de Calladine em escalas distintas.

Figura 15 - Viga biengastada sujeita ao impacto de uma massa.

Figura 16 - Deslocamento final adimensional no centro da viga em função do adimensional para diferentes fatores de escala.

Figura 17 - Viga biengastada sujeita a um impulso de velocidade por todo o comprimento .40

Figura 18 - Comparação entre a equação de Norton-Hoff e Cowper-Symonds. 
Figura 19 - Fator de velocidade, $\beta_{V}$, em função da constante material $q$ e diferentes fatores de escala.

Figura 20 - Curva idealizada para o fator de correção da velocidade inicial, $\beta V$, como função do fator geométrico distorcido, $\beta X$ 50

Figura 21 - Resultados para o modelo de viga com a largura distorcida sujeita ao impacto de uma massa.

Figura 22 - Resultados para o modelo de viga com comprimento distorcido sujeita ao impacto de uma massa.

Figura 23 - Resultados para o modelo de Calladine com a largura distorcida.

Figura 24 - Resultados para o modelo de Calladine com o comprimento distorcido 66 Figura 25 - Resultados para o modelo de Calladine com a espessura distorcida.... 67

Figura 26 - Resultados de modelos parcialmente corrigidos, $\beta_{V}=f_{1}=f(\beta)$. 69

Figura 27 - Modelo de Calladine com distorção no comprimento. (a) modelo corrigido quando o expoente é calculado para a condição $\beta_{L} / \beta>1$. (b) modelo corrigido quando o expoente é calculado para a condição $\beta_{L} / \beta<1$.

Figura 28 - Comparação da função $f_{2}$ obtida analiticamente e através da aproximação feita na seção 3.1 para o caso de viga sujeita ao impacto de uma massa.

Figura 29 - Malha da simulação de tubo biengastado sujeito ao impacto de uma massa na direção radial.

Figura 30 - Resultados para a simulação de tubo biengastado sujeito ao impacto de uma massa rígida, escala $\beta=1 / 20$ e $V_{0}=60 \mathrm{~m} / \mathrm{s}$. 76

Figura 31 - Resultados para a simulação de tubo biengastado sujeito ao impacto de uma massa rígida na direção radial. Comparação do deslocamento máximo em função do tempo para $\beta=1 / 10$ e $V_{0}=60 \mathrm{~m} / \mathrm{s}$. 77

Figura 32 - Simulação do casco de navio. (a) malha do casco e do corpo de impacto. (b) estrutura interna. (c) geometria com dimensões em metros. 78

Figura 33 - Configuração deformada final na simulação do casco do navio. (a) Estrutura inteira. (b) Deformação dos reforços internos. 78

Figura 34 - Comparação do deslocamento horizontal máximo do protótipo com modelos em escala 1/100 na simulação do casco de navio 79

Figura 35 - Comparação dos resultados da simulação do tubo com espessura distorcida....... 
Figura 36 - Comparação dos resultados da simulação do casco de navio com a espessura das chapas distorcida.

Figura 37 - Curva de um material elasto-plástico sem encruamento. 83

Figura 38 - Resultados na simulação do casco de navio. Erro do modelo corrigido em relação ao protótipo em função do expoente de $f_{2}$.

Figura 39 - Esquema para a determinação empírica do fator que relaciona os modelos com a estrutura real.

Figura 40 - Curvas da tensão de escoamento dinâmica em função da taxa de deformação para o aço e alumínio.

Figura 41 - Configuração final de deformação para o tubo engastado sujeito a impacto radial e escala 1/20. (a) tubo de aço. (b) tubo de alumínio. 93

Figura 42 - Resultados do modelo de Calladine com a correção feita através da variação da massa. Massa do corpo de impacto e da estrutura corrigidas.

Figura 43 - Erros para o modelo de Calladine com a correção através da variação da massa de impacto.

Figura 44 - Resultados para o modelo de viga biengastada. (a) Comparação do modelo 1/100 com o fator de massa corrigido com o protótipo. (b) Erros do modelo corrigido para diversas razões entre massa da estrutura e corpo de impacto.

Figura 45 - Modelo de Calladine na primeira fase de movimento............................. iii

Figura 46 - Representação de parte da estrutura de Calladine...............................viii 



\section{LISTA DE TABELAS}

Tabela 1 - Relação entre as variáveis do modelo e do protótipo.

.8

Tabela 2 - Resultados para o modelo de barras presas pelas extremidades e sujeitas ao impacto de uma massa.

Tabela 3 - Valores usuais dos coeficientes da equação de Norton-Hoff para vários tipos de materiais.

Tabela 4 - Modelos materiais e aplicações.

Tabela 5 - Matriz dimensional das principais variáveis do fenômeno de impacto. ..23

Tabela 6 - Valores adotados para o protótipo da estrutura de Calladine. .32

Tabela 7 - Comparação das respostas do protótipo e do modelo para a estrutura de Calladine.

Tabela 8 - Valores adotados para o protótipo da estrutura de viga biengastada sujeita ao impacto de uma massa.

Tabela 9 - Valores usados para o protótipo da estrutura de viga sujeita a um impulso de velocidade.

Tabela 10 - Comparação entre os resultados do protótipo e do modelo para a estrutura de viga biengastada sujeita a um impulso de velocidade.

Tabela 11 - Erros no modelo de Calladine.

Tabela 12 - Processo de determinação do valor do expoente $n$ através do uso de dois modelos.

Tabela 13 - Resultados para a estrutura de viga sujeita a um impulso de velocidade. Comprimento distorcido e velocidade não corrigida.

Tabela 14 - Resultados para a estrutura de viga sujeita a um impulso de velocidade. Comprimento distorcido e velocidade corrigida. 53

Tabela 15 - Resultados para a estrutura de viga sujeita a um impulso de velocidade. Altura distorcida e velocidade não corrigida. 56

Tabela 16 - Resultados para a estrutura de viga sujeita a um impulso de velocidade. Altura distorcida e velocidade corrigida. .56

Tabela 17 - Processo de tentativas para determinação de $n$. Modelo de viga com altura distorcida e sujeita a um impacto de uma massa: $\beta=1 / 20$, $\left(\beta_{H}\right)_{1}=0,02$ e $\left(\beta_{H}\right)_{2}=0,04$. 
Tabela 18 - Resultados para a estrutura de viga sujeita ao impacto de uma massa.

Altura distorcida e velocidade não corrigida.

Tabela 19 - Resultados para a estrutura viga sujeita ao impacto de uma massa.

Altura distorcida e velocidade corrigida.

Tabela 20 - Cálculos dos fatores de transposição do modelo de Calladine com largura distorcida.

Tabela 21 - Resultados da estrutura de Calladine: comparação do modelo com largura distorcida com o protótipo. Valores calculados no final do impacto.

Tabela 22 - Resumo dos resultados para a estrutura de Calladine com geometria distorcida

Tabela 23 - Comparação dos resultados dos métodos aplicados na solução do problema de viga sujeita ao impacto de uma massa. Distorção de -60\% na geometria. 70

Tabela 24 - Comparação dos erros do modelo de tubo sujeito ao impacto de uma massa. A comparação é feita nos valores máximos para cada variável.

Tabela 25 - Resumo dos cálculos para determinação do expoente da função $f_{2}$ na simulação do tubo engastado. 80

Tabela 26 - Cálculo dos fatores de transposição do modelo de tubo engastado com espessura distorcida.

Tabela 27 - Resultados da simulação de tubo engastado: comparação do modelo com espessura distorcida com o protótipo. Valores máximos durante a simulação.

Tabela 28 - Resumo dos cálculos para determinação do expoente da função $f_{2}$ na simulação do casco do navio.

Tabela 29 - Comparação das respostas do protótipo e do modelo para a estrutura de Calladine. Protótipo utiliza uma tensão de escoamento quasi-estática $\left(\sigma_{0}\right)_{\mathrm{m}}=235 \mathrm{MPa}$ e modelo emprega $\left(\sigma_{0}\right)_{\mathrm{p}}=100 \mathrm{MPa}$. 88

Tabela 30 - Dados do material na simulação do tubo engastado nas extremidades e sujeito ao impacto de uma massa...... 90

Tabela 31 - Fatores gerados para a simulação do tubo engastado e modelo com material distinto do protótipo. 90

Tabela 32 - Resultados da simulação de um tubo engastado sujeito ao impacto de uma massa. Modelo em escala 1/20 e material distinto do protótipo.... 91 
Tabela 33 - Resultados para o modelo de Calladine quando a correção é feita através da variação da massa do corpo de impacto.

Tabela 34 - Cálculo dos fatores de transposição do modelo de Calladine com comprimento distorcido.

Tabela 35 - Cálculo dos fatores de transposição do modelo de Calladine com espessura distorcida.

xii

Tabela 36 - Resultados da estrutura de Calladine: comparação do protótipo com o modelo com comprimento distorcido. Valores calculados no final do impacto. xiii

Tabela 37 - Resultados da estrutura de Calladine: comparação do protótipo com o modelo com espessura distorcida. Valores calculados no final do impacto. 



\section{LISTA DE SÍMBOLOS}

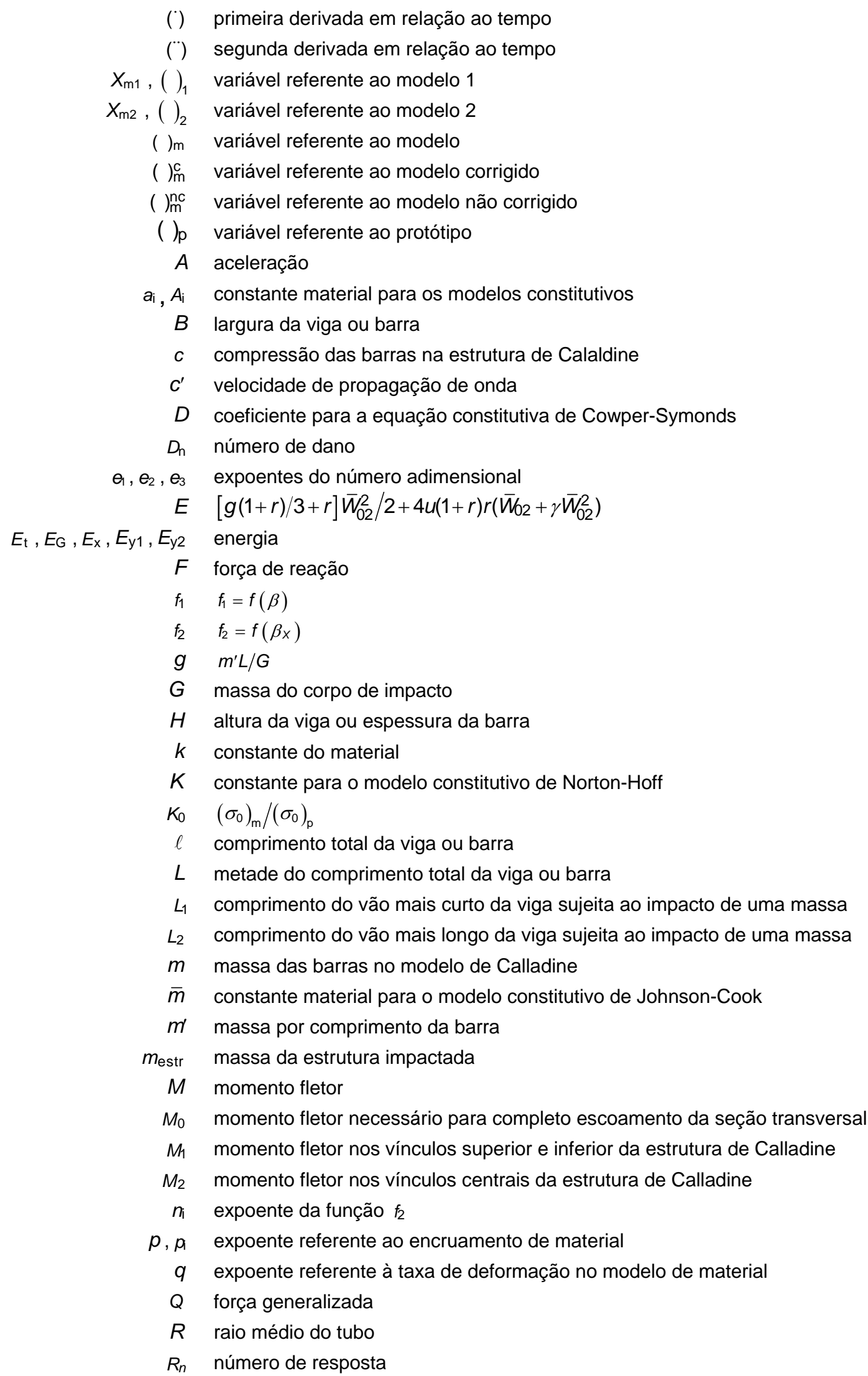




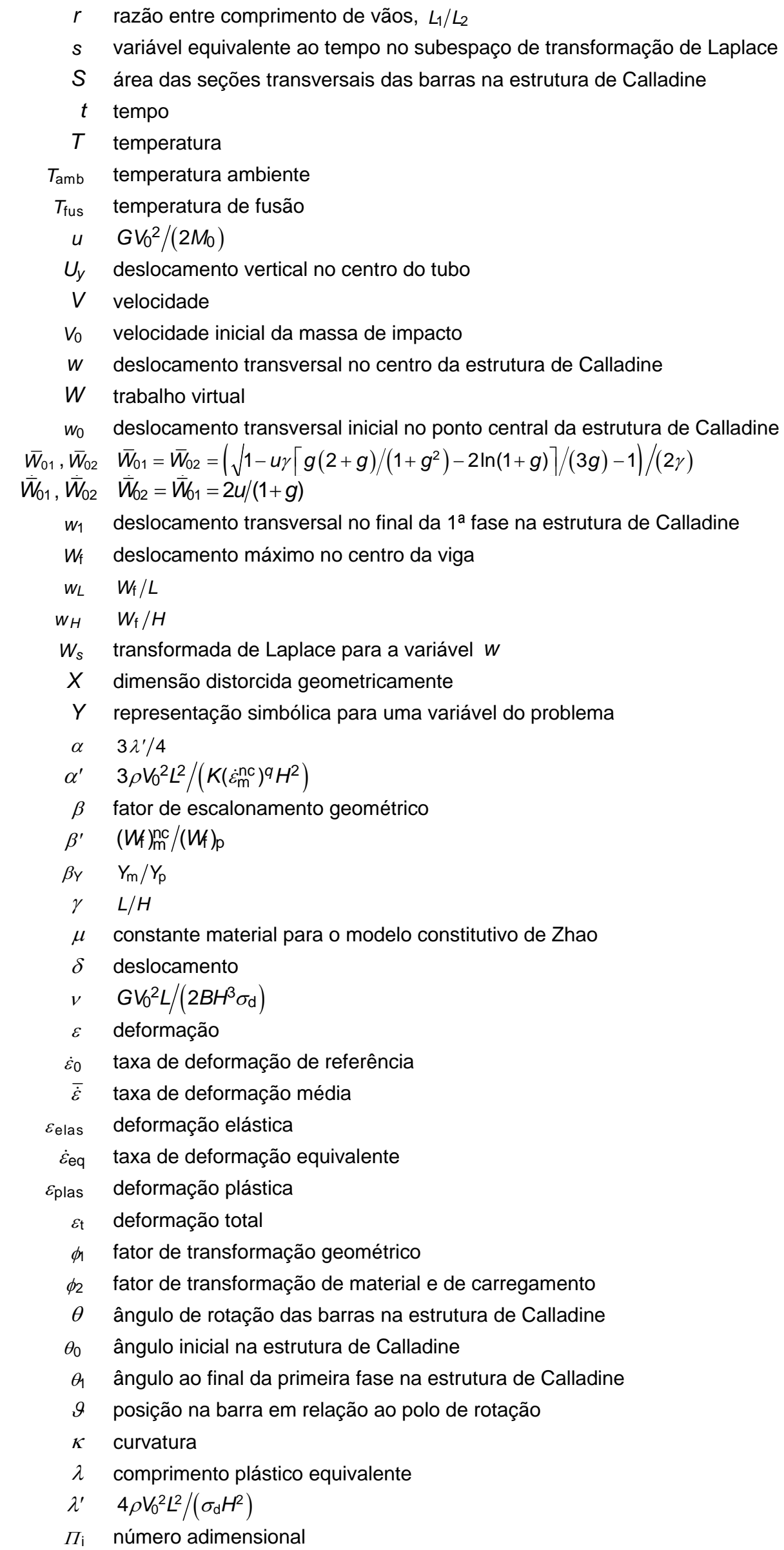


$\rho$ densidade

$\sigma$ tensão

$\sigma_{0}$ tensão de escoamento quasi-estática

$\sigma_{\mathrm{d}}$ tensão de escoamento dinâmica

$\sigma_{\text {true }}$ tensão verdadeira

$\varsigma \quad 12 S \sigma_{\mathrm{d}} /(m \ell)$

$\tau_{1}$ instante do fim da primeira fase no modelo de Calladine

$\tau_{2}$ instante do fim da segunda fase no modelo de Calladine 



\section{SUMÁRIO}

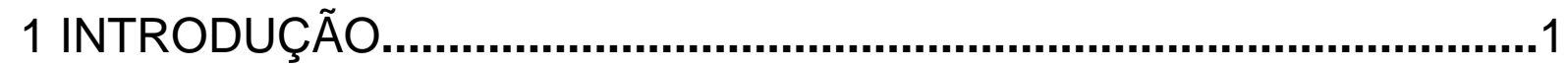

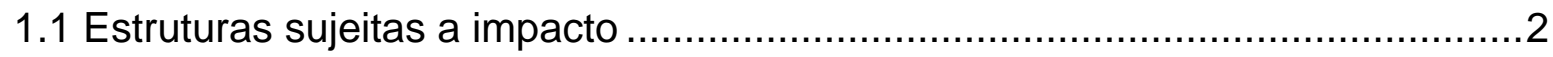

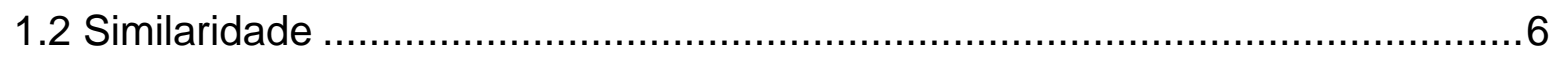

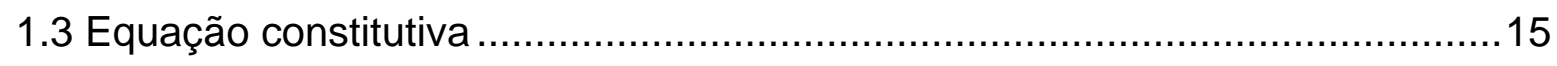

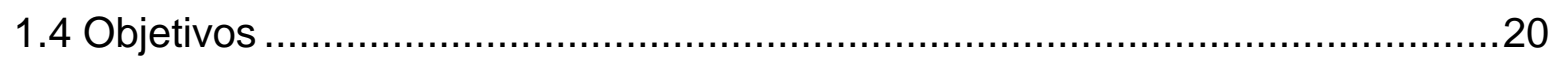

2 MÉTODO DE CORREÇÃO PARA MODELOS SENSÍVEIS À TAXA DE DEFORMAÇÃO ..................................................................................23

2.1 Correção de modelos analíticos..................................................... 26

2.1.1. Modelo de Calladine................................................................ 27

2.1.2 Viga engastada nas extremidades sujeita ao impacto de uma massa......35

2.1.3 Viga engastada em ambas as extremidades sujeita a um impulso de velocidade .................................................................................... 40

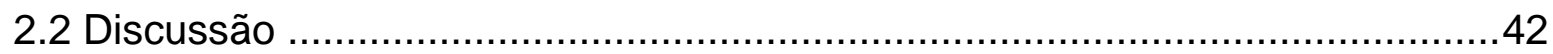

3 MÉTODO DE CORREÇÃO PARA MODELOS COM GEOMETRIA

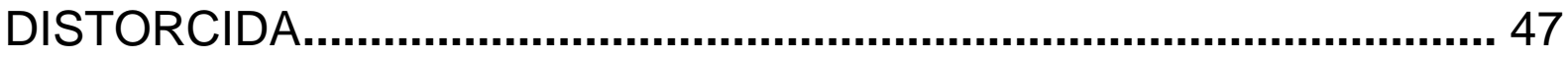

3.1 Método geral para determinação do fator de correção no caso de geometria

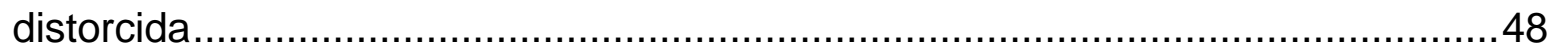

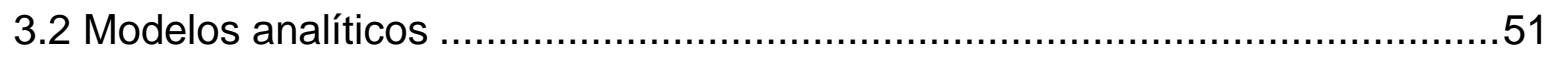

3.2.1 Viga sujeita a um impulso de velocidade por todo o comprimento............52

a) Distorção do comprimento da viga ................................................5

b) Distorção da altura da viga ........................................................ 53

3.2.2 Viga sujeita ao impacto de uma massa no centro ................................56

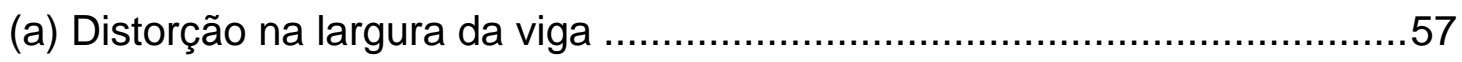

(b) Distorção no comprimento da viga ...............................................59

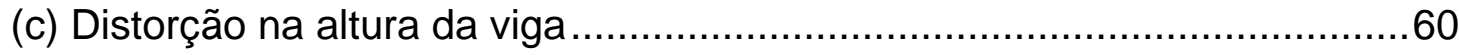

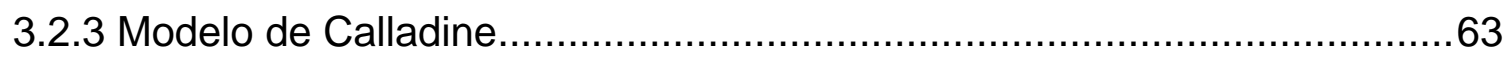

(a) Distorção na largura da barra ................................................. 63

(b) Distorção no comprimento da barra .............................................6 63 


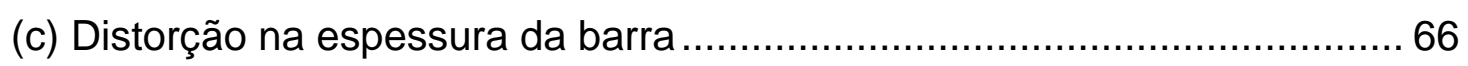

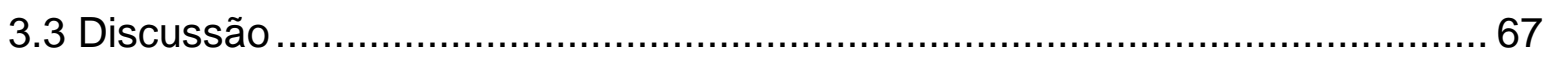

4 MODELOS NUMÉRICOS ................................................................. 73

4.1 Modelo numérico com taxa de deformação.................................................... 73

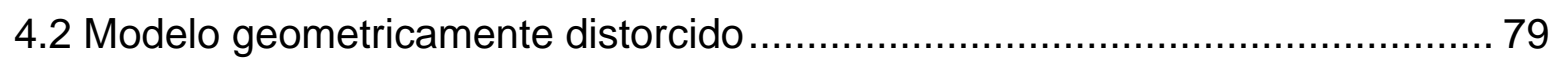

5 VARIAÇÕES DO MÉTODO DE CORREÇÃO .................................... 87

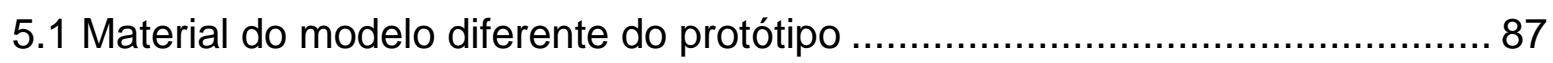

5.2 Correção do modelo através da massa de impacto ........................................ 93

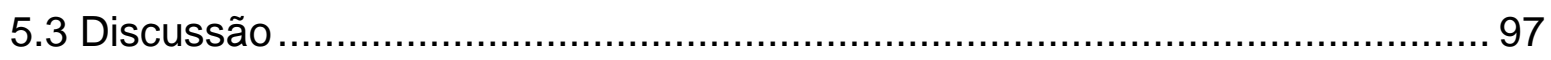

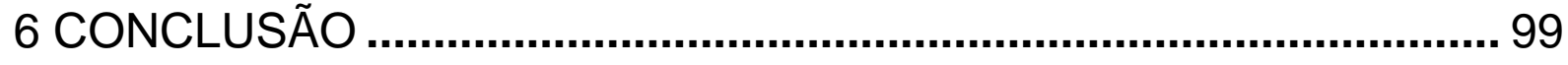

7 REFERÊNCIAS BIBLIOGRÁFICAS ............................................. 103 


\section{INTRODUÇÃO}

A necessidade de se projetar estruturas mais eficientes e que tenham boa capacidade de absorver energia cinética de forma segura faz com que o fenômeno de impacto estrutural seja muito estudado. Idealmente, um sistema sujeito a cargas dinâmicas deve absorver de maneira controlada a energia cinética de modo que a mesma não seja transmitida, por exemplo, aos passageiros, no caso de veículos de transporte. Por isso é necessário estudar o comportamento de estruturas inteiras ou partes dela sob condições de carregamento dinâmico e então definir como elas vão se deformar e quanto de energia cinética podem absorver. A seção 1.1 da Introdução resume vários trabalhos que abordam o carregamento dinâmico em estruturas.

Experimentos com estruturas em tamanho real (protótipo) podem ser inviabilizados se estas possuírem dimensões extremamente grandes ou inversamente, extremamente pequenas. Esta é uma razão importante para testes de modelos em escala. A previsão do comportamento de uma estrutura ou protótipo a partir da resposta de um modelo escalonado ${ }^{1}$ é denominada similaridade ou similitude e constitui o principal foco deste trabalho. Por isso, na seção 1.2 o conceito de similaridade é introduzido e contextualiza-se este estudo em relação à literatura, com ênfase aos trabalhos anteriores do autor.

Uma das razões que dificultam inferir a resposta de um protótipo sujeito a cargas de impacto a partir de dados do modelo é o comportamento dinâmico do material. Por isso, a seção 1.3 faz uma recapitulação de alguns aspectos de equações constitutivas de material. Será mostrado que a escolha da lei que rege o comportamento do material é de vital importância para o desenvolvimento deste trabalho.

Por fim, a seção 1.4 lista os objetivos desta pesquisa, que são paulatinamente perseguidos como descritos ao longo deste texto.

\footnotetext{
${ }^{1}$ No presente trabalho o verbo escalonar será empregado para indicar o ato de ampliar ou reduzir de modo proporcional as dimensões de um corpo, reproduzir em escala geométrica. O mesmo vale para seus derivados: escalonamento, escalonabilidade, escalonado, etc.
} 


\subsection{Estruturas sujeitas a impacto}

É importante conhecer o comportamento da estrutura quando sujeita a um carregamento dinâmico. Se não for bem projetado, um componente pode não conseguir absorver energia cinética suficiente ou colapsar de forma perigosa. Por isso, vários são os trabalhos que estudam o fenômeno de impacto estrutural. Para se modelar o efeito desses eventos nas estruturas envolvidas, utilizam-se experimentos, análise não-linear por elementos finitos e fórmulas analíticas e empíricas.

Impacto é uma área bastante abrangente e engloba desde estruturas simples (vigas, placas, etc.) até complexos sistemas, como os usados na proteção de usinas nucleares. Relatos de acidentes envolvendo aviões, ônibus, trens, navios, etc. são frequentes e por isso a sociedade, as empresas e os órgãos reguladores têm aumentado seu interesse na segurança de estruturas sujeitas a carregamentos dinâmicos.

Os materiais que constituem as estruturas impactadas incluem concreto, metais, polímeros, compósitos, etc. Esses materiais estão sujeitos a velocidades de impacto que podem ser muito baixas, resultando em respostas quasi-estáticas, ou muito altas, fazendo com que suas propriedades se modifiquem de forma significativa devido à viscoelasticidade e viscoplasticidade.

Um carregamento dinâmico produz ondas de tensão plásticas e elásticas que se propagam pela estrutura e podem causar falhas se a carga é suficientemente grande. Esse fenômeno ocorre na mesma ordem de tempo que a onda de tensão leva para se propagar através da estrutura. Portanto, esse tipo de falha geralmente ocorre em microssegundos após o impacto inicial. O tempo total de resposta da estrutura é bem maior e difere significantemente da fase inicial (tipicamente na ordem de milissegundos para estruturas pequenas). Por isso, uma análise mais geral do fenômeno de impacto (que considera o tempo total) não pode ser usada para detalhar o comportamento da fase inicial. Caso a falha ocorra nos instantes iniciais, é necessária uma análise mais detalhada desse trecho.

Um tipo de estrutura que tem sido muito estudada por ser um absorvedor eficiente de energia cinética é o tubo cilíndrico. Jones (1997) identifica dois casos de flambagem de tubos: progressiva (Figura 1 (a)) e dinâmica plástica (Figura 1 (b)). 0 primeiro tipo se caracteriza pela formação de dobras consecutivas que se iniciam 
nas extremidades. Esse caso é geralmente observado para velocidades de impacto menores, quando os efeitos inerciais não são tão significativos e o tempo de duração do carregamento é muito maior que o tempo de transição das ondas elasto-plásticas. O segundo tipo de flambagem se caracteriza pela formação de ondulações permanentes ao longo de todo o cilindro e geralmente ocorre para velocidades maiores de impacto. Um terceiro tipo de colapso é o caso onde o tubo apresenta poucas dobras e colapsa inteiramente em torno de uma ou mais rótulas plásticas (Figura 1(c)). É conhecido como flambagem global.

O impacto axial de tubos tem sido sistematicamente estudado de maneira numérica (KARAGIOZOVA; JONES, 2001a); (KARAGIOZOVA; JONES, 2001b); (KARAGIOZOVA; JONES, 2002); (LANGSETH; HOPPERSTAD; BERSTAD, 1999); (GAMEIRO; CIRNE, 2007), teórica (KARAGIOZOVA; JONES, 1995); (KARAGIOZOVA; JONES, 1996); (LI; JONES, 2000); (WIERZBICKI; ABRAMOWICZ, 1983); (KARAGIOZOVA; JONES, 2008) e experimental (ABRAMOWICZ; JONES, 1997); (ALVES; MICHELI, 2000); (ALVES; MICHELI, 2001); (MENG; AL-HASSANI; SOLDEN, 1983); (REID, 1993). Nesses trabalhos explora-se o modo de colapso dos tubos, a força de pico, a força média ou a capacidade de absorção de energia. Fica demonstrado que vários são os fatores que podem influenciar esses parâmetros, como as condições do impacto, a velocidade e a massa do corpo de impacto, o material da estrutura, a relação de massas entre corpo de impacto e estrutura e a geometria.

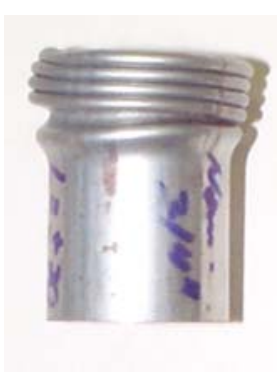

(a)

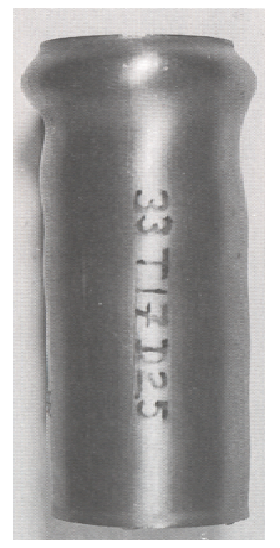

(b)

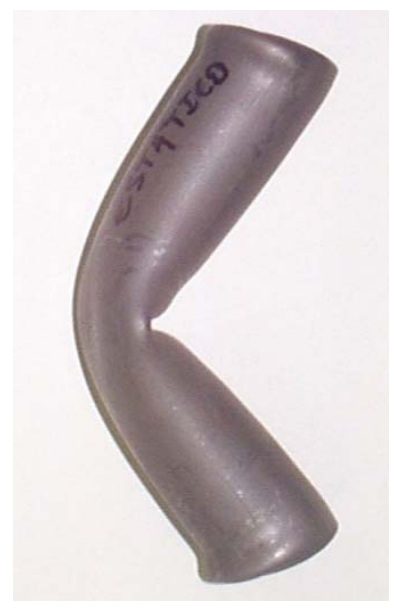

(c)

Figura 1 - Tipos de flambagem. (a) Flambagem dinâmica progressiva (GALLINA, 2004). (b) Flambagem dinâmica plástica (JONES, 1997). (c) Flambagem global. 
Em Karagiozova, Alves e Jones (2000) as faixas de transição entre os modos de colapso de tubos de alumínio foram identificados de forma numérica. Mantendo a mesma energia cinética total, os autores variaram a velocidade inicial e massa de impacto para produzir a Figura 2. Na região "A" ocorre compressão axial uniforme, em "B" uma flambagem plástica dinâmica, em "C1" acontece o início da flambagem plástica dinâmica seguida de flambagem progressiva, em "C2" a flambagem progressiva, "d" é a máxima energia que pode ser absorvida por uma casca feita de material não sensível à taxa de deformação, enquanto "e" identifica a máxima energia quando a estrutura é sensível à taxa de deformação.

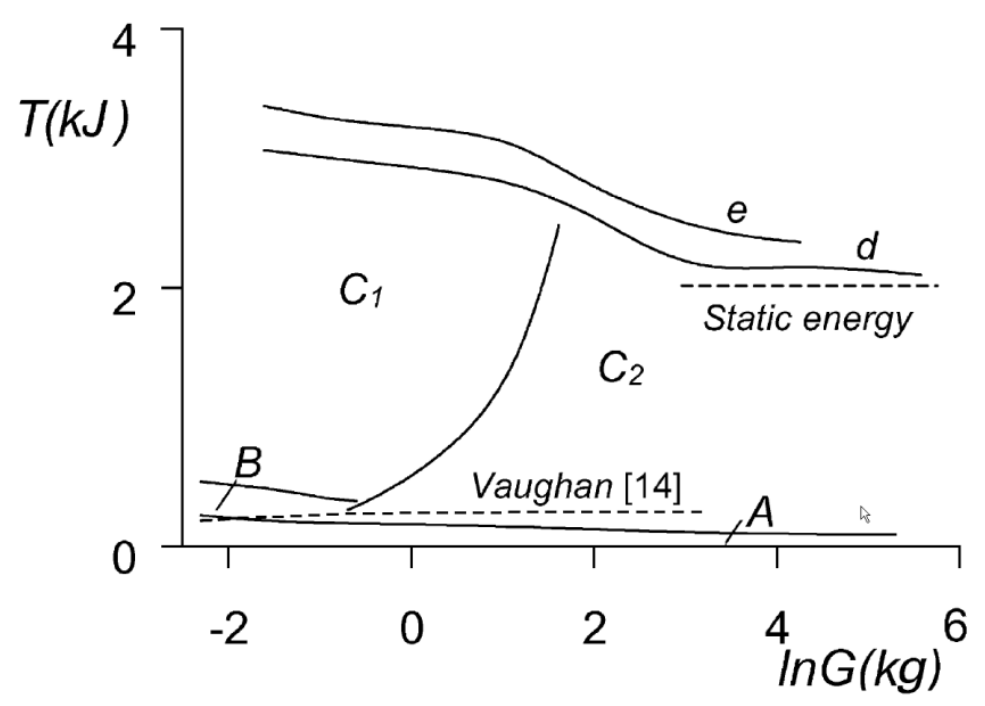

Figura 2 - Identificação das regiões para os diferentes modos de flambagem de um tubo sujeito a um impacto axial (KARAGIOZOVA; ALVES; JONES, 2000).

Estudos de outros tipos de estruturas sujeitas a impacto são encontrados na literatura. Uma estrutura formada por placas metálicas em "sanduíche" com um núcleo do tipo "colméia" foi estudada de forma experimental, analítica e numérica por Zhu et al. (2009a); Zhu et al. (2009b); Dharmasena et al. (2008). A estrutura é exposta a uma carga explosiva disposta um pouco acima da superfície e fica sujeita a um grande impulso gerado pelas ondas da explosão. Adachi et al. (2008) realizaram um estudo teórico e experimental do impacto axial de tubos com vários anéis de reforço ao longo do comprimento. Os autores investigaram como os reforços influenciam no comportamento do tubo como absorvedor de energia.

Vários estudos sobre impacto visam melhorar a proteção dos passageiros nos veículos de transporte. Dubois, Zellmer e Markiewicz (2009) e Kent, Purtsezov e 
Pilkey (2007) estudaram a eficiência de cintos de segurança usados em automóveis. Johnson e Walton (1983) fizeram uma breve revisão da literatura sobre o impacto frontal de caminhões com carros de passeio. Hardy, Khalil e King (1994) sintetizaram vários trabalhos sobre o efeito de cargas dinâmicas sobre a cabeça e cérebro humanos. Kwasniewski et al. (2006) utilizaram o método dos elementos finitos para estudar a colisão frontal e lateral entre dois veículos (Figura 3). Pinnoji et al. (2009) estudaram de forma experimental e numérica o impacto em um capacete de motociclista feito de espuma metálica.

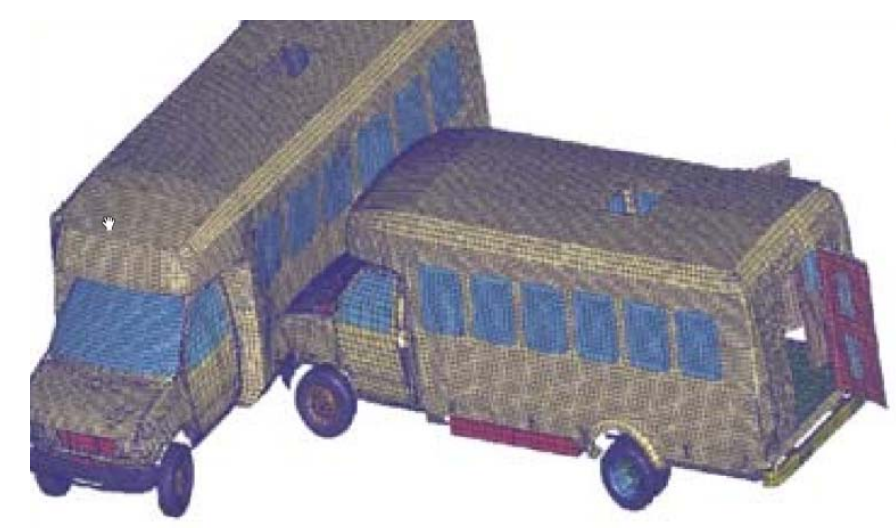

Figura 3 - Simulação de impacto entre dois veículos (KWASNIEWSKI et al., 2006).

Em alguns estudos o objetivo é proteger a estrutura sujeita a impacto. Em Wang et al. (2008) a colisão de um navio contra uma ponte protegida por um dispositivo absorvedor de energia de impacto foi analisada de forma numérica. Pedersen et al. (1993) fizeram uma estimativa das forças resultantes na colisão da proa de uma embarcação mercante contra grandes estruturas fixas no mar.

A colisão entre navios é um incidente muito perigoso, podendo causar grandes prejuízos materiais e ambientais. Por isso, o choque envolvendo esse tipo de estrutura tem recebido grande atenção na literatura. Yagi et al. (2009) utilizaram o método dos elementos finitos para comparar o efeito da colisão de dois tipos diferentes de proa contra o casco de um navio. Ozguc, Das e Barltrop (2005) estudaram a resistência de navios compostos por cascos simples e duplos quando sujeitos ao impacto de outra embarcação. Hisayoshi et al. (2001) analisaram de forma experimental e numérica o dano sofrido por uma proa bulbosa quando ela atinge uma parede rígida. 
Impactos envolvendo aviões também são largamente estudados na literatura. Devido o grande número de ocorrências de colisões de pássaros em partes do avião, vários artigos analisam esse fenômeno. Hansen et al. (2006) analisaram o impacto de um pássaro artificial contra placas de alumínio formando uma estrutura do tipo sanduíche. Meguid, Mao e Ng (2008) utilizaram o método dos elementos finitos para analisar a influência da geometria adotada para o pássaro artificial no impacto contra as pás da turbina de um avião.

Wierzbicki e Teng (2003) fizeram um estudo analítico aproximado do atentado ocorrido no World Trade Center, que sofreu o impacto de um Boeing 767 no ano de 2001. A análise foca no impacto da asa do avião contra as colunas externas da estrutura. Através desse estudo, os autores concluíram que a energia cinética absorvida pelas colunas externas foi muito pequena e a maior parte dela foi dissipada para o interior da construção, causando danos fatais aos componentes internos da estrutura.

Componentes eletrônicos também são alvos do estudo do fenômeno de impacto. Em Shi et al. (2007) o modelo numérico de um disco rígido sujeito a uma queda de uma altura de 1,25 m foi simulado. O comportamento da cabeça de leitura durante o choque devido à queda foi analisado. As forças de impacto na cabeça de leitura de um disco rígido foram medidas de forma experimental por Fujii e Shu (2008). Chakka et al. estudaram as cargas e acelerações a que os componentes eletrônicos estão sujeitos durante o lançamento dos projéteis que as contêm.

\subsection{Similaridade}

Nessa seção resumimos as leis de similaridade, principal foco deste trabalho. A utilidade de se reproduzir o comportamento da estrutura em escalas menores tornase evidente quando os espécimes envolvidos possuem grandes dimensões (navios, trens, aviões, etc.). Estruturas dimensionadas adequadamente em escalas diferentes são então empregadas e elas objetivam reproduzir o comportamento observado em escala real de forma exata. A esta técnica dá-se o nome de similaridade ou similitude. Exemplos de aplicação podem ser encontrados na indústria naval, aeronáutica, etc. 
A similaridade opera a partir de um modelo, ou seja, uma estrutura similar à real, cujo comportamento, quando transposto ao protótipo, permite inferir as forças, momentos e cargas dinâmicas do protótipo. Usando a metodologia corrente, o modelo e o protótipo devem atender aos seguintes requisitos (FOX; MCDONALD, 1998):

- o modelo e o protótipo devem ser geometricamente semelhantes. A semelhança geométrica requer que ambos tenham a mesma forma, e que todas as dimensões lineares do modelo sejam relacionadas com correspondentes dimensões do protótipo por um fator de escala constante;

- deve existir a semelhança cinemática, ou seja, as velocidades em pontos correspondentes deverão estar no mesmo sentido e relacionar-se em magnitude por um fator de escala constante.

Quando protótipo e modelo têm distribuições de forças tais que tipos idênticos de forças são paralelos e relacionam-se em magnitude por um fator de escala constante em todos os pontos correspondentes, então os dois sistemas são dinamicamente semelhantes. Os requisitos para semelhança dinâmica são mais restritivos, pois os sistemas devem possuir tanto semelhança cinemática quanto geométrica.

A fim de estabelecer as condições necessárias para a completa semelhança dinâmica, todas as forças importantes no fenômeno devem ser consideradas. As condições de teste devem ser estabelecidas de tal forma que as principais variáveis do modelo e do protótipo possam relacionar-se por uma transposição dos fatores de escala.

De acordo com o teorema dos $\Pi$ de Buckingham, a condição para similaridade perfeita é atendida se os grupos adimensionais que governam 0 protótipo forem idênticos aos respectivos grupos do modelo (BAKER; WESTINE; DODGE, 1991), ou seja, $\left(\Pi_{\mathrm{i}}\right)_{\text {modelo }}=\left(\Pi_{\mathrm{i}}\right)_{\text {protótipo }}$. Porém, em muitos estudos com modelos, a consecução de semelhança dinâmica exige a reprodução de diversos grupos adimensionais. Em alguns casos, a completa semelhança dinâmica entre modelo e protótipo pode não ser atingida, sendo assim uma similaridade incompleta ou imperfeita.

As variáveis envolvidas no fenômeno devem se relacionar através de fatores de escala definidos, que são obtidos através da análise dimensional (FOX; MCDONALD, 1998); (SKOGLUND, 1967); (SZIRTES, 1997). Para estruturas mecânicas, os fatores são baseados na escala da geometria. Todas as dimensões 
do modelo, $L$, são relacionadas por um fator de escala $\beta$ com a respectiva parte do protótipo, sendo $\beta=(L)_{\text {modelo }} /(L)_{\text {protótipo }}$. Se o material de ambos é o mesmo, as principais variáveis do problema são bem conhecidas na literatura e são geradas através da análise dimensional (JOHNSON, 1972); (JONES, 1997); (BAKER; WESTINE; DODGE, 1991). Elas são resumidas na Tabela 1.

Tabela 1- Relação entre as variáveis do modelo e do protótipo.

\begin{tabular}{cccc}
\hline Variável & Fator & Variável & Fator \\
\hline comprimento, $L$ & $\beta$ & velocidade de onda, $c^{\prime}$ & 1 \\
deslocamento, $\delta$ & $\beta$ & tempo, $t$ & $\beta$ \\
massa, $G$ & $\beta^{3}$ & velocidade, $V$ & 1 \\
deformação, $\varepsilon$ & 1 & taxa de deformação, $\dot{\varepsilon}$ & $1 / \beta$ \\
tensão, $\sigma$ & 1 & aceleração, $A$ & $1 / \beta$ \\
\hline
\end{tabular}

Definidos os fatores de escala, é necessário que os números adimensionais ( $\Pi$ ) sejam determinados. Eles desempenham um papel fundamental no estudo da similaridade. Os números adimensionais são obtidos através da escolha de uma base e da análise dimensional das variáveis, conforme descrito em Baker, Westine e Dodge (1991) e Singer, Arbocz e Weller (1998). Porém, esse método não fornece as ferramentas necessárias para identificar quais $\Pi$ são predominantes do fenômeno. Por isso, vários experimentos são necessários até que os números adimensionais relevantes para o fenômeno sejam identificados. Infelizmente, ao contrário da termodinâmica e da mecânica dos fluídos, a área de impacto em estruturas não possui muitos trabalhos sobre esse tema.

$\mathrm{Na}$ atual literatura, dois números adimensionais foram identificados como relevantes para o fenômeno de impacto em estruturas: número de dano e número de resposta. O primeiro é descrito em Johnson (1972),

$$
D_{\mathrm{n}}=\frac{\rho V_{0}^{2}}{\sigma_{0}}
$$

sendo $\rho$ a densidade do material, $V_{0}$ a velocidade inicial de impacto, $\sigma_{0}$ a tensão de escoamento quasi-estática. Este número pode ser interpretado como a ordem de grandeza das tensões na região onde ocorrem grandes deformações. 
O número de resposta foi definido por Zhao (1998),

$$
R_{\mathrm{n}}=\frac{\rho V_{0}}{\sigma_{0}}\left(\frac{L}{H}\right)^{2}=D_{\mathrm{n}}\left(\frac{L}{H}\right)^{2}
$$

sendo $L$ a metade do comprimento e $H$ a altura da viga ou placa. Além dos parâmetros considerados em $D_{\mathrm{n}}$, o número de resposta considera também a geometria da estrutura. Foi demonstrado também por Hu (2000) que o número de resposta é realmente predominante no caso de estruturas sujeitas a cargas dinâmicas. O mesmo número adimensional é generalizado para vários tipos de cascas por Shi e Gao (2001). Ainda, Li e Jones (2000) adicionaram o efeito do encruamento, taxa de deformação, temperatura e força cortante.

Em alguns casos pode ocorrer a similaridade imperfeita, ou seja, quando um ou mais números adimensionais do modelo não são iguais ao do protótipo. Diversos são os fatores que podem gerar essa imperfeição no fenômeno de impacto em estruturas. Pode-se citar entre elas, o efeito da taxa de deformação, a gravidade e a falha por fratura. Jones (1995) mostra várias tentativas de escalonamento. Em alguns casos, a lei de similaridade é seguida de forma aproximada. Porém, em outros casos também analisados em Jones (1995), uma diferença significativa entre o valor esperado e o obtido foi registrada, mostrando a necessidade de se determinar as variáveis dominantes e suas limitações.

Um exemplo de similaridade imperfeita é apresentado por Booth, Collier e Miles (1983). Eles realizaram uma série de 13 testes em dois tipos de estruturas soldadas (Figura 4) e verificaram que as peças em escala não obedeciam as leis de similaridade linear, como pode ser visto na Figura 5. As peças em escala $1 / 4$ deformaram-se 2,5 vezes menos que o protótipo correspondente. Além disso, as peças maiores tiveram deformações e tempo de impacto maiores que o previsto pela similaridade.

Schleyer et al. (2004) estudaram o escalonamento de algumas placas de aço com diferentes restrições nas bordas e sujeitas a um pulso triangular de pressão distribuído uniformemente. Grandes deformações plásticas foram produzidas, mas nenhuma ruptura foi observada. Foi verificado que a resposta das placas exibiu divergência nas leis de similaridade.

Modelos de pequenos projéteis lançados contra um alvo foram estudados por Gregory (1995) and Me-Bar (1997). Ambos os autores reportaram similaridade imperfeita. Gregory (1995) atribuiu esse resultado às altas taxas de deformação, 
enquanto Me-Bar (1997) identificou como razão a energia gasta pelos efeitos de superfície - atrito, fratura, transferência de calor, etc. Ainda, Neuberger, Peles e Rittel (2007) analisaram de forma numérica e experimental o escalonamento de placas circulares engastadas nas bordas e sujeitas a uma explosão. Os autores obtiveram bons resultados da similaridade com o uso do método de escalonamento de Hopkinson-Cranz (conhecido também como lei de escalonamento da raiz cúbica). Essa lei define que ondas de explosão similares são produzidas a distâncias escalonadas idênticas quando duas cargas explosivas similares, mas de diferentes pesos, são detonadas na mesma atmosfera² .

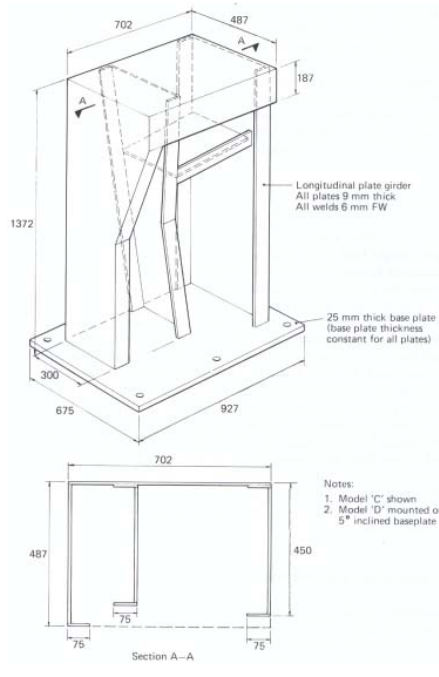

(a)

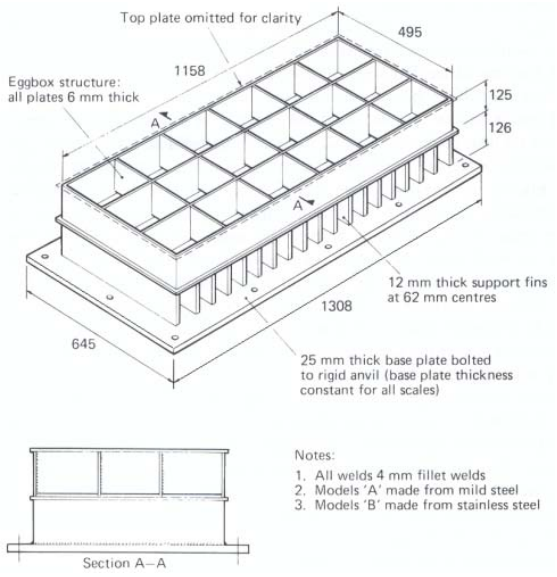

(b)

Figura 4 - Estruturas testadas por Booth, Collier e Miles (1983). (a) cabine. (b) "eggbox".

Vários trabalhos analisam os efeitos de dimensão (BAZANT, 2000); (MORQUIO; RIEIRA, 2004). Esses autores observaram que propriedades como a tensão máxima são maiores em espécimes menores. Esse fenômeno é explicado pela combinação de plasticidade e fratura mecânica e é mais evidente em materiais frágeis.

Para alguns casos, a falha na similaridade pode ser atribuída ao efeito da taxa de deformação. Se a Tabela 1 for analisada, é possível verificar que a resposta estrutura não segue as leis de escalonamento. Suponha que a tensão dinâmica de

${ }^{2} Z=R / E^{1 / 3}, \tau^{*}=\tau / E^{1 / 3}, \zeta=I / E^{1 / 3}, Z$ é a distância escalonada, $\tau^{*}$ é o tempo característico escalonado, $\zeta$ é o impulso escalonado, $R$ é a distância para a centro da explosão e $E$ é a energia total da explosão. 
escoamento, $\sigma_{\mathrm{d}}$, obedeça a lei constitutiva, $\sigma_{\mathrm{d}}=f(\dot{\varepsilon})$, sendo $\dot{\varepsilon}$ a taxa de deformação. De acordo com a Tabela $1, \dot{\varepsilon}_{\mathrm{m}}=(1 / \beta) \dot{\varepsilon}_{\mathrm{p}}$, sendo que o subscrito "m" refere-se ao modelo e "p" ao protótipo. No entanto, as leis de similaridade exigem que $\left(\sigma_{\mathrm{d}}\right)_{\mathrm{m}}=\left(\sigma_{\mathrm{d}}\right)_{\mathrm{p}}$, o que só é possível se $f\left(\dot{\varepsilon}_{\mathrm{m}}\right)=f\left(\dot{\varepsilon}_{\mathrm{p}}\right)=f\left(\dot{\varepsilon}_{\mathrm{m}} / \beta\right)$. Fica claro que as relações da Tabela 1 não são válidas quando a taxa de deformação tem influência no fenômeno.

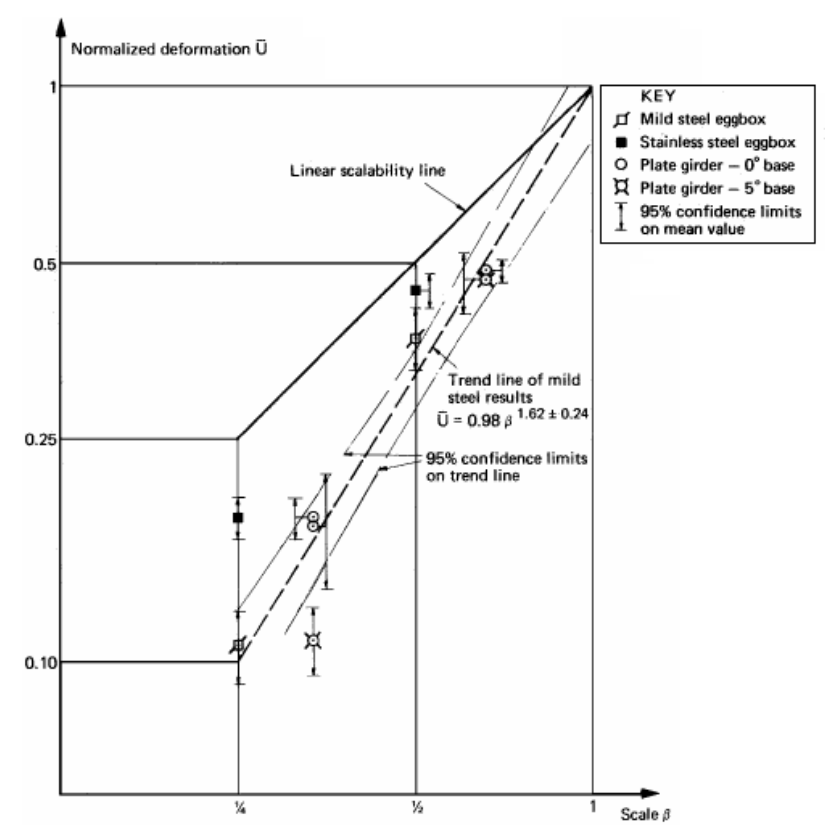

Figura 5 - Modelos escalonados testados sob impacto: ensaio de queda livre para espécimes de aço "eggbox" e placas guias. Booth, Collier e Miles (1983).

Uma forma de considerar o efeito da taxa de deformação na resposta do material é estudada em Drazetic et al. (1994). Eles realizaram uma série de testes simples com barras de aço com centro vazado. Em uma das extremidades da barra uma massa é fixada, enquanto na outra, uma articulação permite a rotação. Ela pode então colidir contra um bloco rígido e assim gerar uma dobra localizada. A estrutura foi produzida em escalas 1:1, 3:4 e 3:8 e sua modelagem considerou distorções do material e da geometria. Uma técnica denominada similaridade indireta é então empregada para corrigir os dados da estrutura em escala, gerando uma melhor semelhança para o fenômeno (Figura 6).

A similitude indireta é baseada no uso da similaridade geométrica imperfeita de Cauchy e no teorema dos $\Pi$ de Buckingham. Basicamente, esta técnica não utiliza um único fator de escala $\beta$ como geralmente é feito. Ela introduz um fator para cada 
uma das variáveis em estudo. Dessa forma, é possível corrigir os resultados levando-se em consideração as imperfeições na construção da estrutura em escala. Além das imperfeições, também é possível corrigir o efeito da taxa de deformação, diminuindo de maneira significativa os erros do modelo em relação ao protótipo devido a esse efeito.

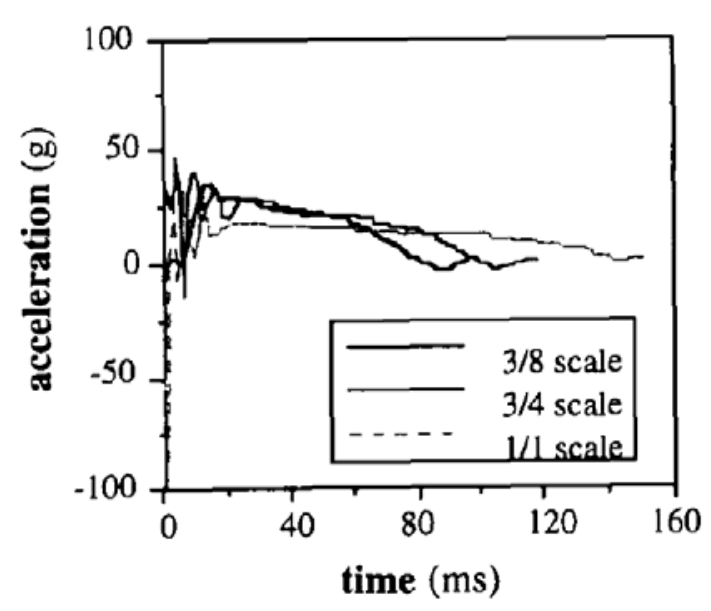

(a)

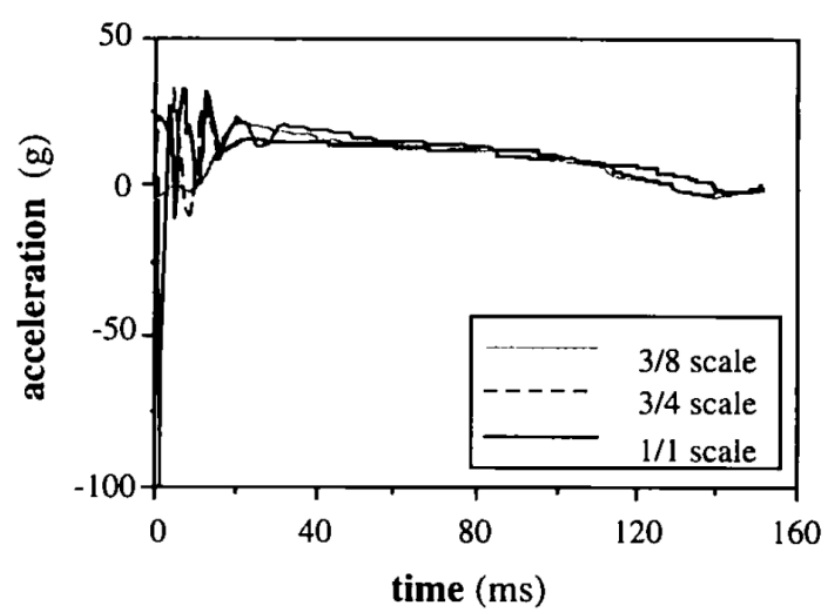

(b)

Figura 6 - Resultados do estudo realizado por Drazetic et al. (1994) com espécimes apresentando distorção na geometria e nas propriedades materiais. (a) antes da correção. (b) depois da correção considerando as distorções e a taxa de deformação.

Recentemente, Oshiro e Alves (2004) apresentaram um método de correção para o problema de similaridade imperfeita devido à taxa de deformação. No trabalho, foi proposta uma mudança no fator de velocidade que compensaria os efeitos da taxa de deformação. Ao invés de utilizar um único fator de escala, $\beta$, um fator para a velocidade inicial de impacto, $\beta_{V}$, também foi usado. A Figura 7 mostra alguns resultados para o modelo de duas barras presas pelas extremidades $\mathrm{e}$ sujeitas ao impacto de uma massa na direção do plano (seção 2.1.1). A Tabela 2 compara numericamente os mesmos resultados para o modelo corrigido e não corrigido ao final do movimento, $\tau_{2}$.

Baseado nesta mesma metodologia, Alves e Oshiro (2006) corrigiram as discrepâncias entre modelo e protótipo alterando a massa de impacto ao invés da velocidade inicial. Erros pequenos também foram observados com o uso dessa técnica. 
Tabela 2 - Resultados para o modelo de barras presas pelas extremidades e sujeitas ao impacto de uma massa (OSHIRO; ALVES, 2004).

\begin{tabular}{lcccc}
\hline \multicolumn{5}{c}{ Modelo não corrigido } \\
\hline escala & 1 & $1 / 2$ & $1 / 4$ & $1 / 10$ \\
ângulo final $\left(^{\circ}\right)$ & 16,31 & 15,57 & 14,82 & 13,81 \\
final da segunda fase $(\mathrm{s})$ & $5,18 \mathrm{E}-4$ & $4,80 \mathrm{E}-4$ & $4,42 \mathrm{E}-4$ & $3,94 \mathrm{E}-4$ \\
aceleração final $\left(\mathrm{m} / \mathrm{s}^{2}\right)$ & 11915 & 12856 & 13947 & 15659 \\
taxa de deformação final $\left(\mathrm{s}^{-1}\right)$ & 300 & 309 & 319 & 334 \\
tensão final (MPa) & 477 & 515 & 559 & 627 \\
\hline \multicolumn{5}{c}{} \\
\hline escala & Modelo corrigido & & \\
fator de velocidade & 1 & $1 / 2$ & $1 / 4$ & $1 / 10$ \\
ângulo final $\left({ }^{\circ}\right)$ & 1 & 1,039 & 1,084 & 1,150 \\
final da segunda fase $(\mathrm{s})$ & 16,31 & 16,35 & 16,36 & 16,38 \\
aceleração final $\left(\mathrm{m} / \mathrm{s}^{2}\right)$ & $5,18 \mathrm{E}-4$ & $5,18 \mathrm{E}-4$ & $5,18 \mathrm{E}-4$ & $5,19 \mathrm{E}-4$ \\
taxa de deformação final $\left(\mathrm{s}^{-1}\right)$ & 11915 & 11918 & 11908 & 11887 \\
tensão final (MPa) & 300 & 302 & 301 & 301 \\
\hline
\end{tabular}

O escalonamento de tubos de aço sensíveis à taxa de deformação e sujeitos ao impacto axial de uma massa foi numericamente estudado por Oshiro e Alves (2007). Os resultados obtidos mostraram que os modelos usando a correção proposta em Oshiro e Alves (2004) têm um comportamento bastante similar ao do protótipo, Figura 8.

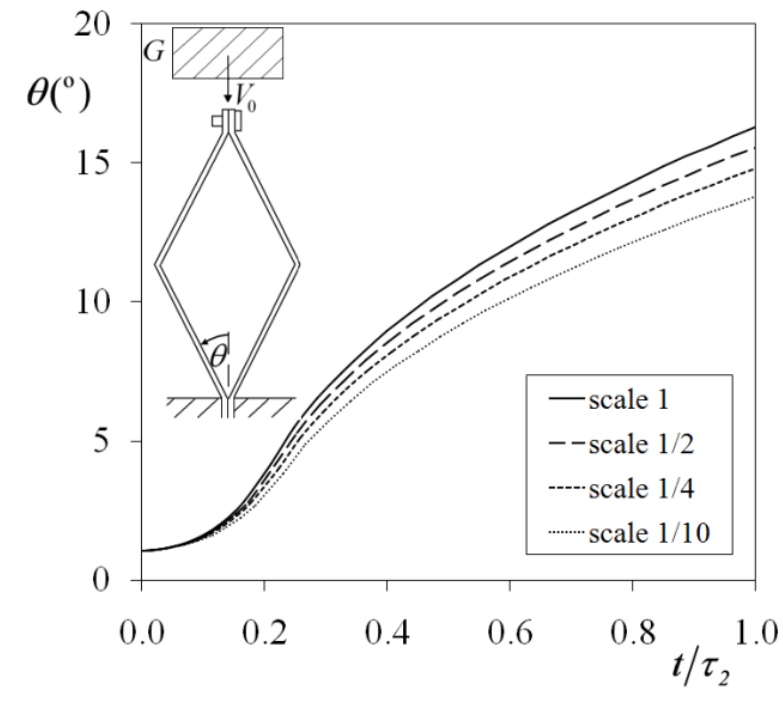

(a)

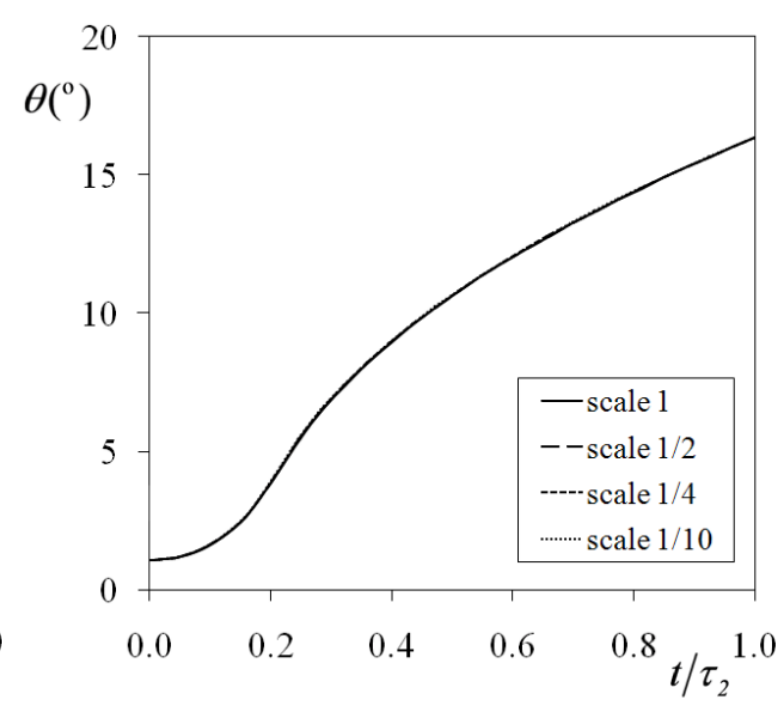

(b)

Figura 7 - Evolução do ângulo de rotação da barra, $\theta$, em função do tempo adimensional, $t / \tau_{2}$, no modelo de Calladine. (a) modelo não corrigido. (b) modelo corrigido (OSHIRO; ALVES, 2004). 
Um trabalho apresentado por Oshiro e Alves (2009) mostra a correção de vários modelos analíticos. A equação constitutiva de Norton-Hoff é utilizada para relacionar a tensão dinâmica de escoamento e a taxa de deformação. Dessa forma é possível calcular o fator para a velocidade inicial de forma mais simples e, para os modelos analisados, a similaridade é perfeita. A mesma técnica é aplicada no presente trabalho e será detalhada no capítulo 2 .

Cho et al. (2005) utilizam em seu trabalho um método em que modelos com geometria, material e carregamento diferentes do protótipo são utilizados para prever o comportamento da estrutura real. As variáveis do modelo são relacionadas com o protótipo através de fatores determinados empiricamente. Dois exemplos foram usados em Cho et al. (2005) para validar o método: a simulação numérica de um arco para disparo de flechas (Figura 9) e um dissipador térmico testado experimentalmente. A técnica empregada para resolver os dois modelos distorcidos é simples e abrangente, mas possui algumas limitações que serão discutidas detalhadamente no capítulo 5 .

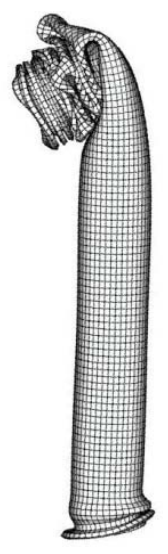

(a)

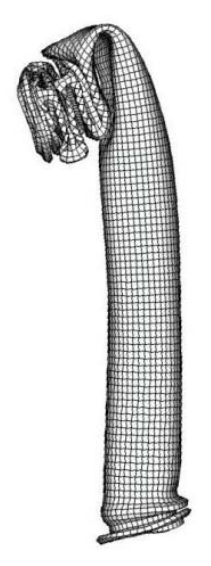

(b)

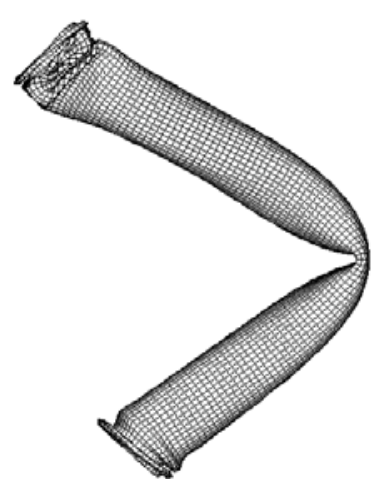

(c)

Figura 8 - Resultados numéricos do escalonamento de tubos de aço impactados à $40 \mathrm{~m} / \mathrm{s}$ na direção axial. (a) protótipo. (b) modelo em escala $1 / 10$ corrigido. (c) modelo em escala 1/10 não corrigido (OSHIRO; ALVES, 2007). Modelos ampliados 10x para comparação direta com o protótipo.

Como uma das grandes razões para a não escalonabilidade de algumas estruturas é a resposta dinâmica do material, apresenta-se a seguir uma pequena revisão das leis constitutivas. Será mostrado que a escolha de uma destas leis 
permitirá a correção exata de alguns problemas de similaridade em estruturas sujeitas a carregamentos de impacto.

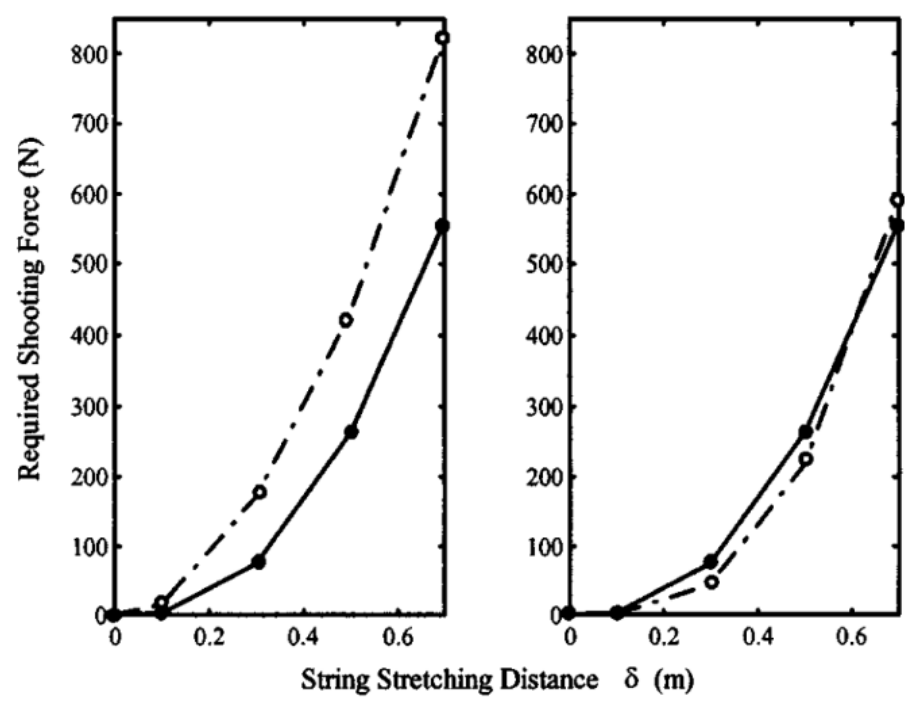

(a)

(b)

Figura 9 -Comparação da resposta do protótipo (curva contínua) com o modelo (curva traço-ponto) na simulação de um arco para disparo de flechas com geometria e material distorcidos. (a) Modelo da similaridade usual. (b) Modelo usando o método de transposição de fatores (CHO et al., 2005).

\subsection{Equação constitutiva}

A taxa de deformação influencia o comportamento do material e esse fenômeno é denominado viscoplasticidade. A Figura 10 mostra como a curva tensão deformação de um aço é alterada para diferentes velocidades do teste de tração. Por exemplo, uma taxa de deformação de $208,8 \mathrm{~s}^{-1}$ aplicada a este aço altera a sua tensão de escoamento em um fator de 1,8 em relação a um carregamento estático. A obtenção do comportamento material em casos de valores extremos da taxa de deformação é um problema. Zukas (1982) resume vários testes que podem ser feitos para obter o comportamento material desde baixas taxas $\left(0 \mathrm{~s}^{-1}\right.$ a $\left.10^{-6} \mathrm{~s}^{-1}\right)$ até valores muito altos $\left(10^{4} \mathrm{~s}^{-1}\right.$ ou mais), onde arranjos especiais são necessários. Um fator observado também por Zukas (1982) é que as forças inerciais começam a ter importância em torno de $1 \mathrm{~s}^{-1}$, abaixo disso elas podem ser ignoradas. 


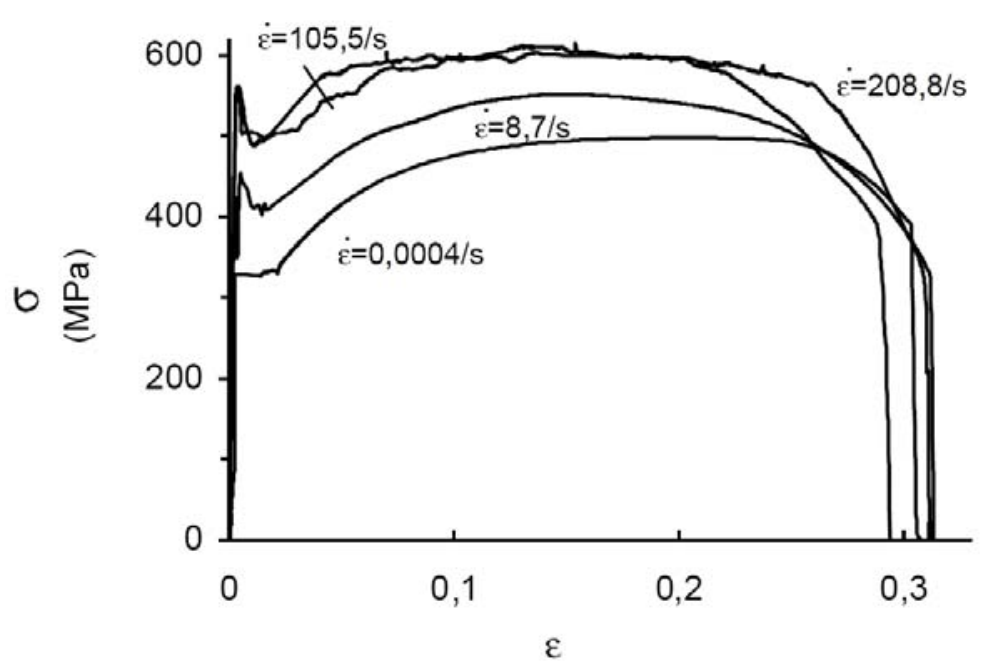

Figura 10 - Curva tensão $(\sigma)$ x deformação $(\varepsilon)$ para aço doce em várias taxas de deformação uniaxial (ALVES; JONES, 2002).

Neste trabalho, a equação que relaciona tensão de escoamento e taxa de deformação é de vital importância. No entanto, a dependência do material em relação à taxa de deformação e temperatura não pode ser descrita de uma forma geral. Vários tipos de equações constitutivas têm sido propostas para descrever esse comportamento. Os modelos podem ser divididos em três grandes grupos, baseados nas propriedades materiais necessárias para descrever a relação constitutiva do material:

1. Modelos fenomenológicos ou empíricos: são baseados nas propriedades macroscópicas do material, como tensão máxima. Eles têm a vantagem de requererem, em geral, poucos parâmetros. Muitos deles estão implementados em códigos de elementos finitos.

2. Modelos micromecânicos: são baseados nos aspectos microscópicos dos materiais e usam propriedades como tamanho de grão, deslocamento de densidade, etc. Em geral, possuem uma grande quantidade de parâmetros e não são comumente encontrados em códigos de elementos finitos.

3. Modelos semifenomenológicos: são uma combinação entre os modelos fenomenológicos e micromecânicos.

Por questões de simplicidade, somente o primeiro grupo é considerado para o atual trabalho, com Slycken (2008) citando cinco modelos fenomenológicos 
importantes: o de Norton-Hoff, Cowper-Symonds, Johnson-Cook, Ludwick e Zhao. Estes são agora brevemente introduzidos.

a) Modelo de Norton-Hoff ${ }^{3}$ :

Neste modelo a relação entre tensão, deformação e taxa de deformação é dada por (LEMAITRE; CHABOCHE, 1991); (DUAN; SHEPPARD, 2004); (POURSINA; EBRAHIMI; PARVIZIAN, 2008)

$$
\sigma_{\text {true }}=K \varepsilon^{p} \dot{\varepsilon}^{q}
$$

sendo $\varepsilon$ a deformação plástica verdadeira, $\dot{\varepsilon}$ a taxa de deformação plástica e $K$, $p$ e $q$ constante do material. É um modelo bastante simples, pois tanto a dependência do encruamento como da taxa de deformação são escritos na forma exponencial.

Os valores de $K, p$ e $q$ são dependentes do material e da temperatura. 1/ $q$ assume valores da ordem de 2 (para materiais muito viscosos) até 100 (para materiais pouco sensíveis à taxa de deformação), 1/p varia aproximadamente entre 2 e 50 e $K$ para os metais varia entre 100 e 10000 MPa. Alguns valores específicos para estes parâmetros são listados na Tabela 3 (LEMAITRE; CHABOCHE, 1991).

b) Modelo de Cowper-Symonds:

Neste modelo, talvez o mais conhecido para descrever metais sensíveis à taxa de deformação, a equação constitutiva é dada por

$$
\sigma(\varepsilon, \dot{\varepsilon})=\sigma_{0}(\varepsilon)\left[1+(\dot{\varepsilon} / D)^{q}\right]
$$

sendo $\sigma_{0}$ a tensão de referência e $D$ e $q$, constantes específicas para cada material.

c) Modelo de Johnson-Cook:

Neste modelo, muito popular em código de elementos finitos, o comportamento dinâmico é descrito por

$$
\sigma_{\text {true }}=\left[A_{1}+A_{2}(\varepsilon)^{p}\right]\left(1+A_{3} \ln \frac{\dot{\varepsilon}}{\dot{\varepsilon}_{0}}\right)\left[1-\left(\frac{T-T_{\text {amb }}}{T_{\text {fus }}-T_{\text {amb }}}\right)^{\bar{m}}\right],
$$

\footnotetext{
${ }^{3}$ Em Slycken (2008) o modelo de Norton-Hoff é citado como modelo de Hollomon.
} 
sendo $\dot{\varepsilon}_{0} 0$ valor de referência para a taxa de deformação, $T$ a temperatura, $T_{\text {fus }}$ a temperatura de fusão e $T_{\text {amb }}$ a temperatura ambiente. Os parâmetros $A_{1}, A_{2}$ e $p$ são obtidos de ensaios quasi-estáticos e $A_{3}$ e $m$ são obtidos de experimentos a altas taxas de deformação. Geralmente a aproximação linear subestima a tensão de escoamento em baixas taxas de deformação $\left(\dot{\varepsilon}<1 \mathrm{~s}^{-1}\right)$ e superestima as tensões para $1 \mathrm{~s}^{-1}<\dot{\varepsilon}<5000 \mathrm{~s}^{-1}$.

Tabela 3 - Valores usuais dos coeficientes da equação de Norton-Hoff para vários tipos de materiais. Adaptado de Lemaitre e Chaboche (1991).

\begin{tabular}{|c|c|c|c|c|}
\hline Material & $T\left({ }^{\circ} \mathrm{C}\right)$ & $p$ & $q$ & $K(\mathrm{MPa})$ \\
\hline aço $0,35 \%$ C & 450 & 0,067 & 0,167 & 762 \\
\hline MARM 509 & 900 & 0,091 & 0,063 & 650 \\
\hline aço Z10 CNT 18 & 800 & 0,077 & 0,167 & 400 \\
\hline HASTELLOY $X$ & 650 & 0,179 & 0,119 & 8843 \\
\hline AISI 304 & 20 & 0,015 & 0,200 & 752 \\
\hline \multirow{5}{*}{ IN 100} & 800 & 0,059 & 0,076 & 2140 \\
\hline & 900 & 0,082 & 0,095 & 2110 \\
\hline & 1000 & 0,093 & 0,102 & 1450 \\
\hline & 1100 & 0,102 & 0,105 & 875 \\
\hline & 800 & 0,074 & 0,018 & 1620 \\
\hline \multirow{2}{*}{ UDIMET 700} & 900 & 0,105 & 0,016 & 1480 \\
\hline & 1000 & 0,143 & 0,014 & 1080 \\
\hline TA6V & 350 & 0,008 & 0,091 & 970 \\
\hline \multirow{2}{*}{ INCO 718} & 550 & 0,007 & 0,077 & 1695 \\
\hline & 600 & 0,011 & 0,056 & 1538 \\
\hline \multirow{2}{*}{ 316L } & 20 & 0,015 & 0,071 & 458 \\
\hline & 550 & 0,008 & 0,167 & 494 \\
\hline liga MG & 260 & 0,041 & 0,053 & 165 \\
\hline 2024 revenido & 208 & 0,078 & 0,065 & 262 \\
\hline \multirow{2}{*}{2024 endurecido } & 130 & 0,020 & 0,048 & 502 \\
\hline & 200 & 0,037 & 0,030 & 386 \\
\hline
\end{tabular}

d) Modelo de Ludwig:

A equação constitutiva neste caso é expressa por

$$
\sigma_{\text {true }}=\left[A_{1}(\dot{\varepsilon})+A_{2}(\dot{\varepsilon})(\varepsilon)^{p(\dot{\varepsilon})}\right](1+\mu \Delta T)
$$

com $A_{1}, A_{2}$ e $A_{3}$ definidos como

$$
\begin{aligned}
& A_{1}(\dot{\varepsilon})=a_{1}+a_{2} \log \left(\dot{\varepsilon} / \dot{\varepsilon}_{0}\right)+a_{3}\left[\log \left(\dot{\varepsilon} / \dot{\varepsilon}_{0}\right)\right]^{3}, \\
& A_{2}(\dot{\varepsilon})=a_{4}+a_{5} \log \left(\dot{\varepsilon} / \dot{\varepsilon}_{0}\right)+a_{6}\left[\log \left(\dot{\varepsilon} / \dot{\varepsilon}_{0}\right)\right]^{1 / 2}
\end{aligned}
$$




$$
p(\dot{\varepsilon})=p_{1}+p_{2} \log \left(\dot{\varepsilon} / \dot{\varepsilon}_{0}\right)+p_{3}\left[\log \left(\dot{\varepsilon} / \dot{\varepsilon}_{0}\right)\right]^{3} .
$$

É um modelo que visa cobrir as limitações do modelo de Johnson-Cook. A taxa de deformação é considerada através das funções $A_{1}, A_{2}$ e $p$. Ao contrário do modelo de Johnson-Cook, o termo que considera a temperatura é reduzido para uma forma linear. Apesar de ser mais preciso que o modelo de Johnson-Cook, a quantidade de parâmetros torna o modelo muito mais complexo.

e) Modelo de Zhao:

Este modelo é regrado pela equação

$$
\sigma_{\text {true }}=\left[A_{1}+A_{2}(\varepsilon)^{p}+\left(A_{3}-A_{4} \varepsilon\right) \ln \left(\dot{\varepsilon} / \dot{\varepsilon}_{0}\right)+A_{5} \dot{\varepsilon}^{q}\right](1-\mu \Delta T),
$$

sendo $A_{1}, A_{2}, A_{3}, A_{4}, A_{5}, p$ e $q$ constantes materiais a serem determinadas. É baseado no modelo físico proposto por Tanimura (SLYCKEN, 2008). Um termo de taxa de deformação é adicionado ao encruamento. O mecanismo de escoamento ativado termicamente é representado por um incremento linear e a viscosidade é descrita por uma função exponencial.

A Tabela 4 resume os tipos de materiais em que os modelos mostrados são geralmente aplicados.

Tabela 4 - Modelos materiais e aplicações (SLYCKEN, 2008).

\begin{tabular}{ll}
\hline \multicolumn{1}{c}{ Modelo } & \multicolumn{1}{c}{ Material } \\
\hline Norton-Hoff & ligas de Al, chapas metálicas, aço perlita, aço DP \\
Cowper-Symonds & ligas de Al, alumínio, aço doce, aço carbono, aço TRIP \\
Johnson-Cook & ligas de Al, aço baixo carbono, chapas metálicas, aço HSS, ligas de Ti, \\
& $\begin{array}{l}\text { aço TRIP } \\
\text { ligas de Al, chapas metálicas, epóxi } \\
\text { Zudwig }\end{array}$ \\
Zhao & alumínio, aço doce \\
\hline
\end{tabular}

Como será visto adiante, no presente trabalho o modelo constitutivo de NortonHoff, eq.(3), é adotado para descrever o comportamento dinâmico do material. O uso da forma exponencial para representar a influência da taxa de deformação na tensão 
de escoamento do material permite simplificar o cálculo do fator de correção da velocidade. Essa propriedade será vista em detalhes no capítulo 2.

\subsection{Objetivos}

A Figura 10 evidencia que a resposta do material a diferentes taxas de deformação varia bastante para certos tipos de materiais. Esse comportamento impede que a similaridade perfeita seja atingida quando as leis usuais de escalonamento são aplicadas (Tabela 1). Por isso, no presente trabalho é feita uma adaptação do método de similitude indireta. No entanto, diferentemente do trabalho de Drazetic et al. (1994), a correção do modelo que considera o efeito da taxa de deformação é feita sem que nenhum dado do protótipo seja empregado.

Foram obtidos bons resultados nos trabalhos anteriores relativos à correção do modelo através da alteração da velocidade inicial de impacto (OSHIRO; ALVES, 2004); (OSHIRO, 2005), (OSHIRO; ALVES, 2007). Porém, o método que foi utilizado exigia que $\dot{\varepsilon}$ fosse conhecido. Por exemplo, em Oshiro e Alves (2007), um valor médio para a taxa de deformação de um tubo sujeito a impacto axial foi adotado. No entanto, para muitas estruturas reais pode ser complicado obter o valor médio de $\dot{\varepsilon}$ que gere bons resultados na correção. Por isso, o atual trabalho aborda uma forma mais simples de correção da velocidade de impacto em um modelo, tal que a resposta no protótipo possa ser exatamente prevista. A independência do procedimento em relação à resposta do protótipo é mantida. Além do mais, não é necessário conhecer a taxa de deformação na estrutura, o que garante maior robustez ao método.

Outro aspecto abordado neste trabalho é a distorção da geometria. Em alguns casos experimentais não é possível a construção de uma determinada dimensão do modelo na escala exata. Isto devido a, por exemplo, o fato de não existirem chapas de aço na espessura requerida para o fator de escala adotado. Em razão dessa limitação, apresenta-se no capítulo 3 um estudo com modelos com uma das dimensões distorcidas em relação ao protótipo $\left(\beta_{X} \neq \beta\right)$. Como será visto, não existe uma formulação geral para a distorção da geometria em modelos. Cada caso exige uma análise específica para que a correção possa ser feita.

Dessa forma, dois fatores geradores da similaridade imperfeita no modelo são 
estudados: a taxa de deformação e a distorção da geometria. Para ambos os casos a correção é feita através da alteração da velocidade inicial do corpo de impacto. A hipótese da correção através da massa de impacto é discutida na seção 5.

O trabalho é organizado da seguinte maneira: o capítulo 2 descreve o método de correção que considera o efeito da taxa de deformação. Essa correção é então aplicada a algumas soluções analíticas. No capítulo 3, analisa-se o método que considera um modelo com a geometria distorcida em relação ao protótipo. No capítulo 4 duas estruturas são implementadas e resolvidas numericamente para avaliar o emprego dos métodos de correção em estruturas mais complexas. No capítulo 5 a hipótese do uso de um modelo com material diferente do protótipo é discutida. No mesmo capítulo é analisada a correção feita através da alteração da massa do corpo de impacto ao invés da velocidade. Finalmente, uma discussão geral sobre a técnica e os resultados é feita no capítulo 6 . 


\section{MÉTODO DE CORREÇÃO PARA MODELOS SENSÍVEIS À TAXA DE DEFORMAÇÃO}

Os fatores que relacionam as variáveis do modelo com as do protótipo são bem conhecidos e já foram listados na Tabela 1. Também foi detalhado na seção 1.3 que para o fator de escala geométrico diferente da unidade, $\beta \neq 1$, o fenômeno de impacto em estruturas não atinge similaridade perfeita se o material da estrutura é sensível à taxa de deformação. Nessa seção, é proposto um método em que a velocidade inicial de impacto é alterada de modo a compensar a resistência mecânica adicional do material devido à taxa de deformação, $\dot{\varepsilon}$. Dessa maneira, modelo e protótipo atingem perfeita similaridade. A correção considera que as estruturas são constituídas de material rígido perfeitamente plástico.

Para desenvolver o método de correção, a técnica de similitude indireta descrita na seção 1.3 - é aplicada. De forma similar ao método desenvolvido em Oshiro e Alves (2004), o fator de velocidade é alterado de forma a produzir a perfeita similaridade. Ao invés da base clássica usada na teoria dos $\Pi$ - massacomprimento-tempo (MLT) -, o procedimento usa uma nova base composta por velocidade inicial, $V_{0}$, tensão de escoamento dinâmica, $\sigma_{\mathrm{d}}$, e massa de impacto, $G$. A Tabela 5 resume as principais variáveis do problema de impacto expressas em função da base $V_{0}-\sigma_{d}-G$.

Tabela 5 - Matriz dimensional das principais variáveis do fenômeno de impacto.

\begin{tabular}{|c|c|c|c|c|c|c|}
\hline & & aceleração & tempo & deslocamento & $\begin{array}{c}\text { taxa de } \\
\text { deformação }\end{array}$ & tensão \\
\hline \multirow{3}{*}{$\begin{array}{l}\mathscr{D} \\
\dddot{N} \\
\infty\end{array}$} & $V_{0}$ & $4 / 3$ & $-1 / 3$ & $2 / 3$ & $1 / 3$ & 0 \\
\hline & $\sigma_{\mathrm{d}}$ & $1 / 3$ & $-1 / 3$ & $-1 / 3$ & $1 / 3$ & 1 \\
\hline & $G$ & $-1 / 3$ & $1 / 3$ & $1 / 3$ & $-1 / 3$ & 0 \\
\hline
\end{tabular}

Os números adimensionais na eq. (11) são gerados usando a base modificada e o procedimento padrão da análise dimensional, conforme descrição detalhada no Apêndice A, 


$$
\underbrace{\left[\frac{A^{3} G}{V_{0}^{4} \sigma_{\mathrm{d}}}\right],}_{\Pi_{1}}, \underbrace{\left[\frac{t^{3} \sigma_{\mathrm{d}} V_{0}}{G}\right]}_{\Pi_{2}}, \underbrace{\left[\frac{\delta^{3} \sigma_{\mathrm{d}}}{G V_{0}^{2}}\right]}_{\Pi_{3}}, \underbrace{\left[\dot{\varepsilon}\left(\frac{G}{\sigma_{\mathrm{d}} V_{0}}\right)^{1 / 3}\right]}_{\Pi_{4}}, \underbrace{\left[\frac{\sigma}{\sigma_{\mathrm{d}}}\right]}_{\Pi_{5}},
$$

sendo $A$ a aceleração, $G$ a massa de impacto, $V_{0}$ a velocidade inicial de impacto, $t$ o tempo, $\delta$ o deslocamento e $\sigma$ a tensão atuante na estrutura.

Os fatores $\beta_{Y}=Y_{\mathrm{m}} / Y_{\mathrm{p}}$ que relacionam as variáveis do modelo e do protótipo são obtidos dos números adimensionais na eq. (11). Eles são definidos como $\beta_{\sigma_{\mathrm{d}}}=$ $\left(\sigma_{\mathrm{d}}\right)_{\mathrm{m}} /\left(\sigma_{\mathrm{d}}\right)_{\mathrm{p}}, \beta_{\sigma}=(\sigma)_{\mathrm{m}} /(\sigma)_{\mathrm{p}}, \beta_{\dot{\varepsilon}}=(\dot{\varepsilon})_{\mathrm{m}} /(\dot{\varepsilon})_{\mathrm{p}}, \beta_{t}=(t)_{\mathrm{m}} /(t)_{\mathrm{p}}, \beta_{A}=(A)_{\mathrm{m}} /(A)_{\mathrm{p}} \mathrm{e}$ $\beta_{V}=\left(V_{0}\right)_{\mathrm{m}} /\left(V_{0}\right)_{\mathrm{p}}$, sendo o subscrito "m" referente ao modelo e "p" ao protótipo. Para que os fatores $\beta_{\dot{\varepsilon}}, \beta_{t}, \beta_{A}$ e $\beta_{\sigma}$ não sejam dependentes da resposta estrutural, eles devem ser definidos em função de $\beta$ e $\beta$ V . Dessa forma, igualando o termo $\Pi_{3}$ do modelo e do protótipo, gera-se

$$
\left(\Pi_{3}\right)_{\mathrm{m}}=\left(\Pi_{3}\right)_{\mathrm{p}} \rightarrow \frac{\beta_{\delta}^{3} \beta_{\sigma_{\mathrm{d}}}}{\beta_{G} \beta_{v_{0}}^{2}}=1
$$

Como $\beta_{\delta}=\beta$ e $\beta_{G}=\beta^{3}$, uma relação direta entre a tensão de escoamento dinâmica e a velocidade de impacto pode ser obtida

$$
\beta_{\sigma_{\mathrm{d}}}=\beta^{2} .
$$

De forma equivalente, o termo $\Pi_{4}$ produz com a ajuda da eq. (12),

$$
\begin{aligned}
\left(\Pi_{4}\right)_{\mathrm{m}}=\left(\Pi_{4}\right)_{\mathrm{p}} & \rightarrow \beta_{\dot{\varepsilon}}\left(\frac{\beta_{\mathrm{G}}}{\beta_{\sigma_{\mathrm{d}}} \beta_{V_{0}}}\right)^{1 / 3}=1 \rightarrow \\
\beta_{\dot{\varepsilon}} & =\beta_{v} / \beta .
\end{aligned}
$$

O termo $\Pi_{2}$ gera a razão de tempo entre modelo e protótipo

$$
\begin{gathered}
\left(\Pi_{2}\right)_{\mathrm{m}}=\left(\Pi_{2}\right)_{\mathrm{p}} \rightarrow \frac{\beta_{t}^{3} \beta_{\sigma_{\mathrm{d}}} \beta_{v_{0}}}{\beta_{\mathrm{G}}}=1 \rightarrow \\
\beta_{t}=\beta / \beta_{v} .
\end{gathered}
$$

O termo $\Pi_{1}$ permite obter o fator de aceleração em função do fator de velocidade e $\beta$

$$
\left(\Pi_{1}\right)_{\mathrm{m}}=\left(\Pi_{1}\right)_{\mathrm{p}} \rightarrow \frac{\beta_{A}{ }^{3} \beta_{\mathrm{G}}}{\beta_{V_{0}}{ }^{4} \beta_{\sigma_{\mathrm{d}}}}=1 \rightarrow
$$




$$
\beta_{A}=\beta V^{2} / \beta
$$

Por último, como a estrutura é constituída de um material rígido perfeitamente plástico, a tensão que atua na estrutura é igual à tensão de escoamento dinâmica, gerando com o uso do termo $\Pi_{5}$ a equação

$$
\beta_{\sigma}=\beta V^{2} .
$$

A relação chave que precisa ser determinada é a eq. (12), pois ela relaciona a velocidade inicial com a tensão de escoamento dinâmica - e portanto, relaciona indiretamente $\beta_{V}$ com $\dot{\varepsilon}$. Nos trabalhos anteriores de Oshiro e Alves (2004) e Oshiro (2004), o modelo constitutivo de Cowper-Symonds, eq. (4), foi aplicado para relacionar a tensão dinâmica de escoamento com a taxa de deformação. No presente trabalho, o modelo de Norton-Hoff é utilizado, eq. (3), sendo que o encruamento é ignorado.

A equação constitutiva de Norton-Hoff,

$$
\sigma=K \varepsilon^{p} \dot{\varepsilon}^{q},
$$

pode ser reduzida a

$$
\sigma_{\mathrm{d}}=K \dot{\varepsilon}^{q}
$$

para o caso de materiais perfeitamente plásticos, ou seja, $p=0$. Para o caso quasiestático tem-se que a tensão de escoamento do material, $\sigma_{0}$, medida em uma taxa de deformação muito baixa de referência, $\dot{\varepsilon}_{0}$, gera

$$
K=\sigma_{0} / \dot{\varepsilon}_{0}^{q} .
$$

Portanto,

$$
\sigma_{\mathrm{d}}=\sigma_{0}\left(\dot{\varepsilon} / \dot{\varepsilon}_{0}\right)^{q} .
$$

A definição de $\beta_{\sigma_{\mathrm{d}}}$ e a eq. (18) fornecem

$$
\beta_{\sigma_{\mathrm{d}}}=\frac{\left(\sigma_{\mathrm{d}}\right)_{\mathrm{m}}}{\left(\sigma_{\mathrm{d}}\right)_{\mathrm{p}}}=\frac{\sigma_{0}\left(\dot{\varepsilon}_{\mathrm{m}} / \dot{\varepsilon}_{0}\right)^{q}}{\sigma_{0}\left(\dot{\varepsilon}_{\mathrm{p}} / \dot{\varepsilon}_{0}\right)^{q}}=\left(\frac{\dot{\varepsilon}_{\mathrm{m}}}{\dot{\varepsilon}_{\mathrm{p}}}\right)^{q}=\left(\beta_{\dot{\varepsilon}}\right)^{q} .
$$

Inserindo a eq. (13) na eq. (19), obtém-se

$$
\beta_{\sigma_{\mathrm{d}}}=(\beta v / \beta)^{q} .
$$


Portanto, as eq. (12) e (20) implicam em

$$
\beta_{V}=\beta^{q /(q-2)}
$$

A eq. (21) tem a vantagem de ser uma função de parâmetros conhecidos: o fator de escala, $\beta$, e a constante material, $q$, e de não precisar de nenhum dado sobre o comportamento da estrutura. Essa é a maior diferença em relação aos trabalhos anteriores (OSHIRO; ALVES, 2004), (OSHIRO, 2004). O material é considerado como rígido perfeitamente plástico. Como será analisado mais adiante, essa hipótese não afeta os modelos analíticos, mas gera algum erro nos modelos numéricos.

Na próxima seção, três modelos analíticos serão resolvidos usando o método proposto. A eq. (21) é utilizada e como será visto, o erro devido ao escalonamento da estrutura será anulado.

\subsection{Correção de modelos analíticos}

Nessa seção, o método de correção é aplicado a alguns modelos analíticos. Para essas estruturas, modelo e protótipo têm comportamento diferente devido ao efeito da taxa de deformação quando a similaridade clássica é usada. Três modelos sensíveis à taxa de deformação e constituídos de material perfeitamente plástico são analisados:

- Duas barras apoiadas lado a lado e engastadas na base. No topo as barras são presas entre si e estão sujeitas ao impacto de uma massa rígida (modelo de Calladine).

- Uma viga engastada nas extremidades e sujeita ao impacto transversal de uma massa no meio comprimento.

- Uma viga engastada nas extremidades e sujeita a um pulso de velocidade por todo o comprimento. 


\subsubsection{Modelo de Calladine}

Esse modelo foi explorado detalhadamente por Calladine e English (1984), Tam e Calaldine (1991) e Zang e Yu (1989) e de forma numérica por Webb, Kormi e Al-Hassani (2001). Ele consiste em duas barras presas entre si pelas extremidades e sujeitas ao impacto de uma massa $G$, com uma velocidade inicial $V_{0}$ (Figura 11). Essa estrutura é classificada como tipo II e é muito sensível aos efeitos da taxa de deformação (TAM; CALLADINE, 1991).

\section{a) Formulação}

Essa estrutura tem duas fases distintas. A primeira fase é dominada pela compressão das barras e termina quando o deslocamento lateral é tal que não ocorre mais deformação plástica axial. A segunda fase é dominada pelo movimento rígido das barras em torno das rótulas plásticas.

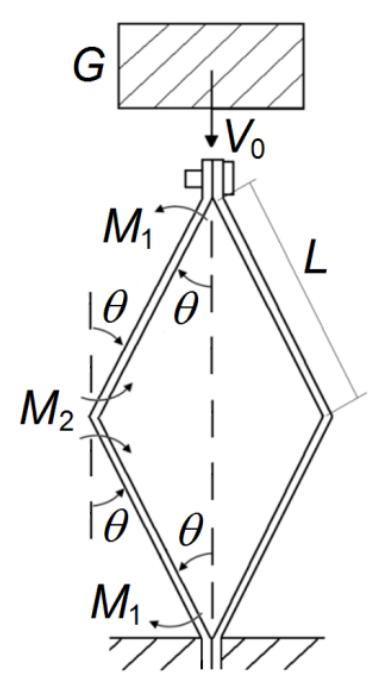

Figura 11 - Modelo de Calladine.

A primeira fase foi analisada por Tam e Calladine (1991) considerando que $\theta$ permanece pequeno e que a massa de impacto está sempre em contato com a estrutura. Para a solução, ainda foi considerado que a taxa de deformação é igual a $V_{0} / \ell$. Resolvendo-se o equilíbrio de forças atuando nas rótulas plásticas centrais é 
possível obter a equação do movimento para a primeira fase (OSHIRO, 2004)

$$
V_{0}-\frac{S \sigma_{\mathrm{d}} t}{G}=2\left(\frac{12 \sigma_{\mathrm{d}} S}{\ell m}\right)^{1 / 2} \frac{w_{0}^{2}}{\ell} \operatorname{senh}\left[2\left(\frac{12 \sigma_{\mathrm{d}} S}{\ell m}\right)^{1 / 2} t\right]+\dot{c}
$$

que termina quando $\dot{c}=0$. Sendo $w_{0}$ o deslocamento vertical inicial no topo da estrutura $\left(w_{0}=L \sin \theta_{0}\right), w$ o deslocamento vertical no topo da estrutura, $c$ a compressão das barras, $S$ a área da seção transversal das duas barras, $m$ a massa combinada das barras e $\ell$ o comprimento total ( $2 L$ ). O lado direito da eq. (22) descreve o deslocamento vertical de $G$ quando uma força constante atua desacelerando a massa de impacto.

No final da primeira fase de movimento, o deslocamento horizontal, $w_{1}$, e a velocidade, $\dot{w}_{1}$, são dadas por

$$
w_{1}=w_{0} \cosh \left[\left(\frac{12 \sigma_{\mathrm{d}} S}{\ell m}\right)^{1 / 2} \tau_{1}\right]
$$

e

$$
\dot{w}_{1}=w_{0}\left(\frac{12 \sigma_{\mathrm{d}} S}{\ell m}\right)^{1 / 2} \operatorname{senh}\left[\left(\frac{12 \sigma_{\mathrm{d}} S}{\ell m}\right)^{1 / 2} \tau_{1}\right]
$$

sendo $\tau_{1} 0$ instante em que a primeira fase termina. $\tau_{1}$ é obtido numericamente fazendo $\dot{c}=0$ na eq. (22).

Para ângulos pequenos, pode-se escrever

$$
\operatorname{sen} \theta=\frac{w}{\ell / 2} \Rightarrow \theta \approx \frac{2 w}{\ell}
$$

Portanto, as equações (23) e (24) podem ser reescritas como

$$
\theta_{1}=\frac{2}{\ell} w_{1}=\frac{2}{\ell} w_{0} \cosh \left[\left(\frac{12 \sigma_{\mathrm{d}} S}{\ell m}\right)^{1 / 2} \tau_{1}\right]
$$

e

$$
\dot{\theta}_{1}=\frac{2}{\ell} \dot{W}_{1}=\frac{2}{\ell} w_{0}\left(\frac{12 \sigma_{\mathrm{d}} S}{\ell m}\right)^{1 / 2} \operatorname{senh}\left[\left(\frac{12 \sigma_{\mathrm{d}} S}{\ell m}\right)^{1 / 2} \tau_{1}\right]
$$

A segunda fase do movimento foi descrita por Zhang; Yu (1989) através da equação 


$$
\ddot{\theta}+\frac{\ell^{2}(m / 4+G) \operatorname{sen} \theta \cos \theta \dot{\theta}^{2}+4\left(M_{1}+M_{2}\right)}{\ell^{2}\left[m / 3+(m / 4+G) \operatorname{sen}^{2} \theta\right]}=0
$$

sendo que as condições iniciais para a equação diferencial são dadas pelas eq. (25) e (26). A eq. (27) é gerada através da equação de Lagrange. $M_{1}$ e $M_{2}$ são os momentos nos pontos 1 e 2 , respectivamente, e são dados por

$$
M=\int \sigma_{\mathrm{d}} z d S=2 \int_{0}^{h / 2}\left[K\left(\dot{\varepsilon}_{z}\right)^{q} B z\right] d z
$$

quando o modelo constitutivo de Norton-Hoff, eq. (17), é adotado. $z$ é a distância em relação à linha neutra, $\dot{\varepsilon}_{z}$ é a taxa de deformação axial na posição $Z, H$ é a espessura da barra e $B$ a largura da barra. $\dot{\varepsilon}_{Z}=\dot{\kappa} Z$, com $\kappa$ sendo o pico de curvatura na rótula plástica. A eq. (28) pode ser escrita como

$$
M=\frac{M_{0} K}{\sigma_{0}} \frac{(\dot{\kappa} H)^{q}}{(q+2) 2^{q-1}}
$$

sendo $M_{0}=\sigma_{0} B H^{2} / 4$. Com o comprimento efetivo plástico dado por $\lambda=4 H$ (CALLADINE; ENGLISH, 1984), obtém-se

$$
\dot{\theta}=\lambda \dot{\kappa}=4 H \dot{\kappa}
$$

que gera

$$
M=\frac{M_{0} K}{\sigma_{0}(q+2) 2^{q-1}}\left(\frac{\dot{\theta}}{4}\right)^{q}
$$

Os momentos nos pontos 1 e 2 da estrutura são então dados por

$$
M_{1}=\frac{M_{0} K}{\sigma_{0}(q+2) 2^{q-1}}\left(\frac{\dot{\theta}}{4}\right)^{q}
$$

e

$$
M_{2}=\frac{M_{0} K}{\sigma_{0}(q+2) 2^{q-1}}\left(\frac{\dot{\theta}}{2}\right)^{q}
$$

A partir das expressões que definem $M_{1}$ e $M_{2}$, a eq. (27) pode ser agora resolvida numericamente. $O$ desenvolvimento mais detalhado das equações do modelo analítico de Calladine é exposto no Apêndice B. 
b) Aplicação do fator de escala

A aplicação dos fatores de escala nas equações de movimento permite apurar o efeito da taxa de deformação no comportamento da estrutura de Calladine. Primeiro, as razões de escala usuais (Tabela 1 ) são aplicados para inferir a resposta do modelo. A seguir, os fatores desenvolvidos pelo método do capítulo 2 (eq. (12) a (16) e (21)) são empregados para avaliar a similaridade.

O ângulo de rotação e sua derivada no final da primeira fase são definidos pelas eq. (25) e (26), respectivamente. Para um modelo utilizando os fatores da Tabela 1, os estados $\theta_{1}$ e $\dot{\theta}_{1}$ são dados por

$$
\begin{gathered}
\left(\theta_{1}\right)_{\mathrm{m}}=\frac{2}{\beta \ell} \beta w_{0} \cosh \left[\left(\frac{12\left(\sigma_{\mathrm{d}}\right)_{\mathrm{m}} \beta^{2} \mathrm{~S}}{\beta \ell \beta^{3} \mathrm{~m}}\right)^{1 / 2}\left(\tau_{1}\right)_{\mathrm{m}}\right] \rightarrow \\
\left(\theta_{1}\right)_{\mathrm{m}}=\frac{2}{\ell} w_{0} \cosh \left[\left(\frac{12\left(\sigma_{\mathrm{d}}\right)_{\mathrm{m}} \mathrm{S}}{\ell \mathrm{m}}\right)^{1 / 2} \frac{\left(\tau_{1}\right)_{\mathrm{m}}}{\beta}\right]
\end{gathered}
$$

e

$$
\begin{gathered}
\left(\dot{\theta}_{1}\right)_{\mathrm{m}}=\frac{2}{\beta \ell} \beta w_{0}\left(\frac{12\left(\sigma_{\mathrm{d}}\right)_{\mathrm{m}} \beta^{2} S}{\beta \ell \beta^{3} \mathrm{~m}}\right)^{1 / 2} \operatorname{senh}\left[\left(\frac{12\left(\sigma_{\mathrm{d}}\right)_{\mathrm{m}} \beta^{2} S}{\beta \ell \beta^{3} \mathrm{~m}}\right)^{1 / 2}\left(\tau_{1}\right)_{\mathrm{m}}\right] \rightarrow \\
\left(\dot{\theta}_{1}\right)_{\mathrm{m}}=\frac{2}{\ell} w_{0}\left(\frac{12\left(\sigma_{\mathrm{d}}\right)_{\mathrm{m}} S}{\beta^{2} \ell \mathrm{m}}\right)^{1 / 2} \operatorname{senh}\left[\left(\frac{12\left(\sigma_{\mathrm{d}}\right)_{\mathrm{m}} S}{\ell \mathrm{m}}\right)^{1 / 2} \frac{\left(\tau_{1}\right)_{\mathrm{m}}}{\beta}\right] .
\end{gathered}
$$

Caso $\left(\sigma_{\mathrm{d}}\right)_{\mathrm{m}}=\left(\sigma_{\mathrm{d}}\right)_{\mathrm{p}}$ e $\left(\tau_{1}\right)_{\mathrm{m}}=\beta\left(\tau_{1}\right)_{\mathrm{p}}$, conforme as leis de similaridade usuais, as eq. (34) e (35) mostram que as igualdades $\left(\theta_{1}\right)_{\mathrm{m}}=\left(\theta_{1}\right)_{\mathrm{p}}$ e $\left(\dot{\theta}_{1}\right)_{\mathrm{m}}=\left(\dot{\theta}_{1}\right)_{\mathrm{p}} / \beta$ seriam verdadeiras, gerando um modelo perfeitamente similar ao protótipo na primeira fase. Porém, como já detalhado, a taxa de deformação altera a tensão de escoamento dinâmica de forma a gerar $\left(\sigma_{\mathrm{d}}\right)_{\mathrm{m}} \neq\left(\sigma_{\mathrm{d}}\right)_{\mathrm{p}}$. Dessa forma, uma similaridade imperfeita é produzida nessa fase.

O comportamento a estrutura na segunda fase do modelo também é não similar ao protótipo. Ela é descrita pela inserção dos fatores da Tabela 1 na eq. (27),

$$
\ddot{\theta}_{\mathrm{m}} / \beta^{2}+\frac{(\beta \ell)^{2}\left(\beta^{3} \mathrm{~m} / 4+\beta^{3} G\right) \operatorname{sen} \theta_{\mathrm{m}} \cos \theta_{\mathrm{m}}\left(\dot{\theta}_{\mathrm{m}} / \beta\right)^{2}+4\left[\left(M_{1}\right)_{\mathrm{m}}+\left(M_{2}\right)_{\mathrm{m}}\right]}{(\beta \ell)^{2}\left[\beta^{3} m / 3+\left(\beta^{3} m / 4+\beta^{3} G\right) \operatorname{sen}^{2} \theta_{\mathrm{m}}\right]}=0 .
$$


Caso $\left(M_{1}\right)_{\mathrm{m}}=\beta^{3}\left(M_{1}\right)_{\mathrm{p}}$ e $\left(M_{2}\right)_{\mathrm{m}}=\beta^{3}\left(M_{2}\right)_{\mathrm{p}}$, a eq. (36) é idêntica à eq. (27), que define o protótipo. No entanto, para materiais sensíveis à taxa de deformação os momentos $M_{1}$ e $M_{2}$ não obedecem a essas igualdades, gerando uma resposta não similar do modelo

$$
\left(M_{1}\right)_{\mathrm{m}}=\left[\frac{M_{0} K}{\sigma_{0}(q+2) 2^{q-1}}\left(\frac{\dot{\theta}}{4}\right)^{q}\right] \beta^{3-q}=\left(M_{1}\right)_{\mathrm{p}} \beta^{3-q}
$$

e

$$
\left(M_{2}\right)_{\mathrm{m}}=\left[\frac{M_{0} K}{\sigma_{0}(q+2) 2^{q-1}}\left(\frac{\dot{\theta}}{2}\right)^{q}\right] \beta^{3-q}=\left(M_{2}\right)_{\mathrm{p}} \beta^{3-q} .
$$

Portanto, fica claro pelas eq. (34) a (38) que a similaridade imperfeita do modelo em relação ao protótipo se deve exclusivamente devido ao efeito da taxa de deformação. Se o material fosse insensível à taxa de carregamento, nenhuma correção seria necessária.

Por outro lado, se as relações desenvolvidas nesse trabalho forem empregadas, uma similaridade perfeita entre modelo e protótipo será obtida. As eq. (14) e (16) fornecem $\beta_{\sigma}=\beta_{V}^{2}$ e $\beta_{t}=\beta / \beta_{V}$, respectivamente. Inserindo essas duas relações nas eq. (34) e (35), as relações corrigidas para a primeira fase são geradas,

$$
\left(\theta_{1}\right)_{\mathrm{m}}=\frac{2}{\ell} w_{0} \cosh \left[\left(\frac{12 \beta V^{2} \sigma_{\mathrm{d}} S}{\ell m}\right)^{1 / 2} \frac{\beta / \beta_{V} \tau_{1}}{\beta}\right] \rightarrow\left(\theta_{1}\right)_{\mathrm{m}}=\left(\theta_{1}\right)_{\mathrm{p}}
$$

e

$$
\left(\dot{\theta}_{1}\right)_{\mathrm{m}}=\frac{2}{\ell} w_{0}\left(\frac{12 \beta^{2} \sigma_{\mathrm{d}} S}{\beta^{2} \ell m}\right)^{1 / 2} \operatorname{senh}\left[\left(\frac{12 \beta^{2} \sigma_{\mathrm{d}} S}{\ell m}\right)^{1 / 2} \frac{\beta / \beta V}{\beta}\right] \rightarrow \frac{\left(\dot{\theta}_{1}\right)_{\mathrm{m}}}{\left(\dot{\theta}_{1}\right)_{\mathrm{p}}}=\frac{\beta_{V}}{\beta} .
$$

As eq. (39) e (40) mostram que a perfeita similaridade é alcançada, pois seguem as relações previstas pelo presente trabalho. De forma similar, a segunda fase também obedece as razões determinadas no início do segundo capítulo, pois introduzindo $\beta_{\dot{\varepsilon}}=\beta / \beta$ nas eq. (37) e (38)

$$
\left(M_{1}\right)_{\mathrm{m}}=\beta^{3}\left[\frac{M_{0} K}{\sigma_{0}(q+2) 2^{q-1}}\left(\frac{\dot{\theta}}{4} \frac{\beta_{V}}{\beta}\right)^{q}\right]
$$




$$
\left(M_{2}\right)_{\mathrm{m}}=\beta^{3}\left[\frac{M_{0} K}{\sigma_{0}(q+2) 2^{q-1}}\left(\frac{\dot{\theta}}{2} \frac{\beta V}{\beta}\right)^{q}\right]
$$

As eq. (41) e (42) na eq. (27) geram

$$
\begin{gathered}
\ddot{\theta} \beta^{2} / \beta^{2}+\frac{(\beta \ell)^{2}\left(\beta^{3} m / 4+\beta^{3} G\right) \operatorname{sen} \theta \cos \theta(\dot{\theta} \beta / \beta)^{2}+4 \beta^{3-q} \beta_{V}^{q}\left[M_{1}+M_{2}\right]}{(\beta \ell)^{2}\left[\beta^{3} m / 3+\left(\beta^{3} m / 4+\beta^{3} G\right) \operatorname{sen}^{2} \theta\right]}=0 \rightarrow \\
\ddot{\theta} \beta_{V}^{2}+\frac{\ell^{2}(m / 4+G) \operatorname{sen} \theta \cos \theta(\dot{\theta} \beta)^{2}+4(\beta / \beta)^{q}\left[M_{1}+M_{2}\right]}{(\ell)^{2}\left[m / 3+(m / 4+G) \operatorname{sen}^{2} \theta\right]}=0
\end{gathered}
$$

A eq.(43) exprime a segunda fase do movimento para o modelo com os fatores calculados na tese e produz similaridade perfeita. O próximo tópico da seção corrobora a análise com valores numéricos.

\section{c) Resultados}

A Tabela 6 mostra os valores adotados para a geometria do protótipo, as constantes do material e as condições iniciais. Os parâmetros para a equação de Norton-Hoff foram obtidos de forma que o erro registrado entre esse modelo e o de Cowper-Symonds fosse minimizado numa faixa de taxa de deformação entre 0 a $2000 \mathrm{~s}^{-1}$. Nesse caso, os parâmetros para a equação de Cowper-Symonds utilizaram os valores padrão do aço doce: $\sigma_{0}=235 \mathrm{MPa}, q=0,2$ e $D=40 \mathrm{~s}^{-1}$ (JONES, 1997).

Tabela 6 - Valores adotados para o protótipo da estrutura de Calladine.

\begin{tabular}{lcc}
\hline \multicolumn{4}{c}{ Geometria da barra } \\
\hline comprimento & $\ell$ & $50 \mathrm{E}-3 \mathrm{~m}$ \\
espessura & $H$ & $5 \mathrm{E}-3 \mathrm{~m}$ \\
largura & $B$ & $5 \mathrm{E}-3 \mathrm{~m}$ \\
ângulo inicial & $\theta 0$ & $1,07^{\circ}$ \\
\hline \multicolumn{3}{c}{ Material (aço doce) } \\
\hline densidade & $\rho$ & $7800 \mathrm{~kg} / \mathrm{m}^{3}$ \\
tensão de escoamento quasi-estática & $\sigma_{0}$ & $235 \mathrm{MPa}$ \\
constante material & $q$ & 0,077 \\
taxa de deformação de referência & $\dot{\varepsilon}_{0}$ & $0,001 \mathrm{~s}^{-1}$ \\
\hline \multicolumn{3}{c}{ Condições iniciais } \\
\hline velocidade inicial & $V_{0}$ \\
massa de impacto & $\mathrm{G}$ & $7,0 \mathrm{~m} / \mathrm{s}$ \\
\hline
\end{tabular}


Os resultados são resumidos na Figura 12 e Tabela 7. Como pode ser observado, os erros são relativamente grandes quando as leis usuais de escalonamento (Tabela 1) são aplicadas. Para um modelo em escala 1/100, 0 desvio no ângulo final de rotação do modelo em relação ao protótipo é de $20 \%$. Por outro lado, quando o presente método é utilizado, mesmo para escalas pequenas como 1/100, a resposta do modelo coincide com a do protótipo perfeitamente. $\mathrm{Na}$ Tabela 6 as variáveis do modelo foram devidamente escalonadas usando as eq. (13) a (16). Dessa maneira, a comparação direta com a resposta do protótipo pode ser feita. A Tabela 6 mostra que quando a velocidade inicial de impacto é corrigida de acordo com a eq. (21), o erro é nulo para todas as variáveis.

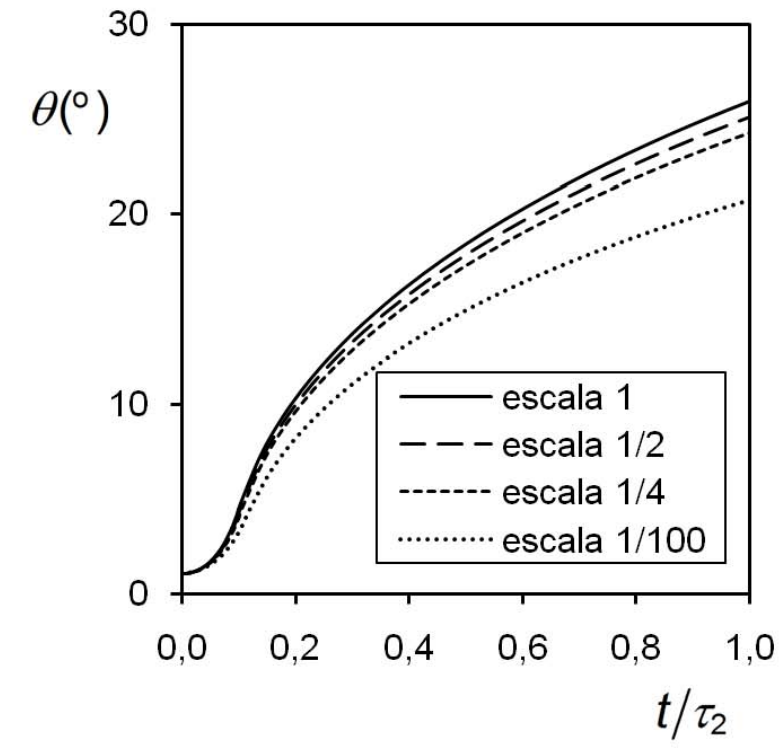

(a)

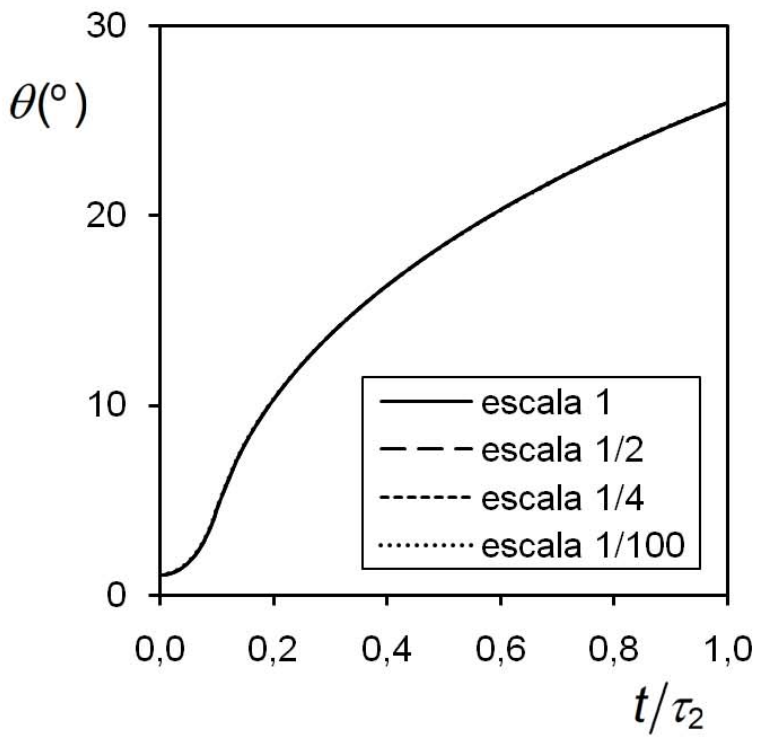

(b)

Figura 12 - Ângulo de rotação em função do tempo adimensional, $t / \tau_{2}$, para o modelo de Calladine em diversas escalas. (a) modelo sem correção. (b) modelo corrigido.

A Figura 13 mostra como a taxa de deformação varia em função do tempo para o modelo de Calladine. Pela análise dessas curvas, é possível verificar como o fator de escala, $\beta$, influencia a taxa de deformação no modelo. Para os modelos não corrigidos, é evidente que as curvas de taxa de deformação divergem da resposta do protótipo. Por outro lado, nos modelos corrigidos a taxa de deformação coincide com a resposta da estrutura em escala real.

Para analisar um pouco mais os resultados do modelo analítico e o procedimento de correção, o ângulo final de rotação, $\theta_{2}$, de modelos em escala 1/4 é comparado para diferentes energias de impacto, $G V_{0} L /\left(2 B H^{3} \sigma_{d}\right)$, na Figura $14(a)$ 
e (b). Na Figura 14 (c) a constante material $q$, que indica o quanto o material é sensível à taxa de deformação, é variada entre 0,05 e 0,15. Como pode ser observado, quando o modelo é corrigido com o procedimento detalhado no atual trabalho, as curvas coincidem com o protótipo, como requerido pela similaridade perfeita.

Tabela 7 - Comparação das respostas do protótipo e do modelo para a estrutura de Calladine.

\begin{tabular}{|c|c|c|c|c|}
\hline \multicolumn{5}{|c|}{ Modelo sem correção } \\
\hline escala & 1 & $1 / 2$ & $1 / 4$ & $1 / 100$ \\
\hline rotação final $\left({ }^{\circ}\right)$ & 25,95 & 25,10 & 24,27 & 20,76 \\
\hline final da primeira fase (s) & $1,13 \mathrm{E}-4$ & $1,10 \mathrm{E}-4$ & $1,06 \mathrm{E}-4$ & $0,91 E-4$ \\
\hline final da segunda fase (s) & $1,10 \mathrm{E}-3$ & $1,05 \mathrm{E}-3$ & 0,99E-3 & $0,77 \mathrm{E}-3$ \\
\hline aceleração final $\left(\mathrm{m} / \mathrm{s}^{2}\right)$ & $6,34 \mathrm{E} 4$ & $6,69 E 4$ & 7,07E4 & $9,09 \mathrm{E} 4$ \\
\hline taxa de deformação final $\left(\mathrm{s}^{-1}\right)$ & 184,57 & 186,93 & 189,22 & 198,35 \\
\hline tensão final (MPa) & 517,37 & 546,26 & 576,75 & 741,66 \\
\hline \multicolumn{5}{|c|}{ Modelo corrigido } \\
\hline escala & 1 & $1 / 2$ & $1 / 4$ & $1 / 100$ \\
\hline fator de velocidade & 1 & 1,0281 & 1,0571 & 1,2025 \\
\hline rotação final $\left({ }^{\circ}\right)$ & 25,95 & 25,95 & 25,95 & 25,95 \\
\hline final da primeira fase (s) & $1,13 \mathrm{E}-4$ & $1,13 \mathrm{E}-4$ & $1,13 \mathrm{E}-4$ & $1,13 E-4$ \\
\hline final da segunda fase (s) & $1,10 \mathrm{E}-3$ & $1,10 \mathrm{E}-3$ & $1,10 \mathrm{E}-3$ & $1,10 \mathrm{E}-3$ \\
\hline aceleração final $\left(\mathrm{m} / \mathrm{s}^{2}\right)$ & $6,34 \mathrm{E} 4$ & $6,34 \mathrm{E} 4$ & $6,34 \mathrm{E} 4$ & $6,34 \mathrm{E} 4$ \\
\hline taxa de deformação final $\left(\mathrm{s}^{-1}\right)$ & 184,57 & 184,57 & 184,57 & 184,57 \\
\hline tensão final (MPa) & 517,37 & 517,37 & 517,37 & 517,37 \\
\hline
\end{tabular}

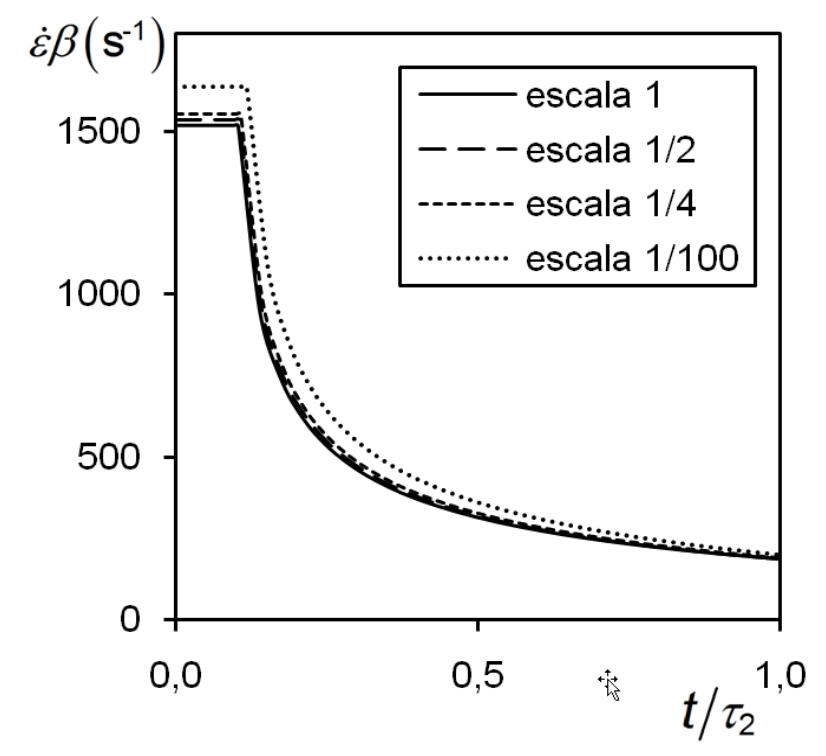

(a)

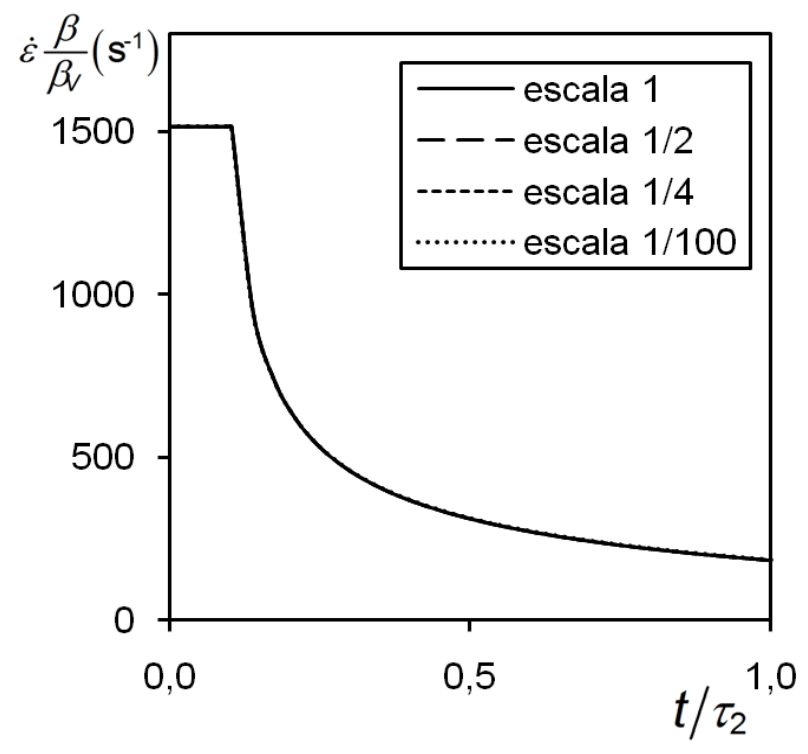

(b)

Figura 13 - Histórico da taxa de deformação para o modelo de Calladine em diversas escalas. (a) modelo sem correção. (b) modelo corrigido. 


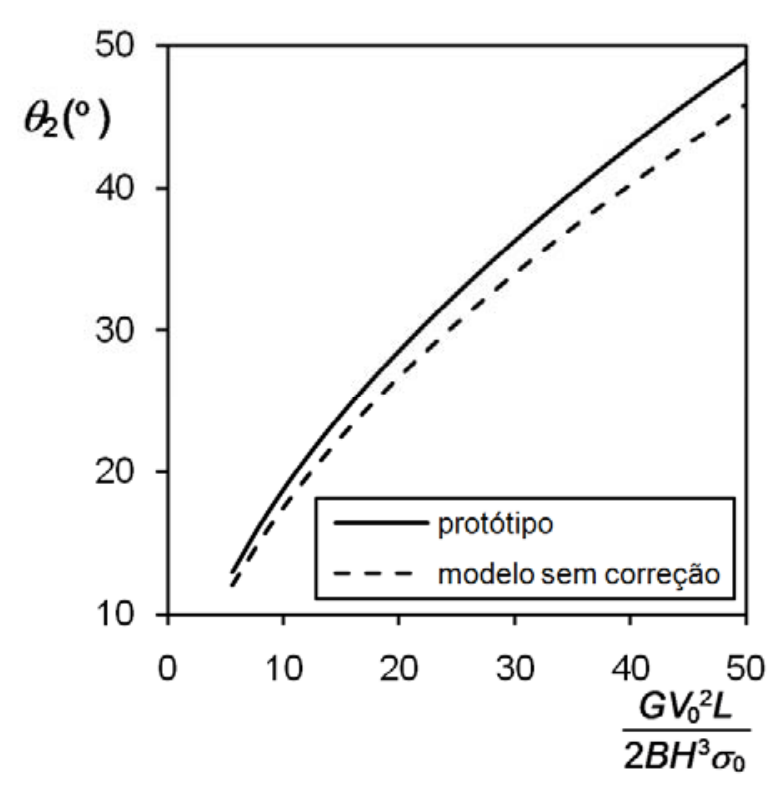

(a)

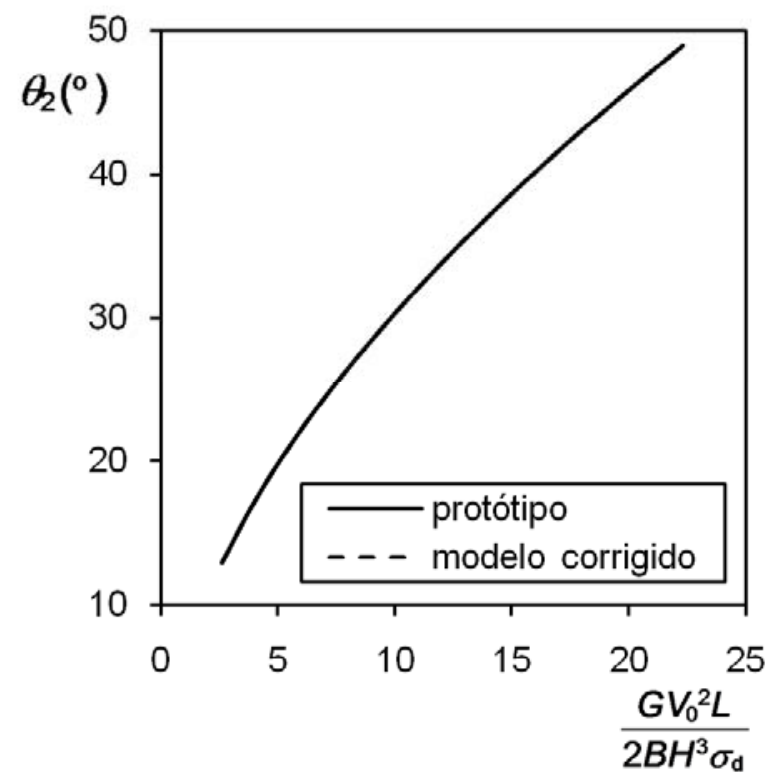

(b)

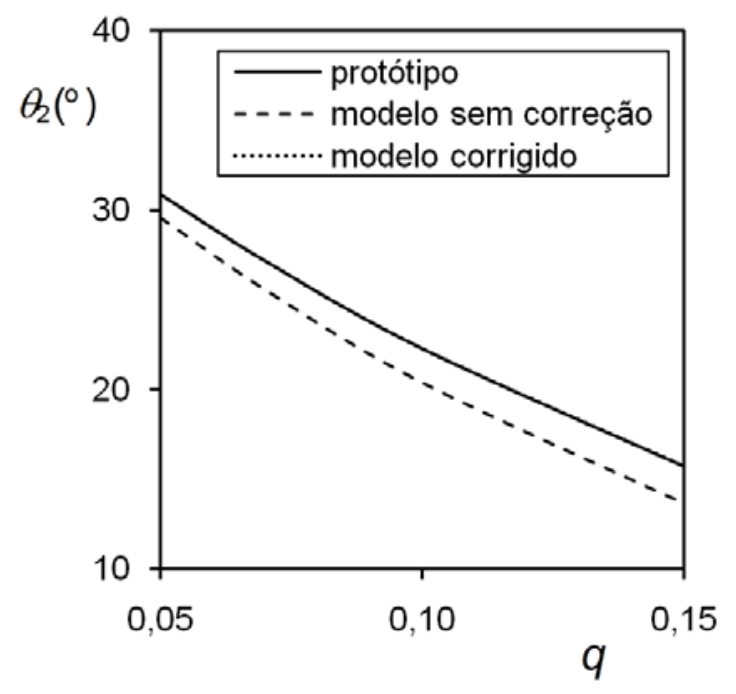

(c)

Figura 14 - Ângulo final de rotação, $\theta_{2}$, como função da energia de impacto, $G V_{0} L /\left(2 B H^{3} \sigma_{\mathrm{d}}\right)$, para o modelo de Calladine em escalas distintas. (a) sem correção. (b) corrigido. (c) Ângulo final de rotação em função da constante material $q$.

\subsubsection{Viga engastada nas extremidades sujeita ao impacto de uma massa}

O segundo modelo analítico estudado é uma viga com seção transversal retangular, de largura igual a $B$, altura $H$ e comprimento total $2 L$. A estrutura é 
engastada em ambas as extremidades e sofre o impacto de uma massa $G$, com velocidade inicial $V_{0}$ na metade do comprimento (Figura 15).

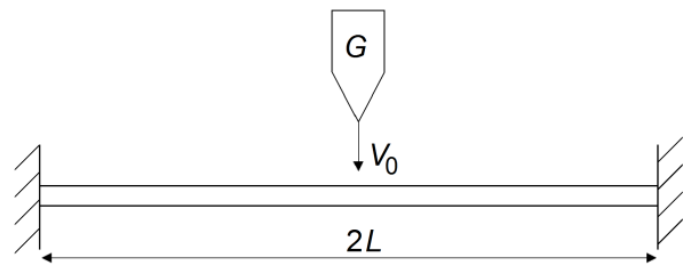

Figura 15 - Viga biengastada sujeita ao impacto de uma massa.

\section{a) Formulação}

A solução teórica para o modelo de viga biengastada sujeita ao impacto de uma massa em qualquer ponto do comprimento foi proposto em Liu e Jones (1988). Três fases de movimento foram identificadas. Na primeira fase, uma rótula plástica estacionária desenvolve-se no ponto de impacto, enquanto duas rótulas plásticas despontam do ponto de impacto e movem-se em direção aos suportes. As duas partes da viga entre a rótula estacionária e as móveis giram como corpos rígidos, enquanto o restante da viga permanece sem deformação. A segunda fase do movimento se inicia quando a rótula plástica no vão mais curto da viga atinge o suporte e termina quando a segunda rótula móvel - no vão mais longo da viga atinge o suporte no lado oposto. Durante a fase final de movimento, as rótulas plásticas permanecem estacionárias no ponto de impacto e nos suportes. 0 movimento termina completamente quando toda a energia cinética é dissipada na forma de deformação plástica. O modelo analítico considera deformações finitas e é assumido que as forças de membrana são constantes por todo o comprimento. Um material com comportamento perfeitamente plástico é adotado.

O deslocamento final, $w_{L}$, no ponto de impacto é dado por

$$
w_{L}=\frac{\sqrt{1+E \gamma /[u r(1+r)]}-1}{2 \gamma},
$$

sendo $w_{L}=W_{f} / L, u=G V_{0}^{2} /(2 M), \gamma=L_{1} / H, r=L_{1} / L_{2}$ e $M=\sigma_{d} B H^{2} / 4 . L_{1}$ é o comprimento do vão mais curto da viga e $L_{2}$ o comprimento do vão mais longo da viga (no caso em que o impacto não ocorre no centro). No presente trabalho, a viga 
é impactada exatamente na metade do comprimento. Essa hipótese permite ignorar a segunda fase do movimento. Nessa situação, $L_{1}=L_{2}=L, \gamma=L / H$ e $r=1$. $E$ pode então ser definido por

$$
E=\frac{1}{2}\left[\frac{g}{3}(1+r)+r\right] \dot{\bar{W}}_{02}^{2}+4 u(1+r) r\left(\bar{W}_{02}+\gamma \bar{W}_{02}^{2}\right)
$$

sendo $g=m^{\prime} L / G, m^{\prime}$ é a massa por unidade de comprimento e $\bar{W}_{02}$ é o deslocamento no ponto de impacto quando a rótula plástica no vão mais longo da viga atinge o suporte. Com as simplificações adotadas, $\bar{W}_{02}=\bar{W}_{01}$ e $\dot{\bar{W}}_{02}=\dot{\bar{W}}_{01}$ e portanto,

$$
\dot{\bar{W}}_{02}=\dot{\bar{W}}_{01}=2 u /(1+g)
$$

e

$$
\bar{W}_{02}=\bar{W}_{01}=\frac{\sqrt{1-\frac{u \gamma}{3 g}\left[\frac{g(2+g)}{1+g^{2}}-2 \ln (1+g)\right]}-1}{2 \gamma}
$$

sendo $\sigma_{\mathrm{d}}$ a tensão de escoamento dinâmica, dada pela eq. (17). A taxa de deformação é calculada conforme Alves e Jones (2002)

$$
\dot{\varepsilon}_{\mathrm{eq}}=\frac{V_{0}}{L} \sqrt{\frac{9}{8}\left(\frac{1+r^{2}}{\gamma}\right)^{2}+\frac{8}{3} k^{2}} \text { para } w_{L} \leq 1
$$

e

$$
\dot{\varepsilon}_{\mathrm{eq}}=\frac{V_{0}}{L} \sqrt{\frac{1}{8}\left(\frac{1+r^{2}}{\gamma}\right)^{2} w_{L}+\frac{8}{3} k^{2}} \text { para } w_{L}>1
$$

sendo $r=1$ para o caso de impacto no centro e $k$ uma constante material que considera o efeito do cisalhamento causado pela geometria da massa impactante.

b) Aplicação do fator de escala

No caso de um modelo gerado conforme as leis de escala usuais, a resposta da estrutura é produzida introduzindo-se os fatores de escala da Tabela 1 na eq. (44) 


$$
\left(w_{L}\right)_{\mathrm{m}}=\frac{\sqrt{1+(E)_{\mathrm{m}} \gamma /\left[2(u)_{\mathrm{m}}\right]}-1}{2 \gamma}
$$

$\operatorname{com}(E)_{m}$ definido por

$$
\begin{aligned}
(E)_{\mathrm{m}}= & {\left[\frac{g}{3}+\frac{1}{2}\right] \dot{\bar{W}}_{02}^{2}+8 u\left(\bar{W}_{02}+\gamma \bar{W}_{02}^{2}\right), } \\
& \left(\dot{\bar{W}}_{01}\right)_{\mathrm{m}}=2 u_{\mathrm{m}} /(1+g)
\end{aligned}
$$

e

$$
\left(\bar{W}_{01}\right)_{\mathrm{m}}=\frac{\sqrt{1-\frac{u_{\mathrm{m} \gamma}}{3 g}\left[\frac{g(2+g)}{1+g^{2}}-2 \ln (1+g)\right]}-1}{2 \gamma}
$$

As eq. (50) a (53) mostram que a resposta do modelo é idêntica ao do protótipo se $(u)_{\mathrm{m}}=(u)_{\mathrm{p}}$. Porém, $u$ do modelo é dado por

$$
(u)_{\mathrm{m}}=4 G V_{0}^{2} /\left[B H^{2}\left(\sigma_{\mathrm{d}}\right)_{\mathrm{m}}\right] \text {. }
$$

Como $\left(\sigma_{\mathrm{d}}\right)_{\mathrm{m}} \neq\left(\sigma_{\mathrm{d}}\right)_{\mathrm{p}}$ devido ao efeito da taxa de deformação, a resposta da estrutura em escala não tem similaridade perfeita com o protótipo. A eq. (54) mostra que a não escalonabilidade da estrutura de viga sujeita ao impacto de uma massa é gerada por $\dot{\varepsilon}$, pois todas as equações de movimento são idênticas para escalas diferentes. Por outro lado, se os fatores desenvolvidos na tese forem empregados, $u$ do modelo e do protótipo são idênticos, gerando perfeita similaridade

$$
(u)_{\mathrm{m}}=4 G \beta v^{2} V_{0}^{2} /\left[B H^{2} \beta v^{2} \sigma_{\mathrm{d}}\right] \rightarrow(u)_{\mathrm{m}}=(u)_{\mathrm{p}} .
$$

c) Resultados

Os valores adotados para a solução do problema são resumidos na Tabela 8. Os deslocamentos no ponto central da viga para diferentes energias de impacto e diferentes fatores de escala são mostrados na Figura 16. Os resultados mostram claramente que o método de correção utilizado no trabalho anula completamente o erro na resposta do modelo quando comparado ao protótipo, mesmo para um fator 
de escala 1/100 (Figura 16 (b)). Por outro lado, quando o fator para a velocidade inicial de impacto não é alterada, o modelo atinge um erro de $17,60 \%$ para $\beta=1 / 100$, Figura 16 (a).

Tabela 8 - Valores adotados para o protótipo da estrutura de viga biengastada sujeita ao impacto de uma massa.

\begin{tabular}{|c|c|c|}
\hline \multicolumn{3}{|c|}{ Geometria da viga } \\
\hline meio comprimento & $L$ & $0,2 \mathrm{~m}$ \\
\hline altura & $H$ & $0,02 \mathrm{~m}$ \\
\hline largura & $B$ & $0,02 \mathrm{~m}$ \\
\hline \multicolumn{3}{|c|}{ Material (aço doce) } \\
\hline massa por comprimento & $m^{\prime}$ & $3,12 \mathrm{~kg} / \mathrm{m}$ \\
\hline tensão de escoamento quasi-estática & $\sigma_{0}$ & $235 \mathrm{MPa}$ \\
\hline constante material & $q$ & 0,077 \\
\hline taxa de deformação de referência & $\dot{\varepsilon}_{0}$ & $0,001 \mathrm{~s}^{-1}$ \\
\hline constante material & $k$ & 0,26 \\
\hline \multicolumn{3}{|c|}{ Condições iniciais } \\
\hline velocidade inicial & $V_{0}$ & 10 to $60 \mathrm{~m} / \mathrm{s}$ \\
\hline massa de impacto & $G$ & $5 \mathrm{~kg}$ \\
\hline
\end{tabular}

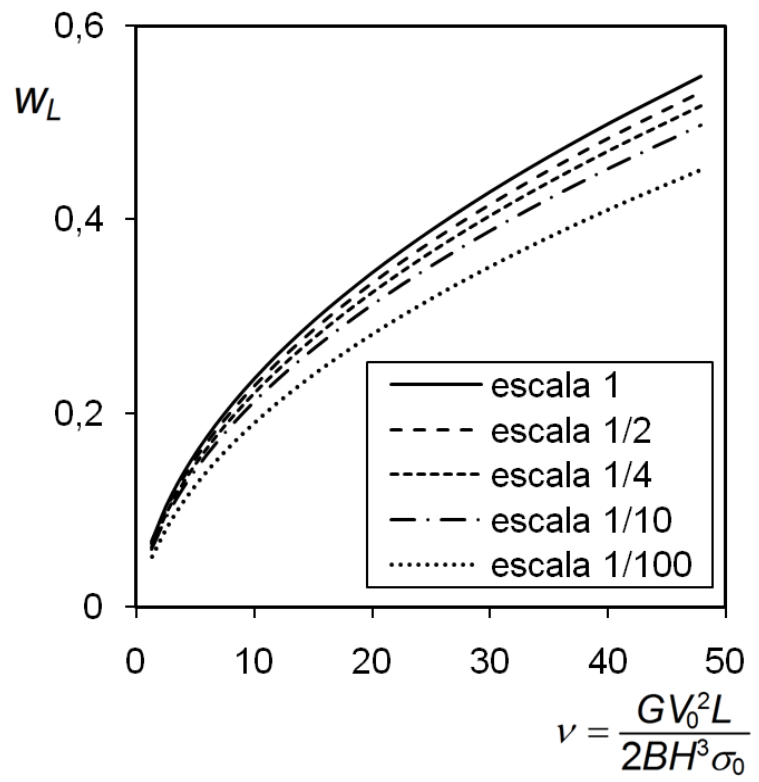

(a)

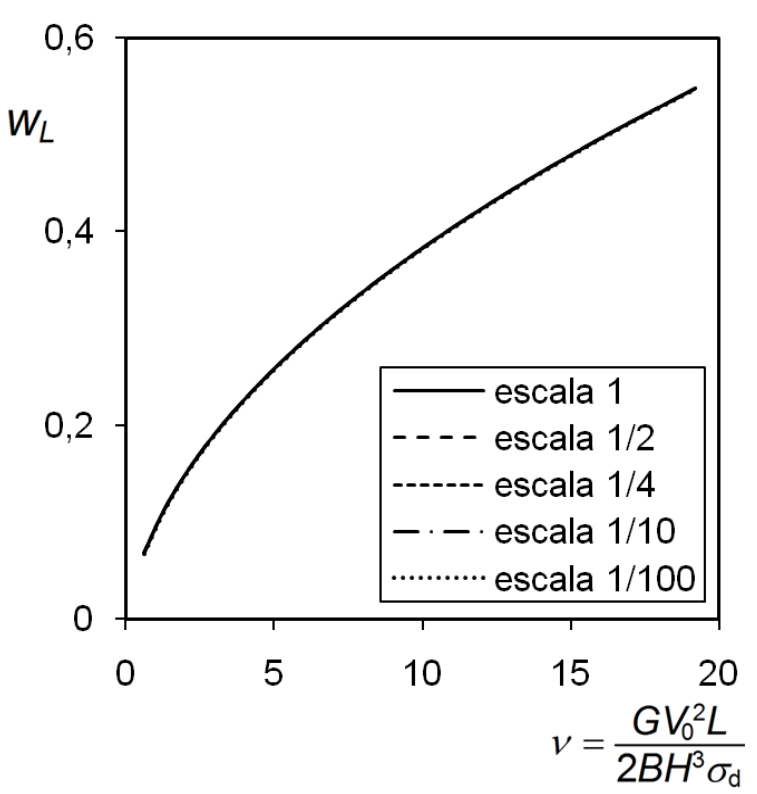

(b)

Figura 16 - Deslocamento final adimensional no centro da viga, $w_{L}$, em função do adimensional $v$ para diferentes fatores de escala. (a) modelo sem correção. (b) modelo corrigido. 


\subsubsection{Viga engastada em ambas as extremidades sujeita a um impulso de velocidade}

O terceiro modelo analítico estudado é uma viga de comprimento $2 L$ e altura $H$, engastada em ambas as extremidades e sujeita a um impulso de velocidade, $V_{0}$, por todo o comprimento (Figura 17).

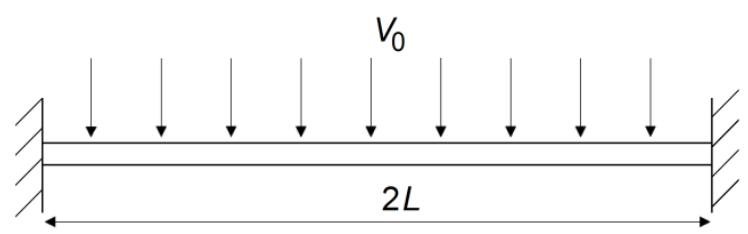

Figura 17 - Viga biengastada sujeita a um impulso de velocidade por todo o comprimento.

a) Formulação

Esse modelo foi estudado analiticamente em detalhes em Jones (1997). Diferentes fases de movimento foram identificadas, com o deslocamento vertical no centro da viga ao final do movimento sendo dado por

$$
w_{H}=\frac{1}{2}\left\{\left(1+3 \lambda^{\prime} / 4\right)^{1 / 2}-1\right\}
$$

$\operatorname{com} w_{H}=W_{\mathrm{f}} / H \mathrm{e}$

$$
\lambda^{\prime}=\frac{4 \rho V_{0}^{2} L^{2}}{\sigma_{\mathrm{d}} H^{2}},
$$

sendo $\rho$ a densidade do material da viga. A tensão de escoamento dinâmica é dada pela equação de Norton-Hoff e a taxa de deformação é dada pela relação de Badra e Perrone (JONES, 1997)

$$
\dot{\varepsilon}=\frac{V_{0} W_{\mathrm{f}}}{3 \sqrt{2} L^{2}}
$$

b) Aplicação do fator de escala 
A eq. (56) define o deslocamento final no centro da viga. Para um modelo em escala $\beta$, a equação é idêntica. Porém, o efeito da taxa de deformação é considerado através do fator $\lambda^{\prime}$, eq. (57). No caso do modelo escalonado de acordo com as leis usuais (Tabela 1 ), $\lambda^{\prime}$ é dado por

$$
\left(\lambda^{\prime}\right)_{\mathrm{m}}=\frac{4 \rho V_{0}^{2}(\beta L)^{2}}{\left(\sigma_{\mathrm{d}}\right)_{\mathrm{m}}(\beta H)^{2}}=\frac{4 \rho V_{0}^{2} L^{2}}{\left(\sigma_{\mathrm{d}}\right)_{\mathrm{m}} H^{2}} .
$$

A similaridade perfeita só ocorre caso $\left(\lambda^{\prime}\right)_{m}=\left(\lambda^{\prime}\right)_{p}$. Nota-se na eq. (59) que a não similaridade ocorre devido à taxa de deformação, pois $\left(\sigma_{\mathrm{d}}\right)_{\mathrm{m}} \neq\left(\sigma_{\mathrm{d}}\right)_{\mathrm{p}}$. Se, no entanto, a eq. (16) for inserida na eq. (59) obtém a igualdade requerida,

$$
\left(\lambda^{\prime}\right)_{\mathrm{m}}=\frac{4 \rho\left(\beta V^{2} V_{0}^{2}\right)(\beta L)^{2}}{\left(\beta V^{2} \sigma_{\mathrm{d}}\right)(\beta H)^{2}} \rightarrow\left(\lambda^{\prime}\right)_{\mathrm{m}}=\left(\lambda^{\prime}\right)_{\mathrm{p}}
$$

Através da eq. (60) é possível notar que a perfeita similaridade é produzida caso os fatores calculados na tese forem utilizados.

\section{c) Resultados}

O problema foi solucionado usando os valores listados na Tabela 9. Os resultados são resumidos na Tabela 10 e mostram novamente que os erros são nulos, mesmo para um fator de escala muito pequeno de 1/2000.

\begin{tabular}{|c|c|c|}
\hline \multicolumn{3}{|c|}{ Geometria da viga } \\
\hline meio comprimento & $L$ & $65 E-3 m$ \\
\hline altura & $H$ & $2,5 \mathrm{E}-3 \mathrm{~m}$ \\
\hline \multicolumn{3}{|c|}{ Material (aço doce) } \\
\hline densidade & $\rho$ & $7800 \mathrm{~kg} / \mathrm{m}^{3}$ \\
\hline tensão de escoamento quasi-estática & $\sigma_{0}$ & $235 \mathrm{MPa}$ \\
\hline constante material & $q$ & 0,077 \\
\hline taxa de deformação de referência & $\dot{\varepsilon}_{0}$ & $0,001 \mathrm{~s}^{-1}$ \\
\hline \multicolumn{3}{|c|}{ Condições iniciais } \\
\hline Velocidade inicial & $V_{0}$ & $50 \mathrm{~m} / \mathrm{s}$ \\
\hline
\end{tabular}

Tabela 9 - Valores usados para o protótipo da estrutura de viga sujeita a um impulso de velocidade. 
Tabela 10 - Comparação entre os resultados do protótipo e do modelo para a estrutura de viga biengastada sujeita a um impulso de velocidade.

\begin{tabular}{cccccc}
\hline & \multicolumn{3}{c}{ Modelo sem correção } & \multicolumn{3}{c}{ Modelo corrigido } \\
$\beta$ & $w_{H}$ & erro (\%) & $\beta_{V}$ & $w_{H}$ & erro (\%) \\
\hline 1 & 3,9060 & 0,00 & 1,000 & 3,9060 & 0 \\
$1 / 2$ & 3,7962 & 2,81 & 1,0281 & 3,9060 & 0 \\
$1 / 4$ & 3,6891 & 5,55 & 1,0571 & 3,9060 & 0 \\
$1 / 10$ & 3,5519 & 9,07 & 1,0966 & 3,9060 & 0 \\
$1 / 20$ & 3,4511 & 11,65 & 1,1274 & 3,9060 & 0 \\
$1 / 2000$ & 2,8477 & 27,17 & 1,3557 & 3,9060 & 0 \\
\hline
\end{tabular}

\subsection{Discussão}

Existem dois aspectos principais no atual trabalho que permitem que o modelo sensível à taxa de deformação tenha perfeita similaridade com o protótipo. 0 primeiro é que, uma base diferente de massa - comprimento - tempo foi aplicada. Através do uso da base velocidade inicial - massa de impacto - tensão dinâmica de escoamento foi possível gerar um novo conjunto de fatores (eq.(12) a (16)) entre modelo e protótipo. O uso desses fatores permite que o modelo possa prever de forma perfeita o comportamento do protótipo através de uma transposição de escalas. Em particular, a eq. (12) é vital para o desenvolvimento do método, pois relaciona a velocidade inicial com a tensão de escoamento - é a relação que introduz o efeito da taxa de deformação no modelo através da velocidade.

O outro aspecto fundamental da presente teoria é a lei constitutiva usada para obter a tensão dinâmica devido ao efeito da taxa de deformação. Ao invés da forma clássica de Cowper-Symonds (eq. (4)) o modelo de Norton-Hoff (eq. (17)) é aplicado. A comparação no comportamento desses dois modelos constitutivos é feita na Figura 18, onde os parâmetros da lei constitutiva exponencial são calculados para ajustar-se à equação de Cowper-Symonds que descreve o aço doce. A vantagem do uso da forma de Norton-Hoff é que a relação entre $\beta v$ e $\beta$ pode ser obtida de forma direta, eq. (21). Em Oshiro e Alves (2004) e Oshiro (2005) o fator para a velocidade inicial é calculado como 


$$
\beta_{V}=\left[\frac{\left(1+\left(\beta v \overline{\dot{\varepsilon}}_{\mathrm{m}} / D\right)^{q}\right)}{\left(1+\left(\beta \overline{\dot{\varepsilon}}_{\mathrm{m}} / D\right)^{q}\right)}\right]^{1 / 2}
$$

sendo $\overline{\dot{\varepsilon}}_{\mathrm{m}}$ uma estimativa do valor da taxa de deformação do modelo sem correção. Como já mencionado, o valor de $\dot{\varepsilon}_{\mathrm{m}}^{\text {nc }}$ nem sempre é fácil de ser obtido, principalmente para modelos complexos. Por exemplo, em Oshiro e Alves (2007) $\dot{\varepsilon}_{\mathrm{m}}^{\mathrm{nc}}$ foi aproximado como $V_{0} /(4 R)$, pois no tipo de estrutura analisado naquele trabalho o valor da taxa de deformação varia em função do tempo e da posição na estrutura. Em contrapartida, a forma proposta no atual trabalho, eq. (21),

$$
\beta v=\beta^{q /(q-2)},
$$

facilita muito o cálculo de $\beta_{V}$, já que nenhum dado de resposta da estrutura é necessário - o fator $\beta$ é imposto e $q$ é uma constante do material. Isso torna o método mais simples e mais robusto, podendo ser aplicado a qualquer tipo de estrutura. As curvas para a eq. (21) são mostradas na Figura 19 para diferentes valores do fator de escala e $q$ variando entre 0 a 0,5 . Obviamente, quanto mais sensível à taxa de deformação for o material - maiores valores de $q-$, maior é o fator de correção da velocidade.

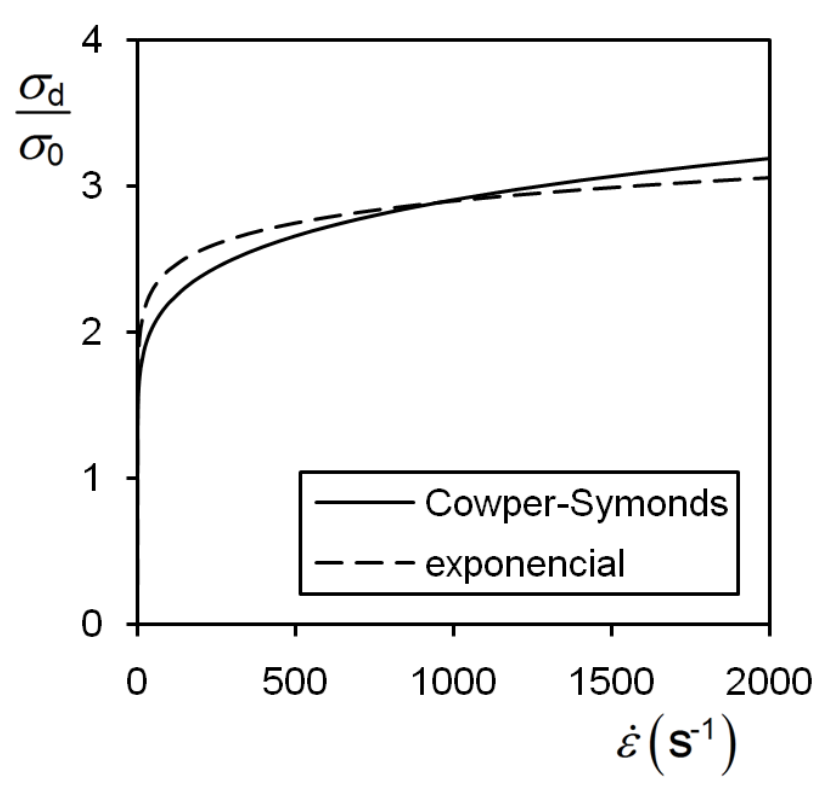

Figura 18 - Comparação entre a equação de Norton-Hoff ( $\sigma_{0}=235 \mathrm{MPa}, \dot{\varepsilon_{0}}=0,001 \mathrm{~s}^{-1}$ e $\left.q=0,077\right)$ e Cowper-Symonds ( $\sigma_{0}=235 \mathrm{MPa}, D=40 \mathrm{~s}^{-1}$ e $\left.q=0,2\right)$. 
Outro aspecto da atual técnica é que a perfeita similaridade é gerada, ou seja, o comportamento dos modelos é idêntico ao protótipo. Esse fato pode ser comprovado pelos três modelos analíticos estudados na seção 2.1. Por exemplo, a Tabela 11 resume os erros do modelo de Calladine relativamente ao protótipo quando o problema é resolvido com os valores numéricos da Tabela 6 . Enquanto o erro no ângulo final de rotação em um modelo não corrigido de escala 1/100 é de $20 \%$ e a tensão é 1,43 vezes maior do que o esperado, as mesmas variáveis atingem similaridade perfeita quando a velocidade inicial de impacto é corrigida. Nenhuma aproximação no método de correção é feita nos modelos analíticos, por isso o erro é nulo nesses casos.

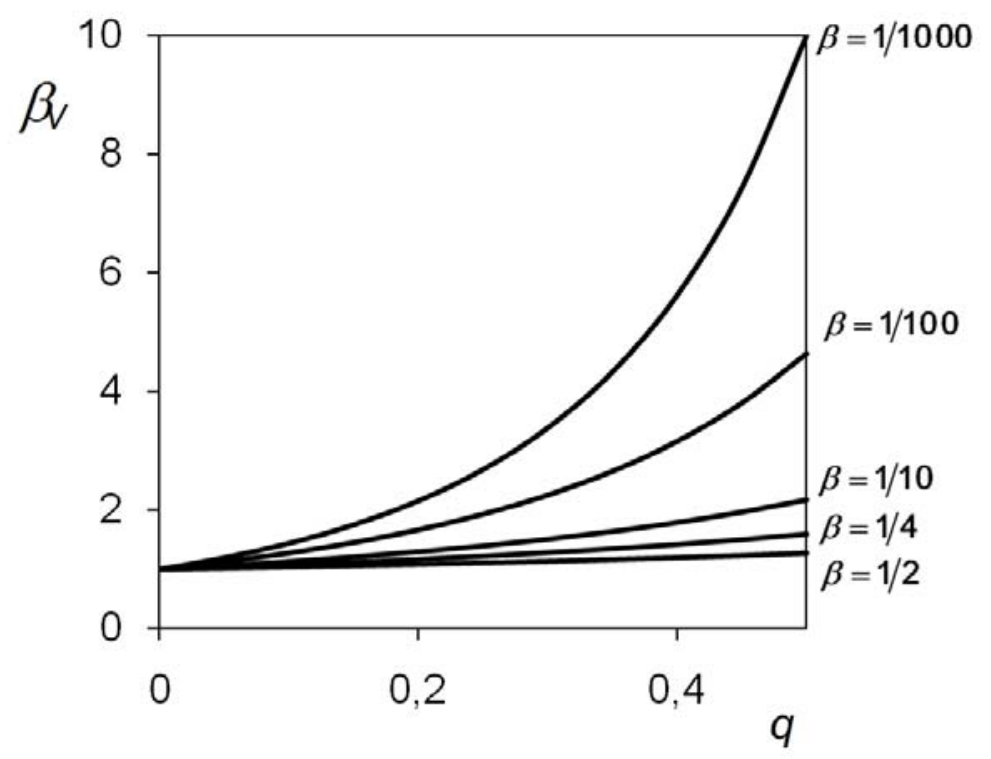

Figura 19 - Fator de velocidade, $\beta_{V}$, em função da constante material $q$ e diferentes fatores de escala.

Apesar dos erros gerados em Oshiro e Alves (2004) serem pequenos (ver Tabela 2 e Figura 7), o método atual é mais robusto e simples. No capítulo 4, a mesma técnica será aplicada a dois modelos numéricos: um tubo engastado em ambas as extremidades e sujeito ao impacto radial de uma massa rígida no centro e o casco de um navio impactado por uma esfera rígida. Antes, no capítulo 3, o efeito de uma distorção na geometria da estrutura é estudado e uma forma de correção é proposta. 
Tabela 11 - Erros no modelo de Calladine.

\begin{tabular}{lccc}
\hline \multicolumn{3}{c}{ Modelo sem correção } \\
\hline escala & $1 / 2$ & $1 / 4$ & $1 / 100$ \\
& & erro (\%) \\
rotação final & 3,27 & 6,45 & 20,00 \\
final da primeira fase & 3,30 & 6,49 & 20,05 \\
final da segunda fase & 5,29 & 10,30 & 30,24 \\
aceleração final & 5,59 & 11,48 & 43,35 \\
taxa de deformação final & 1,28 & 2,52 & 7,47 \\
tensão final & 5,59 & 11,48 & 43,35 \\
\hline & Modelo corrigido & & \\
\hline escala & $1 / 2$ & $1 / 4$ & $1 / 100$ \\
fator de velocidade & 1,047 & 1,097 & 1,359 \\
& & erro (\%) & \\
rotação final & 0 & 0 & 0 \\
final da primeira fase & 0 & 0 & 0 \\
final da segunda fase & 0 & 0 & 0 \\
aceleração final & 0 & 0 & 0 \\
taxa de deformação final & 0 & 0 & 0 \\
tensão final & 0 & 0 & 0 \\
\hline
\end{tabular}




\section{MÉTODO DE CORREÇÃO PARA MODELOS COM GEOMETRIA DISTORCIDA}

Em determinadas situações experimentais pode ser necessário empregar uma geometria distorcida no modelo, pois pode inviável reproduzir uma das dimensões devido a limitações de fabricação. Por exemplo, se um navio for reproduzido em escala 1/100, a espessura da chapa é um fator complicador, pois pode não ser exequível a construção de uma réplica com uma espessura de chapa 100 vezes menor. Devido a esse obstáculo experimental na reprodução das dimensões do protótipo, apresenta-se nesta seção, um método em que a distorção de geometria na escala é considerada através da mudança na velocidade inicial de impacto.

Para que seja possível inserir o efeito de distorção de geometria no modelo de correção é necessário criar um novo fator

$$
\beta_{X}=X_{\mathrm{m}} / X_{\mathrm{p}}
$$

onde $X$ é a dimensão geométrica distorcida, ou seja, $\beta_{X} \neq \beta$. O fator de correção da velocidade inicial de impacto é agora uma função de $\beta$ e $\beta_{X}, \beta_{V}=f\left(\beta, \beta_{X}\right)$. A maior diferença para esse caso é que não existe uma expressão geral para $f$ que exprima a variação de $\beta_{V}$ como função de $\beta_{X}$ e $\beta$ para todos os tipos de estrutura. Portanto, $f$ deve ser determinado para cada tipo de estrutura e para distorções diferentes na geometria. A função $f$ não pode ser estabelecida de uma forma geral devido à dependência da taxa de deformação em relação à geometria da estrutura. Por exemplo, a taxa de deformação para o caso de uma viga engastada nas extremidades e sujeita a um impulso de velocidade por todo o comprimento é dada aproximadamente pela eq. (58), $\dot{\varepsilon}=V_{0} W_{f} /\left(3 \sqrt{2} L^{2}\right)$. No entanto, a taxa de deformação para o caso de viga sujeita ao impacto de uma massa no centro é aproximada pela eq. (48)

$$
\dot{\varepsilon}_{\mathrm{eq}}=V_{0} / L\left[9\left(1+r^{2}\right)^{2} h^{2} / 8+8 k^{2} / 3\right]^{1 / 2}
$$

Consequentemente, uma variação do fator $\beta_{L}=L_{m} / L_{p}$ influencia de forma distinta esses dois tipos de estrutura. 
Na próxima seção, um método geral de correção para modelos com geometria distorcida é proposto. A seguir, na seção 3.2, os modelos analíticos estudados na seção 2.1 são novamente analisados, mas uma das dimensões é propositalmente distorcida em relação às demais. Em algumas situações será possível obter de forma explícita a relação $\beta_{V}=f\left(\beta, \beta_{X}\right)$, mas para outros será usado o método aproximado apresentado na seção 3.1.

\subsection{Método geral para determinação do fator de correção no caso de geometria distorcida}

Apesar de uma distorção da geometria não atender as condições impostas pela teoria dos $\Pi$, ainda pode existir uma relação consistente entre modelo e protótipo (CHO et al., 2005). É possível correlacionar diferentes tipos de contorno e valores iniciais do problema. Por isso, nessa seção considera-se que existe um fator que relaciona o comportamento das estruturas, mesmo quando uma das dimensões é distorcida em relação ao fator de escala geométrico. Dessa maneira, uma razão entre as velocidades, $\beta v$, que relaciona as respostas das estruturas deve ser definida. Como em alguns casos práticos a definição de $\beta V$ é muito complexa ou impossível, um método aproximado mais abrangente é desenvolvido.

Se a dimensão distorcida do modelo for $X$, a razão $\beta_{X}=X_{\mathrm{m}} / X_{\mathrm{p}}$ é diferente de $\beta$. Assim, a função

$$
\beta V=f\left(\beta, \beta_{X}\right)
$$

que relaciona a razão de forma e a distorção da geometria com o fator de velocidade, $\beta V$, precisa ser determinada. A influência dos fatores que causam a não similaridade (taxa de deformação e distorção da geometria) é considerada independente, ou seja, $f$ pode ser decomposta em duas funções

$$
f=f_{1}(\beta) f_{2}\left(\beta_{X}\right) .
$$

A função que considera apenas o efeito da taxa de deformação, $f_{1}$, é conhecida e foi detalhada no capítulo 2, eq.(21).

Considera-se que a função $f_{2}$ tem um formato similar a $f_{1}$, ou seja, 


$$
f_{2}=\beta_{X}^{n}
$$

Portanto, é necessário determinar o expoente $n$ da função $f_{2}$. A definição de $n$ é feita produzindo-se uma variação premeditada do fator de distorção geométrico, $\beta_{X}$, e analisando a variação de $f_{2}$ correspondente. Dois modelos em uma escala $\beta$, mas distorcidos geometricamente por fatores $\beta_{X_{1}}$ e $\beta_{X_{2}}$ em uma determinada dimensão são utilizados

$$
\left.\begin{array}{l}
\beta_{V_{2}}=f_{1}(\beta) \beta_{X_{2}}{ }^{n} \\
\beta_{V_{1}}=f_{1}(\beta) \beta_{X_{1}}{ }^{n}
\end{array}\right\} \rightarrow \frac{\beta_{V_{2}}}{\beta_{V_{1}}}=\left(\frac{\beta_{X_{2}}}{\beta_{X_{1}}}\right)^{n}
$$

O modelo 1 tem um fator distorcido $\beta_{X_{1}}=X_{\mathrm{m}_{1}} / X_{\mathrm{p}}$ e fator de velocidade $\beta_{V_{1}}=\left(V_{\mathrm{m}}\right)_{1} / V_{\mathrm{p}}$ e o modelo 2, $\beta_{X_{2}}=X_{\mathrm{m}_{2}} / X_{\mathrm{p}}$ e $\beta_{V_{2}}=\left(V_{\mathrm{m}}\right)_{2} / V_{\mathrm{p}}$. Quando existe similaridade perfeita entre os modelos e o protótipo, eles compartilham o mesmo expoente $n$ (Figura 20). Portanto,

$$
\frac{\left(V_{\mathrm{m}}\right)_{2}}{\left(V_{\mathrm{m}}\right)_{1}}=\left(\frac{\beta_{X_{2}}}{\beta_{X_{1}}}\right)^{n}
$$

ou

$$
n=\log \left[\left(V_{m}\right)_{2} /\left(V_{m}\right)_{1}\right] / \log \left(\beta_{X_{2}} / \beta_{X_{1}}\right)
$$

Sendo a razão $\beta_{X_{2}} / \beta_{X_{1}}$ conhecida, deve-se determinar a razão entre as velocidades $\left(V_{\mathrm{m}}\right)_{2} /\left(V_{\mathrm{m}}\right)_{1}$ que gere respostas similares dos dois modelos. Dois processos são possíveis: variar a razão de velocidades e determinar $n$ através da eq. (65) ou variar $n$ e determinar a razão de velocidades através da eq. (64). A principal característica do método é o uso de dois modelos para calcular o efeito da distorção da geometria e a transposição dos resultados através de $f_{2}$. A Figura 20 exibe de forma esquemática a curva de similaridade perfeita que representa a solução idealizada para o problema. A Tabela 12 mostra o processo de tentativas para determinar $f_{2}$. No exemplo da Tabela 12 , a variável deslocamento, $\delta$ m, é usada como referência de comparação do comportamento dos dois modelos. O processo termina quando $\left(\delta_{\mathrm{m}}\right)_{2} /\left(\delta_{\mathrm{m}}\right)_{1} \approx 1$, indicando perfeita similaridade entre os modelos 1 e 2 .

As demais variáveis do modelo também podem ser relacionadas com as variáveis do protótipo através de fatores de escala calculados. Assim como no caso 
da velocidade, o fator é dividido em duas partes, $f_{1}$ e $f_{2}$. O primeiro termo considera o efeito da taxa de deformação e é calculado através das eq. (12) a (16). O segundo termo considera a distorção da geometria e possui o mesmo formato da eq. (63). Nesse caso, o expoente $n_{Y}$ deve ser determinado para cada variável medida no modelo, $Y$. As variáveis são medidas nos modelos 1 e 2 já determinados no processo de correção da velocidade inicial e $n_{Y}$ é calculado de forma idêntica à eq. (65),

$$
n_{Y}=\log \left[\left(Y_{\mathrm{m}}\right)_{2} /\left(Y_{\mathrm{m}}\right)_{1}\right] / \log \left(\beta_{X_{2}} / \beta_{X_{1}}\right)
$$

Dessa forma,

$$
(Y)_{\mathrm{m}}=f_{1} f_{2}(Y)_{\mathrm{p}}
$$

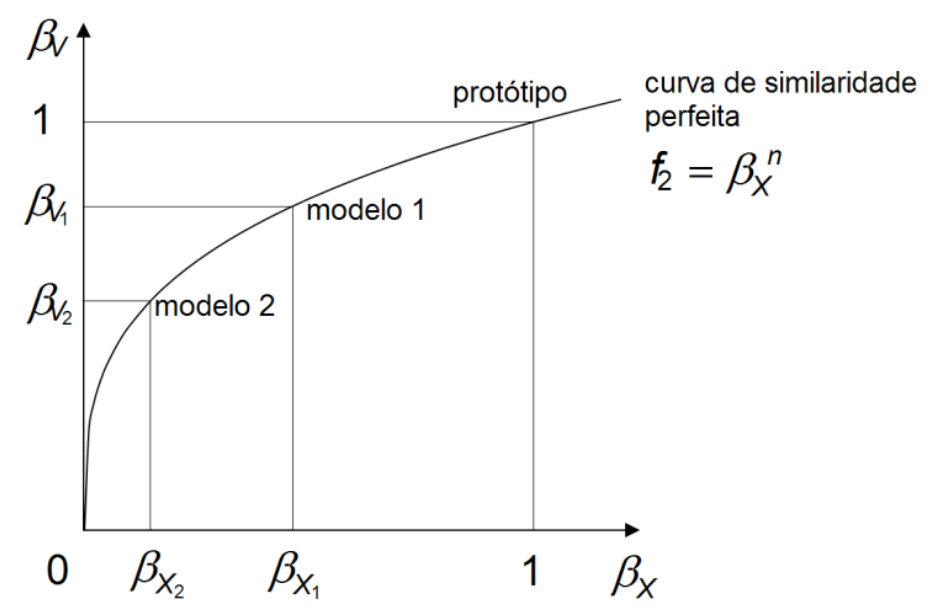

Figura 20 - Curva idealizada para o fator de correção da velocidade inicial, $\beta V$, como função do fator geométrico distorcido, $\beta_{X}$.

Tabela 12 - Processo de determinação do valor do expoente $n$ através do uso de dois modelos.

\begin{tabular}{cccc}
\hline tentativa & $\begin{array}{c}\text { velocidade } \\
V_{\mathrm{m}_{2}} / V_{\mathrm{m}_{1}}\end{array}$ & $\begin{array}{c}\text { expoente } \\
n\end{array}$ & $\begin{array}{c}\text { variável de comparação } \\
\left(\delta_{\mathrm{m}}\right)_{2} /\left(\delta_{\mathrm{m}}\right)_{1}\end{array}$ \\
\hline 1 & $\left(v_{\mathrm{m}_{2}} / V_{\mathrm{m}_{1}}\right)_{1}$ & $n_{1}$ & {$\left[\left(\delta_{\mathrm{m}}\right)_{2} /\left(\delta_{\mathrm{m}}\right)_{1}\right]_{1}$} \\
2 & $\left(V_{\mathrm{m}_{2}} / V_{\mathrm{m}_{1}}\right)_{2}$ & $n_{2}$ & {$\left[\left(\delta_{\mathrm{m}}\right)_{2} /\left(\delta_{\mathrm{m}}\right)_{1}\right]_{2}$} \\
$\ldots$ & $\ldots$ & $\ldots$ & $\ldots$ \\
$\mathrm{i}$ & $\left(v_{\mathrm{m}_{2}} / V_{\mathrm{m}_{1}}\right)_{\mathrm{i}}$ & $n_{\mathrm{i}}$ & {$\left[\left(\delta_{\mathrm{m}}\right)_{2} /\left(\delta_{\mathrm{m}}\right)_{1}\right]_{\mathrm{i}}$} \\
\hline
\end{tabular}


No caso de geometria distorcida, a transposição das variáveis do modelo não pode ser feita de forma direta, usando as eq. (12) a (16). O vínculo das respostas do modelo e do protótipo é feita através de

$$
\begin{aligned}
& (\dot{\varepsilon})_{\mathrm{m}}=\frac{\beta_{V}}{\beta}\left(\frac{\beta_{X}}{\beta}\right)^{n_{\dot{\varepsilon}}}(\dot{\varepsilon})_{\mathrm{p}}, \\
& (t)_{\mathrm{m}}=\frac{\beta}{\beta_{V}}\left(\frac{\beta_{X}}{\beta}\right)^{n_{t}}(t)_{\mathrm{p}}, \\
& (A)_{\mathrm{m}}=\frac{\beta^{2}}{\beta}\left(\frac{\beta_{X}}{\beta}\right)^{n_{A}}(A)_{\mathrm{p}}
\end{aligned}
$$

e

$$
(\sigma)_{\mathrm{m}}=\frac{1}{\beta^{2}}\left(\frac{\beta_{X}}{\beta}\right)^{n_{A}}(\sigma)_{\mathrm{p}}
$$

sendo $n_{\dot{\varepsilon}}, n_{t}, n_{A}$ e $n_{\sigma}$ os expoentes da função $f_{2}$ para as variáveis taxa de deformação, tempo, aceleração e tensão, respectivamente, calculados conforme a eq. (66). O fator $\beta$ nesse caso é dado pela eq. (21) e $\beta_{x}$ pela eq. (62). Na hipótese do modelo ter a mesma escala do protótipo, ou seja, a similaridade imperfeita se deve somente à distorção da geometria, as eq. (68) a (71) são simplificadas com $\beta=\beta=1$.

Para analisar os resultados desse método, a viga com altura distorcida sujeita ao impacto de uma massa (seção 3.2.2 c)) e estrutura de Calladine (seção 3.2.3) são corrigidos usando a função $f_{2}$ proposta. No capítulo 4 o mesmo processo de correção é aplicado a dois modelos numéricos.

\subsection{Modelos analíticos}

Os três modelos analíticos estudados na seção 2.1 foram solucionados para analisar o método de correção de estruturas com geometria distorcida. Nos casos onde a solução direta é possível, a equação que relaciona o fator de velocidade aos fatores $\beta$ e $\beta_{X}$ é calculada. Porém, para alguns modelos a solução explícita não é possível - estrutura de Calladine e viga sujeita ao impacto de uma massa com 
distorção na altura. Para esses casos, o método mais geral exposto na seção 3.1 é aplicado.

\subsubsection{Viga sujeita a um impulso de velocidade por todo o comprimento}

O problema de uma viga sujeita a um impulso de velocidade, estudado na seção 2.1.3, é solucionado novamente. Porém, a geometria da viga será distorcida de duas formas: (a) no comprimento, (b) na altura. Como será mostrado, a forma como o fator de velocidade é calculado nestes dois casos é diferente.

(a) Distorção do comprimento da viga

O comprimento da viga, $L$, do modelo é distorcido em relação ao fator geométrico geral, ou seja, $\beta \neq L_{\mathrm{m}} / L_{\mathrm{p}}$. O fator geométrico do comprimento é dado pela relação $\beta_{L}=L_{m} / L_{p}$. Dessa forma, o fator de velocidade tem algumas diferenças em relação ao modelo sem distorção de geometria. O deslocamento máximo adimensional no centro da viga é dado pela eq. (56),

$$
w_{H}=\frac{1}{2}\left\{\left(1+3 \lambda^{\prime} / 4\right)^{1 / 2}-1\right\} \text {. }
$$

Para que $\left(W_{H}\right)_{\mathrm{m}}=\left(W_{H}\right)_{\mathrm{p}}$, deve-se gerar a seguinte condição $\left(\lambda^{\prime}\right)_{\mathrm{m}}=\left(\lambda^{\prime}\right) \mathrm{p}$. Portanto,

$$
\left[\frac{4 \rho V_{0}^{2} L^{2}}{\sigma_{\mathrm{d}} H^{2}}\right]_{\mathrm{p}}=\left[\frac{4 \rho V_{0}^{2} L^{2}}{\sigma_{\mathrm{d}} H^{2}}\right]_{\mathrm{m}} \rightarrow \frac{\left(\sigma_{\mathrm{d}}\right)_{\mathrm{m}}}{\left(\sigma_{\mathrm{d}}\right)_{\mathrm{p}}}=\left(\frac{\beta_{V} \beta_{L}}{\beta}\right)^{2}
$$

Ainda, $\sigma_{\mathrm{d}}=K \dot{\varepsilon}^{q}$, com a taxa de deformação, $\dot{\varepsilon}$, sendo dada pela eq. (58), $\dot{\varepsilon}=V_{0} W_{\mathrm{f}} / 3 \sqrt{2} L^{2}$, que gera

$$
\frac{\left(\sigma_{\mathrm{d}}\right)_{\mathrm{m}}}{\left(\sigma_{\mathrm{d}}\right)_{\mathrm{p}}}=\left(\left[\frac{V_{0} W_{\mathrm{f}}}{3 \sqrt{2} L^{2}}\right]_{\mathrm{m}}\left[\frac{V_{0} W_{\mathrm{f}}}{3 \sqrt{2} L^{2}}\right]_{\mathrm{p}}^{-1}\right)^{q}=\left(\frac{\beta V}{\beta_{L}^{2}}\right)^{q} .
$$

Igualando eq. (72) com (73) tem-se 


$$
\left(\frac{\beta_{V} \beta}{\beta_{L}{ }^{2}}\right)^{q}=\left(\frac{\beta_{V} \beta_{L}}{\beta}\right)^{2} \rightarrow \beta_{V}=\left(\beta^{q+2} \beta_{L}^{-2 q-2}\right)^{1 /(2-q)}
$$

Portanto, o fator de correção para o modelo de viga sujeita a um impulso de velocidade pode ser calculado diretamente usando a eq. (74). Os resultados são comparados na Tabela 13, para o modelo sem correção e Tabela 14, para o modelo com a velocidade inicial corrigida. Os valores utilizados para a solução do problema são resumidos na Tabela 9. Na segunda e terceira linhas da Tabela 13 o fator de escala foi mantido igual a 1 , mas com $\beta_{L} \neq \beta$. Dessa forma, é possível averiguar o erro devido somente à distorção do comprimento da viga. Na quarta e quinta linhas da Tabela 13 o erro é oriundo da combinação de um fator de escala $\beta=1 / 20$ e $\beta_{L} \neq \beta$.

Tabela 13 - Resultados para a estrutura de viga sujeita a um impulso de velocidade. Comprimento distorcido e velocidade não corrigida.

\begin{tabular}{ccccc}
\hline$\beta$ & $\beta_{L}$ & distorção $(\%)$ & $W_{H}$ & erro (\%) \\
\hline 1 & 1,000 & 0 & 3,9060 & 0,00 \\
1 & 0,500 & -50 & 1,7001 & 56,47 \\
1 & 2,000 & +100 & 8,4776 & 117,04 \\
$1 / 20$ & 0,025 & -50 & 1,4833 & 62,03 \\
$1 / 20$ & 0,100 & +100 & 7,5390 & 93,01 \\
\hline
\end{tabular}

Tabela 14 - Resultados para a estrutura de viga sujeita a um impulso de velocidade. Comprimento distorcido e velocidade corrigida.

\begin{tabular}{cccccc}
\hline$\beta$ & $\beta_{L}$ & distorção (\%) & $\beta V$ & $W_{H}$ & erro (\%) \\
\hline 1 & 1,000 & 0 & 1,0000 & 3,9060 & 0 \\
1 & 0,500 & -50 & 2,1737 & 3,9060 & 0 \\
1 & 2,000 & +100 & 0,4601 & 3,9060 & 0 \\
$1 / 20$ & 0,025 & -50 & 2,4507 & 3,9060 & 0 \\
$1 / 20$ & 0,100 & +100 & 0,5187 & 3,9060 & 0 \\
\hline
\end{tabular}

(b) Distorção da altura da viga

Diferentemente do problema proposto em a), o comprimento da viga agora obedece normalmente a lei de similaridade, mas a altura da viga no modelo é 
alterada e relaciona-se com o protótipo através do fator $\beta_{H}=H_{\mathrm{m}} / H_{\mathrm{p}}$, diferente de $\beta$. Aqui, é necessário fazer a distinção do modelo corrigido do não corrigido. $O$ sobrescrito "c" é usado para identificar as variáveis relativas ao primeiro caso e "nc" para o segundo.

De forma similar à seção anterior, o fator de velocidade será recalculado usando as equações de dinâmica do modelo (seção 2.1.3), sendo que $\alpha$ é definido como

$$
\alpha=\frac{3 \lambda^{\prime}}{4}=\frac{3 \rho V_{0}^{2} L^{2}}{\sigma_{\mathrm{d}} H^{2}}=\frac{3 \rho V_{0}^{2} L^{2}}{K \dot{\varepsilon}^{q} H^{2}} .
$$

Para o modelo corrigido e protótipo, $\alpha$ é dado por

$$
\alpha_{\mathrm{m}}^{\mathrm{c}}=\frac{3 \rho V_{0}^{2} L^{2}}{\left(\sigma_{\mathrm{d}}\right)_{\mathrm{m}}^{\mathrm{c}} H^{2}} \frac{\beta V^{2} \beta^{2}}{\beta_{H^{2}}}
$$

e

$$
\alpha_{\mathrm{p}}=\frac{3 \rho V_{0}^{2} L^{2}}{\left(\sigma_{\mathrm{d}}\right)_{\mathrm{p}} H^{2}}
$$

sendo que $\sigma_{\mathrm{d}}$ para modelo e protótipo é dado por $\left(\sigma_{\mathrm{d}}\right)_{\mathrm{m}}=K\left(\dot{\varepsilon}_{\mathrm{m}}^{\mathrm{c}}\right)^{q}$ e $\left(\sigma_{\mathrm{d}}\right)_{\mathrm{p}}=K\left(\dot{\varepsilon}_{\mathrm{p}}\right)^{q}$, respectivamente. Porém, para que não seja necessário nenhum dado do protótipo, $\dot{\varepsilon}_{\mathrm{m}}^{\mathrm{c}}$ e $\dot{\varepsilon}_{\mathrm{p}}$ devem ser expressos em função da taxa de deformação do modelo não corrigido, $\dot{\varepsilon}_{\mathrm{m}}^{\text {nc }}$. Lembrando que a taxa de deformação é dada pela eq. (58), tem-se

$$
\begin{gathered}
\dot{\varepsilon}_{\mathrm{m}}^{\mathrm{c}}=\frac{V_{0}^{2}\left(W_{\mathrm{f}}\right)_{\mathrm{p}}}{3 \sqrt{2} L^{2}} \frac{\beta V^{2}}{\beta}, \\
\dot{\varepsilon}_{\mathrm{p}}=\frac{V_{0}^{2}\left(W_{\mathrm{f}}\right)_{\mathrm{p}}}{3 \sqrt{2} L^{2}}
\end{gathered}
$$

e

$$
\dot{\varepsilon}_{\mathrm{m}}^{\mathrm{nc}}=\frac{V_{0}^{2}\left(W_{\mathrm{f}}\right)_{\mathrm{p}}}{3 \sqrt{2}^{2}} \frac{\beta^{\prime}}{\beta^{2}}
$$

sendo $\beta^{\prime}=\left(W_{\mathrm{f}}\right)_{\mathrm{m}}^{\mathrm{nc}} /\left(W_{\mathrm{f}}\right)_{\mathrm{p}}$. $\left(W_{\mathrm{f}}\right)_{\mathrm{p}}$ é o deslocamento no centro da viga para o protótipo e $\left(W_{\mathrm{f}}\right)_{\mathrm{m}}^{\text {nc }}$ para o modelo não corrigido. Portanto,

$$
\frac{\dot{\varepsilon}_{\mathrm{m}}^{\mathrm{c}}}{\dot{\varepsilon}_{\mathrm{m}}^{\mathrm{c}}}=\frac{\beta^{2} \beta}{\beta^{\prime}}
$$




$$
\frac{\dot{\varepsilon}_{\mathrm{p}}}{\dot{\varepsilon}_{\mathrm{m}}^{\mathrm{nc}}}=\frac{\beta^{2}}{\beta^{\prime}} .
$$

Inserindo (81) e (82) em (76) e (77) obtém-se

$$
\alpha_{\mathrm{m}}^{\mathrm{c}}=\frac{3 \rho V_{0}^{2} L^{2}}{K\left(\dot{\varepsilon}_{\mathrm{m}}^{\mathrm{nc}}\right)^{q} H^{2}} \frac{\beta v^{2} \beta^{2}}{\beta_{H^{2}}}\left(\frac{\beta^{\prime}}{\beta^{2} \beta}\right)^{q}=\alpha^{\prime} \frac{\beta V^{2} \beta^{2}}{\beta_{H^{2}}}\left(\frac{\beta^{\prime}}{\beta^{2} \beta}\right)^{q}
$$

e

$$
\alpha_{p}=\frac{3 \rho V_{0}^{2} L^{2}}{K\left(\dot{\varepsilon}_{\mathrm{m}}^{\mathrm{nc}}\right)^{q} H^{2}}\left(\frac{\beta^{\prime}}{\beta^{2}}\right)^{q}=\alpha^{\prime}\left(\frac{\beta^{\prime}}{\beta^{2}}\right)^{q}
$$

sendo que

$$
\alpha^{\prime}=\frac{3 \rho V_{0}^{2} L^{2}}{K\left(\dot{\varepsilon}_{\mathrm{m}}^{\mathrm{nc}}\right)^{q} H^{2}}
$$

Portanto,

$$
\frac{\left(W_{H}\right)_{\mathrm{m}}}{\left(w_{H}\right)_{\mathrm{p}}}=\frac{\beta}{\beta_{H}}=\frac{\left(\alpha_{\mathrm{m}}^{\mathrm{c}}+1\right)^{1 / 2}-1}{\left(\alpha_{\mathrm{p}}+1\right)^{1 / 2}-1}=\frac{\left(\alpha^{\prime} \beta^{2-2 q} \beta^{2} / \beta_{\left.H^{2}+1\right)^{1 / 2}-1}\right.}{\left(\alpha^{\prime} \beta^{\prime q} / \beta^{2 q}+1\right)^{1 / 2}-1} .
$$

Usando a aproximação $\left(\beta^{\prime} / \beta\right)^{q} \approx 1$ e rearranjando a eq. (86) de forma a isolar $\beta_{V}$, obtém-se a equação para o cálculo do fator de velocidade quando há distorção na altura do modelo e para material sensível à taxa de deformação

$$
\beta_{V}=\left\{\left\{\left\{\frac{\beta}{\beta_{H}}\left[\left(\frac{\alpha^{\prime}}{\beta^{q}}+1\right)^{1 / 2}-1\right]+1\right\}^{2}-1\right\} \frac{\alpha^{\prime} \beta^{2}}{\beta_{H^{2}}}\right\}^{1 /(2-2 q)},
$$

sendo $\alpha^{\prime}$ dado pela eq. (85) e $\dot{\varepsilon}_{\mathrm{m}}^{\text {nc }}$ pela eq. (58) calculado para o modelo não corrigido.

Os resultados para o modelo não corrigido são resumidos na Tabela 15, sendo que os valores usados para a solução são os mesmos do problema anterior (Tabela 9). A segunda e terceira linhas da Tabela 15 mostram o erro gerado devido somente à distorção da altura, ou seja, $\beta=1$ e $\beta_{H} \neq \beta$. O efeito conjunto da aplicação do fator de escala $\beta=1 / 20$ e de $\beta_{H} \neq \beta$ é observado na quarta e quinta linhas da mesma tabela. A Tabela 16 mostra os resultados quando o fator de correção da velocidade é aplicado. Na última coluna da Tabela 16 a razão $\left(\beta^{\prime} / \beta\right)^{q}$ é calculada 
para que a aproximação feita durante a solução possa ser averiguada. Como se pode perceber, a aproximação é bastante razoável, fato comprovado também pelos erros pequenos observados com a aplicação do fator de correção no modelo. Obviamente, quanto mais distante a razão $\left(\beta^{\prime} / \beta\right)^{q}$ estiver de 1 , maior é o erro de $W_{f} / L$.

Tabela 15 - Resultados para a estrutura de viga sujeita a um impulso de velocidade. Altura distorcida e velocidade não corrigida.

\begin{tabular}{ccccc}
\hline$\beta$ & $\beta_{H}$ & distorção (\%) & $W_{\mathrm{f}} / L$ & erro (\%) \\
\hline 1 & 1 & 0 & 0,1502 & 0 \\
1 & 0,5 & -50 & 0,1588 & 5,62 \\
1 & 2 & +100 & 0,1349 & 10,19 \\
$1 / 20$ & 0,025 & -50 & 0,1411 & 6,09 \\
$1 / 20$ & 0,1 & +100 & 0,1178 & 21,60 \\
\hline
\end{tabular}

Tabela 16 - Resultados para a estrutura de viga sujeita a um impulso de velocidade. Altura distorcida e velocidade corrigida.

\begin{tabular}{ccccccc}
\hline$\beta$ & $\beta_{H}$ & distorção (\%) & $\beta_{V}$ & $W_{\mathrm{f}} / L$ & erro (\%) & $\left(\beta^{\prime} / \beta\right)^{q}$ \\
\hline 1 & 1 & 0 & 1 & 0,1502 & 0 & 1 \\
1 & 0,5 & -50 & 0,9351 & 0,1486 & 1,09 & 1,004 \\
1 & 2 & +100 & 1,1196 & 0,1530 & 1,84 & 0,9918 \\
$1 / 20$ & 0,025 & -50 & 1,0598 & 0,1494 & 0,58 & 0,9952 \\
$1 / 20$ & 0,1 & +100 & 1,2680 & 0,1538 & 2,35 & 0,9814 \\
\hline
\end{tabular}

\subsubsection{Viga sujeita ao impacto de uma massa no centro}

O modelo analítico apresentado na seção 2.1.2 é usado mais uma vez para estudar o método de correção com distorção na geometria. Conforme visto, o deslocamento máximo no centro da viga, $w_{L}$, para o caso da viga sujeita ao impacto de uma massa é dado pela eq. (44) ou

$$
w_{L}=\frac{\sqrt{2 G V_{0}^{2} L /\left(\sigma_{\mathrm{d}} B H^{3}\right)+1}-1}{2 L / H},
$$


sendo $W_{L}$ definido como $W_{f} / L$. No caso de similaridade perfeita a razão

$$
\left(W_{\mathrm{f}}\right)_{\mathrm{m}} /\left(W_{\mathrm{f}}\right)_{\mathrm{p}}=\beta
$$

precisa ser verdadeira.

Na parte (a) uma distorção na largura é introduzida no modelo e através da correção da velocidade inicial de impacto, a relação (88) é reproduzida. A seguir, na parte (b), é considerada uma distorção no comprimento da viga com as outras dimensões do modelo seguindo fielmente a razão $\beta$. Por último, será introduzida uma desproporcionalidade na altura (parte (c)).

(a) Distorção na largura da viga

Neste caso $\beta_{B} \neq \beta$, sendo $\beta_{B}=B_{\mathrm{m}} / B_{\mathrm{p}}$. Para que a relação (44) seja verdadeira, somente parte da eq. (88) precisa ser atendida

$$
\left[\frac{2 G V_{0}^{2} L}{\sigma_{\mathrm{d}} B H^{3}}\right]_{\mathrm{m}}=\left[\frac{2 G V_{0}^{2} L}{\sigma_{\mathrm{d}} B H^{3}}\right]_{\mathrm{p}} .
$$

Portanto,

$$
\frac{\beta^{3} \beta_{V}^{2} \beta}{\beta_{\sigma} \beta_{B} \beta^{3}}=1 \rightarrow \beta^{2}=\frac{\beta_{\sigma} \beta_{B}}{\beta} .
$$

Ainda, de acordo com a eq. (48), $\beta_{\sigma}$ para o caso em que $W_{\mathrm{f}} \leq 1$ é dado por

$$
\beta_{\sigma}=\frac{K \dot{\varepsilon}_{\mathrm{m}}{ }^{q}}{K \dot{\varepsilon}_{\mathrm{p}}}=\left[\frac{\beta V V /(\beta L) \sqrt{9(H / L)^{2} / 2+8 k^{2} / 3}}{V / L \sqrt{9(H / L)^{2} / 2+8 k^{2} / 3}}\right]=\left(\frac{\beta_{V}}{\beta}\right)^{q}
$$

e usando a eq. (49), $\beta_{\sigma}$ para $W_{\mathrm{f}}>1$ é dado por

$$
\beta_{\sigma}=\left[\frac{\beta V V /(\beta L) \sqrt{(H / L)^{2} W_{f} / 2+8 k^{2} / 3}}{V / L \sqrt{(H / L)^{2} W_{f} / 2+8 k^{2} / 3}}\right]=\left(\frac{\beta V}{\beta}\right)^{q} .
$$

Portanto, inserindo (91) e (92) na eq. (90) obtém-se a relação para a velocidade inicial que considera a distorção da largura da viga, $\beta_{B}$,

$$
\beta_{V}=\left(\beta_{B} / \beta^{1+q}\right)^{1 /(2-q)} .
$$

A eq. (93) é independente da condição $w_{\mathfrak{f}} \leq 1$ ou $w_{\mathfrak{f}}>1$, assumindo o mesmo valor para ambos os casos. 
Os resultados para os dados fornecidos na Tabela 8 são mostrados na Figura 21. A Figura 21 (a) compara a variação do deslocamento final, $w_{L}$, devido somente à distorção na largura da viga, ou seja, $\beta=1$ e $\beta_{B}$ variando entre 0,4 e 2,0. A Figura 21 (b) resume os resultados para o modelo em escala 1/20 e $\beta_{B}$ variando entre 0,02 e 0,1, sendo que a velocidade inicial não é alterada. A Figura 21 (c) mostra a solução nas mesmas condições de (b), mas com $\beta_{V}$ considerando o efeito da taxa de deformação e da distorção da largura, conforme a eq. (93). Como não houve aproximação na dedução da eq. (93), a similaridade é perfeita neste caso.

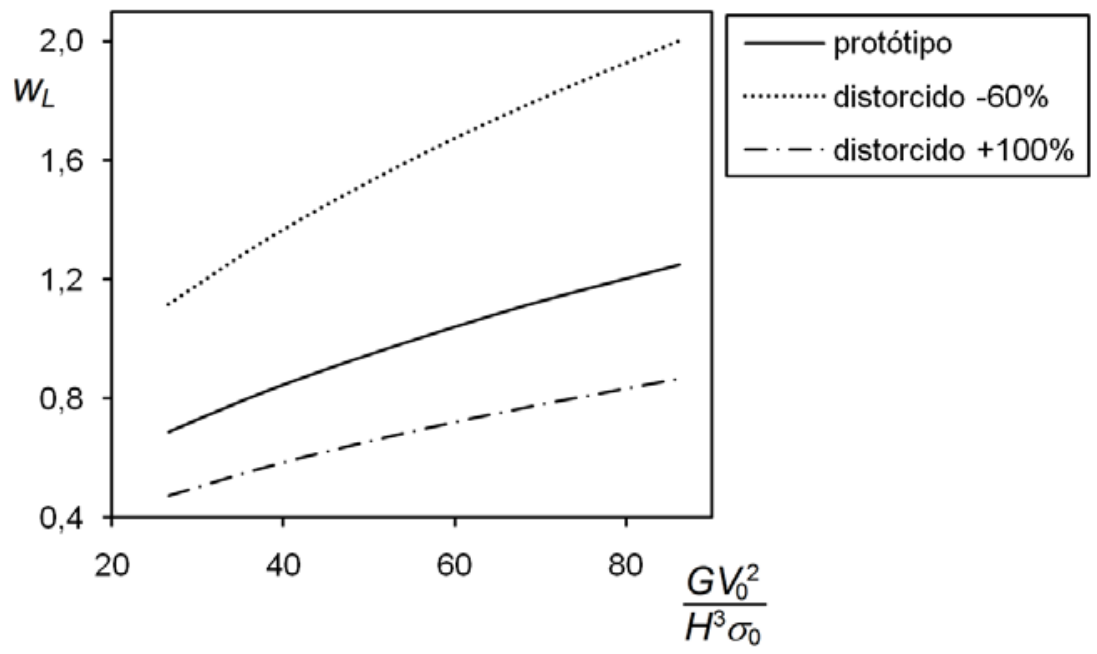

(a)

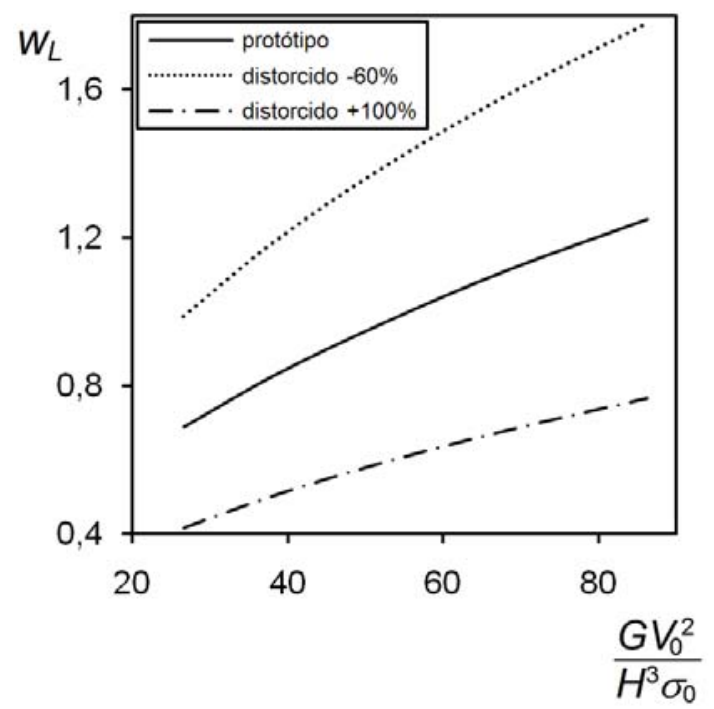

(b)

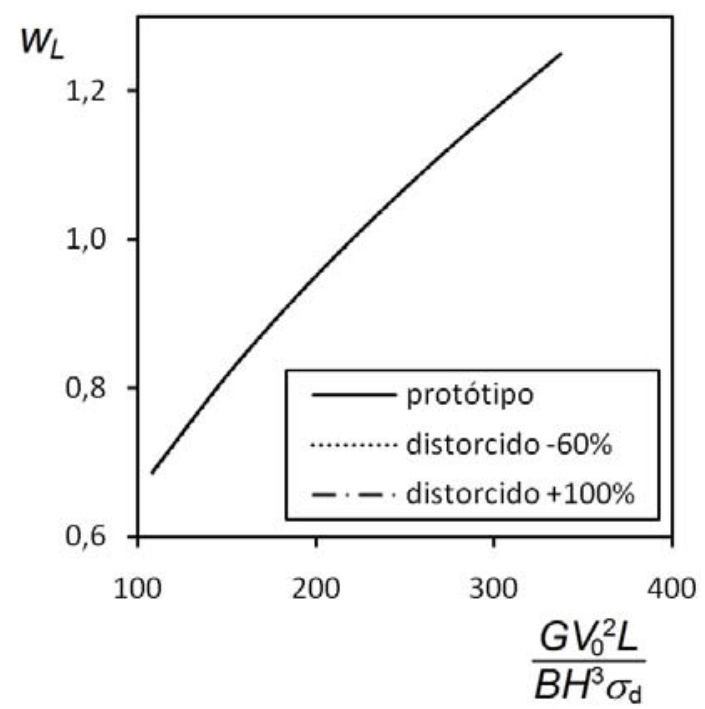

(c)

Figura 21 - Resultados para o modelo de viga com a largura distorcida sujeita ao impacto de uma massa. (a) Avaliação da distorção devido somente à variação da largura, $\beta=1$ e $\beta_{B} \neq \beta$. (b) $\beta=$ $1 / 20$ e $\beta_{B} \neq \beta$, com a velocidade inicial não corrigida. (c) $\beta=1 / 20$ e $\beta_{B} \neq \beta$, com a velocidade inicial corrigida. 
(b) Distorção no comprimento da viga

Analogamente ao item (a), uma distorção é introduzida em uma das dimensões da viga. Dessa vez o comprimento do modelo não segue a razão de proporcionalidade geométrica com o protótipo, ou seja, $\beta_{L} \neq \beta$, sendo $\beta_{L}=L_{\mathrm{m}} / L_{\mathrm{p}}$. Porém, a largura e a altura seguem perfeitamente a relação geométrica, $\beta_{B}=\beta_{H}=\beta$. Nessa situação, a relação entre os deslocamentos do modelo e do protótipo é dada por

$$
\frac{\left(W_{f} / L\right)_{\mathrm{m}}}{\left(W_{f} / L\right)_{\mathrm{p}}}=\frac{\left(W_{L}\right)_{\mathrm{m}}}{\left(W_{L}\right)_{\mathrm{p}}}=\beta / \beta_{L}
$$

Inserindo a eq. (44) para o modelo e para o protótipo na eq. (94) gera-se

$$
\frac{\beta}{\beta_{L}}=\left[\frac{\sqrt{\frac{2 G V_{0}^{2} L}{\sigma_{\mathrm{d}} B H^{3}} \frac{\beta V^{2} \beta_{L}}{\beta_{\sigma} \beta}+1}-1}{2 \beta_{L} L /(\beta H)}\right]\left[\frac{\sqrt{\frac{2 G V_{0}^{2} L}{\sigma_{\mathrm{d}} B H^{3}}+1}-1}{2 L / H}\right]^{-1},
$$

que pode ser manipulada para produzir uma relação simples entre o fator de velocidade e a tensão de escoamento dinâmica,

$$
\frac{\beta_{V}^{2} \beta_{L}}{\beta_{\sigma} \beta}=1 \rightarrow \beta_{V}=\sqrt{\frac{\beta_{\sigma} \beta}{\beta_{L}}} .
$$

A relação entre a tensão de escoamento dinâmica do modelo e do protótipo, $\beta_{\sigma}$, para o caso em que $w_{\mathrm{f}} \leq 1$ é dada por

$$
\beta_{\sigma}=\left(\frac{\dot{\varepsilon}_{\mathrm{m}}^{c}}{\dot{\varepsilon}_{\mathrm{p}}}\right)^{q}=\left[\frac{\beta V V /\left(\beta_{L} L\right) \sqrt{9 / 2(H / L)^{2}\left(\beta / \beta_{L}\right)^{2}+8 / 3 k^{2}}}{V / L \sqrt{9 / 2(H / L)^{2}+8 / 3 k^{2}}}\right]^{q} .
$$

Inserindo a eq. (96) na eq. (95), obtém-se o fator de velocidade para o caso em que $w_{f} \leq 1$

$$
\beta_{V}=\left\{\frac{\beta}{\beta_{L}{ }^{1+q}}\left[\frac{9 / 2(H / L)^{2}\left(\beta / \beta_{L}\right)^{2}+8 / 3 k^{2}}{9 / 2(H / L)^{2}+8 / 3 k^{2}}\right]^{q / 2}\right\}^{1 /(2-q)} .
$$

Para o caso em que $w_{f}>1$, não há uma forma de calcular $\beta_{v}$ de forma 
explícita. Por isso a simplificação $\beta_{\dot{\varepsilon}}=\beta_{V} / \beta_{L}$ é feita. Dessa forma, a partir da eq. (95), obtém-se

$$
\beta_{V}=\left(\frac{\beta_{V}}{\beta_{L}}\right)^{q / 2}\left(\frac{\beta}{\beta_{L}}\right)^{1 / 2} \rightarrow \beta_{V}=\left(\frac{\beta}{\beta_{L}{ }^{q+1}}\right)^{1 /(2-q)}
$$

válido para $w_{\mathfrak{f}}>1$.

Para uma situação prática, a diferença nos resultados entre a eq. (97) e (98) é relativamente pequena. Por isso, para esses casos, a solução pode ser unificada e o fator de correção em ambas as condições $-w_{f} \leq 1$ e $w_{f}>1$ - pode calculado usando somente a eq. (98).

O problema é resolvido usando os valores da Tabela 8. Os resultados são resumidos na Figura 22. A Figura 22 (a) considera a variação gerada somente devido à distorção no comprimento da viga, ou seja, $\beta=1 \mathrm{e} \beta L$ variando entre $0,4 \mathrm{e}$ 2,0. Na Figura 22 (b) a dissimilaridade oriunda do fator de escala geométrico é considerada aplicando-se $\beta=1 / 20$ e $\beta_{L}$ variando entre 0,02 e 0,1 , mas sem corrigir a velocidade inicial de impacto. Na Figura 22 (c) as mesmas condições de (b) são aplicadas, mas com $\beta_{V}$ sendo corrigido segundo as eq. (97) e (98).

(c) Distorção na altura da viga

Analogamente aos itens anteriores, uma distorção é introduzida em uma das dimensões da viga. Dessa vez a altura do modelo não segue a razão de proporcionalidade geométrica com o protótipo, ou seja, $\beta_{H} \neq \beta$, sendo $\beta_{H}=H_{\mathrm{m}} / H_{\mathrm{p}}$. Porém, a largura e o comprimento da viga seguem o fator dimensional global, $\beta_{B}=\beta_{L}=\beta$. A eq. (99) deve ser resolvida para se obter o fator $\beta_{V}$ para este caso

$$
\begin{gathered}
\left(w_{L}\right)_{\mathrm{m}}=\left(w_{L}\right)_{\mathrm{p}} \rightarrow \\
\frac{\sqrt{2 G V_{0}^{2} L /\left(\sigma_{\mathrm{d}} B H^{3}\right)\left[\beta^{3} \beta V^{2} /\left(\beta_{\sigma} \beta_{H}^{3}\right)\right]+1}-1}{2 L / H\left(\beta / \beta_{H}\right)}=\frac{\sqrt{2 G V_{0}^{2} L /\left(\sigma_{\mathrm{d}} B H^{3}\right)+1}-1}{2 L / H} .
\end{gathered}
$$

Porém, não é possível solucionar a eq. (99) de forma a se obter uma relação explícita para o fator $\beta_{V}$. Por essa razão, a solução proposta na seção 3.1 foi utilizada para determinar o expoente $n$. Dois valores de $n$ foram calculados: um para $\beta_{H} / \beta<1$ e outro para $\beta_{H} / \beta>1$. Para o primeiro caso, foram utilizados dois modelos com $\beta=1 / 20$, mas $\beta_{H}$ distorcido de $-60 \%\left(\beta_{H}=0,02\right)$ e $-20 \%\left(\beta_{H}=0,04\right)$. 
A variação de $\beta_{H}$ permite que se avalie a influência de uma variação na altura da viga sobre $\beta_{V}$ e, portanto, que se defina $n$. Da mesma forma, $\beta_{H}$ é distorcido de $+40 \%\left(\beta_{H}=0,07\right)$ e $+100 \%\left(\beta_{H}=0,10\right)$ para que $n$ possa ser determinado no caso $\beta_{H} / \beta>1$ e $\beta=1 / 20$. A Tabela 17 mostra o processo iterativo do cálculo de $n$ para o caso $\beta_{H} / \beta<1$ e uma velocidade do protótipo de $50 \mathrm{~m} / \mathrm{s}$. O processo termina, quando o erro do modelo 1 relativamente ao modelo 2 é considerado pequeno $(0,2 \%$ quando $n=0,56)$.

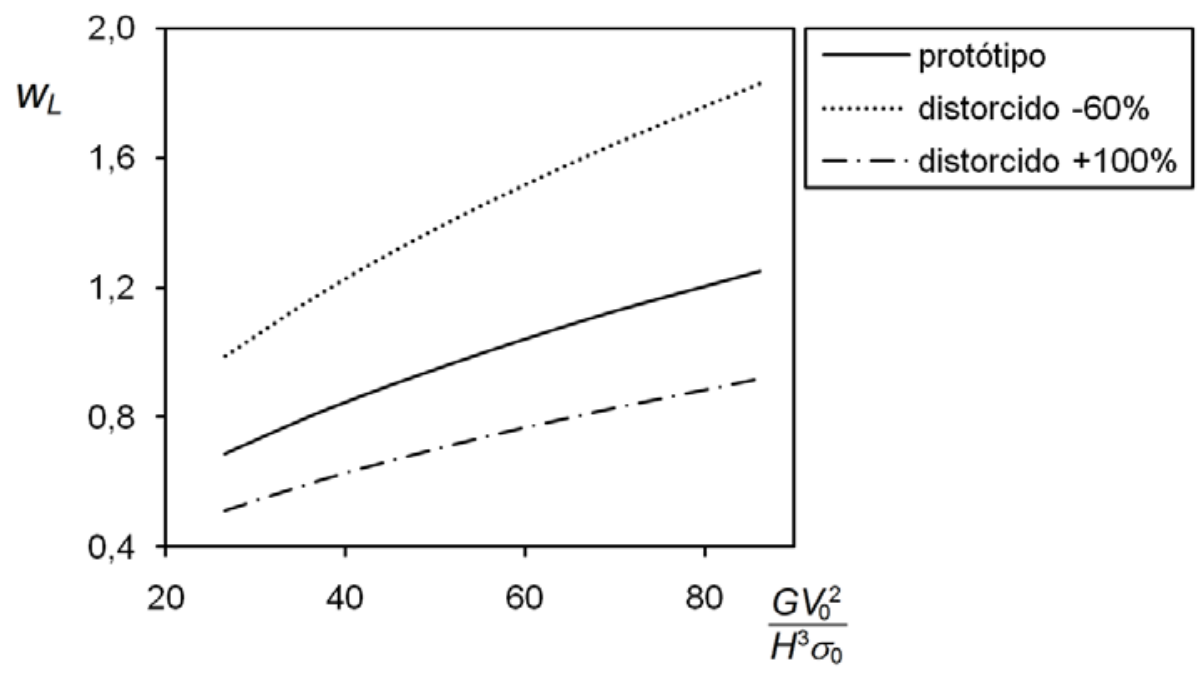

(a)

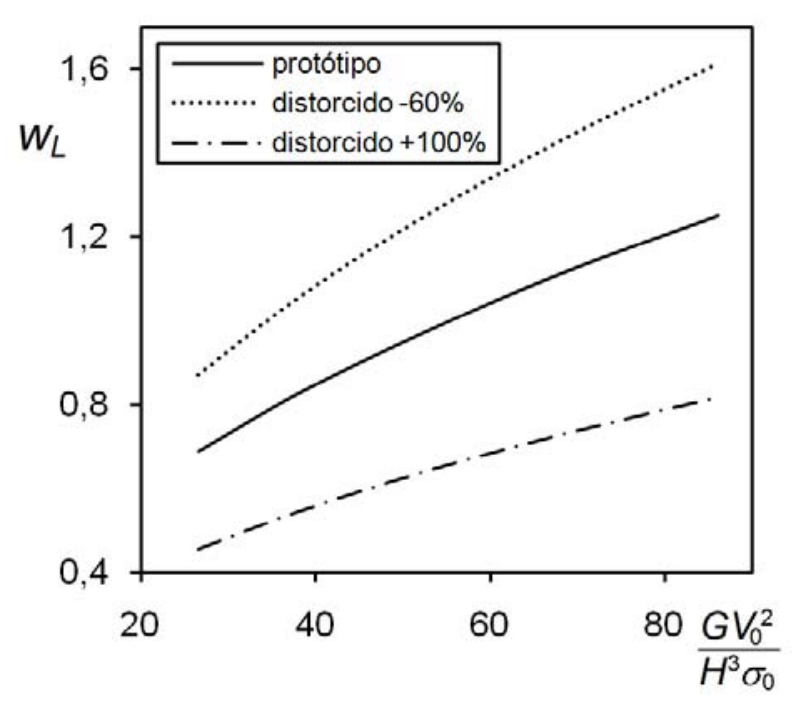

(b)

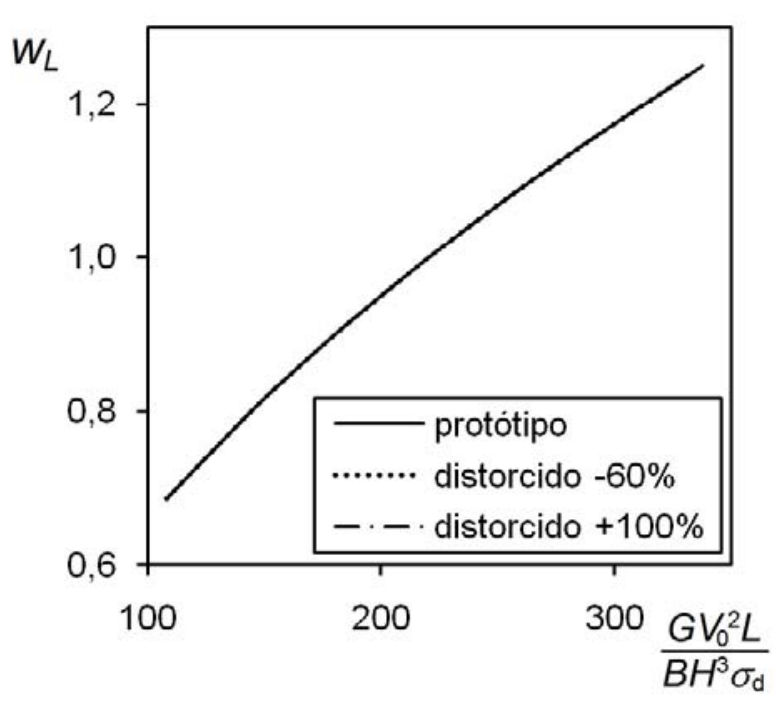

(c)

Figura 22 - Resultados para o modelo de viga com comprimento distorcido sujeita ao impacto de uma massa. (a) Avaliação da distorção devido somente à variação do comprimento, $\beta=1$ e $\beta_{L} \neq \beta$. (b) $\beta=1 / 20$ e $\beta_{L} \neq \beta$, com a velocidade inicial não corrigida. (c) $\beta=1 / 20$ e $\beta_{L} \neq \beta$, com a velocidade inicial corrigida. 
Tabela 17 - Processo de tentativas para determinação de $n$. Modelo de viga com altura distorcida e sujeita a um impacto de uma massa: $\beta=1 / 20,\left(\beta_{H}\right)_{1}=0,02$ e $\left(\beta_{H}\right)_{2}=0,04$.

\begin{tabular}{cccccccc}
\hline tentativa & $V_{1}$ & $V_{2}$ & $V_{2} / V_{1}$ & $\left(w_{L}\right)_{1}$ & $\left(w_{L}\right)_{2}$ & $\left(w_{L}\right)_{2} /\left(w_{L}\right)_{1}$ & $n$ \\
\hline 1 & 31,62 & 44,72 & 1,4142 & 0,73142 & 0,70072 & 0,9580 & 0,50 \\
2 & 31,05 & 44,52 & 1,4340 & 0,71830 & 0,69756 & 0,9711 & 0,52 \\
3 & 30,48 & 44,32 & 1,4540 & 0,70542 & 0,69441 & 0,9844 & 0,54 \\
4 & 29,93 & 44,13 & 1,4743 & 0,69276 & 0,69127 & 0,9978 & 0,56 \\
\hline
\end{tabular}

As Tabela 18 e Tabela 19 resumem os resultados obtidos quando o problema é solucionado assumindo os valores da Tabela 8 e velocidade inicial de $50 \mathrm{~m} / \mathrm{s}$. Nessas tabelas, a primeira linha mostra o modelo com erro devido somente à distorção da altura da viga, ou seja, $\beta=1$ e $\beta_{H} \neq \beta$. A segunda linha mostra o erro devido à aplicação do fator $\beta=1 / 20$ e de $\beta_{H} \neq \beta$. Como mostrado na Tabela 19, para o caso em que $\beta_{H} / \beta<1$, o expoente $n$ encontrado é igual a 0,56 . Para o caso $\beta_{H} / \beta>1, n=0,64$.

Tabela 18 - Resultados para a estrutura de viga sujeita ao impacto de uma massa. Altura distorcida e velocidade não corrigida.

\begin{tabular}{ccccccc}
\hline & $\beta$ & $\beta_{H}$ & distorção(\%) & $n$ & $\beta_{V}$ & erro não corrigido (\%) \\
\hline \multirow{3}{*}{$\beta_{H} / \beta<1$} & 1 & 0,40 & -60 & 0 & 1 & 67,05 \\
& $1 / 20$ & 0,02 & -60 & 0 & 1 & 48,55 \\
& $1 / 20$ & 0,04 & -20 & 0 & 1 & 1,12 \\
\hline \multirow{3}{*}{$\beta_{H} / \beta>1$} & 1 & 2 & +100 & 0 & 1 & 38,15 \\
& $1 / 20$ & 0,07 & +40 & 0 & 1 & 29,21 \\
& $1 / 20$ & 0,1 & +100 & 0 & 1 & 46,16 \\
\hline
\end{tabular}

Tabela 19 - Resultados para a estrutura viga sujeita ao impacto de uma massa. Altura distorcida e velocidade corrigida.

\begin{tabular}{ccccccc}
\hline & $\beta$ & $\beta_{H}$ & distorção (\%) & $n$ & $\beta_{V}$ & erro corrigido (\%) \\
\hline \multirow{3}{*}{$\beta_{H} / \beta<1$} & 1 & 0,40 & -60 & 0,56 & 0,5986 & 0,82 \\
& $1 / 20$ & 0,02 & -60 & 0,56 & 0,6749 & 0,82 \\
& $1 / 20$ & 0,04 & -20 & 0,56 & 0,9950 & 0,61 \\
\hline \multirow{3}{*}{$\beta_{H} / \beta>1$} & 1 & 2 & +100 & 0,64 & 1,5583 & 1,26 \\
& $1 / 20$ & 0,07 & +40 & 0,64 & 1,3983 & 1,17 \\
& $1 / 20$ & 0,10 & +100 & 0,64 & 1,7568 & 1,26 \\
\hline
\end{tabular}




\subsubsection{Modelo de Calladine}

O modelo de Calladine - detalhado na 2.1.1 - é novamente analisado para o caso de distorção da geometria. As dimensões do modelo estão relacionadas com o protótipo por fatores diferentes de $\beta$. Primeiro, a largura do modelo é alterada por um fator $\beta_{B} \neq \beta$ em (a). Em seguida, o problema é resolvido com o comprimento distorcido, $\beta_{L} \neq \beta$, em (b). Finalmente, a espessura é relacionada por um fator $\beta_{H} \neq \beta$ em (c). Nos três casos, o fator de velocidade, $\beta v$, foi obtido através do método proposto em 3.1, pois uma solução direta não é possível. Para o protótipo, os valores da Tabela 6 foram utilizados em todos os casos. A Tabela 22 resume os resultados e os expoentes obtidos para todos os casos.

(a) Distorção na largura da barra

Com a barra distorcida na largura por um fator $\beta_{B}$, mas mantendo $\beta_{H}=\beta_{L}=\beta$, o problema foi solucionado. Novamente, dois expoentes $n$ são determinados: um para $\beta_{B} / \beta<1$ e outro para $\beta_{B} / \beta>1$. A Figura 23 resume os resultados, sendo que em (a) o erro se deve somente à distorção da largura $\left(\beta=1\right.$ e $\beta_{B} \neq \beta$ ). Em (b) a diferença entre as curvas tem origem no fator de escala, $\beta=1 / 10$, e na distorção da largura $\beta_{B} \neq \beta$. Nos gráficos (c) e (d) a velocidade inicial é corrigida com o modelo utilizando um fator $\beta=1 / 10$ conjuntamente com uma distorção na largura $\left(\beta_{B}<\beta\right.$ em (c) e $\beta_{B}>\beta$ em (d)).

Para as variáveis tempo total, aceleração, taxa de deformação e tensão, a Tabela 20 resume os cálculos dos fatores de transposição, $f_{1}$ e $f_{2}$, do modelo quando a largura é geometricamente distorcida. A Tabela 21 compara os resultados do modelo corrigido com o protótipo após a aplicação dos fatores de transposição. Para o caso de comprimento e espessura distorcida do modelo de Calladine, a obtenção dos fatores e os resultados são expostos no Apêndice C.

(b) Distorção no comprimento da barra

Os resultados para o caso com distorção no comprimento, $\beta_{L} \neq \beta$, são 
resumidos na Figura 24. Repetindo o procedimento para o caso de distorção na largura da barra, (a) e (b) na Figura 24 mostram os erros gerados. Em (c) e (d) o fator de velocidade é aplicado com os fatores de velocidade exibidos na Tabela 22.

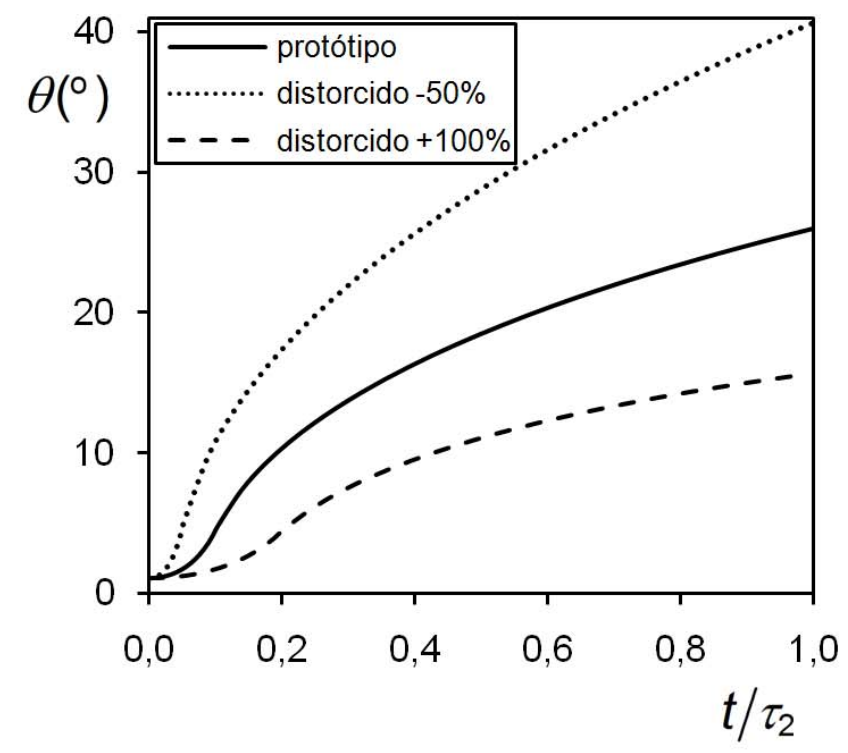

(a)

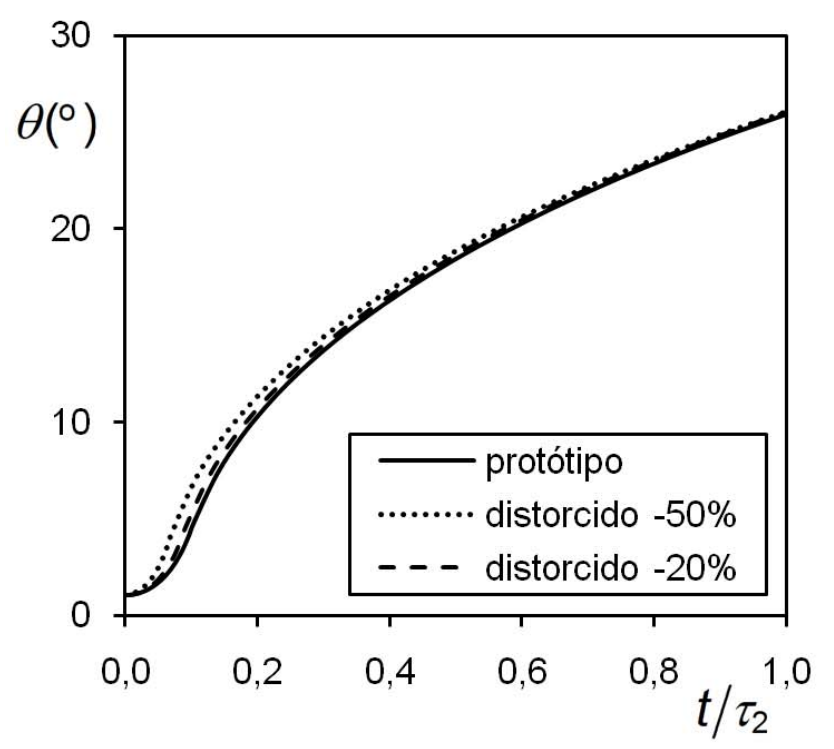

(c)

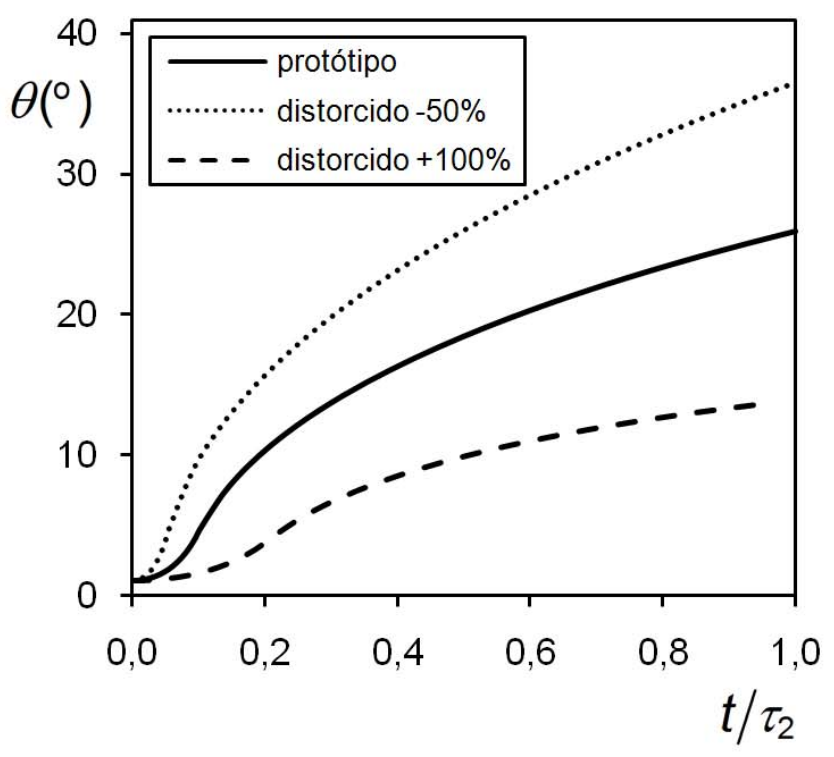

(b)

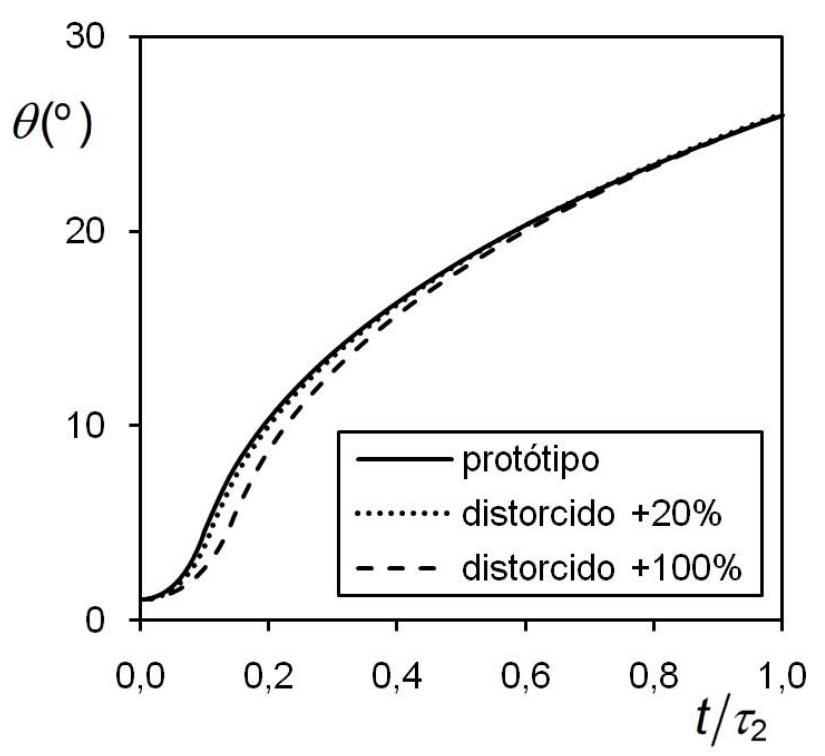

(d)

Figura 23 - Resultados para o modelo de Calladine com a largura distorcida. (a) Avaliação da distorção do modelo devido somente à variação da largura, $\beta=1$ e $\beta_{B} \neq \beta$. (b) Avaliação do erro devido ao fator de escala, $\beta=1 / 10$, e distorção da largura $\beta_{B} \neq \beta$. (c) Modelo corrigido quando $\beta_{B} / \beta<1$. (d) Modelo corrigido quando $\beta_{B} / \beta>1$. 
Tabela 20 - Cálculos dos fatores de transposição do modelo de Calladine com largura distorcida.

\begin{tabular}{|c|c|c|c|c|c|c|c|}
\hline \multicolumn{8}{|c|}{$\beta_{B} / \beta<1$} \\
\hline & $\beta$ & $\beta_{B}$ & $\beta_{B} / \beta$ & $\begin{array}{c}Y=\tau_{2} \\
(\mathrm{~ms})\end{array}$ & $\begin{array}{l}Y=A \\
\left(\mathrm{~m} / \mathrm{s}^{2}\right)\end{array}$ & $\begin{array}{c}Y=\dot{\varepsilon} \\
\left(s^{-1}\right)\end{array}$ & $\begin{array}{l}Y=\sigma \\
(\mathrm{MPa})\end{array}$ \\
\hline modelo 1 & 0,1 & 0,050 & 0,50 & 0,1415 & 37059,95 & 1402,95 & 604,82 \\
\hline modelo 2 & 0,1 & 0,075 & 0,75 & 0,1159 & 56518,20 & 1739,59 & 614,92 \\
\hline \multicolumn{3}{|l|}{$Y_{1} / Y_{2}$} & 0,6667 & 1,2209 & 0,6557 & 0,8065 & 0,9836 \\
\hline \multicolumn{3}{|c|}{$n_{\mathrm{i}}=\log \left(Y_{1} / Y_{2}\right) / \log \left(\beta_{B_{1}} / \beta_{B_{2}}\right)$} & & $-0,4908$ & 1,0408 & 0,5304 & 0,0408 \\
\hline \multicolumn{3}{|c|}{$f_{2}=\left(\beta_{B} / \beta\right)^{n_{1}}$} & & 1,4053 & 0,4860 & 0,6923 & 0,9721 \\
\hline \multirow[t]{2}{*}{ modelo 1} & $f_{1}$ & & & 0,0912 & 12,0249 & 10,9658 & 1,2025 \\
\hline & $f_{1} f_{2}$ & & & 0,1282 & 5,8446 & 7,5921 & 1,1689 \\
\hline \multicolumn{8}{|c|}{$\beta_{B} / \beta>1$} \\
\hline & $\beta$ & $\beta_{B}$ & $\beta_{B} / \beta$ & $\begin{array}{c}Y=\tau_{2} \\
(\mathrm{~ms})\end{array}$ & $\begin{array}{l}Y=A \\
\left(\mathrm{~m} / \mathrm{s}^{2}\right)\end{array}$ & $\begin{array}{c}Y=\dot{\varepsilon} \\
\left(s^{-1}\right)\end{array}$ & $\begin{array}{l}Y=\sigma \\
(\mathrm{MPa})\end{array}$ \\
\hline modelo 1 & 0,1 & 0,20 & 2,0 & 0,0731 & $1,5689 \mathrm{E} 5$ & 2931,27 & 640,13 \\
\hline modelo 2 & 0,1 & 0,15 & 1,5 & 0,0835 & 1,1630E5 & 2516,31 & 632,65 \\
\hline \multicolumn{3}{|l|}{$Y_{1} / Y_{2}$} & 1,3333 & 0,8754 & 1,3490 & 1,1649 & 1,0118 \\
\hline \multicolumn{3}{|c|}{$n_{\mathrm{i}}=\log \left(Y_{1} / Y_{2}\right) / \log \left(\beta_{B_{1}} / \beta_{B_{2}}\right)$} & & $-0,4609$ & 1,0409 & 0,5306 & 0,0409 \\
\hline \multicolumn{3}{|c|}{$f_{2}=\left(\beta_{B} / \beta\right)^{n_{1}}$} & & 0,7266 & 2,0574 & 1,4445 & 1,0287 \\
\hline \multirow[t]{2}{*}{ modelo 1} & $f_{1}$ & & & 0,0912 & 12,0249 & 10,9658 & 1,2025 \\
\hline & $f_{1} f_{2}$ & & & 0,0663 & 24,7407 & 15,8403 & 1,2370 \\
\hline
\end{tabular}

Tabela 21 - Resultados da estrutura de Calladine: comparação do modelo com largura distorcida com o protótipo. Valores calculados no final do impacto.

\begin{tabular}{lcccccc}
\hline & $\beta$ & $\beta_{B}$ & $\tau_{2}(\mathrm{~ms})$ & $A\left(\mathrm{~m} / \mathrm{s}^{2}\right)$ & $\dot{\varepsilon}\left(\mathrm{s}^{-1}\right)$ & $\sigma(\mathrm{MPa})$ \\
\hline$\beta_{B} / \beta<1$ & 1 & 1 & 1,1041 & 6340,26 & 184,57 & 517,37 \\
protótipo & 0,10 & 0,05 & 1,1040 & 6340,84 & 184,79 & 517,41 \\
modelo corrigido & 0,10 & 0,05 & 1,8692 & 3744,92 & 160,69 & 611,17 \\
modelo não corrigido & 1 & 1 & 1,1041 & 6340,26 & 184,57 & 517,37 \\
\hline$\beta_{B} / \beta>1$ & 0,10 & 0,20 & 1,1038 & 6341,53 & 185,05 & 517,47 \\
protótipo & 0,10 & 0,20 & 0,4603 & 15209,00 & 195,73 & 620,53 \\
modelo corrigido & & & & & &
\end{tabular}




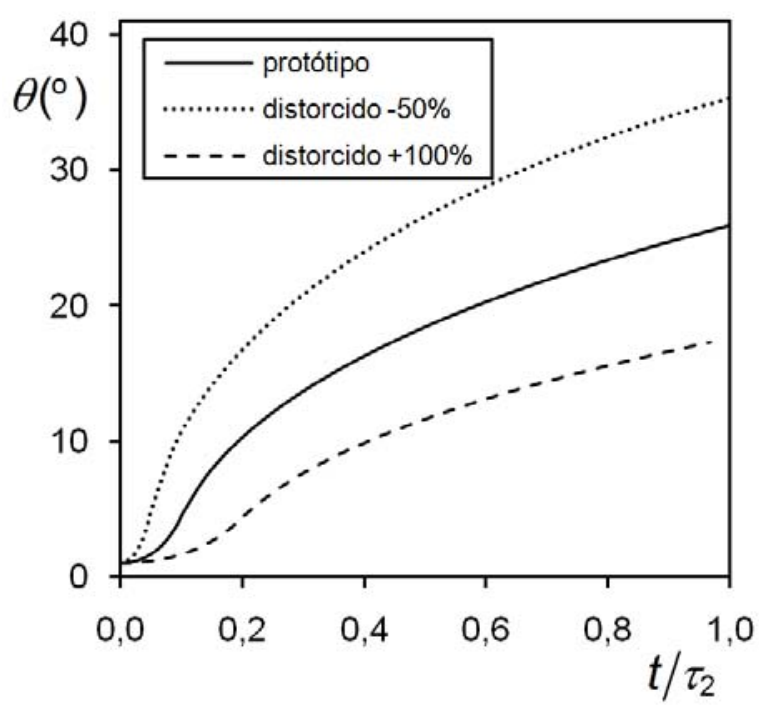

(a)

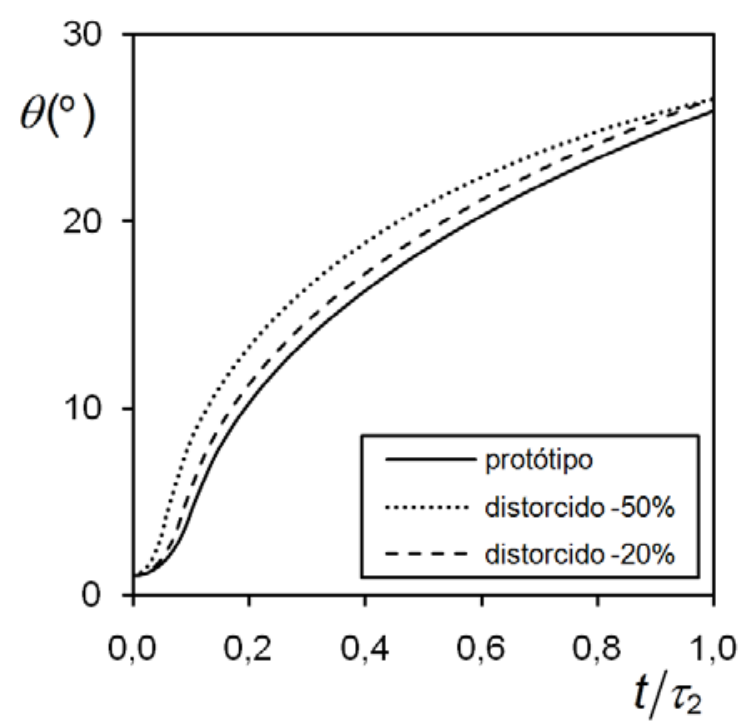

(c)

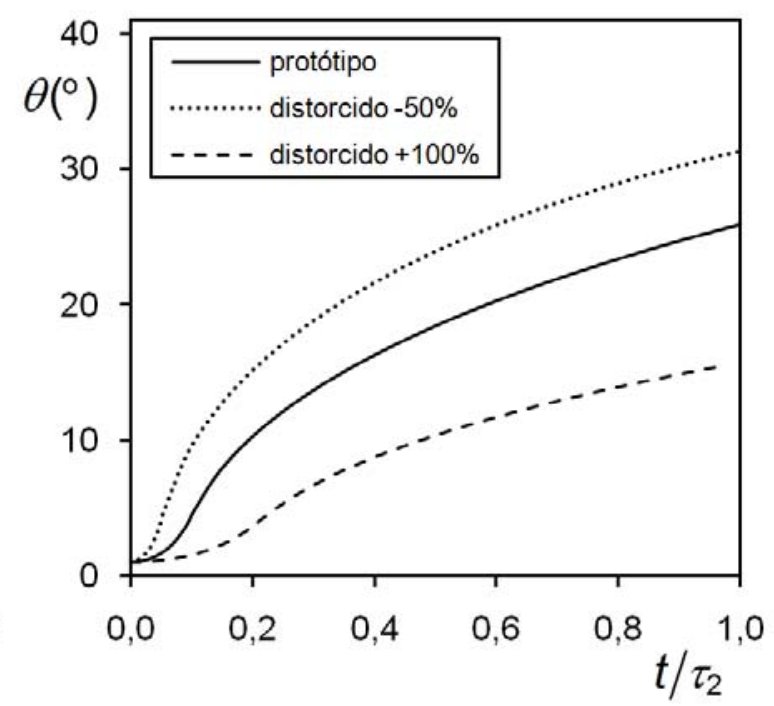

(b)

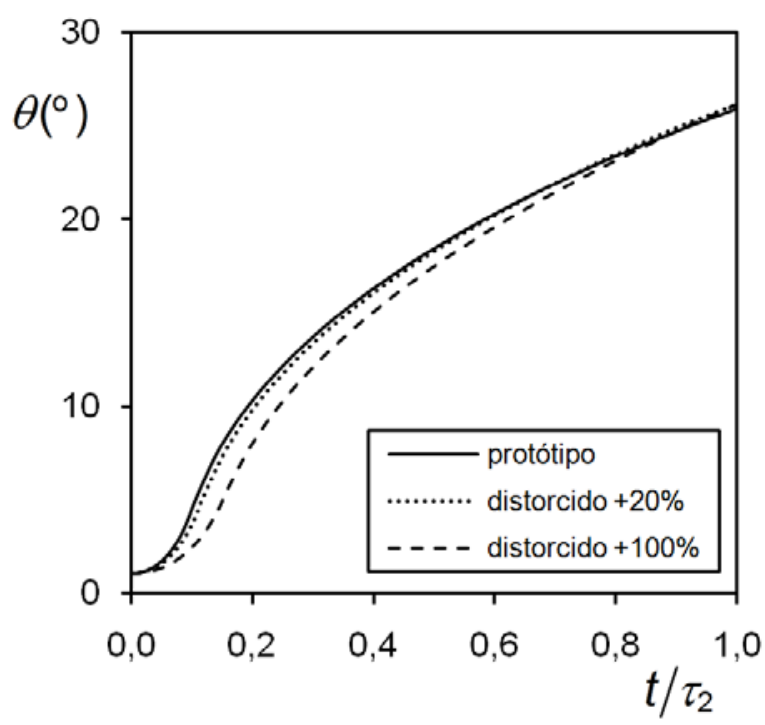

(d)

Figura 24 - Resultados para o modelo de Calladine com o comprimento distorcido. (a) Avaliação da distorção do modelo devido somente à variação do comprimento, $\beta=1$ e $\beta_{L} \neq \beta$. (b) Avaliação do erro devido ao fator de escala, $\beta=1 / 10$, e distorção do comprimento, $\beta_{L} \neq \beta$. (c) Modelo corrigido quando $\beta_{L} / \beta<1$. (d) Modelo corrigido quando $\beta_{L} / \beta>1$.

\section{(c) Distorção na espessura da barra}

O caso em que a espessura da barra não segue o fator geométrico $-\beta_{H} \neq \beta-$ produz os resultados mostrados na Figura 25. As curvas do ângulo $\theta$ em função do tempo para os modelos corrigidos são mostrados em (c) e (d). Nota-se uma melhora bastante significativa dos resultados quando comparados aos modelos não corrigidos, Figura 25 (a) e (b). 


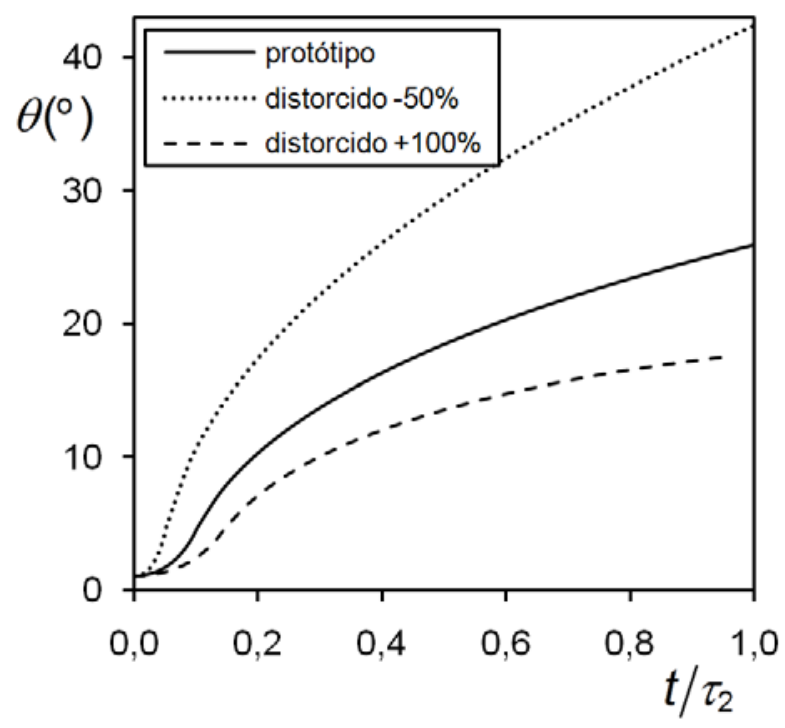

(a)

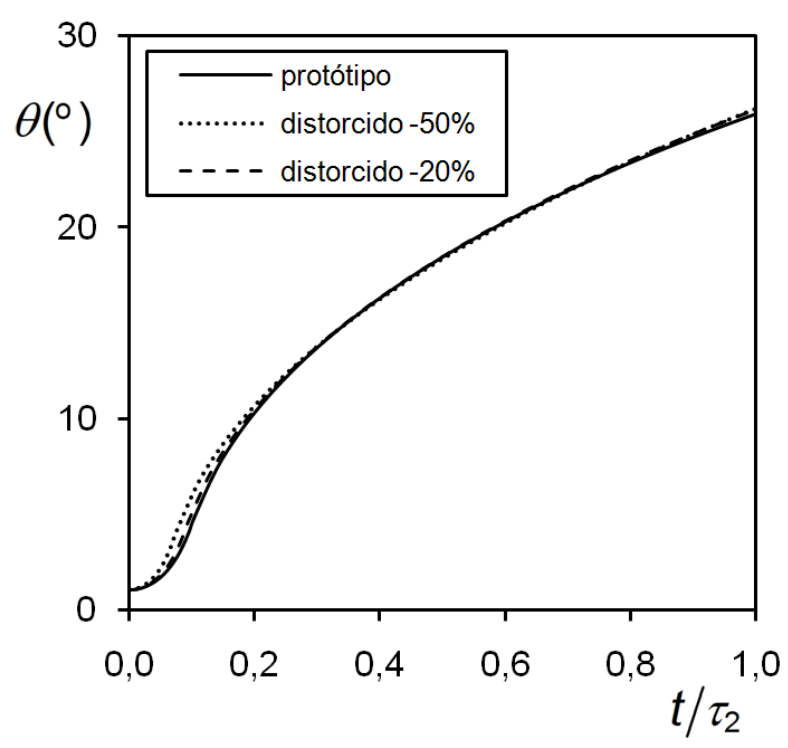

(c)

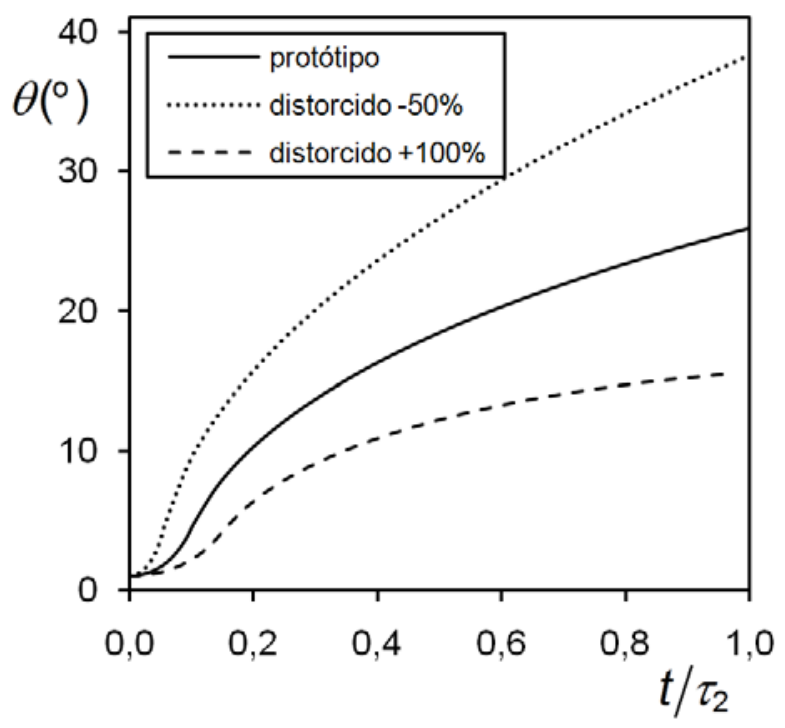

(b)

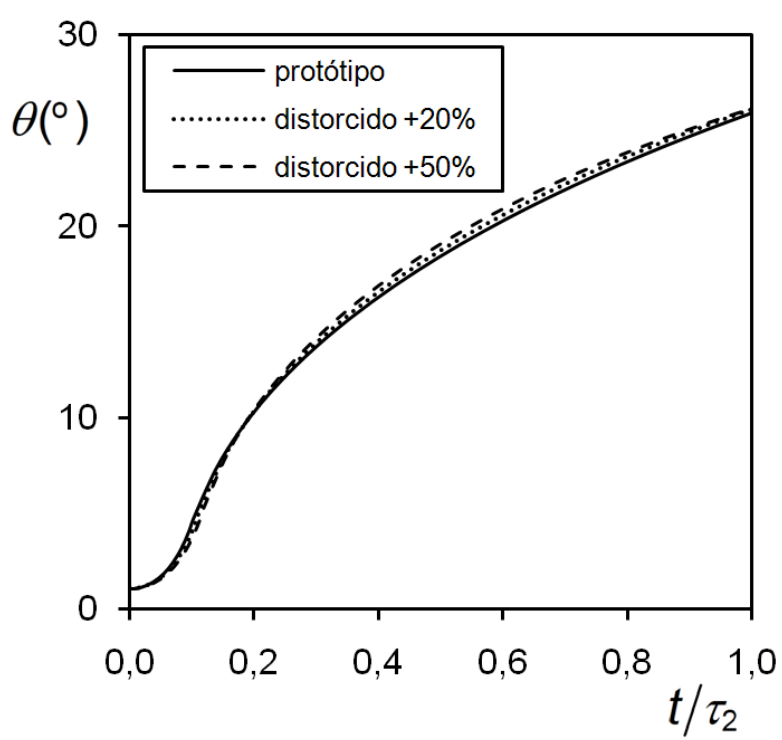

(d)

Figura 25 - Resultados para o modelo de Calladine com a espessura distorcida. (a) Avaliação da distorção do modelo devido somente à variação da espessura, $\beta=1$ e $\beta_{H} \neq \beta$. (b) Avaliação do erro devido ao fator de escala, $\beta=1 / 10$, e distorção da espessura, $\beta_{H} \neq \beta$. (c) Modelo corrigido quando $\beta_{H} / \beta<1$. (d) Modelo corrigido quando $\beta_{H} / \beta>1$.

\subsection{Discussão}

A diminuição da diferença das respostas entre modelo e protótipo é bastante significativa com a aplicação do método de correção. O maior erro para o caso de 
viga sujeita a um impulso de velocidade (seção 3.2.1) cai de 57,11\% para 1,14\% para uma distorção de $+100 \%$ na altura e uma escala 1/100 (Tabela 16). Na seção 3.2.2 (viga sujeita ao impacto de uma massa) o maior erro ocorre para $\beta_{H} \neq \beta$, mas mesmo assim, o desvio cai de 48,55\% para 0,82\% quando considera-se uma distorção de $-60 \%$ e uma escala $1 / 20$ (Tabela 19). Para o modelo de Calladine, descrito na seção 3.2.3, a maior diferença ocorre quando $\beta=1 / 10$ e $\beta_{H}$ é distorcido em $-50 \%$. Nessa situação o erro cai de $47,80 \%$ para 0,83\% (Tabela 22 ).

Tabela 22 - Resumo dos resultados para a estrutura de Calladine com geometria distorcida.

\begin{tabular}{|c|c|c|c|c|c|c|c|}
\hline \multirow[b]{2}{*}{$\beta$} & \multirow[b]{2}{*}{$\beta_{B}$} & \multicolumn{2}{|c|}{$n$} & \multicolumn{2}{|c|}{$\beta V$} & \multicolumn{2}{|c|}{ erro no ângulo final (\%) } \\
\hline & & $\beta_{B} / \beta<1$ & $\beta_{B} / \beta>1$ & $\beta_{B} / \beta<1$ & $\beta_{B} / \beta>1$ & sem correção & corrigido \\
\hline \multirow{4}{*}{$1 / 10$} & 0,05 & \multirow{2}{*}{0,55} & \multirow{2}{*}{-} & 0,749 & \multirow{2}{*}{-} & 40,90 & 0,58 \\
\hline & 0,08 & & & 0,970 & & 4,05 & 0,35 \\
\hline & 0,12 & & \multirow{2}{*}{0,58} & & 1,219 & 21,22 & 0,24 \\
\hline & 0,20 & & & - & 1,639 & 46,50 & 0,15 \\
\hline$\beta$ & $\beta_{L}$ & $\beta_{\llcorner} / \beta<1$ & $\beta_{\llcorner} / \beta>1$ & $\beta_{\llcorner} / \beta<1$ & $\beta_{L} / \beta>1$ & sem correção & corrigido \\
\hline \multirow{4}{*}{$1 / 10$} & 0,05 & \multirow{2}{*}{0,31} & \multirow{2}{*}{-} & 0,885 & \multirow[b]{2}{*}{-} & 20,63 & 2,31 \\
\hline & 0,08 & & & 1,023 & & 0,52 & 2,33 \\
\hline & 0,12 & \multirow{2}{*}{-} & \multirow{2}{*}{0,48} & \multirow{2}{*}{ - } & 1,197 & 18,44 & 1,04 \\
\hline & 0,20 & & & & 1,530 & 39,27 & 0,88 \\
\hline$\beta$ & $\beta_{H}$ & $\beta_{H} / \beta<1$ & $\beta_{H} / \beta>1$ & $\beta_{H} / \beta<1$ & $\beta_{H} / \beta>1$ & sem correção & corrigido \\
\hline \multirow{4}{*}{$1 / 10$} & 0,05 & \multirow{2}{*}{0,63} & \multirow{2}{*}{ - } & 0,709 & \multirow[t]{2}{*}{ - } & 47,80 & 0,83 \\
\hline & 0,08 & & & 0,953 & & 6,70 & 0,87 \\
\hline & 0,12 & \multirow{2}{*}{ - } & \multirow{2}{*}{0,72} & \multirow[t]{2}{*}{ - } & 1,250 & 23,86 & 0,71 \\
\hline & 0,15 & & & & 1,468 & 39,85 & 0,78 \\
\hline
\end{tabular}

Como pode ser observado nesse capítulo, a correção do modelo com geometria distorcida não possui uma lei geral que possa ser aplicada a todos os tipos de estrutura. Além disso, o fator de correção também é função da direção da distorção - por exemplo: altura, largura e comprimento da viga. Como já mencionado, isso se deve ao fato da taxa de deformação ser dependente da geometria da estrutura. Através das Tabela 18 a Tabela 22 é possível notar a grande variação do expoente $n$. Por exemplo, na Tabela 22, mesmo usando fatores de 
distorção idênticos (-50\%), o expoente encontrado para uma distorção na largura é $n=0,31$, enquanto uma distorção na altura gera $n=0,63$.

A hipótese de independência entre as funções $-f=f_{1} f_{2}$, sendo $f_{1}=f(\beta)$ a função que expressa o efeito devido ao fator de escala $\beta$ e $f_{2}=f\left(\beta_{Y}\right)$ a função que considera a distorção da geometria - mostrou-se válida para os casos analíticos estudados. A independência das funções pode ser explicada pelo fato do erro devido ao efeito de $\beta$ ser completamente eliminado quando a relação $\beta_{V}=\beta_{\sigma}{ }^{1 / 2}$ é atendida, com $\beta_{\sigma}$ relacionando de forma exata as tensões dinâmicas do modelo corrigido e do protótipo, $\sigma_{\mathrm{m}} / \sigma_{\mathrm{p}}$. Esse fato pode ser comprovado comparando-se a Figura 26 com as Figura 21 e Figura 24.

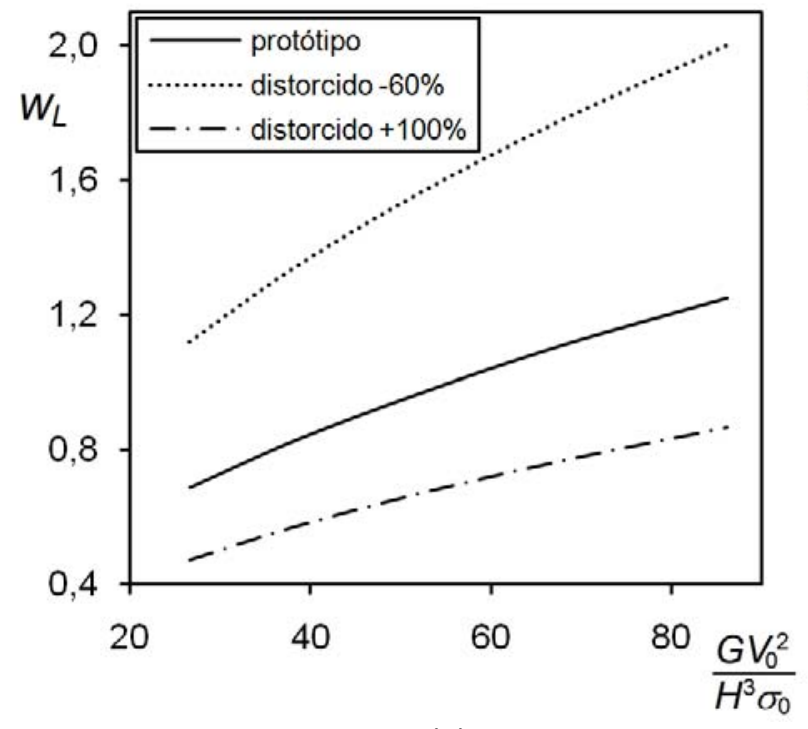

(a)

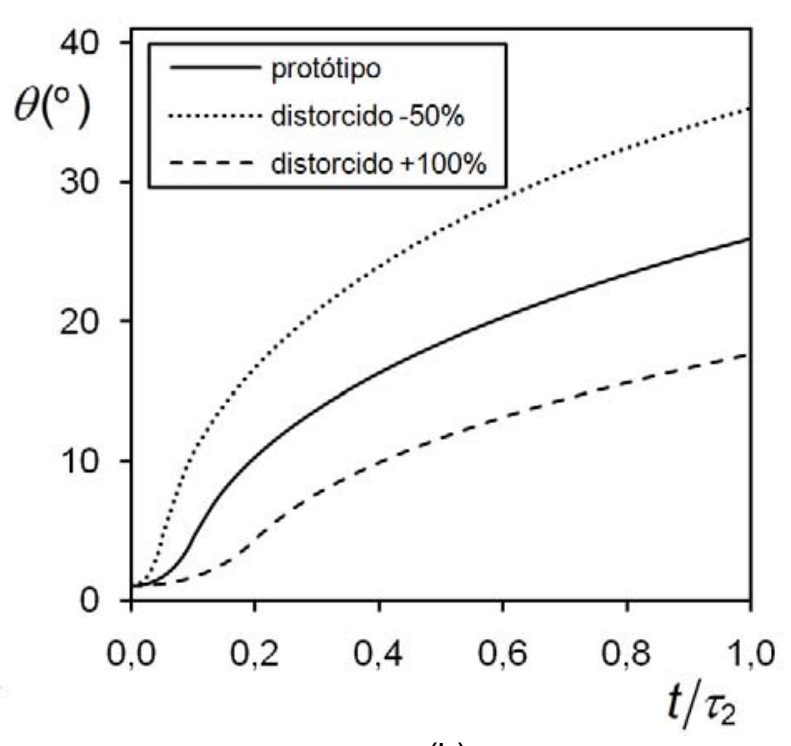

(b)

Figura 26 - Resultados de modelos parcialmente corrigidos, $\beta_{V}=f_{1}=f(\beta)$. (a) Modelo de viga sujeita ao impacto de uma massa com a largura distorcida, $\beta=1 / 20, \beta_{H} \neq \beta$ e velocidade inicial corrigida considerando apenas o erro devido ao fator de escala. (b) Modelo de Calladine com comprimento distorcido, $\beta=1 / 10, \beta_{L} \neq \beta$ e $\beta=f(\beta)$.

Na Figura 21 (a) os resultados para o caso de uma viga sujeita ao impacto de uma massa são resumidos, sendo que $\beta=1, \beta_{H} \neq \beta$ e nenhum fator de correção é aplicado. A diferença entre os modelos tem origem somente devido à distorção da geometria. Os mesmos resultados são reproduzidos na Figura 26 (a), mas com $\beta=1 / 20, \beta_{H} \neq \beta$ e $\beta_{V}=f_{1}\left(f_{2}=1\right)$. Dessa forma, somente o efeito de $\beta$ é corrigido e o erro devido ao fator de distorção permanece. Como pode ser observado, solucionando-se o problema nessas condições, as curvas da Figura 21 (a) e Figura 26 (a) são idênticas. 
Na Figura 26 (b) a comparação nas mesmas condições pode ser feita para o modelo de Calladine com distorção no comprimento. Na Figura 24 (a) o modelo é solucionado com $\beta=1, \beta_{L} \neq \beta$ e $\beta_{V}=1$. Na Figura 26 (b) o mesmo problema é analisado, mas com $\beta=1 / 10$ e velocidade inicial corrigida considerando apenas 0 efeito do fator de escala, $\beta_{V}=f_{1}$ e $f_{2}=1$. Novamente, como pode ser observado, as curvas são idênticas. Portanto, pelo menos para os casos analíticos estudados, a hipótese de funções independentes é satisfeita.

Para comparar a eficiência do método empregado na determinação da função $f_{2}=\beta_{X}{ }^{n}$, o expoente $n$ obtido para o modelo de viga sujeita ao impacto de uma massa é comparado. No caso de viga com comprimento distorcido, o expoente pôde ser obtido de forma explícita na seção 3.2 .2 (b), $n=-0,5759$. Com o método apresentado em 3.1 sendo aplicado, o valor de $n$ é igual a -0,5778. No caso de distorção da largura, o expoente calculado de forma direta em 3.2.2 (a) é igual a 0,5200 e pelo método apresentado em 3.1 o valor gerado é 0,5190 . A Tabela 23 resume os resultados obtidos para o deslocamento final, $W_{L}$, para o caso em que $\beta=1$ e $\beta_{X}=0,4$.

Tabela 23 - Comparação dos resultados dos métodos aplicados na solução do problema de viga sujeita ao impacto de uma massa. Distorção de $-60 \%$ na geometria.

\begin{tabular}{ccccc}
\hline & \multicolumn{2}{c}{ comprimento distorcido } & \multicolumn{2}{c}{ largura distorcida } \\
\cline { 2 - 5 } velocidade & solução 3.2.2 (a) & solução 3.1 & solução 3.2.2 (b) & solução 3.1 \\
inicial (m/s) & $n=-0,5759$ & $n=-0,5778$ & $n=0,5200$ & $n=0,5190$ \\
& erro $W_{L}(\%)$ & erro $w_{L}(\%)$ & erro $w_{L}(\%)$ & erro $w_{L}(\%)$ \\
\hline 50 & 0 & 0,19 & 0 & 0,09 \\
60 & 0 & 0,19 & 0 & 0,09 \\
70 & 0 & 0,19 & 0 & 0,09 \\
80 & 0,72 & 0,90 & 0 & 0,09 \\
90 & 0,79 & 0,82 & 0 & 0,09 \\
\hline
\end{tabular}

A separação do problema para dois casos $\left(\beta_{X} / \beta<1\right.$ e $\left.\beta_{X} / \beta>1\right)$ é necessária para que o expoente $n$ possa ser determinado com maior precisão. Por exemplo, a Figura 27 mostra a correção para o caso do modelo de Calladine com comprimento distorcido. A Figura 27 (a) exibe a tentativa de correção quando o modelo é distorcido em $-50 \%$, mas com o expoente obtido através de variações positivas (+20\% e +100\%). Na Figura 27 (b), o fator de correção foi calculado usando 
variações negativas (-50\% e -80\%) do comprimento e aplicado em um modelo com distorção positiva (+100\%). Como pode ser observado em ambos os gráficos da Figura 27, os erros são significantemente maiores do que os observados na Figura 24 (c) e (d), quando a classificação do problema em $\beta_{X} / \beta<1$ ou $\beta_{X} / \beta>1$ foi considerada.

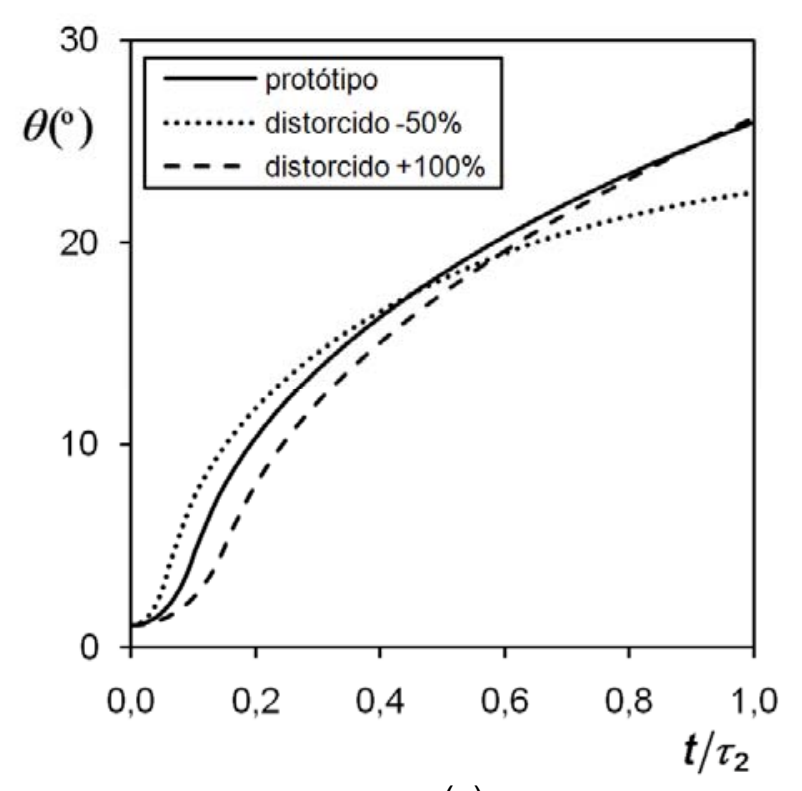

(a)

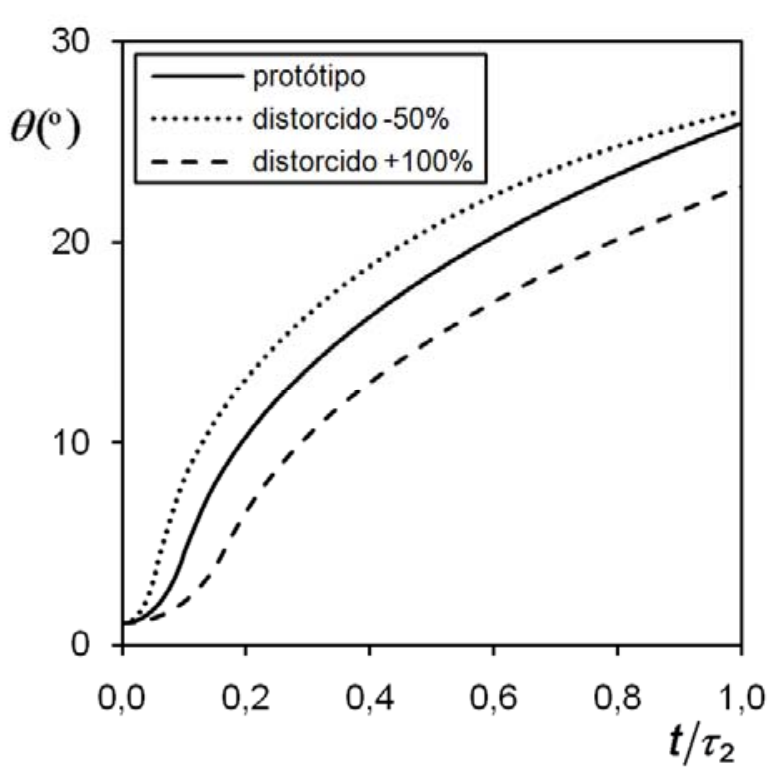

(b)

Figura 27 - Modelo de Calladine com distorção no comprimento. (a) modelo corrigido quando o expoente é calculado para a condição $\beta L / \beta>1$. (b) modelo corrigido quando o expoente é calculado para a condição $\beta\llcorner/ \beta<1$.

A aproximação da função $f_{2}$ por um formato exponencial $\beta x^{n}$ mostrou-se satisfatória para os casos estudados. Na Figura 28 a variação de $f_{2}$ em função da distorção da altura, $\beta_{H} / \beta$, é exibida para o modelo de viga sujeita ao impacto de uma massa. A curva tracejada expõe o resultado gerado quando a aproximação feita na seção 3.1 é aplicada, ou seja, o valor de $n$ é determinado e a eq. (63) é usada. A curva contínua mostra o valor obtido analiticamente. Nesse caso o problema é solucionado de forma a obter o fator de correção para distorção, $f_{2}$, para cada valor de $\beta_{H} / \beta$. Através da comparação dessas duas curvas pode-se notar que a hipótese $f_{2}=\beta X^{n}$ é bastante satisfatória para esse caso. Como parâmetro de comparação, o maior erro entre os modelos onde essa aproximação é feita é observada na estrutura de Calladine. Nesse caso, a diferença entre o modelo em escala 1/10 e 
distorcido de $-20 \%$ no comprimento e o respectivo protótipo é de $2,33 \%$ no ângulo final.

Em 3.2.1, na correção do modelo de viga sujeita a um impulso de velocidade, é possível resolver o problema de distorção da geometria de forma explícita através dos fatores gerados pelas eq. (74) e (87). Em 3.2.2 (modelo de viga sujeita ao impacto de uma massa no centro) a distorção na largura é corrigida através da eq. (93). De forma similar, a distorção do comprimento é considerada através das equações (97) e (98). Porém, o caso de distorção da altura mostrou-se mais complicado e, por isso, o método proposto na seção 3.1 foi aplicado. No modelo de Calladine (seção 3.2.3), todos os casos foram resolvidos usando a técnica exposta em 3.1. Apesar da correção do efeito da distorção na geometria que foi apresentado no atual trabalho não ser um método geral e simples, nenhum dado do protótipo foi utilizado para resolver os problemas abordados. A solução para a estrutura em escala unitária só foi utilizada para comparar a eficiência do método.

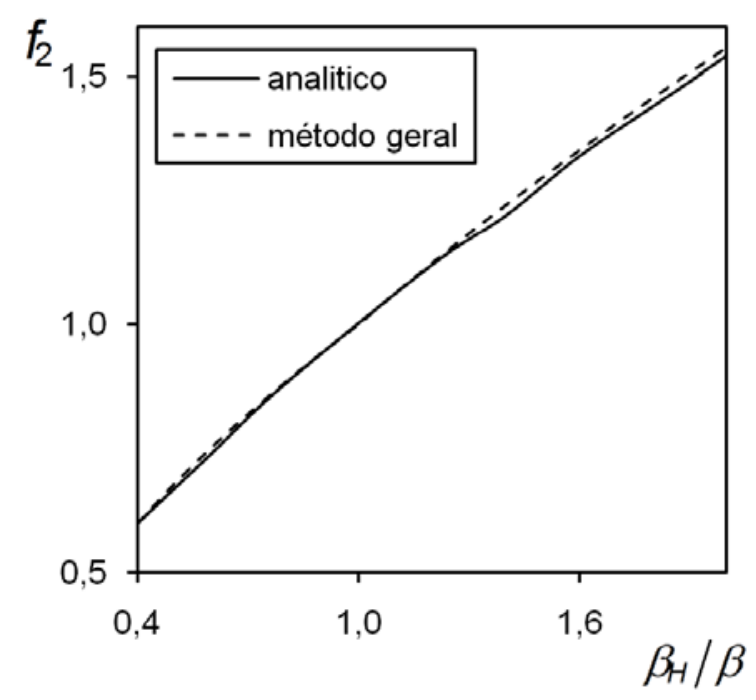

Figura 28 - Comparação da função $f_{2}$ obtida analiticamente (curva contínua) e através da aproximação feita na seção 3.1 (curva tracejada) para o caso de viga sujeita ao impacto de uma massa. 


\section{MODELOS NUMÉRICOS}

Nesse capítulo, os métodos de correção desenvolvidos nas seções 2 e 3 são aplicados a dois modelos numéricos: a) tubo engastado nas extremidades e sujeito a um impacto radial, b) parte do casco de um navio sujeito ao impacto de uma esfera rígida. Primeiro, na seção 4.1, os modelos em escala são estudados e corrigidos de forma a considerar o efeito da taxa de deformação devido ao fator $\beta$. Em seguida, em 4.2, os modelos têm uma configuração geométrica distorcida em relação ao protótipo e a correção será feita conforme a seção 3.1. Finalmente, uma discussão dos resultados é feita na seção 4.3.

\subsection{Modelo numérico com taxa de deformação}

Nessa seção, as estruturas são escalonadas por um fator $\beta$ e solucionadas numericamente. Os erros do modelo não corrigido se devem à dependência da tensão de escoamento em relação à taxa de deformação, conforme descrito no capítulo 2. Dessa maneira, a correção do fator de velocidade do modelo é feita de acordo com a eq. (21). O fator $\beta_{V}$ pode ser calculado de forma simples e direta através do fator de escala e das propriedades materiais (expoente $q$ ), mesmo para os problemas relativamente complexos das estruturas analisadas nessa seção.

a) Tubo engastado

Nessa estrutura, um tubo protótipo possui $600 \mathrm{~mm}$ de comprimento, $40 \mathrm{~mm}$ de diâmetro médio e $2 \mathrm{~mm}$ de espessura é implementado numericamente. As propriedades materiais são de um aço comum: densidade de $7800 \mathrm{~kg} / \mathrm{m}^{3}$, módulo de elasticidade de $210 \mathrm{GPa}$, coeficiente de Poisson de 0,3 e a taxa de deformação sendo dada pela eq. (18), onde os coeficientes materiais são $\sigma_{0}=235 \mathrm{MPa}, \dot{\varepsilon}_{0}=1$ $\mathrm{E}-3 \mathrm{~s}^{-1}$ e $q=0,077$. A massa de impacto rígida tem terminação esférica de $40 \mathrm{~mm}$ de diâmetro e uma massa de 1,6 kg. O tubo está engastado em ambas as 
extremidades e sofre o impacto na metade do comprimento. A velocidade inicial da massa de impacto é de $60 \mathrm{~m} / \mathrm{s}$.

O comportamento material em função da taxa de deformação, eq. (18), é aplicado no programa de elementos finitos Abaqus na forma de uma tabela de dados. Com esse tipo de implementação, o programa interpola os pontos necessários para obter a tensão de escoamento correspondente a cada valor de deformação e taxa de deformação. Para os dados materiais utilizados no trabalho, o valor mínimo de taxa de deformação - caso em que se considera a estrutura sujeita a uma carga estática - é igual a $\dot{\varepsilon}_{0}=1 \mathrm{E}-3 \mathrm{~s}^{-1}$. Para valores inferiores a $\dot{\varepsilon}_{0}, \sigma_{\mathrm{d}}=\sigma_{0}$.

O modelo em elementos finitos foi desenvolvido no programa Abaqus 6.7 Explicit. O tubo é constituído por elementos do tipo casca de quatro nós e integração reduzida, S4R. Possui 40 elementos na direção circunferencial e 210 elementos na direção longitudinal.

A massa de impacto é constituída por elementos rígidos tridimensionais de 4 nós, R3D4. O único movimento permitido para o corpo impactante é a direção vertical. O contato entre as superfícies possui um coeficiente de atrito de 0,10.

A Figura 29 mostra a malha da simulação do tubo engastado na configuração deformada final. A Figura 30 mostra os resultados em um ponto central na face superior do tubo (local que está em contato com a terminação esférica do corpo impactante e onde ocorre o maior deslocamento no tubo). Nessa figura mostra-se também a simulação com fator de escala aplicado nos modelos de $1 / 20$ e a velocidade inicial da massa de impacto ainda de $60 \mathrm{~m} / \mathrm{s}$, de modo a obedecer as leis usuais de escalonamento. A Figura 30 apresenta também os resultados quando o fator de correção é aplicado. Quando se compara o máximo deslocamento, Figura 30 (a), o erro em relação ao protótipo cai de 10,97\% (sem correção) para 0,90\% (corrigido). A Tabela 24 exibe os erros quando os valores de pico de cada variável são confrontados com a resposta da estrutura em escala real.

A Figura 31 mostra o resultado da simulação do tubo engastado, mas utilizando um fator de escala $1 / 10$ e um fator corrigido, $\beta v=1,0965$. O erro nesse caso cai de $10,27 \%$ para $0,79 \%$ quando o deslocamento máximo no centro do tubo é comparado.

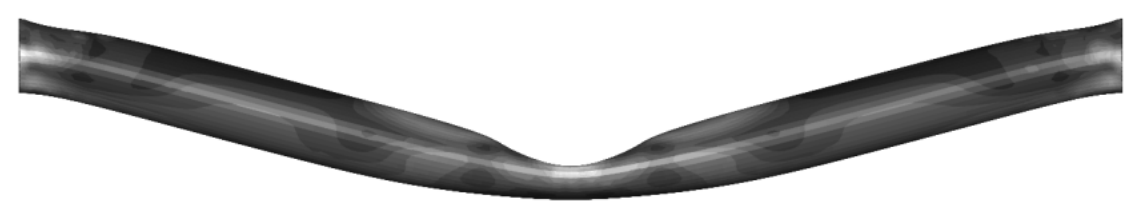

(a) 


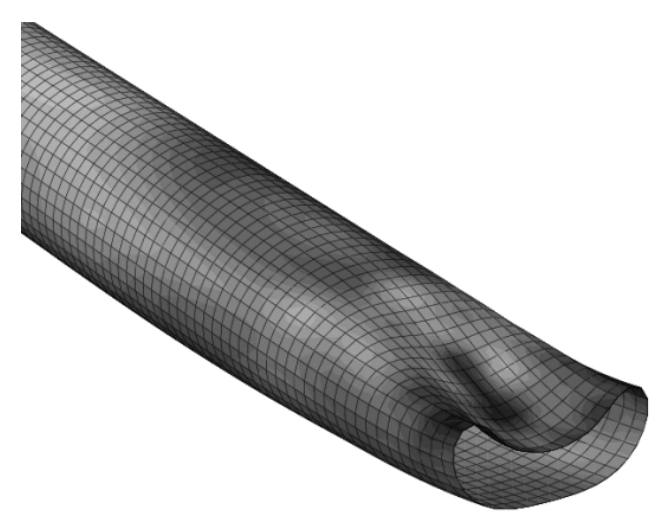

(b)

Figura 29 - Malha da simulação de tubo biengastado sujeito ao impacto de uma massa na direção radial. (a) deformação final. (b) visão em corte e malha.

Tabela 24 - Comparação dos erros do modelo de tubo sujeito ao impacto de uma massa. A comparação é feita nos valores máximos para cada variável. $\beta=1 / 20$ e $\beta_{V}=1,174$.

\begin{tabular}{lccc}
\hline & & $\begin{array}{c}\text { modelo sem correção } \\
\text { erro (\%) }\end{array}$ & $\begin{array}{c}\text { modelo corrigido } \\
\text { erro (\%) }\end{array}$ \\
\hline deslocamento & $\delta$ & 10,97 & 0,90 \\
tensão equivalente de Von Mises & $\sigma$ & 19,75 & 6,10 \\
deformação plástica equivalente & $\varepsilon p$ & 4,23 & 1,47 \\
taxa de deformação plástica & $\dot{\varepsilon p}$ & 1,57 & 6,92 \\
reação nos apoios & $F$ & 26,08 & 0,48 \\
\hline
\end{tabular}

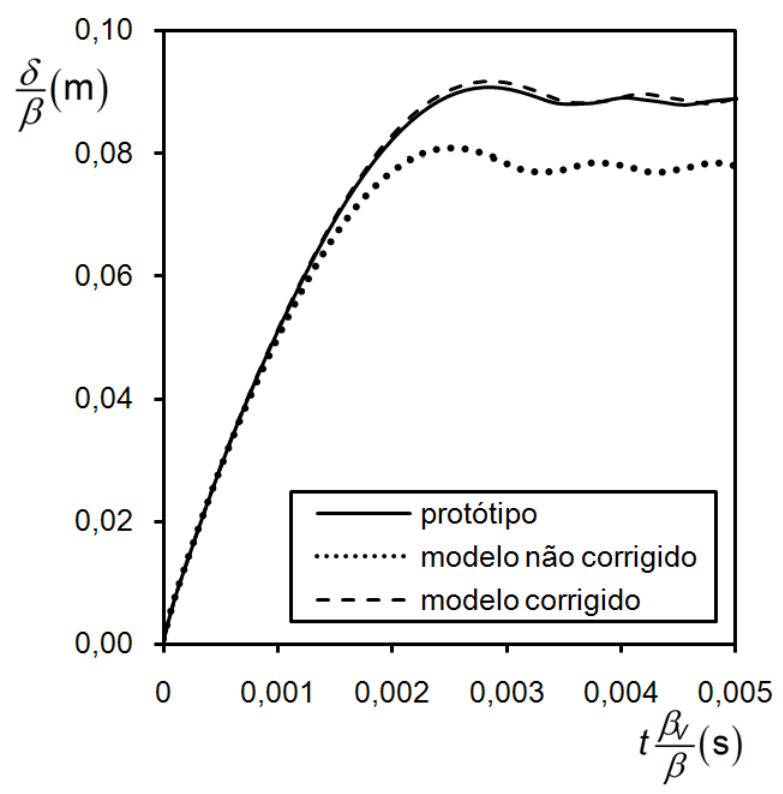

(a)

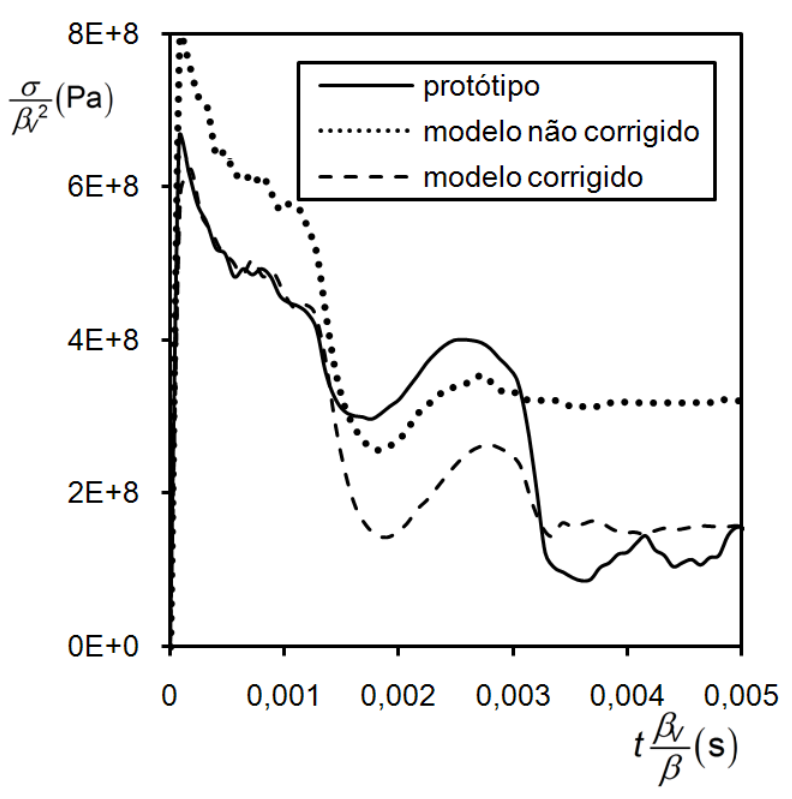

(b) 


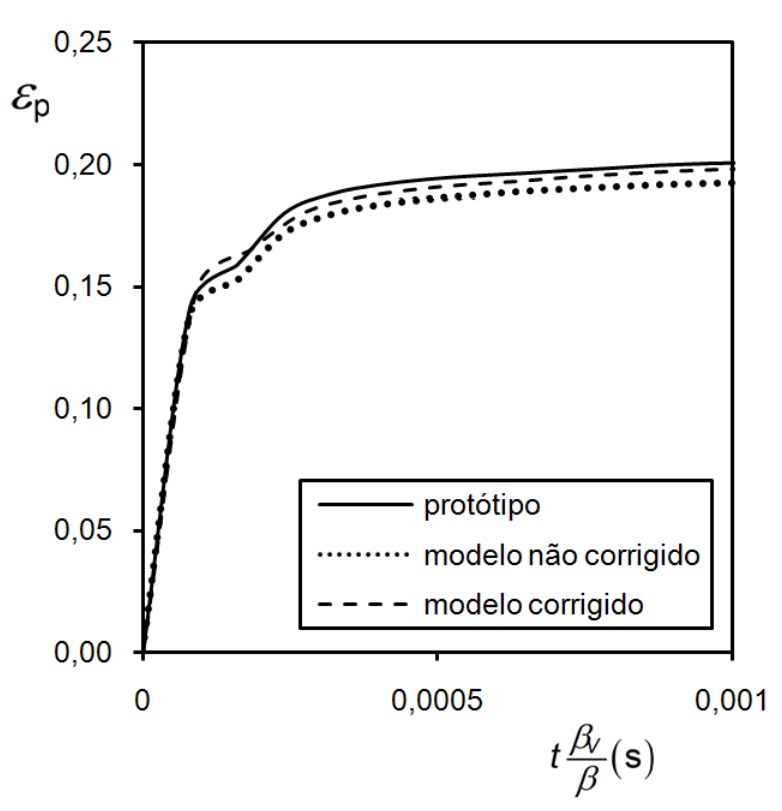

(c)

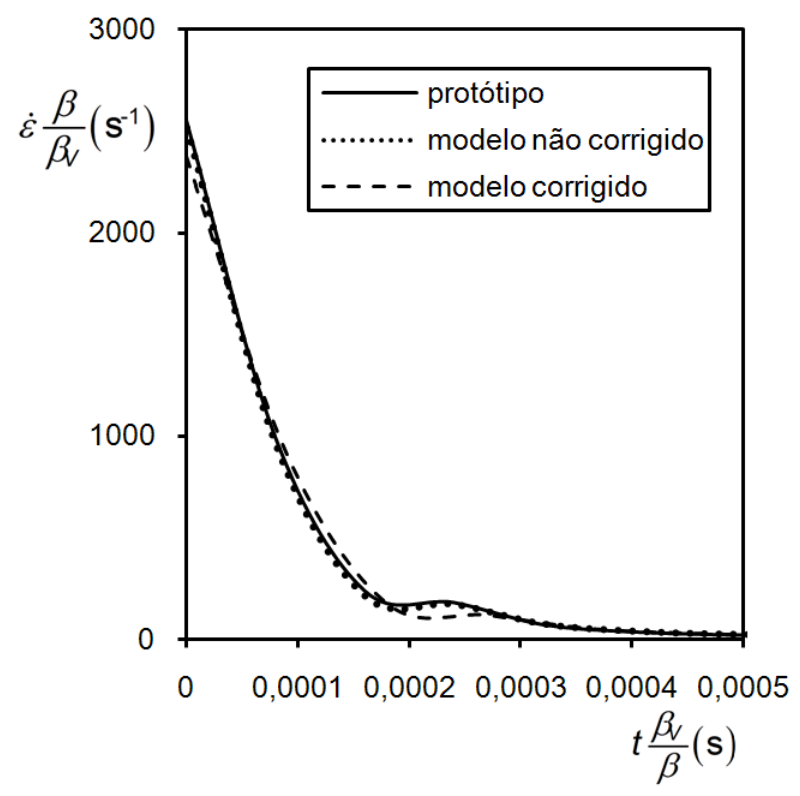

(d)

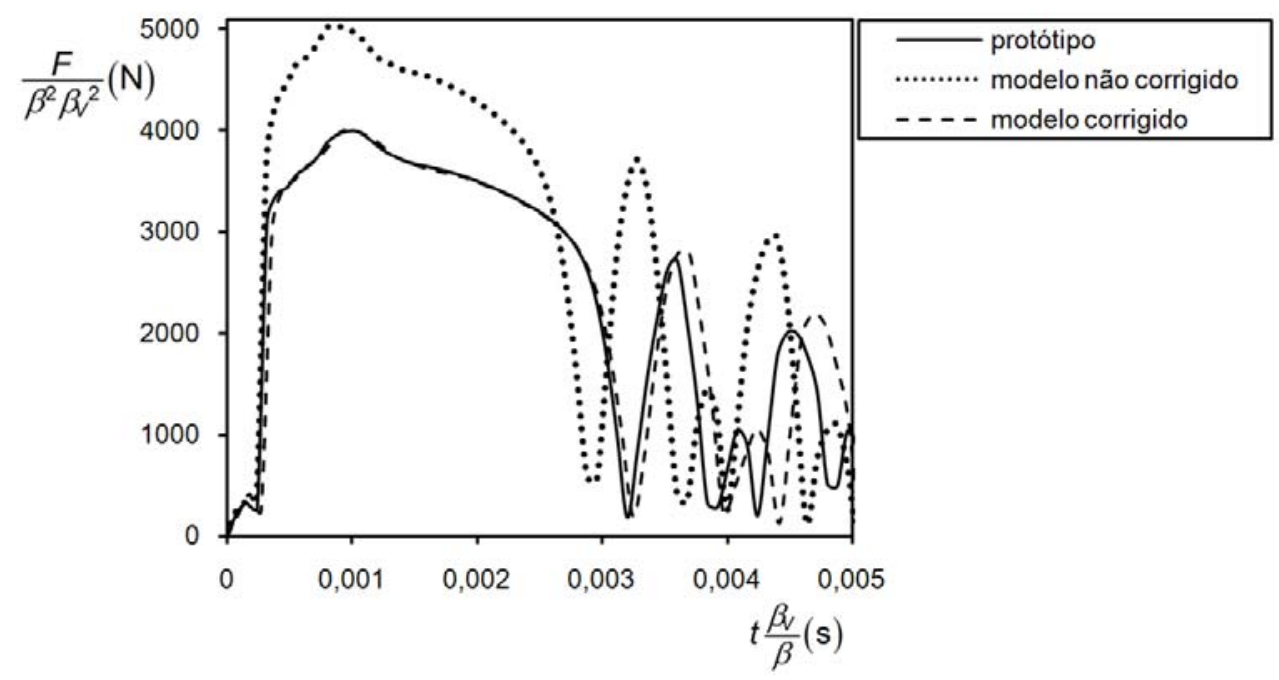

(e)

Figura 30 - Resultados para a simulação de tubo biengastado sujeito ao impacto de uma massa rígida, escala $\beta=1 / 20$ e $V_{0}=60 \mathrm{~m} / \mathrm{s}$. (a) deslocamento máximo no centro. (b) tensão no ponto de impacto. (c) deformação plástica no centro. (d) taxa de deformação no centro. (e) máxima força de reação nos apoios.

b) casco de navio

Simula-se agora a lateral de um dos compartimentos de um navio. Um navio de casco duplo DWT 150K (CHO et al., 2005) foi usado como referência. As dimensões 
utilizadas são apresentadas na Figura 32, com a estrutura constituída de chapas de $18 \mathrm{~mm}$ de espessura para o caso do protótipo. A malha e a estrutura interna entre as duas paredes cascos são apresentados na Figura 32, sendo que foram utilizados 25905 elementos de casca S4R. Os nós internos do convés e da base do navio estão engastados. O material utilizado é o mesmo do caso do tubo engastado, mas com uma tensão de escoamento quasi-estática de $400 \mathrm{MPa}$. A esfera rígida tem $8 \mathrm{~m}$ de diâmetro, massa de 500 toneladas e uma velocidade inicial de $35 \mathrm{~m} / \mathrm{s}$. O impacto ocorre no centro da placa em um ângulo reto com a superfície e a 16,5 m de altura em relação à base.

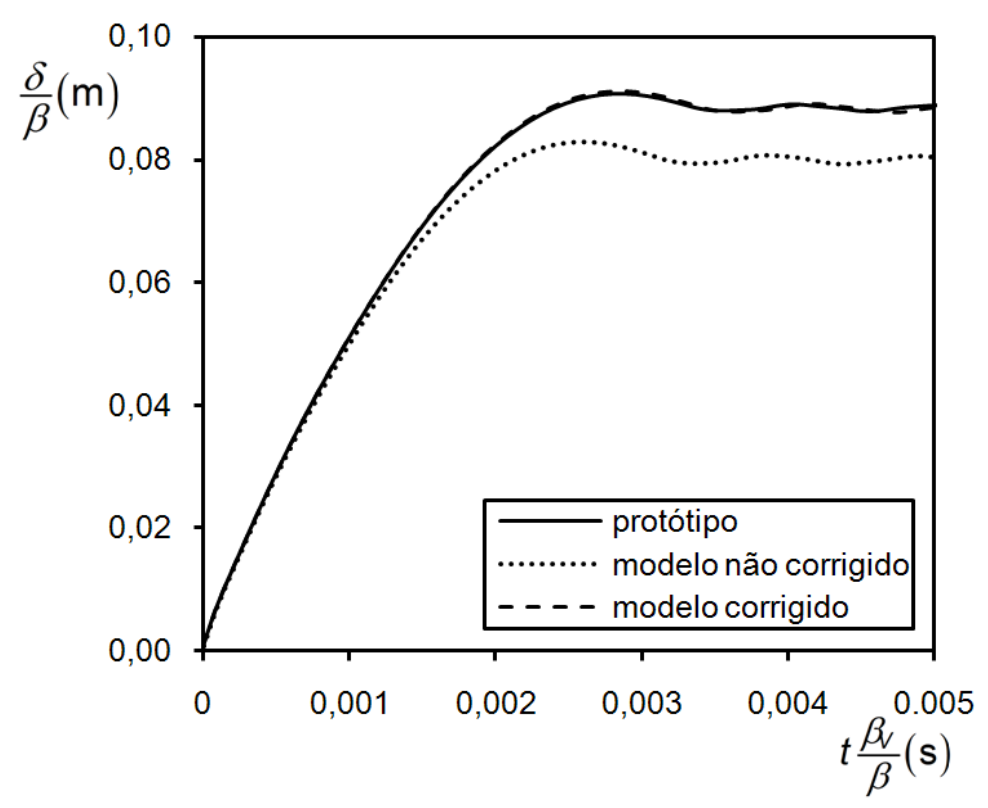

Figura 31 - Resultados para a simulação de tubo biengastado sujeito ao impacto de uma massa rígida na direção radial. Comparação do deslocamento máximo em função do tempo para $\beta=1 / 10$ e $v_{0}=60 \mathrm{~m} / \mathrm{s}$.

A Figura 33 mostra a configuração deformada final na simulação do protótipo. A Figura 34 mostra o deslocamento horizontal máximo no ponto onde ocorre o contato com a esfera. Comparando-se os modelos em escala 1/100 com o protótipo, o erro é de $19,36 \%$ quando não há correção da velocidade inicial e diminui para $6,22 \%$ quando $\beta_{V}=1,2025$, calculado de acordo com a eq. (21). 


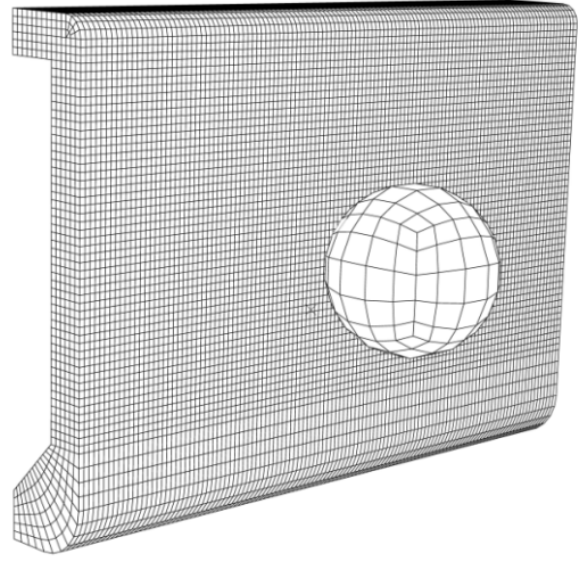

(a)

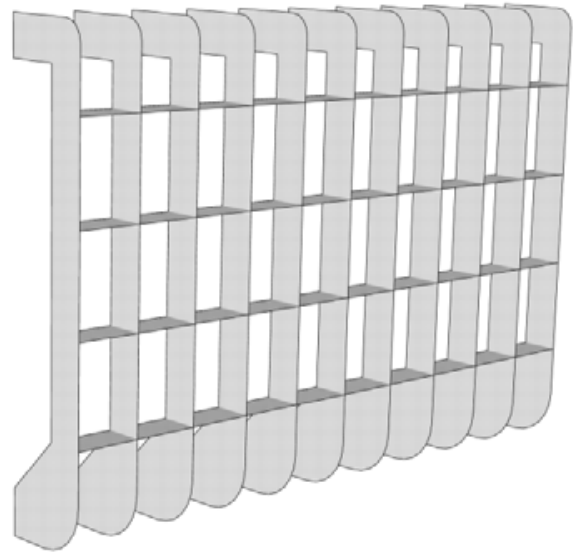

(b)
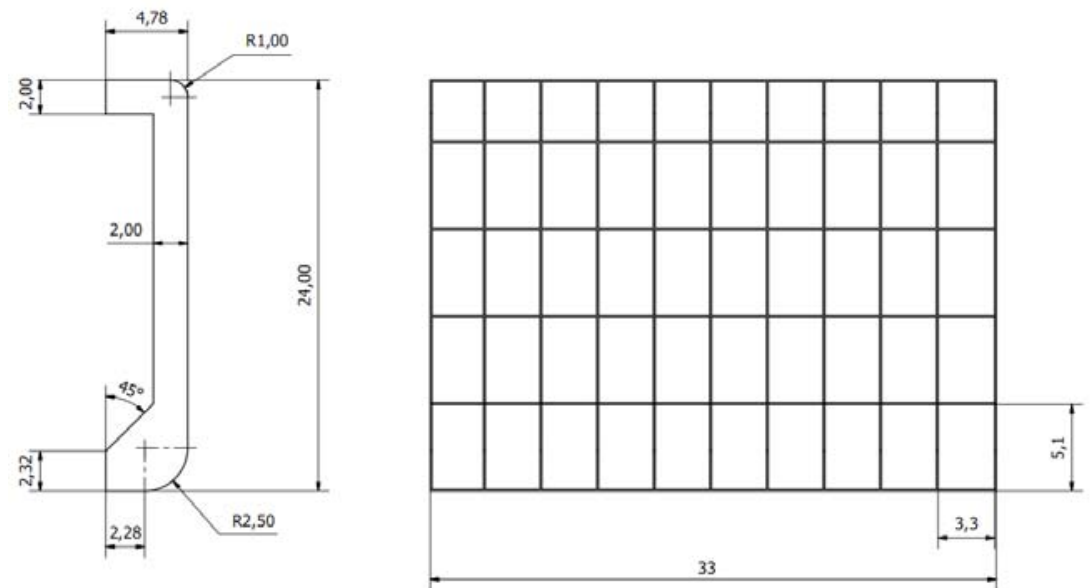

(c)

Figura 32 - Simulação do casco de navio. (a) malha do casco e do corpo de impacto. (b) estrutura interna. (c) geometria com dimensões em metros.

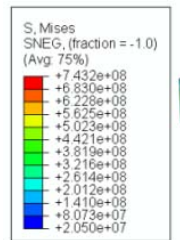

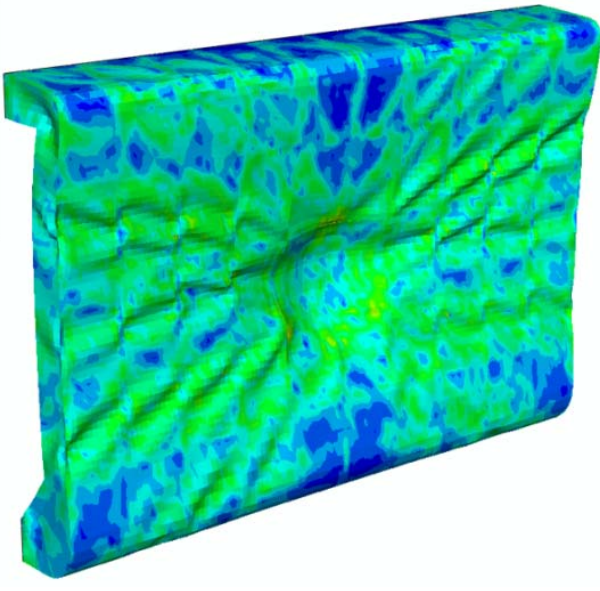

(a)

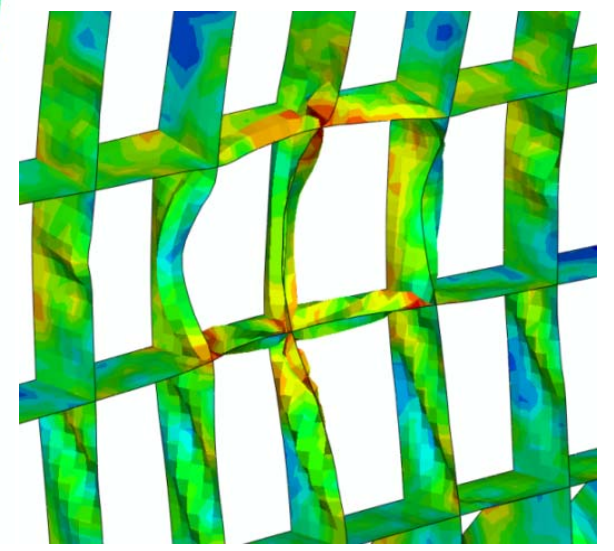

(b)

Figura 33 - Configuração deformada final na simulação do casco do navio. (a) estrutura inteira. (b) deformação dos reforços internos. 


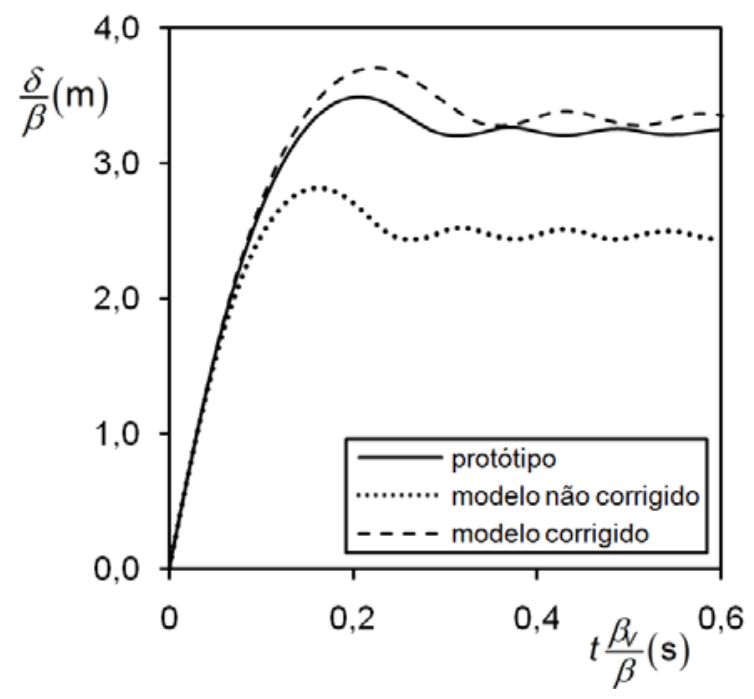

Figura 34 - Comparação do deslocamento horizontal máximo do protótipo com modelos em escala 1/100 na simulação do casco de navio.

\subsection{Modelo geometricamente distorcido}

Nesta seção, o efeito de uma configuração distorcida da geometria do modelo é considerado. Para corrigir o erro devido a essa variação, o método descrito na seção 3.1 é empregado. Foram estudadas a distorção na espessura do tubo e das chapas do casco do navio, pois essas são as dimensões mais complexas de serem reproduzidas em escala exata no caso de experimentos reais. Os dados de geometria, material e condições iniciais são as mesmas da seção 4.1.

a) Tubo engastado

Como já discutido na seção 3.1, são necessários dois modelos distorcidos geometricamente em relação ao protótipo para fazer a correção. Por isso, dois modelos de tubo engastado em escala $1 / 20$ e a espessura distorcida em $\beta_{e} / \beta=2,0$ (modelo 1) e $\beta_{e} / \beta=1,5$ (modelo 2) são utilizados, sendo

$$
\beta_{e}=\frac{\text { espessura do modelo }}{\text { espessura do protótipo }}
$$


De acordo com a aproximação feita na seção 3.1, o expoente que permite que 0 modelo seja similar ao protótipo é o mesmo que gera uma resposta similar entre os modelos 1 e 2. Portanto, os dois modelos com geometria distorcida são simulados em pares e o expoente é obtido quando ambos tiverem a mesma resposta estrutural. Dessa maneira não é necessário nenhum dado do protótipo para resolver o problema. O máximo deslocamento vertical no tubo, $\delta / \beta$, é a variável utilizada para a comparação quantitativa da similaridade.

A Tabela 25 resume as simulações feitas para determinar o expoente de $f_{2}$; o valor encontrado é $n=0,60$. Como pode ser observado, seis simulações foram realizadas, com o expoente variando de 0,50 a 0,70. A Figura 35 compara a resposta do modelo corrigido com o protótipo quando o valor encontrado para $f_{2}$ é utilizado e $\beta_{e} / \beta=2,0$. A diferença no máximo deslocamento vertical cai de $47,13 \%$ (para o modelo sem correção) para 1,11\% (para o modelo corrigido). Caso os expoentes 0,50 ou 0,70 fossem utilizados, os erros relativos ao protótipo seriam de $8,17 \%$ e 6,58\%, respectivamente. Como será visto na discussão, não é necessária uma exatidão muito grande na obtenção do expoente de $f_{2}$ para gerar resultados satisfatórios.

Tabela 25 - Resumo dos cálculos para determinação do expoente da função $f_{2}$ na simulação do tubo engastado.

\begin{tabular}{ccccccccc}
\hline$n$ & simulação & modelo & $\beta e / \beta$ & $f_{1}$ & $f_{2}$ & $\beta V$ & $\delta / \beta$ & $\begin{array}{c}\text { erro relativo entre } \\
\text { modelos 1 e 2 }\end{array}$ \\
\hline \multirow{2}{*}{0,50} & 1 & modelo 1 & 2,0 & 1,1274 & 1,4142 & 1,5944 & 0,083 & $4,07 \%$ \\
& 2 & modelo 2 & 1,5 & 1,1274 & 1,2247 & 1,3808 & 0,087 & \\
\hline \multirow{2}{*}{0,60} & 3 & modelo 1 & 2,0 & 1,1274 & 1,5157 & 1,7089 & 0,090 & $1,07 \%$ \\
& 4 & modelo 2 & 1,5 & 1,1274 & 1,2754 & 1,4380 & 0,091 & \\
\hline \multirow{2}{*}{0,70} & 5 & modelo 1 & 2,0 & 1,1274 & 1,6245 & 1,8315 & 0,097 & $2,26 \%$ \\
& 6 & modelo 2 & 1,5 & 1,1274 & 1,3282 & 1,4975 & 0,095 & \\
\hline
\end{tabular}

O cálculo dos fatores de transposição para algumas variáveis da simulação do tubo com espessura distorcida é resumido na Tabela 26. Os resultados, após a correção com os fatores calculados, são exibidos na Tabela 27, sendo comparados os valores máximos de cada variável. 


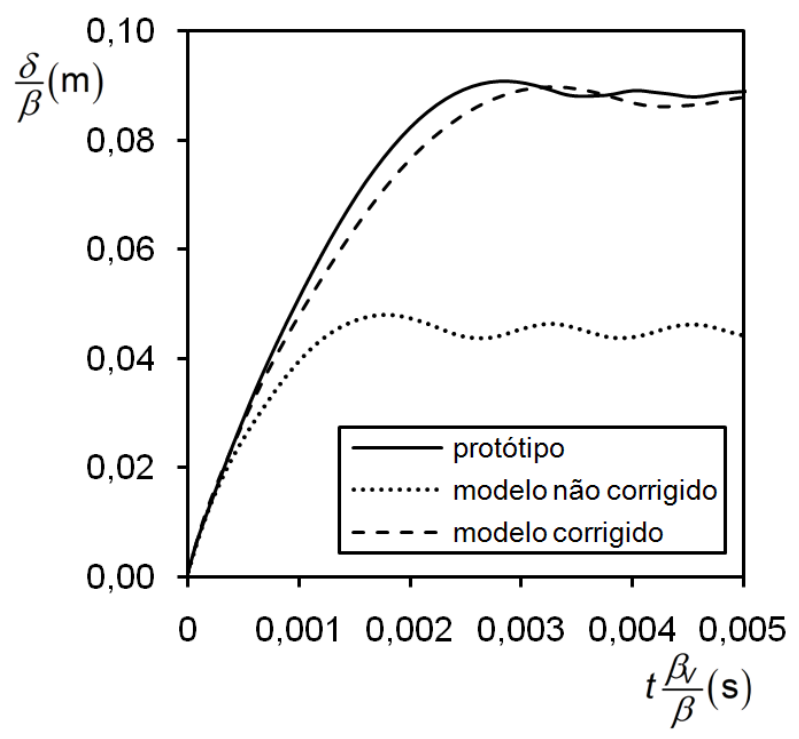

Figura 35 - Comparação dos resultados da simulação do tubo com espessura distorcida.

Tabela 26 - Cálculo dos fatores de transposição do modelo de tubo engastado com espessura distorcida.

\begin{tabular}{|c|c|c|c|c|c|c|c|}
\hline & $\beta$ & $\beta_{e}$ & $\beta_{e} / \beta$ & $\begin{array}{c}Y=F \\
(\mathrm{~N})\end{array}$ & $\begin{array}{l}Y=\sigma \\
(\mathrm{MPa})\end{array}$ & $\begin{array}{c}Y=\dot{\varepsilon}_{\text {plas }} \\
\left(\mathrm{s}^{-1}\right)\end{array}$ & $Y=\varepsilon_{\text {plas }}$ \\
\hline modelo 1 & 0,05 & 0,100 & 2,0 & 26,44 & 797,1 & 54245 & 0,7426 \\
\hline modelo 2 & 0,05 & 0,075 & 1,5 & 19,54 & 801,1 & 49828 & 0,5592 \\
\hline \multicolumn{3}{|l|}{$Y_{1} / Y_{2}$} & 1,3333 & 1,3531 & 0,9950 & 1,0886 & 1,3280 \\
\hline \multicolumn{4}{|c|}{$n_{\mathrm{i}}=\log \left(Y_{1} / Y_{2}\right) / \log \left(\beta_{\mathrm{e}_{1}} / \beta_{\mathrm{e}_{2}}\right)$} & 1,0512 & $-0,0174$ & 0,2952 & 0,9860 \\
\hline & \multicolumn{3}{|c|}{$f_{2}=\left(\beta_{e} / \beta\right)^{n_{1}}$} & 2,0723 & 0,9880 & 1,2271 & 1,9807 \\
\hline \multirow[t]{2}{*}{ modelo 1} & $f_{1}$ & & & 0,0032 & 1,2711 & 22,5489 & 1,0000 \\
\hline & $f_{1} f_{2}$ & & & 0,0066 & 1,2559 & 27,6690 & 1,9807 \\
\hline
\end{tabular}

Tabela 27 - Resultados da simulação de tubo engastado: comparação do modelo com espessura distorcida com o protótipo. Valores máximos durante a simulação.

\begin{tabular}{lcccccc}
\hline & $\beta$ & $\beta_{e}$ & $F(\mathrm{~N})$ & $\sigma(\mathrm{MPa})$ & $\dot{\varepsilon}_{\text {plas }}\left(\mathrm{s}^{-1}\right)$ & $\varepsilon_{\text {plas }}$ \\
\hline protótipo & 1 & 1 & 3996 & 712,2 & 1716,16 & 0,3767 \\
modelo corrigido & 0,05 & 0,10 & 4015 & 634,7 & 1960,51 & 0,3749 \\
modelo não corrigido & 0,05 & 0,10 & 10404 & 810,8 & 2394,73 & 0,5017 \\
\hline
\end{tabular}


b) casco do navio

O casco do navio apresentado na Seção 4.2 é novamente solucionado, mas com a espessura das chapas distorcidas em $\beta_{e} / \beta=1,5$ e $\beta_{e} / \beta=2,0$ e $\beta=1 / 100$, como feito no item a. Foram feitas seis simulações com o expoente de $f_{2}$ variando de 0,60 a 0,80. A Figura 36 compara o resultado do modelo corrigido usando $n=0,80$ com o protótipo. Quando o máximo deslocamento horizontal na placa do navio é comparado, o erro quando a velocidade inicial não é alterada é de 57,82\%. Em contrapartida, o mesmo erro diminui para $6,59 \%$ no caso do fator de velocidade corrigido. Na seção 4.3 é discutido detalhadamente a precisão necessária para determinar o expoente.

Tabela 28 - Resumo dos cálculos para determinação do expoente da função $f_{2}$ na simulação do casco do navio.

\begin{tabular}{ccccccccc}
\hline$n$ & simulação & modelo & $\beta_{e} / \beta$ & $f_{1}$ & $f_{2}$ & $\beta V$ & $\delta / \beta$ & $\begin{array}{c}\text { erro relativo entre } \\
\text { modelos 1 e 2 }\end{array}$ \\
\hline \multirow{2}{*}{0,60} & 1 & modelo 1 & 1,5 & 1,2025 & 1,5157 & 1,8226 & 3,08 & $7,01 \%$ \\
& 2 & modelo 2 & 2,0 & 1,2025 & 1,2754 & 1,5337 & 3,30 & \\
\hline \multirow{2}{*}{0,70} & 3 & modelo 1 & 1,5 & 1,2025 & 1,6245 & 1,9535 & 3,39 & $3,31 \%$ \\
& 4 & modelo 2 & 2,0 & 1,2025 & 1,3282 & 1,5972 & 3,50 & \\
\hline \multirow{2}{*}{0,80} & 5 & modelo 1 & 1,5 & 1,2025 & 1,7411 & 2,0937 & 3,72 & \multirow{2}{*}{$0,02 \%$} \\
& 6 & modelo 2 & 2,0 & 1,2025 & 1,3832 & 1,6632 & 3,72 & \\
\hline
\end{tabular}

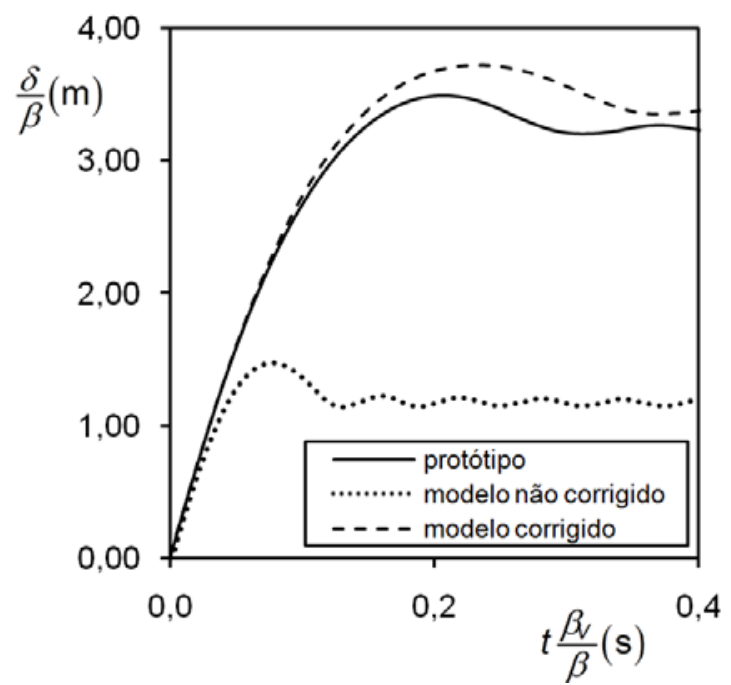

Figura 36 - Comparação dos resultados da simulação do casco de navio com a espessura das chapas distorcida. 


\subsection{Discussão}

Na seção 4.1, onde somente o efeito da taxa de deformação foi considerado, os erros dos modelos com correção se devem ao fato do método dos elementos finitos implementado no Abaqus não ter um material perfeitamente plástico. Como descrito nos detalhes das simulações, as estruturas foram implementadas com um módulo de elasticidade padrão do aço, $210 \mathrm{GPa}$. A elasticidade não é prevista pelo modelo teórico e por isso, um pequeno erro no processo de correção é gerado.

No caso de um modelo elasto-plástico, a deformação total, $\varepsilon_{\mathrm{t}}$, divide-se em um componente elástico, $\varepsilon_{\text {elas }}$, e outro plástico, $\varepsilon_{\text {plas }}$. Idealmente, um modelo que tenha similaridade perfeita deve ter a configuração final de deformações idêntica ao do protótipo, ou seja, $\left(\varepsilon_{\text {plas }}\right)_{\mathrm{m}}=\left(\varepsilon_{\text {plas }}\right)_{\mathrm{p}}$. No entanto, a similaridade não distingue a diferença entre variáveis de mesma dimensão e tenta igualar a deformação total. Como pode ser observado na Figura 37, o incremento da tensão de escoamento dinâmica devido à taxa de deformação e o retorno elástico geram uma pequena diferença na deformação final, pois

$$
\begin{gathered}
\left(\varepsilon_{\mathrm{t}}\right)_{\mathrm{m}}=\left(\varepsilon_{\mathrm{t}}\right)_{\mathrm{p}} \rightarrow \\
\left(\varepsilon_{\text {plas }}\right)_{\mathrm{m}}+\left(\varepsilon_{\text {elas }}\right)_{\mathrm{m}}=\left(\varepsilon_{\text {plas }}\right)_{\mathrm{p}}+\left(\varepsilon_{\text {elas }}\right)_{\mathrm{p}}
\end{gathered}
$$

Como $\left(\varepsilon_{\text {elas }}\right)_{\mathrm{m}} \neq\left(\varepsilon_{\text {elas }}\right)_{\mathrm{p}}$, tem-se que $\left(\varepsilon_{\text {plas }}\right)_{\mathrm{m}} \neq\left(\varepsilon_{\text {plas }}\right)_{\mathrm{p}}$. Pelo menos no modelo numérico estudado, esse erro é relativamente pequeno e a similaridade é quase perfeita. Porém, estruturas sensíveis a pequenas variações de deformação (flambagem, por exemplo) podem gerar erros maiores ou um comportamento distinto. No caso de um modelo perfeitamente plástico esse problema não ocorre, pois $\varepsilon_{\mathrm{t}}=\varepsilon_{\text {plas }}$.

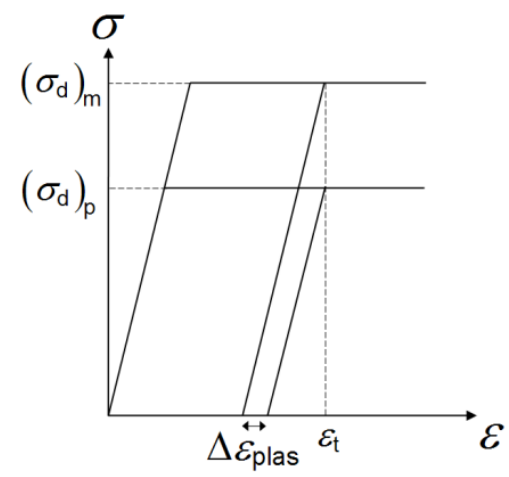

Figura 37 - Curva de um material elasto-plástico sem encruamento. 
Como discutido, o modelo numérico não apresenta similaridade perfeita. Porém, o comportamento do modelo corrigido é substancialmente melhor quando comparado à resposta da estrutura em escala com fator de velocidade unitária. A Figura 30 e Tabela 24 mostram os resultados para diversas variáveis medidas no ponto central na face superior do tubo, assim como a Figura 34 compara os resultados para o modelo de casco de navio. Nesse caso a correção foi feita em duas estruturas relativamente complexas sem que nenhum dado do protótipo fosse necessário. O fator de velocidade foi calculado somente com o uso da eq. (21).

$\mathrm{Na}$ simulação do casco do navio, os valores escolhidos como condições iniciais para o corpo de impacto não são reais: massa de 500 toneladas e velocidade inicial de $35 \mathrm{~m} / \mathrm{s}$ (68 nós), gerando uma energia cinética de 306,25E6 J. Em uma simulação mais real, por exemplo, usando uma massa de 150000 toneladas e 3,6 m/s (7 nós), a energia total desenvolvida é de 972,00E6 J. Os valores para a simulação foram escolhidos para que o efeito da taxa de deformação fosse mais evidente com o uso de uma velocidade maior. Por outro lado, não poderia haver uma deformação excessiva do casco do navio, pois a fratura não é prevista na correção do modelo. A estrutura tem menos resistência a um impacto lateral devido à ausência de vigas transversais de reforço - característica comum também em relação à geometria de referência (CHO et al., 2005).

$\mathrm{Na}$ seção 4.2 as duas estruturas foram distorcidas geometricamente em relação ao protótipo. Nesse caso, a razão entre as espessuras do modelo e do protótipo não seguem o fator $\beta$. Para que o fator de correção para a velocidade inicial de impacto fosse determinado sem nenhum dado do protótipo, o método descrito na seção 3.1 foi empregado. Dois modelos distorcidos por fatores $\beta_{e} / \beta=1,5$ e $\beta_{e} / \beta=2,0$ são utilizados para determinar o expoente da função $f_{2}$. No caso do tubo engastado foi determinado um expoente $n=0,60$ e no caso do casco do navio, $n=0,80$. Isso significa que quando a espessura é duas vezes maior que 0 valor correto, um aumento de $51,57 \%$ e $74,11 \%$ na velocidade inicial de impacto é necessário para corrigir o tubo engastado e o casco do navio, respectivamente.

Foram necessárias seis simulações para que o expoente pudesse ser determinado - três com o modelo de espessura distorcida em $+50 \%$ e três com a espessura distorcida em $+100 \%$. Uma análise da precisão na similaridade dos modelos 1 e 2 pode ser feita para as estruturas estudadas. No caso do tubo engastado o valor determinado foi $n=0,60$, mas o expoente igual a 0,50 ou 0,70 gera erros de $8,17 \%$ e $6,58 \%$, respectivamente. A melhora em relação ao modelo 
não corrigido $(57,82 \%)$ já é bastante significativa mesmo com essa diferença no expoente.

A Figura 38 mostra um resumo dos erros para a simulação da estrutura do casco de navio. A linha contínua mostra o erro do modelo corrigido em escala 1/100 quando somente o efeito da taxa de deformação é considerado (estudado na seção 4.1). Na seção 4.2 o efeito da taxa de deformação é cumulativo com a distorção da espessura. Por isso, qualquer erro próximo do valor registrado na seção 4.1 (6,59\%) pode ser considerado satisfatório. A análise da Figura 38 mostra que o valor de $n$ entre 0,66 a 0,80 produz um erro inferior ao já registrado na seção 4.1. Essa constatação permite afirmar, pelo menos para as estruturas estudadas, que não é necessária uma precisão muito alta na definição do expoente de $f_{2}$. Outros erros oriundos da elasticidade, das aproximações teóricas, etc. podem ser mais significativos do que a exatidão para determinar $n$. Essa característica permite economizar recursos com a realização de menos simulações ou experimentos. Nos casos do tubo engastado e do casco do navio, somente duas ou quatro simulações já poderiam produzir bons resultados.

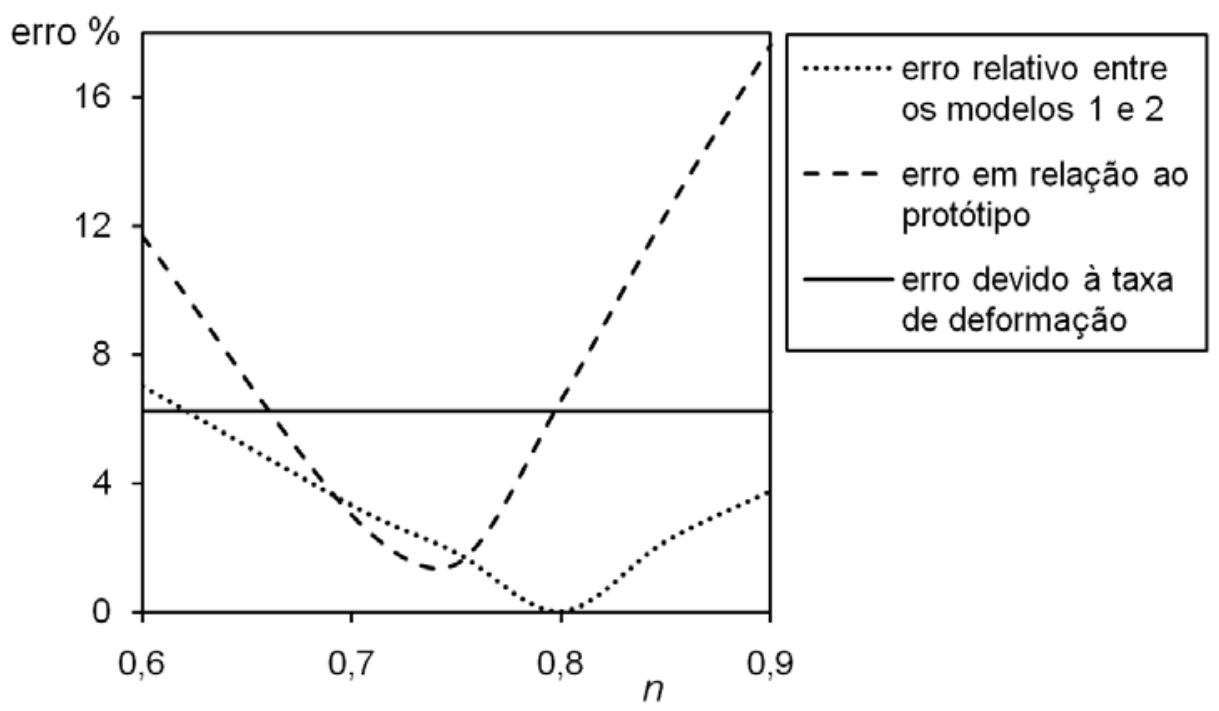

Figura 38 - Resultados na simulação do casco de navio. Erro do modelo corrigido em relação ao protótipo em função do expoente de $f_{2}$.

A aproximação da função $f_{2}$ por um formato exponencial parece razoável, pois o erro relativo entre os modelos 1 e 2 (linha pontilhada na Figura 38) tem um comportamento próximo ao erro relativo entre o modelo corrigido e o protótipo (linha 
tracejada na Figura 38). Enquanto o menor erro entre os modelos 1 e 2 ocorre para $n=0,80$, o erro mínimo em relação ao protótipo ocorre para $n=0,73$. Deve-se observar que a simulação do protótipo só foi necessária para a discussão do método de correção, mas nenhum dado da estrutura em escala real foi utilizado.

A simulação do casco do navio ignora vários fatores importantes: não considera a carga do navio e a massa adicional da água, simplificação do corpo de impacto como uma esfera rígida, somente parte do casco é implementado, etc. No entanto, ela cumpre o objetivo principal do atual trabalho que é a análise do método de correção de um modelo em escala. Simular um caso mais real com todos os fatores agravantes do fenômeno de impacto entre navios exigiria um tempo de simulação muito maior. Além disso, dificultaria a análise mais detalhada dos resultados do procedimento de correção, pois adicionaria muitas variáveis ao problema. 


\section{VARIAÇÕES DO MÉTODO DE CORREÇÃO}

Nesse capítulo são discutidas duas possibilidades de correção da resposta do modelo. Primeiro é analisado um modelo construído com material diferente do protótipo. A seguir, é estudada uma variação do método exibido no capítulo 2. Ao invés de alterar a velocidade inicial, a massa do corpo de impacto é alterada de forma a considerar o efeito da taxa de deformação.

\subsection{Material do modelo diferente do protótipo}

A possibilidade de o modelo utilizar um material diferente do protótipo possui um grande caráter prático, pois nem sempre é viável construir estruturas em escalas diferentes com o mesmo material. No método estudado no atual trabalho é possível utilizar tensões de escoamento quasi-estáticas, $\sigma_{0}$, distintas para modelo e protótipo. Para isso, uma pequena modificação na eq. (19) é considerada

$$
\beta_{\sigma_{\mathrm{d}}}=\frac{\left(\sigma_{\mathrm{d}}\right)_{\mathrm{m}}}{\left(\sigma_{\mathrm{d}}\right)_{\mathrm{p}}}=\frac{\left(\sigma_{0}\right)_{\mathrm{m}}\left(\dot{\varepsilon}_{\mathrm{m}} / \dot{\varepsilon}_{0}\right)^{q}}{\left(\sigma_{0}\right)_{\mathrm{p}}\left(\dot{\varepsilon}_{\mathrm{p}} / \dot{\varepsilon}_{0}\right)^{q}}=K_{0}\left(\frac{\dot{\varepsilon}_{\mathrm{m}}}{\dot{\varepsilon}_{\mathrm{p}}}\right)^{q}=K_{0}\left(\beta_{\dot{\varepsilon}}\right)^{q},
$$

sendo $K_{0}=\left(\sigma_{0}\right)_{\mathrm{m}} /\left(\sigma_{0}\right)_{\mathrm{p}}$. Portanto, a variante da eq. (21), que calcula o fator de correção considerando $\sigma_{0}$ diferentes e o efeito da taxa de deformação é dada por

$$
\beta_{v}^{2-q}=K_{0} \beta^{-q} \rightarrow \beta_{v}=\left(\beta^{q} / K_{0}\right)^{1 /(q-2)} .
$$

No caso em que $q=0$ (o comportamento do material não é afetado pela taxa de deformação), o fator de velocidade é simplificado para

$$
\beta V=\sqrt{K_{0}} .
$$

A Tabela 29 resume os resultados da estrutura de Calaldine quando o protótipo usa uma tensão de escoamento quasi-estática de $\left(\sigma_{0}\right)_{\mathrm{p}}=235 \mathrm{MPa}$, enquanto o modelo emprega $\left(\sigma_{0}\right)_{\mathrm{m}}=100 \mathrm{MPa}$. Após a correção os erros são nulos, pois a solução é exata. 
O método em estudo não permite, porém, alterar outras propriedades materiais como a elasticidade, a densidade e o expoente na eq. de Norton-Hoff. O primeiro fator, a elasticidade, só poderia ser alterado se o material fosse perfeitamente elástico, pois nesse caso a tensão é sempre linearmente proporcional à deformação. A densidade não pode ser alterada em razão de uma limitação da teoria de similaridade: o método não distingue a massa do corpo de impacto da massa da estrutura impactada.

No caso da Tabela 29, o expoente de Norton-Hoff do modelo tem que ser idêntico ao do protótipo para manter a independência do cálculo de $\beta_{V}$ em relação à resposta estrutural (ver eq. (19)). Mesmo pequenas variações do expoente podem ter efeitos consideráveis no comportamento do material (ver Figura 40).

Tabela 29 - Comparação das respostas do protótipo e do modelo para a estrutura de Calladine. Protótipo utiliza uma tensão de escoamento quasi-estática $\left(\sigma_{0}\right)_{\mathrm{p}}=235 \mathrm{MPa}$ e modelo emprega $\left(\sigma_{0}\right)_{\mathrm{m}}=100 \mathrm{MPa}$.

\begin{tabular}{|c|c|c|c|c|}
\hline \multicolumn{5}{|c|}{ Modelo sem correção } \\
\hline escala & 1 & $1 / 2$ & $1 / 4$ & $1 / 100$ \\
\hline rotação final $\left({ }^{\circ}\right)$ & 25,95 & 42,43 & 41,07 & 35,31 \\
\hline final da primeira fase (s) & $1,13 \mathrm{E}-4$ & $1,87 \mathrm{E}-4$ & $1,81 \mathrm{E}-4$ & $1,55 \mathrm{E}-4$ \\
\hline final da segunda fase (s) & $1,10 \mathrm{E}-3$ & $2,50 \mathrm{E}-3$ & $2,37 \mathrm{E}-3$ & $1,84 \mathrm{E}-3$ \\
\hline aceleração final $\left(\mathrm{m} / \mathrm{s}^{2}\right)$ & 6,34E4 & $2,80 \mathrm{E} 4$ & 2,95E4 & 3,81E4 \\
\hline taxa de deformação final $\left(\mathrm{s}^{-1}\right)$ & 184,57 & 146,68 & 149,08 & 160,72 \\
\hline tensão final (MPa) & 517,37 & 228,15 & 240,96 & 310,53 \\
\hline \multicolumn{5}{|c|}{ Modelo corrigido } \\
\hline escala & 1 & $1 / 2$ & $1 / 4$ & $1 / 100$ \\
\hline fator de velocidade & 1 & 0,6593 & 0,6779 & 0,7711 \\
\hline rotação final $\left({ }^{\circ}\right)$ & 25,95 & 25,95 & 25,95 & 25,95 \\
\hline final da primeira fase (s) & $1,13 \mathrm{E}-4$ & $1,13 \mathrm{E}-4$ & $1,13 \mathrm{E}-4$ & $1,13 E-4$ \\
\hline final da segunda fase (s) & $1,10 \mathrm{E}-3$ & $1,10 \mathrm{E}-3$ & $1,10 \mathrm{E}-3$ & $1,10 \mathrm{E}-3$ \\
\hline aceleração final $\left(\mathrm{m} / \mathrm{s}^{2}\right)$ & $6,34 E 4$ & $6,34 \mathrm{E} 4$ & $6,34 E 4$ & $6,34 \mathrm{E} 4$ \\
\hline taxa de deformação final $\left(\mathrm{s}^{-1}\right)$ & 184,57 & 184,57 & 184,57 & 184,57 \\
\hline tensão final (MPa) & 517,37 & 517,37 & 517,37 & 517,37 \\
\hline
\end{tabular}

Uma alternativa para contornar essas limitações é aplicar o método empírico utilizado em Cho et al. (2005). Dois modelos de mesma escala, mas constituídos de materiais distintos são comparados. A primeira estrutura é construída do mesmo 
material do protótipo, enquanto a segunda emprega o material do modelo. Fatores relacionando o comportamento dos dois modelos são gerados e extrapolados para o protótipo, como exposto na Figura 39.

A mudança de estado $\phi_{1}$ descreve a variação do modelo devido unicamente à geometria. O fator $\phi_{2}$ expressa uma mudança do material e do carregamento na estrutura. Dessa forma, o modelo 2 está distorcido em relação ao protótipo 1 (estrutura real) na geometria, no material e no carregamento. O modelo 2 relacionase com pontos análogos do protótipo 1 através de

$$
Y_{\mathrm{p} 1}=\phi_{1} \phi_{2} Y_{\mathrm{m} 2}
$$

sendo $\phi_{1}=Y_{\mathrm{m} 1} / Y_{\mathrm{p} 1}=Y_{\mathrm{m} 2} / Y_{\mathrm{p} 2}$ e $\phi_{2}=Y_{\mathrm{m} 2} / Y_{\mathrm{m} 1}=Y_{\mathrm{p} 2} / Y_{\mathrm{p} 1}$

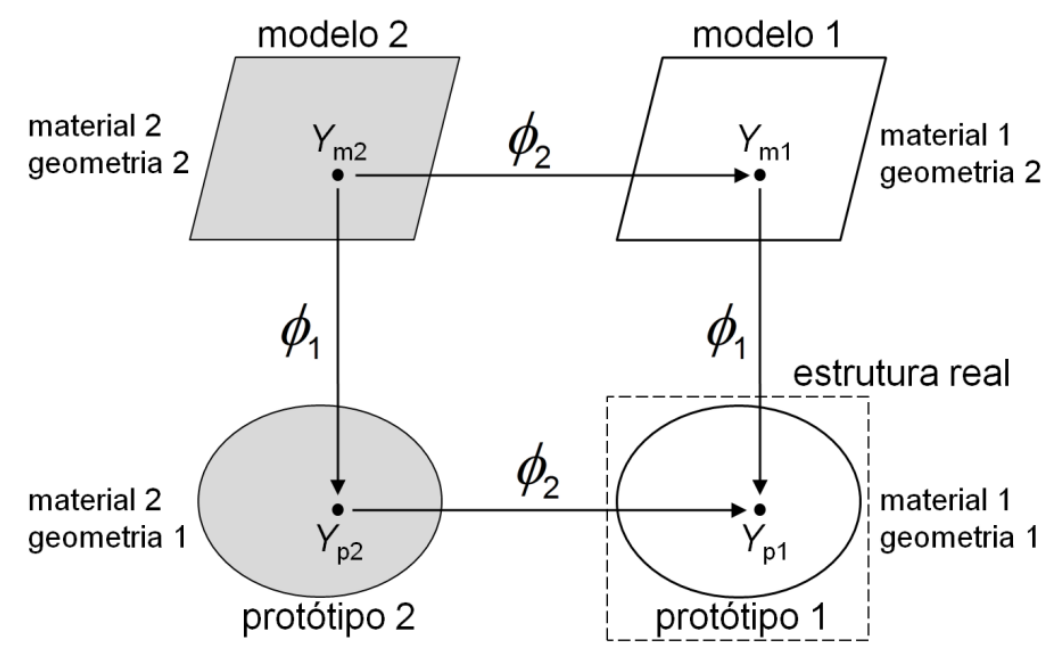

Figura 39 - Esquema para a determinação empírica do fator que relaciona os modelos com a estrutura real.

A avaliação do método proposto em Cho et al. (2005) é feita usando a mesma simulação do capítulo 4, um tubo engastado nas extremidades e sujeito ao impacto de um indentador rígido. O corpo de impacto tem uma velocidade inicial de $30 \mathrm{~m} / \mathrm{s}$ e uma massa de 1,6 kg. Nesse problema, a variação geométrica se dá através de um fator de escala 1/20, sendo a velocidade inicial calculada conforme eq. (21) e os fatores $\phi_{1}$ dados pelas equações (12) a (16). Por outro lado, os dois modelos têm propriedades de materiais distintos: o primeiro é feito de aço (mesmo material do protótipo) e o segundo tem a estrutura em alumínio, como mostra a Tabela 30. 
Tabela 30 - Dados do material na simulação do tubo engastado nas extremidades e sujeito ao impacto de uma massa.

\begin{tabular}{clcc}
\hline & & $\begin{array}{c}\text { material 1 } \\
\text { aço }\end{array}$ & $\begin{array}{c}\text { material 2 } \\
\text { alumínio }\end{array}$ \\
\hline$\sigma 0$ & tensão de escoamento quasi-estática & $235 \mathrm{MPa}$ & $100 \mathrm{MPa}$ \\
$q$ & expoente para equação de Norton-Hoff & 0,077 & 0,034 \\
$E$ & módulo de elasticidade & $210 \mathrm{GPa}$ & $70 \mathrm{GPa}$ \\
$\rho$ & densidade & $7800 \mathrm{~kg} / \mathrm{m}^{3}$ & $2100 \mathrm{~kg} / \mathrm{m}^{3}$ \\
\hline
\end{tabular}

$\mathrm{Na}$ Tabela 31 os fatores entre as variáveis dos modelos 1 e 2 são calculados (são considerados os valores máximos durante a simulação). Somente como validação, os valores de $\phi_{2}$ gerados para as estruturas em escala unitária também são exibidos. Pode-se observar que os fatores obtidos nas duas escalas são relativamente próximos. Finalmente, a Tabela 32 compara os resultados do modelo 2 (escala $1 / 20$ e feito de alumínio) com o protótipo 1 (feito de aço). A transposição das respostas do modelo 2 para o protótipo 1 é feita através da eq. (103). Os erros em relação à estrutura real (protótipo 1) são significantemente menores.

Tabela 31 - Fatores gerados para a simulação do tubo engastado e modelo com material distinto do protótipo. $U_{y}$ é o deslocamento vertical no centro do tubo, $\sigma$ é a tensão de Von Mises, $F$ é a força de reação e $s p$ a deformação plástica.

\begin{tabular}{ccccccc}
\hline & & $\beta$ & $U_{\mathrm{y}}(\mathrm{m})$ & $\sigma(\mathrm{MPa})$ & $F(\mathrm{~N})$ & $\varepsilon \mathrm{p}$ \\
\hline modelo 1 & material 1 & $1 / 20$ & $1,745 \mathrm{E}-3$ & 796 & 11,65 & 0,2277 \\
modelo 2 & material 2 & $1 / 20$ & $4,237 \mathrm{E}-3$ & 171 & 2,784 & 0,3875 \\
\multirow{2}{*}{ fator entre as variáveis } & $\phi_{2}=Y_{\mathrm{m} 2} / Y_{\mathrm{m} 1}$ & 2,4281 & 0,2153 & 0,2390 & 1,7018 \\
\hline protótipo 1 & material 1 & 1 & $4,022 \mathrm{E}-2$ & 681 & 3723 & 0,2324 \\
protótipo 2 & material 2 & 1 & $8,951 \mathrm{E}-2$ & 161 & 1009 & 0,4212 \\
& & & 2,2255 & 0,2364 & 0,2710 & 0,18124 \\
\hline
\end{tabular}

Os dois materiais implementados nas simulações têm propriedades bastante distintas. $\mathrm{O}$ aço que constitui a estrutura em escala unitária é muito mais sensível à 
taxa de deformação que o alumínio. A Figura 40 compara a diferença de comportamento dos dois materiais. Para $\dot{\varepsilon}=2000 \mathrm{~s}^{-1}$, a tensão de escoamento no aço é 87 \% maior que no alumínio. Além disso, o módulo de elasticidade, a tensão de escoamento quasi-estática e a densidade são notavelmente menores para o alumínio, fazendo com que o modelo apresente uma deformação mais aparente (Figura 41).

Tabela 32 - Resultados da simulação de um tubo engastado sujeito ao impacto de uma massa. Modelo em escala 1/20 e material distinto do protótipo.

\begin{tabular}{ccccc}
\hline & $U_{\mathrm{y}}(\mathrm{m})$ & $\sigma(\mathrm{MPa})$ & $F(\mathrm{~N})$ & $\varepsilon \mathrm{p}$ \\
\hline $\begin{array}{c}\text { valor do modelo 2 } \\
\left(Y_{\mathrm{m} 2}\right)\end{array}$ & $4,49 \mathrm{E}-3$ & 171 & 2,78 & 0,430 \\
\hline$\phi_{1}$ & & & & \\
$\phi \phi_{2}$ & 0,0500 & 1,1092 & 0,0028 & 1,0000 \\
\hline $\begin{array}{c}\text { valor convertido do modelo } 2 \\
\left(Y_{\mathrm{p} 1} \phi_{1} \phi_{2}=Y_{\mathrm{m} 2}\right)\end{array}$ & 3,4281 & 0,2153 & 0,2390 & 1,7018 \\
\hline $\begin{array}{c}\text { valor do protótipo 1 } \\
\left(Y_{\mathrm{p} 1}\right)\end{array}$ & & 718 & 4200 & 0,2527 \\
\hline erro (\%) & $4,02 \mathrm{E}-2$ & 681 & 3723 & 0,2324 \\
\hline
\end{tabular}

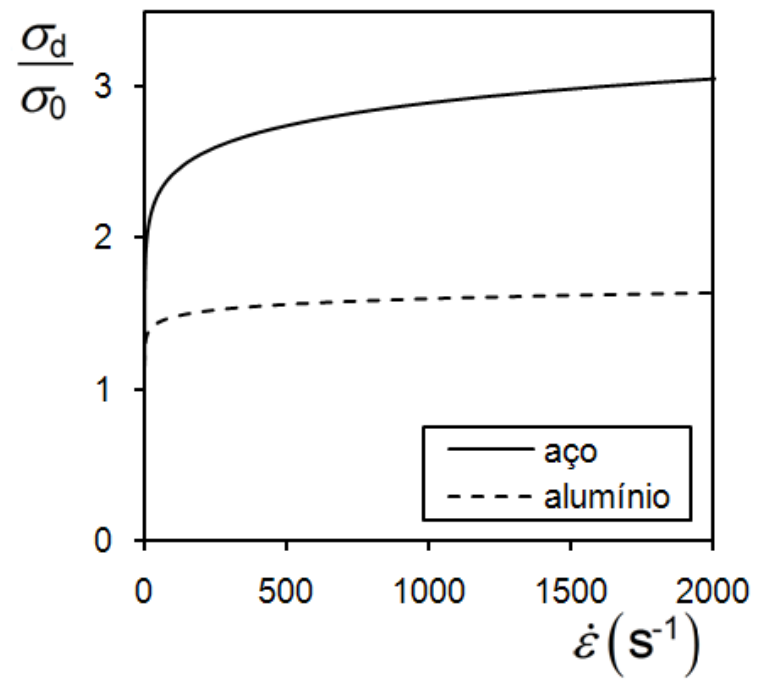

Figura 40 - Curvas da tensão de escoamento dinâmica em função da taxa de deformação para o aço $(q=0,077)$ e alumínio $(q=0,034)$. 
O método empírico para determinar os fatores que relacionam o comportamento de estruturas feitas de materiais diferentes possui algumas limitações. Primeiro, é necessário construir um modelo com o mesmo material do protótipo. Como apontado anteriormente, é exatamente essa dificuldade que induz o uso do método exposto em Cho et al. (2005). Uma maneira de resolver esse problema é usar um modelo com geometria parecida com do protótipo (não necessariamente idêntica) de forma a viabilizar a construção da estrutura a escala.

Outra restrição no uso da solução proposta em Cho et al. (2005) é necessidade de a estrutura ter uma configuração única de deformação, ou seja, o modo de colapso deve ser sempre o mesmo. Estruturas com diferentes modos de colapso podem gerar problemas para a aplicação desse método. Por exemplo, um tubo carregado na direção axial pode colapsar de modo global durante um teste, mas de modo progressivo em outro (JONES, 1997). Dessa forma, não há como relacionar pontos correspondentes através de um fator de transposição, pois as estruturas comparadas apresentam configurações distintas de deformação.

A quantidade de energia cinética inicial também é um fator limitante para o método estudado em Cho et al. (2005). Uma deformação excessiva em um dos materiais pode inviabilizar a comparação. Por exemplo, para a estrutura analisada nessa seção foi necessário diminuir a velocidade inicial de impacto utilizada no capítulo 4 pela metade ( $75 \%$ menos energia cinética), caso contrário o modelo feito de alumínio apresentaria deformação excessiva. A Figura 41 mostra a configuração de deformação final para o tubo sujeito a um impacto de $30 \mathrm{~m} / \mathrm{s}$ (somente metade do comprimento está representada na figura). Enquanto o tubo de aço (a) tem um deslocamento relativamente pequeno, o tubo de alumínio (b) já apresenta uma deformação bem mais desenvolvida, atingindo o limite viável de comparação entre as configurações.

Os fatores que relacionam o comportamento do modelo com o protótipo são válidos somente para as condições em que eles foram calculados. Em caso de mudança de material, carregamento, condições iniciais ou geometria, todos os fatores devem ser determinados novamente. Por exemplo, se $\phi_{1}$ e $\phi_{2}$ foram determinados para relacionar um modelo em escala 1/10 com a estrutura em tamanho real, eles não podem ser extrapolados para escalas diferentes.

Apesar do método proposto em Cho et al. (2005) permitir que o modelo esteja geometricamente distorcido em relação ao protótipo, as características geométricas básicas devem ser mantidas. Por exemplo, se houver um orifício na estrutura real, o 
modelo também deve apresentar um orifício. Dessa maneira, todos os pontos do modelo podem ser relacionados com pontos equivalentes no protótipo.

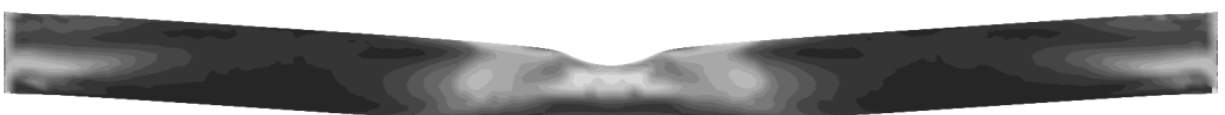

(a)

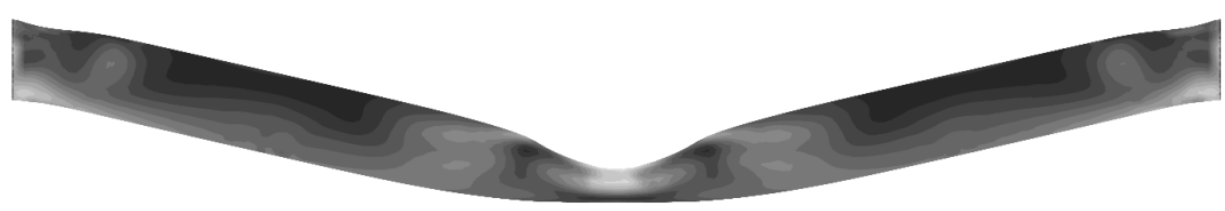

(b)

Figura 41 - Configuração final de deformação para o tubo engastado sujeito a impacto radial e escala 1/20. (a) tubo de aço. (b) tubo de alumínio.

\subsection{Correção do modelo através da massa de impacto}

De forma similar ao capítulo 2, a correção de um modelo rígido, perfeitamente plástico e sensível à taxa de deformação é desenvolvida. Porém, diferentemente daquele método, a massa do corpo de impacto é alterada ao invés da velocidade inicial. Essa diferença no processo de correção pode ser conveniente em algumas situações experimentais.

A relação que determina o fator de massa é obtida a partir da eq. (11)

$$
\begin{gathered}
\Pi_{3}=\frac{\delta^{3} \sigma}{G V^{2}} \\
\left(\Pi_{3}\right)_{\text {modelo }}=\left(\Pi_{3}\right)_{\text {protótipo }} \rightarrow \frac{\beta^{3} \beta_{\sigma}}{\beta_{G} \beta V^{2}}=1 .
\end{gathered}
$$

No caso de correção através da modificação da massa de impacto, o fator de velocidade não é alterado, $\beta v=1$, e $\beta_{G} \neq \beta^{3}$ quando $\beta \neq 1$. Portanto,

$$
\beta_{G}=\beta^{3} \beta_{\sigma} .
$$


Do número adimensional $\Pi_{4}$,

$$
\Pi_{4}=\dot{\varepsilon}\left(\frac{G}{\sigma V}\right)^{1 / 3} \rightarrow \beta_{\dot{\varepsilon}}=\left(\beta_{\sigma} / \beta_{G}\right)^{1 / 3}
$$

Inserindo a eq. (19) em (105)

$$
\beta_{\sigma^{1 / q}}=\left(\frac{\beta_{\sigma}}{\beta_{G}}\right)^{1 / 3} \rightarrow \beta_{G}=\beta_{\sigma}^{(q-3) / q}
$$

A razão entre as massas do modelo e do protótipo é gerada inserindo a eq. (106) na eq. (104)

$$
\beta_{G}=\beta^{3} \beta_{G}^{q /(q-3)} \rightarrow \beta_{G}=\beta^{3-q}
$$

Assim como a eq. (21), a eq. (107) depende somente de uma propriedade do material e do fator de escala. As demais relações são obtidas dos números adimensionais $\Pi_{1}$ a $\Pi_{5}$, eq. (11)

$$
\begin{gathered}
\Pi_{1}=\frac{A^{3} G}{V^{4} \sigma} \rightarrow \frac{\beta_{A} \beta_{G}}{\beta_{\sigma}}=1 \rightarrow \beta_{A}=\beta_{G}^{1 /(q-3)} \\
\Pi_{2}=\frac{t^{2} \sigma V}{G} \rightarrow \frac{\beta_{t}^{3} \beta_{\sigma}}{\beta_{G}}=1 \rightarrow \beta_{t}=\beta_{G}^{1 /(3-q)} \\
\Pi_{4}=\dot{\varepsilon}\left(\frac{G}{\sigma V}\right)^{1 / 3} \rightarrow \beta_{\dot{\varepsilon}}\left(\frac{\beta_{G}}{\beta_{\sigma}}\right)^{1 / 3}=1 \rightarrow \beta_{\dot{\varepsilon}}=\beta_{G}^{1 /(q-3)}
\end{gathered}
$$

e

$$
\Pi_{5}=\frac{\sigma}{\sigma_{\mathrm{d}}} \rightarrow \beta_{\sigma}=\frac{\beta_{\mathrm{G}}}{\beta^{3}}
$$

No entanto, essa correção apresenta uma limitação. Como já apontado, o método de similaridade não distingue variáveis de mesma dimensão e por isso, a técnica considera que uma variação da massa de impacto, $G$, também implica em uma variação pelo mesmo fator da massa da estrutura impactada, $m_{\text {estr }}$. Essa modificação só é possível se a densidade das estruturas seguir a relação

$$
\frac{\left(m_{\text {estr }}\right)_{\mathrm{m}}}{\left(m_{\text {estr }}\right)_{\mathrm{p}}}=\frac{(\rho)_{\mathrm{m}} \beta^{3} L^{3}}{(\rho)_{\mathrm{p}} L^{3}}=\beta_{\mathrm{G}} \rightarrow \frac{(\rho)_{\mathrm{m}}}{(\rho)_{\mathrm{p}}}=\frac{\beta_{\mathrm{G}}}{\beta^{3}} .
$$

Em casos reais, obviamente não é possível reproduzir essa razão. Por esse motivo, uma abordagem aproximada é considerada para resolver o problema. A 
massa de impacto do modelo é escalonada conforme a eq. (107), mas a massa da estrutura segue as leis usuais de escalonamento, $\left(m_{\text {estr }}\right)_{m}=\beta^{3}\left(m_{\text {estr }}\right)_{\mathrm{p}}$. Essa aproximação gera resultados satisfatórios se a condição $G>m_{\text {estrutura é atendida, }}$ pois nesse caso, a inércia da estrutura é irrelevante quando comparada com a energia cinética do corpo impactante.

Para testar o fator de correção, eq. (107), os modelos analíticos de Calladine e viga biengastada sujeita ao impacto de uma massa (seção 2.1) são novamente resolvidos. A Tabela 33 resume os resultados para o modelo corrigido de Calladine (seção 2.1.1), com escalas variando de 1 a 1/100 e valores da Tabela 6. Como pode ser observado, os valores previstos após correção são semelhantes ao protótipo; o erro na rotação final para um escala $1 / 100$ é de $1,73 \%$. Os erros são pequenos nesse caso, pois $m_{\text {estr }} / G=0,0024$, atendendo a condição $G>m_{\text {estr }}$.

Apenas como análise teórica e para corroborar as afirmações feitas nessa seção, foi feita a análise do modelo de Calladine em escala 1/100 cuja massa da estrutura também foi escalonada conforme a eq. (107). A Figura 42 mostra a resposta do modelo corrigido, sendo que a densidade do material da estrutura impactada foi alterada de $7800 \mathrm{~kg} / \mathrm{m}^{3}$ para $11119,74 \mathrm{~kg} / \mathrm{m}^{3}$ de forma a atender a eq. (112). O erro nesse caso é nulo, como previsto pela teoria.

Tabela 33 - Resultados para o modelo de Calladine quando a correção é feita através da variação da massa do corpo de impacto.

\begin{tabular}{lcccc}
\hline \multicolumn{5}{c}{ Modelo corrigido } \\
\\
\hline escala & 1 & $1 / 2$ & $1 / 4$ & $1 / 100$ \\
fator de massa & 1 & 0,1319 & 0,0174 & 0,00000143 \\
rotação final $\left({ }^{\circ}\right)$ & 25,95 & 26,02 & 26,09 & 26,40 \\
final da primeira fase (s) & $1,1368 \mathrm{E}-4$ & $1,1010 \mathrm{E}-4$ & $1,0664 \mathrm{E}-4$ & $0,9185 \mathrm{E}-4$ \\
final da segunda fase $(\mathrm{s})$ & $1,1041 \mathrm{E}-3$ & $1,1040 \mathrm{E}-3$ & $1,1040 \mathrm{E}-3$ & $1,1038 \mathrm{E}-3$ \\
aceleração final $\left(\mathrm{m} / \mathrm{s}^{2}\right)$ & $4,45 \mathrm{E} 5$ & $4,45 \mathrm{E} 5$ & $4,45 \mathrm{E} 5$ & $4,45 \mathrm{E} 5$ \\
taxa de deformação final $\left(\mathrm{s}^{-1}\right)$ & 184,57 & 184,68 & 184,79 & 185,18 \\
tensão final (MPa) & 517,37 & 517,39 & 517,41 & 517,50 \\
\hline
\end{tabular}

A influência da razão $m_{\text {estr }} / G$ na resposta da estrutura de Calladine é resumida na Figura 43. Quanto menor for a massa da estrutura em relação à massa de impacto, menor será o erro gerado após a correção.

A mesma análise é feita para o modelo analítico de viga biengastada sujeita ao 
impacto de uma massa (seção 2.1.2). Na Figura 44 (a), o modelo corrigido em escala 1/100 e valores da Tabela 8 é comparado com o protótipo. Na Figura 44 (b), os erros são expostos para diferentes razões da massa da estrutura e do corpo de impacto. Caso a densidade do material da estrutura também fosse escalonada de acordo com a eq. (112), o erro seria nulo.

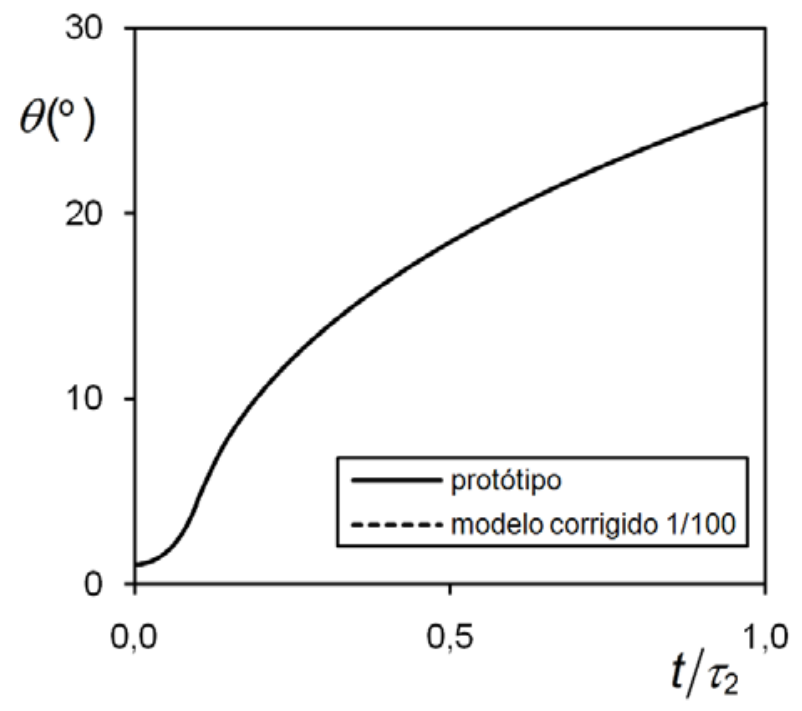

Figura 42 - Resultados do modelo de Calladine com a correção feita através da variação da massa. Massa do corpo de impacto e da estrutura corrigidas.

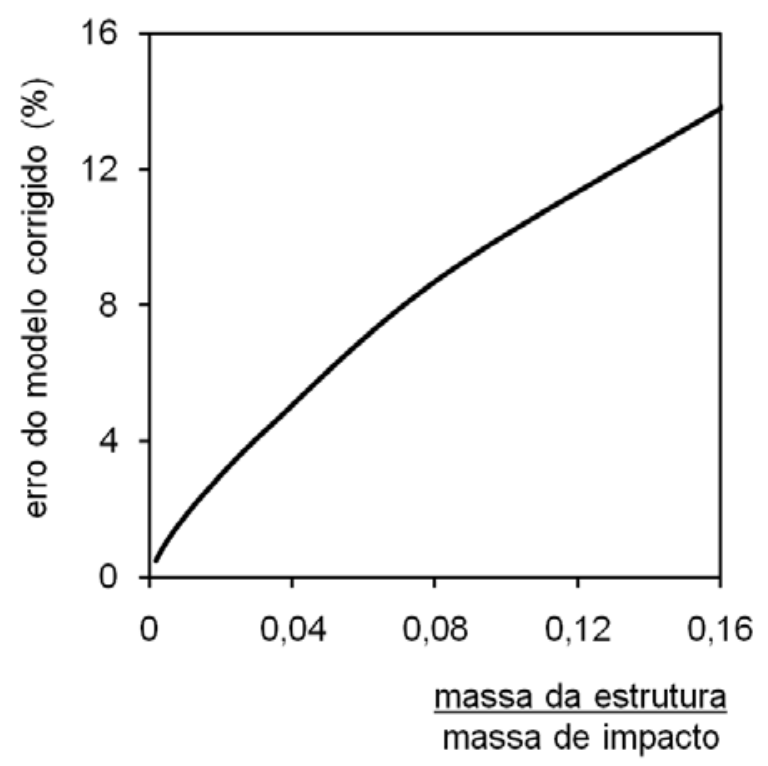

Figura 43 - Erros para o modelo de Calladine com a correção através da variação da massa de impacto. 


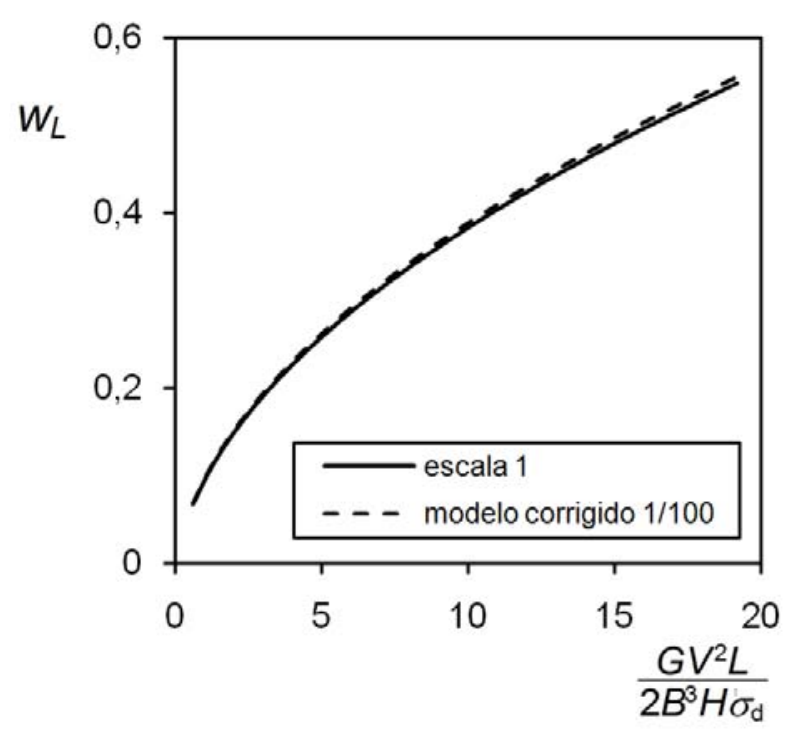

(a)

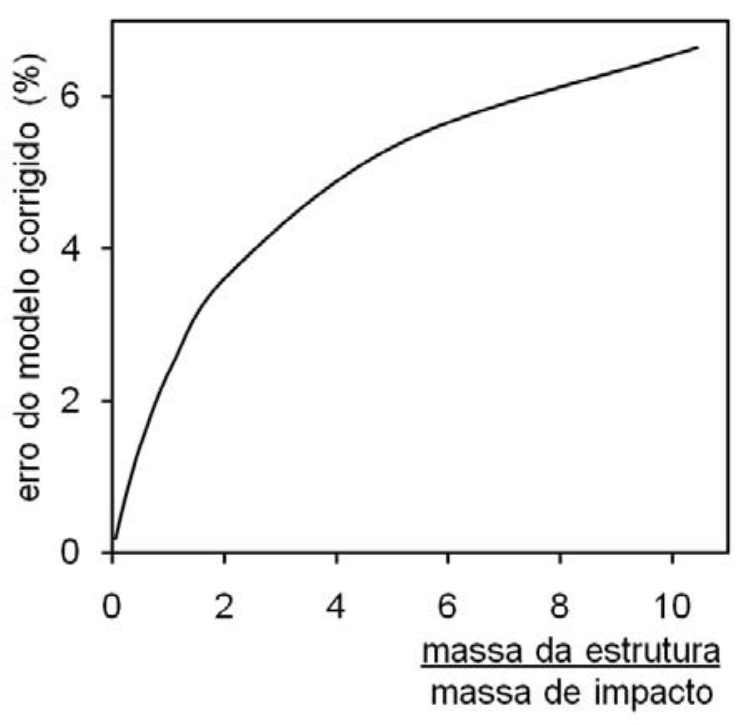

(b)

Figura 44 - Resultados para o modelo de viga biengastada. (a) Comparação do modelo 1/100 com o fator de massa corrigido com o protótipo. (b) Erros do modelo corrigido para diversas razões entre massa da estrutura e corpo de impacto.

\subsection{Discussão}

O uso de um modelo com material distinto do protótipo é limitado para o método proposto no atual trabalho. Opcionalmente, uma técnica simples proposta em Cho et al. (2005) foi analisada. Ela permite que material, geometria e carregamento do modelo sejam distorcidos em relação à estrutura em escala unitária. Porém, como discutido na seção 5.1, existem várias limitações no uso desse método, como o modo de colapso da estrutura, a energia cinética inicial e a necessidade de produzir um modelo na mesma escala do protótipo.

O tubo engastado em escala $1 / 20$ e material distorcido foi usado como exemplo. Nesse caso, os fatores geométricos, $\phi_{1}$, foram calculados usando as equações (12) a (16) e (21). Os fatores de transposição devido à distorção material, $\phi_{2}$, foram obtidos empiricamente, conforme proposto em Cho et al. (2005). O modelo corrigido (Tabela 32) tem um comportamento mais próximo ao protótipo 1 do que o modelo convencional (Tabela 31).

Para a proposta do atual trabalho o uso do método em Cho et al. (2005) é limitado, pois além das restrições já citadas, o fator de correção para o caso de 
escalas diferentes só pode ser gerado se for possível construir a estrutura em escala real. No entanto, o presente estudo prioriza estruturas cujos testes em tamanho real são inviáveis, justificando o uso de modelos.

A correção do modelo sensível à taxa de deformação através da alteração da massa do corpo de impacto ( $\beta_{G} \neq \beta^{3}$ ) é feita de forma aproximada pela eq. (107). A solução nesse caso só gera bons resultados caso a massa de impacto seja muito maior do que a massa da estrutura. As Figura 43 e Figura 44 (b) mostram a análise de erros para as os modelos de Calladine e viga sujeita a impacto de uma massa, respectivamente. 


\section{CONCLUSÃO}

O atual trabalho propõe um método que corrige a similaridade imperfeita gerada devido ao efeito da taxa de deformação (capítulo 2) e de imperfeições geométricas (capítulo 3). No caso da correção do desvio procedente da taxa de deformação, o estudo apresenta uma técnica mais robusta e simples do que obras anteriores (OSHIRO; ALVES, 2004), (OSHIRO, 2004), pois nenhum dado da resposta estrutural é necessário. A eq. (21) exprime de forma direta o fator para a velocidade inicial de impacto, $\beta_{V}$, em função de $\beta$

$$
\beta_{V}=\beta^{q /(q-2)} .
$$

A eq. (21) é gerada com o auxílio do modelo constitutivo de Norton-Hoff para a tensão de escoamento dinâmica, eq. (18). A comparação entre a forma exponencial e o modelo de Cowper-Symonds é feita na Figura 17 para a taxa de deformação variando de 0 a $2000 \mathrm{~s}^{-1}$.

No capítulo 2, os três modelos analíticos em escala e sensíveis à taxa de deformação foram corrigidos pela técnica apresentada nesse trabalho. Eles produziram perfeita similaridade, ou seja, com a aplicação dos fatores de transposição de escala, os modelos tiveram um comportamento idêntico ao do protótipo. Por exemplo, quando o ângulo final de rotação na estrutura de Calladine em escala 1/100 é comparado com a resposta do protótipo, um desvio de $20 \%$ é verificado. O mesmo modelo corrigido com o uso da eq. (21) tem erro nulo (Tabela 11).

$\mathrm{Na}$ seção 4.1, dois modelos sensíveis à taxa de deformação foram solucionados com o programa de elementos finitos Abaqus e corrigidos conforme o método descrito no capítulo 2. A primeira análise é feita para um tubo biengastado e sujeito ao impacto transversal de uma massa. Alguns resultados são comparados na Tabela 24 e em particular, pode-se observar que o erro no deslocamento máximo diminui de 10,97\% para $0,90 \%$ após o uso da correção. O segundo modelo representa o casco lateral de um navio sujeito ao impacto de uma esfera rígida. A comparação do deslocamento horizontal da chapa externa do navio é apresentada na Figura 34. Em ambas as estruturas simuladas um pequeno erro foi observado, mesmo após a correção. A explicação para esse erro é o fato do programa de 
elementos finitos não permitir o emprego de um material perfeitamente plástico, como exige o método de correção.

Para a correção do desvio devido à distorção geométrica, $\beta_{X} \neq \beta$, não é possível desenvolver uma expressão geral na forma $\beta_{V}=f\left(\beta_{X}\right)$ que sirva para qualquer tipo de estrutura. Nessa situação, a análise é feita individualmente para cada caso. Em alguns modelos analíticos foi possível obter o fator de velocidade de forma explícita, como nos casos de viga sujeita a um impulso de velocidade (seção 3.2.1) e viga sujeita ao impacto de uma massa no centro com distorção na largura e no comprimento (seção 3.2.2). Para esses problemas, o erro diminui significantemente, como pode ser comprovado nas Tabela 14 e Tabela 16 e Figura 21 e Figura 22.

No entanto, não foi possível gerar uma relação explícita para o cálculo de $\beta_{V}$ nos modelos de viga sujeita ao impacto de uma massa com distorção na altura e modelo de Calladine (seção 3.2.3). Nesses casos foi necessário usar uma solução aproximada que permite calcular $\beta_{V}$ sem que seja necessário o conhecimento das equações de movimento da estrutura (seção 3.1). O método proposto para corrigir a distorção nesses modelos é mais abrangente, mas exige uma solução iterativa para que nenhum dado do protótipo seja requerido. Os erros resultantes são pequenos quando a correção é aplicada, como pode-se observar na Tabela 19 para o modelo de viga e na Tabela 22 para o modelo de Calladine.

Simulações numéricas de estruturas distorcidas geometricamente foram feitas na seção 4.2. A correção do fator de velocidade foi feita utilizando o método genérico descrito na seção 3.1, pois as estruturas estudadas não possuem solução analítica. No caso do tubo biengastado com espessura distorcida, o processo para determinação da função $f_{2}$ é resumido na Tabela 25 . O erro relativo no deslocamento vertical entre modelo e protótipo cai de $47,13 \%$ para 1,11\% após a correção. Na simulação do casco do navio, chapas duas vezes mais grossas que o requerido pelo fator $\beta$ foram utilizadas. Após a correção considerando a taxa de deformação e a distorção da geometria, uma melhora significativa no comportamento do modelo é observada (Tabela 28 e a Figura 36).

A precisão necessária para determinar o expoente da função $f_{2}$ é largamente discutida na seção 4.3. Para as estruturas resolvidas de forma numérica concluiu-se que valores aproximados de $n$ já geram resultados satisfatórios do modelo corrigido. Caso uma precisão muita alta fosse exigida, o número de simulações ou testes necessários inviabilizaria o método. 
A aproximação feita no caso de modelo com distorção geométrica, $f_{2}=\beta_{X}{ }^{n}$, e a hipótese de funções independentes, $\beta_{V}=f\left(\beta, \beta_{X}\right)=f_{1}(\beta) f_{2}\left(\beta_{X}\right)$, mostraram-se bastante coerentes. A suposição de independência das funções pode ser claramente observada comparando-se a Figura 21 (a) com a Figura 26 (a). Na Figura 26 (a) a estrutura em escala $1 / 20$ e com distorção geométrica é corrigida apenas considerando o efeito da taxa de deformação $\left(\beta V=f_{1}(\beta)\right)$. A resposta gerada é idêntica ao modelo sem correção na Figura 21 (a), que utiliza um fator de escala unitário e $\beta_{X} \neq \beta$.

No capítulo 5 , duas variações da correção do modelo foram analisadas. $\mathrm{Na}$ primeira, o uso de um modelo com material diferente do protótipo é analisado. Nesse aspecto, o método é limitado e, para manter a independência do cálculo de $\beta_{v}$ em relação a qualquer dado estrutural, somente a tensão de escoamento quasi-estática pode ser variada, $\left(\sigma_{0}\right)_{\mathrm{m}} \neq\left(\sigma_{0}\right)_{\mathrm{p}}$. Por isso, a técnica que emprega fatores determinados empiricamente ( $\mathrm{CHO}$ et al., 2005) é discutida. Na simulação do modelo do tubo biengastado em escala $1 / 20$ e material distorcido o erro cai de $110,69 \%$ para $8,11 \%$ quando o deslocamento vertical é comparado (Tabela 32). No entanto, apesar do método permitir o uso de um material bastante distinto na construção do modelo, ela também impõe várias limitações que são analisadas na seção 5.1.

Na seção 5.2 foi analisada a correção feita através do fator de massa ao invés da velocidade inicial do corpo de impacto. Nesse caso, $\beta_{G}$ é dado pela eq. (107)

$$
\beta_{G}=\beta^{3-q}
$$

e $\beta_{V}=1$. No entanto, devido à limitação do método de similaridade de não distinguir variáveis de mesma dimensão, a eq. (107) não é exata. A precisão da equação está vinculada à condição da massa do corpo de impacto ser muito maior do que a massa da estrutura. A Tabela 33 exibe os resultados da estrutura de Calladine quando a correção é feita através da massa. Os erros gerados pela aproximação da eq. (107) são mostrados nas Figura 43 e Figura 44 (b) para o modelo de Calladine e viga biengastada, respectivamente. Na hipótese da densidade da estrutura também ser alterada pelo fator $\beta_{G}$, o erro é nulo, como ficou demonstrado na Figura 42.

As limitações de cada técnica já foram minuciosamente discutidas no final de cada capítulo. Com os métodos exibidos nessa tese é possível criar um modelo em escala com geometria e material distorcidos em relação ao protótipo. Os dados da 
resposta do protótipo não foram utilizados para corrigir o modelo. A estrutura em escala unitária só foi resolvida para comparar a eficiência do método de correção. 


\section{REFERÊNCIAS BIBLIOGRÁFICAS}

ABRAMOWICZ, W.; JONES, N. Transition from initial global bending to progressive buckling of tubes loaded statically and dynamically. International Journal of Impact Engineering, v. 19, p. 415-437, 1997.

ADACHI, T. et al. Energy absorption of a thin-walled cylinder with ribs subjected to axial impact. International Journal of Impact Engineering, v. 35, n. 2, p. 65-79, 2008.

ALVES, M.; JONES, N. Impact failure of beams using damage mechanics: Part II - Application. International Journal of Impact Engineering, v. 27, n. 2, p. 863-890, 2002.

ALVES, M.; MICHELI, G.B. Flambagem visco-plástica de tubos sob impacto. In: Associação Brasileira de Engenharia Automotiva, 2000, São Paulo.

ALVES, M.; MICHELI, G.B. Some experimental findings on the plastic buckling of shells under axial impact loads. In: Congresso Brasileiro e Engenharia Mecânica, 2001, Uberlândia.

ALVES, M.; OSHIRO, R.E. Scaling the impact of mass on a structure. International Journal of Impact Engineering, v. 32, n. 7, p. 1158-1173, 2006.

BAKER, W.E.; WESTINE, P.S.; DODGE, F.T. Similarity methods in engineering dynamics: Theory and practice of scale modeling. Amsterdam: Elsevier Science Publishers, 1991. $348 \mathrm{p}$.

BAZANT, Z.P. Size effect. International Journal of Solids and Structures, v. 37, p. 69-80, 2000.

BOOTH, E.; COLLIER, D.; MILES, J. Impact scalability of plated steel structures. In: JONES, N.; WIERZBICKI, T. (Ed). Structural Crashworthiness. London: Butterworths, 1983, p. 136-174.

CALLADINE, C.R.; ENGLISH, R.W. Strain-rate and inertia effects in the collapse of two types of energy-absorbing structure. International Journal Mechanical Sciences, v. 26, p. 689-701, 1984. 
CHAKKA, $\mathrm{V}$. et al. Modeling and reduction of shocks on electronic components within a projectile. International Journal of Impact Engineering, v. 35, n. 11, 2008, p. 1326-1338.

$\mathrm{CHO}, \mathrm{U}$. et al. An advanced method to correlate scale models with distorted configurations. Journal of Mechanical Design, v. 127, n. 1, p. 78-85, 2005.

DHARMASENA, K.P. et al. Mechanical response of metallic honeycomb sandwich panel structures to high-intensity dynamic loading. International Journal of Impact Engineering, v. 35, n. 9, p. 1063-1074, 2008.

DRAZETIC, P. et al. Applying non-direct similitude technique to the dynamic bending collapse of rectangular section tubes. International Journal of Impact Engineering, v. 15, n. 6, p. 797-814, 1994.

DUAN, X.; SHEPPARD, T. The influence of the constitutive equation on the simulation of a hot rolling process. Journal of Materials Processing Technology, v. 150, n. 1-2, p. 100-106, 2004.

FOX, R.W.; MCDONALD, A.T. Introduction to fluids mechanics. $4^{\text {th }}$ ed. New York: John Wiley \& Sons, 1998. 848 p.

DUBOIS, D.; ZELLMER, H.; MARKIEWICZ, E. Experimental and numerical analysis of seat belt bunching phenomenon. International Journal of Impact Engineering, v. 36, n. 6, 2009, p. 763-774.

FUJII, Y.; SHU, D. Impact force measurement of an actuator arm of a hard disk drive. International Journal of Impact Engineering, v. 35, n. 2, 2008, p. 98-108.

GALLINA, F. Flambagem progressiva e global de cascas cilíndricas de aço sob impacto axial. 2004. 195 p. Dissertação (Mestrado) - Escola Politécnica, Universidade de São Paulo, São Paulo, 2004.

GAMEIRO, C.P.; CIRNE, J. Dynamic axial crushing of short to long circular aluminum tubes with agglomerate cork filler. International Journal of Mechanical Sciences, v. 49, p. 1029-1037, 2007.

GREGORY, L.F. Replica model scaling for high strain-rate events. International Journal of Impact Engineering, v. 16, n. 4, p. 571-583, 1995. 
HARDY, W.N..; KHALIL, T.B.; KING, A.I. Literature review of head injury biomechanics. International Journal of Impact Engineering, v. 15, n. 4, 1994, p. 561586.

HANSSEN, A.G. et al. A numerical model for bird strike of aluminium foambased sandwich panels. International Journal of Impact Engineering, v. 32, n. 7, 2006, p. 1127-1144.

HISAYOSHI, E. et al. Model test on the collapse strength of the buffer bow structures. Marine structures, v. 15, n. 4-5, p. 365-381, 2001.

HU, Y.Q. Application of response number for dynamic plastic response of plates subjected to impulsive loading. International Journal of Pressure Vessels and Piping, v. 77, p. 711-714, 2000.

JOHNSON, W. Impact strength of materials. London: Edward Arnold, 1972. 376 p.

JOHNSON, W.; WALTON, A.C. Protection of car occupants in frontal impacts with heavy lorries: frontal structures. International Journal of Impact Engineering, v. 1, n. 2,1983 , p. 111-123.

JONES, N. Some comments on the scaling of inelastic structures loaded dynamically. In: BATRA, R.C.; MAL, A.K.; MACSITHIGH, G.P. (Ed.). Impact, Waves and Fracture, AMD-Vol.205, ASME (1995), p. 153-167.

JONES, N. Structural impact. Cambridge: Cambridge University Press, 1997. 592 p.

KARAGIOZOVA, D.; ALVES, M.; JONES, N. Inertia effects in axisymmetrically deformed cylindrical shells under axial impact. International Journal of Impact Engineering, v. 24, n. 10, p. 1083-1115, 2000.

KARAGIOZOVA, D.; JONES, N. Some observations on the dynamic elasticplastic buckling of a structural model. International Journal of Impact Engineering, v. 16, n. 4, p. 621-635, 1995.

KARAGIOZOVA, D.; JONES, N. Dynamic elastic-plastic buckling phenomena in a rod due to axial impact. International Journal of Impact Engineering, v. 18, n. 7-8, p. 919-947, 1996. 
KARAGIOZOVA, D.; JONES, N. (A). Dynamic effects on buckling and energy absorption of cylindrical shells under axial impact. Thin walled structures, v. 39, n. 7, p. 583-610, 2001.

KARAGIOZOVA, D.; JONES, N. (B). Influence of stress waves on the dynamic progressive and dynamic plastic bucking of cylindrical shells. International Journal of Solids and Structures, v. 38, p. 6723-6749, 2001.

KARAGIOZOVA, D.; JONES, N. On dynamic buckling phenomena in axially loaded elastic-plastic cylindrical shells. International Journal of Non-linear Mechanics, v. 37, n. 7, p. 1223-1238, 2002.

KARAGIOZOVA, D.; JONES, N. On the mechanics of the global bending collapse of circular tubes under dynamic axial load - Dynamic buckling transition. International Journal of Impact Engineering, v. 35, n. 5, p. 397-424, 2008.

KENT, R.W.; PURTSEZOV, S.V.; PILKEY, W.D. Limiting performance analysis of a seat belt system with slack. International Journal of Impact Engineering, v. 34, n. 8, 2007, p. 1382-1395.

KWASNIEWSKI, L. et al. Crashworthiness assessment of a paratransit bus. International Journal of Impact Engineering, v. 32, n. 5, 2006, p. 883-888.

LANGSETH, M.; HOPPERSTAD, O.S.; BERSTAD, T. Crashworthiness of aluminium extrusions: validation of numerical simulation, effect of mass ratio and impact velocity. International Journal of Impact Engineering, v. 22, n. 9-10, p. 829-854, 1999.

LEMAITRE, J.; CHABOCHE, J.L. Mechanics of solids materials. Cambridge: Cambridge University Press, 1991. 584 p.

LI, Q.M.; JONES, N. On dimensionless number for dynamic plastic response of structural members. Archive of Applied Mechanics, v. 70, n. 4, p. 245-254, 2000.

LIU, J.H.; JONES, N. Dynamic response of a rigid plastic clamped beam struck by a mass at any point on the span. International Journal of Solids Structures, v. 24, p. 251-270, 1988.

ME-BAR, Y. A method for scaling ballistic penetration phenomena. International Journal of Impact Engineering v. 19, n. 9-10, 821-829, 1997. 
MEGUID, S.A.; MAO, R.H.; NG, T.Y. FE analysis of geometry effects of an artificial bird striking an aeroengine fan blade. International Journal of Impact Engineering, v. 35, n. 6, 2008, p. 487-498.

MENG, Q.; AL-HASSANI, S.T.S.; SODEN, P.D. Axial crushing of square tubes. International Journal of Mechanical Sciences, v. 25, p. 747-773, 1983.

MORQUIO, A.; RIERA, J.D. Size and strain rate effects in steel structures. Engineering Structures, v. 26, n. 5, p. 669-679, 2004.

NEUBERGER, A.; PELES, S.; RITTEL, D. Scaling the response of circular plates subjected to large and close-range spherical explosions. Part I: Air-blast loading. International Journal of Impact Engineering, v. 34, n. 5, p. 859-873, 2007.

OSHIRO, R.E. Leis de similaridade aplicadas a estruturas sob impacto. 2004. 107p. Dissertação (Mestrado) - Escola Politécnica, Universidade de São Paulo, São Paulo, 2004.

OSHIRO, R.E.; ALVES, M. Scaling impacted structures. Archive of Applied Mechanics, v. 74, p. 130-145, 2004.

OSHIRO, R.E.; ALVES, M. Scaling of cylindrical shells under axial impact. International Journal of Impact Engineering, v. 34, n. 1, p. 89-103, 2007.

OSHIRO, R. E.; ALVES, M. Scaling of structures subject to impact loads when using a power law constitutive equation. International Journal of Solids and Structures, v. 46, p. 3412-3421, 2009.

OZGUR, O.; DAS, P.K.; BARLTROP, N. A comparative study on the structural integrity of single and double side skin bulk carriers under collision damage. Marine Structures, v. 18, n. 7-8, p. 511-547, 2005.

PEDERSEN, P.T. et al. Ship impacts: bow collisions. International Journal of Impact Engineering, v. 13, n. 2, 1993, p. 163-187.

PINNOJI, P.K. et al. Impact dynamics of metal foam shells for motorcycle helmets: experiments \& numerical modeling. International Journal of Impact Engineering, 2009. No prelo. 
POURSINA, M.; EBRAHIMI, H.; PARVIZIAN, J. Flow stress behavior of two stainless steels: An experimental-numerical investigation. Journal of Materials Processing Technology, v. 199. n. 1, p. 287-294, 2008.

REID, S.R. Plastic deformation mechanisms in axially compressed metal tubes used as impact energy absorbers. International Journal of Mechanical Sciences, v. 35, p. 1035-1052, 1993.

SCHLEYER, G.K.; HSU, S.S.; WHITE, M.D. Scaling of pulse loaded mild steel plates with different edge restraint. International Journal of Mechanical Sciences, v. 46, p. 1267-1287, 2004.

SHI, B. et al. Drop test simulation and Power spectrum analysis of a head actuator assembly in a hard disk drive. International Journal of Impact Engineering, v. 34, n. 1, 2007, p. 120-133.

SHI, X.H.; GAO, Y.G. Generalization of response number for dynamic plastic response of shells subjected to impulsive loading. International Journal of Pressure Vessels and Piping, v. 78, n. 6, p. 453-459, 2001.

SINGER, J.; ARBOCZ, J.; WELLER, T. Buckling experiments: Experimental methods in buckling of thin-walled structures. New York: John Wiley \& Sons, 1998. v. 1.

SKOGLUND, V.J. Similitude: Theory and Applications. Pennsylvania: International Textbook Company, 1967.

SLYCKEN, J.V. Advanced use of a split Hopkinson bar setup - Application to TRIP steels, 2008.290 p. Tese (Doutorado) - Universiteit Gent, Bélgica, 2008.

SZIRTES, T. Applied Dimensional Analysis and Modeling. $1^{\text {st }}$ ed. New York: McGraw-Hill, 1997. 790 p.

TAM, L.L.; CALLADINE, C.R. Inertia and strain-rate effects in a simple platestructure under impact loading. International Journal of Impact Engineering, v. 11, n. 3, p. 349-377, 1991.

WANG, L. et al. An impact dynamic analysis on a new crashworthy device against ship-bridge collision. International Journal of Impact Engineering, v. 35, n. 8, p. 895-904, 2008. 
WEBB, D.C.; KORMI, K.; AL-HASSANI, S.T.S. The influence of inertia and strainrate on large deformation of plate-structures under impact loading. Computer \& structures, v. 79, p. 1781-1797, 2001.

WIERZBICKI, T.; ABRAMOWICZ, W. On the crushing mechanics of thin-walled structures. Journal of Applied Mechanics, v. 50, p. 727-734, 1983.

WIERZBICKI, T.; TENG, $X$. How the airplane wing cut through the exterior columns of the World Trade Center. International Journal of Impact Engineering, $v$. 28, n. 6,2003 , p. 601-625.

XIA, J. Finite element analysis of ship collisions. 2001. 267p. Dissertação (Mestrado) - Virginia Polytechnic Institute and State University, Blacksburg, Virginia, 2001.

YAGI, S. et al. A study on collision buffer characteristic of sharp entrance angle bow structure. Marine structures, v. 22, n. 1, p. 12-23, 2009.

ZHANG, T.G.; YU, T.X. A note on a 'velocity sensitive' energy-absorbing structure. International Journal of Impact Engineering, v. 8, p. 43-51, 1989.

ZHAO, Y.P. Suggestion of a new dimensionless number for dynamic plastic response of beams and plates. Archive of Applied Mechanics, v. 68, p. 524-38, 1998.

ZHU, F. et al. (A). A numerical simulation of the blast impact of square metallic sandwich panels. International Journal of Impact Engineering, v. 36, p. 687-699, 2009.

ZHU F. et al. (B). Analytical investigation and optimal design of sandwich panels subjected to shock loading. Materials and Design, v. 30, p. 91-100, 2009.

ZUKAS, J.A. Impact dynamics. New York: John Wiley \& Sons, 1982. 452 p. 


\section{APÊNDICE A - Geração dos números adimensionais}

Os números adimensionais da eq. (11) são obtidos da análise dimensional considerando-se a base: velocidade inicial, $V_{0}$, tensão de escoamento dinâmica, $\sigma_{\mathrm{d}}$, e massa de impacto, $G$. As variáveis da nova base podem expressas em função da base clássica, massa-comprimento-tempo, MLT

$$
\begin{gathered}
{\left[V_{0}\right]=\mathrm{LT}^{-1},} \\
{[G]=\mathrm{M}}
\end{gathered}
$$

e

$$
\left[\sigma_{\mathrm{d}}\right]=\mathrm{ML}^{-1} \mathrm{~T}^{-2},
$$

sendo que os colchetes indicam a dimensão da variável.

Os números adimensionais $\Pi_{1}$ a $\Pi_{5}$ são obtidos escrevendo-se as variáveis do fenômeno em função da nova base. No caso da aceleração, $\Pi_{1}$ é gerado

$$
\left[\Pi_{1}\right]=[1] \rightarrow[A]\left[V_{0}\right]^{e_{1}}\left[\sigma_{d}\right]^{e_{2}}[G]^{e_{3}}=[1] \rightarrow \mathrm{LT}^{-2}\left(\mathrm{LT}^{-1}\right)^{e_{1}}\left(\mathrm{ML}^{-1} \mathrm{~T}^{-2}\right)^{e_{2}}(\mathrm{M})^{e_{3}}=[1]
$$

Portanto, o seguinte sistema precisa ser resolvido para determinar os expoentes $e_{1}$, $e_{2}$ e $e_{3}$,

$$
\left\{\begin{array}{l}
e_{2}+e_{3}=0 \\
1+e_{1}-e_{2}=0 \\
-2-e_{1}-2 e_{2}=0
\end{array},\right.
$$

gerando $e_{1}=-4 / 3, e_{2}=-1 / 3$ e $e_{3}=1 / 3$. O adimensional $\Pi_{1}$ é obtido

ou, sem perder a funcionalidade,

$$
\Pi_{1}=\frac{A G^{1 / 3}}{V_{0}^{4 / 3} \sigma_{d^{1 / 3}}} .
$$

$$
\Pi_{1}=\frac{A^{3} G}{V_{0}^{4} \sigma_{\mathrm{d}}}
$$

De forma análoga, o número adimensional $\Pi_{2}$ é gerado quando a variável tempo é escrita na base $V_{0}-\sigma_{\mathrm{d}}-G$,

$$
\left[\Pi_{2}\right]=[1] \rightarrow[t]\left[V_{0}\right]^{e_{1}}\left[\sigma_{d}\right]^{e_{2}}[G]^{e_{3}}=[1] \rightarrow \mathrm{T}\left(\mathrm{LT}^{-1}\right)^{e_{1}}\left(\mathrm{ML}^{-1} \mathrm{~T}^{-2}\right)^{e_{2}}(\mathrm{M})^{e_{3}}=[1] \rightarrow
$$




$$
\left\{\begin{array}{l}
e_{2}+e_{3}=0 \\
e_{1}-e_{2}=0 \\
1-e_{1}-2 e_{2}=0
\end{array}\right.
$$

Nesse caso, $e_{1}=1 / 3, e_{2}=1 / 3$ e $e_{3}=-1 / 3$ e portanto,

$$
\Pi_{2}=\frac{t^{3} \sigma_{\mathrm{d}} V_{0}}{G}
$$

O número adimensional $\Pi_{3}$ é gerado através da variável deslocamento

$$
\begin{gathered}
{\left[\Pi_{3}\right]=[1] \rightarrow[\delta]\left[V_{0}\right]^{e_{1}}\left[\sigma_{d}\right]^{e_{2}}[G]^{e_{3}}=[1] \rightarrow \mathrm{L}\left(\mathrm{LT}^{-1}\right)^{e_{1}}\left(\mathrm{ML}^{-1} \mathrm{~T}^{-2}\right)^{e_{2}}(\mathrm{M})^{e_{3}}=[1] \rightarrow} \\
\left\{\begin{array}{l}
e_{2}+e_{3}=0 \\
1+e_{1}-e_{2}=0, \\
e_{1}-2 e_{2}=0
\end{array}\right.
\end{gathered}
$$

que gera $e_{1}=-2 / 3, e_{2}=1 / 3$ e $e_{3}=-1 / 3$,

$$
\Pi_{3}=\frac{\delta^{3} \sigma_{\mathrm{d}}}{G V_{0}^{2}}
$$

O número adimensional $\Pi_{4}$ é gerado escrevendo-se a variável taxa de deformação em função da nova base

$$
\begin{gathered}
{\left[\Pi_{4}\right]=[1] \rightarrow[\dot{\varepsilon}]\left[V_{0}\right]^{e_{1}}\left[\sigma_{\mathrm{d}}\right]^{e_{2}}[G]^{e_{3}}=[1] \rightarrow \mathrm{T}^{-1}\left(\mathrm{LT}^{-1}\right)^{e_{1}}\left(\mathrm{ML}^{-1} \mathrm{~T}^{-2}\right)^{e_{2}}(\mathrm{M})^{e_{3}}=[1] \rightarrow} \\
\left\{\begin{array}{l}
e_{2}+e_{3}=0 \\
e_{1}-e_{2}=0 \\
-1+e_{1}-2 e_{2}=0
\end{array}\right.
\end{gathered}
$$

A solução do sistema gera $e_{1}=-1 / 3, e_{2}=-1 / 3$ e $e_{3}=1 / 3$ e portanto,

$$
\Pi_{4}=\dot{\varepsilon}\left(\frac{G}{\sigma_{\mathrm{d}} V_{0}}\right)^{1 / 3} .
$$

Finalmente, o número adimensional $\Pi_{5}$ é facilmente obtido, pois tem a mesma dimensão de $\sigma_{\mathrm{d}}$,

$$
\Pi_{5}=\frac{\sigma}{\sigma_{\mathrm{d}}}
$$




\section{APÊNDICE B - Equações dinâmicas da estrutura de Calladine}

A equação de movimento da estrutura tem duas fases distintas: a primeira fase é dominada pela compressão das barras. A segunda fase é dominada pelo movimento rígido das barras em torno das rótulas plásticas.

a) Primeira fase

O modelo teórico para esta fase é descrito por Tam; Calladine (1991) e considera que a estrutura é composta por barras deformáveis na direção axial. Este efeito é predominante até que o deslocamento lateral se torne suficientemente grande e então a segunda fase comece a atuar. A Figura 45 representa a estrutura durante essa fase: as partes superior e inferior são simétricas durante o carregamento. Como simplificação, é assumido que a estrutura é rígida até que $\sigma_{\mathrm{d}}$ seja atingido. Uma força constante $S \sigma_{d}$ começa então a atuar, sendo $S$ a área transversal das duas vigas.

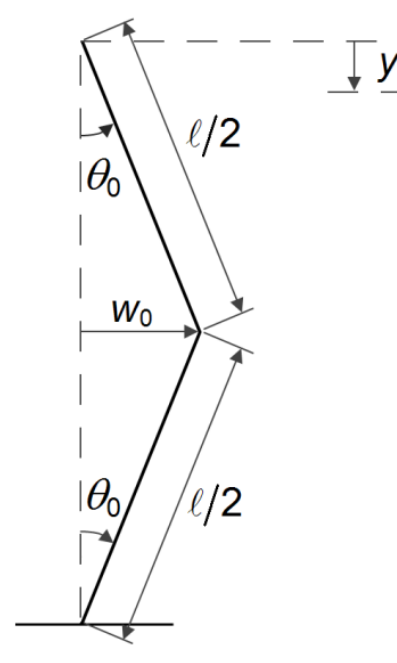

(a)

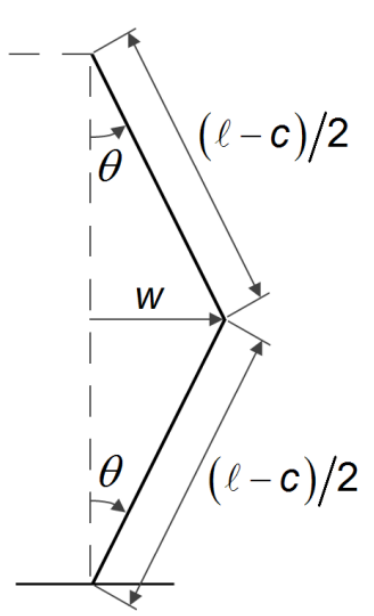

(b)

Figura 45 - Modelo de Calladine na primeira fase de movimento. (a) configuração inicial. (b) configuração deformada.

Pela geometria, as seguinte relação é gerada 


$$
y=\ell \cos \theta_{0}-(\ell-c) \cos \theta \rightarrow y=\ell\left(\cos \theta_{0}-\cos \theta\right)+c \cos \theta
$$

sendo $q$ o encurtamento da barra devido à compressão, y o deslocamento do topo em relação à configuração inicial, $\theta$ o ângulo de rotação e $\ell$ o comprimento total da barra. Assumindo que na primeira fase $\theta$ permanece pequeno, a série de Taylor é aplicada e os valores de ordem maior são descartados, gerando

$$
y=\ell / 2\left(\theta^{2}-\theta_{0}^{2}\right)+c .
$$

Substituindo a relação $w=\theta \ell / 2$, obtida através da geometria, na eq. (114), obtém-se

$$
y=2 / \ell\left(w^{2}-w_{0}^{2}\right)+c
$$

sendo $w_{0}$ e $w$ o deslocamento horizontal no centro da barra na configuração inicial e atual, respectivamente.

Adotando a hipótese de que não há descolamento entre a massa de impacto e as barras, o topo da estrutura terá a mesma velocidade $V$ da massa,

$$
V=\frac{d y}{d t} \rightarrow V=(4 / \ell) w \dot{w}+\dot{c},
$$

sendo que o primeiro termo do lado direito da eq. (116) refere-se ao comportamento da estrutura como corpo rígido enquanto o segundo termo é devido à compressão axial das barras.

A força axial $S \sigma_{\mathrm{d}}$ permanece atuando nas barras e gera uma aceleração lateral nas massas concentradas. O equilíbrio na dobra central das barras é dado por

$$
\begin{gathered}
F_{\mathrm{C}}=4 S \sigma_{\mathrm{d}} \operatorname{sen} \theta=4 S \sigma_{\mathrm{d}} w / \ell \rightarrow \\
(m / 3) \ddot{W}=4 S \sigma_{\mathrm{d}} w / \ell,
\end{gathered}
$$

sendo $m$ a massa das duas barras. Resolvendo a eq. (117) através da transformada de Laplace, $\mathcal{L}$, e as condições iniciais $w(0)=w_{0}$ e $\dot{w}(0)=0$

$$
\begin{gathered}
\mathcal{L}(\ddot{W}-\varsigma W)=\mathcal{L}(0) \rightarrow \\
s^{2} W_{s}-\dot{W}(0)-s W(0)-\varsigma W_{s}=0 \rightarrow \\
s^{2} W_{s}-s W_{0}-\varsigma W_{s}=0,
\end{gathered}
$$


sendo $\varsigma=12 S \sigma_{\mathrm{d}} /(m \ell), s$ a variável equivalente ao tempo no subespaço de transformação e $W_{s}$ a transformada de Laplace de $W$. Portanto,

$$
W_{s}=\frac{s W_{0}}{s^{2}-s}
$$

A transformada inversa da eq. (119) produz a solução da eq. (117) no subespaço do tempo

$$
\begin{aligned}
& \mathcal{L}\left[\frac{s w_{0}}{s^{2}-\varsigma}\right]=w_{0} \cosh (\sqrt{\varsigma} t) \rightarrow \\
& w=w_{0} \cosh \left(\sqrt{\frac{12 S \sigma_{\mathrm{d}} W}{m \ell} t}\right) .
\end{aligned}
$$

Substituindo a eq. (120) na eq. (116) tem-se

$$
V=2\left(\frac{12 \sigma_{\mathrm{d}} S}{\ell m}\right)^{1 / 2} \frac{w_{0}^{2}}{\ell} \operatorname{senh}\left[2\left(\frac{12 \sigma_{\mathrm{d}} S}{\ell m}\right)^{1 / 2} t\right]+\dot{C} .
$$

A tensão de escoamento $\sigma_{\mathrm{d}}$ varia segundo a eq. (18), $\sigma_{\mathrm{d}}=\sigma_{0}\left(\dot{\varepsilon} / \dot{\varepsilon}_{0}\right)^{p}$. Se a taxa de deformação durante esta fase for aproximada por $\dot{\varepsilon}=V_{0} / \ell$, obtém-se

$$
\sigma_{\mathrm{d}}=\sigma_{0}\left(\frac{V_{0}}{\dot{\varepsilon}_{0} \ell}\right)^{p}
$$

Com uma força constante $S \sigma_{\mathrm{d}}$ atuando sobre a massa de impacto, o equilíbrio no corpo de impacto é dado por

$$
G \dot{V}=-S \sigma_{\mathrm{d}} \rightarrow \dot{V}=-S \sigma_{\mathrm{d}} / G
$$

A eq. (123) solucionada com a condição inicial $V(0)=V_{0}$, fornece

$$
V=V_{0}-\left(S \sigma_{\mathrm{d}} / G\right) t
$$

Igualando a eq. (121) a eq. (124) obtém-se a equação de movimento para a primeira fase

$$
V_{0}-\left(S \sigma_{\mathrm{d}} / G\right) t=2\left(\frac{12 \sigma_{\mathrm{d}} S}{\ell m}\right)^{1 / 2} \frac{w_{0}^{2}}{\ell} \operatorname{senh}\left[2\left(\frac{12 \sigma_{\mathrm{d}} S}{\ell m}\right)^{1 / 2} t\right]+\dot{c}
$$


Quando $\dot{c}=0$ não ocorre mais compressão das barras e então inicia-se a segunda fase do fenômeno. Resolvendo a eq. (125) para esta condição, $\tau_{1}$ (instante do final da primeira fase) pode ser obtido numericamente de

$$
V_{0}-\left(S \sigma_{\mathrm{d}} / G\right) \tau_{1}=2\left(\frac{12 \sigma_{\mathrm{d}} S}{\ell m}\right)^{1 / 2} \frac{w_{0}^{2}}{\ell} \operatorname{senh}\left[2\left(\frac{12 \sigma_{\mathrm{d}} S}{\ell m}\right)^{1 / 2} \tau_{1}\right]
$$

Finalmente, o deslocamento e a velocidade horizontais no ponto central das barras no final da primeira fase $\left(t=\tau_{1}\right)$ são dados respectivamente pela eq. (120) e sua derivada

$$
w_{1}=w_{0} \cosh \left[\left(\frac{12 \sigma_{\mathrm{d}} S}{\ell m}\right)^{1 / 2} \tau_{1}\right]
$$

e

$$
\dot{w}_{1}=w_{0}\left(\frac{12 \sigma_{\mathrm{d}} S}{\ell m}\right)^{1 / 2} \operatorname{senh}\left[\left(\frac{12 \sigma_{\mathrm{d}} S}{\ell m}\right)^{1 / 2} \tau_{1}\right]
$$

Como os ângulos ainda são pequenos e desprezando-se o encurtamento sofrido pelas barras devido à compressão, o deslocamento angular pode ser aproximado por

$$
\operatorname{sen} \theta=\frac{w}{\ell / 2} \Rightarrow \theta \approx \frac{2 w}{\ell}
$$

Substituindo a eq. (129) nas eq. (127) e (128), obtém-se $\theta$ e $\dot{\theta}$ do final da primeira fase

$$
\theta_{1}=\frac{2}{\ell} w_{1}=\frac{2}{\ell} w_{0} \cosh \left[\left(\frac{12 \sigma_{\mathrm{d}} S}{\ell m}\right)^{1 / 2} \tau_{1}\right]
$$

e

$$
\dot{\theta}_{1}=\frac{2}{\ell} \dot{w}_{1}=\frac{2}{\ell} w_{0}\left(\frac{12 \sigma_{d} S}{\ell m}\right)^{1 / 2} \operatorname{senh}\left[\left(\frac{12 \sigma_{d} S}{\ell m}\right)^{1 / 2} \tau_{1}\right] .
$$

b) Segunda fase

Essa fase foi formulada por Zhang; Yu (1989) e considera que a estrutura é composta de 4 barras rígidas ligadas através de pinos como mostrado na Figura 11. A energia cinética do sistema para uma coordenada generalizada $\theta$ é dada pela 
soma das energias de translação vertical e horizontal de cada uma das barras e da massa de impacto

$$
E_{\mathrm{t}}=E_{G}+4 E_{\mathrm{x}}+2 E_{\mathrm{y} 1}+2 E_{\mathrm{y} 2}
$$

sendo $E_{G}$ a energia da massa de impacto, $E_{x}$ a energia na direção horizontal nas barras, $E_{\mathrm{y} 1}$ a energia na direção vertical nas duas barras inferiores e $E_{\mathrm{y} 2}$ a energia na direção vertical nas duas barras superiores. Na direção horizontal tem-se

$$
\begin{gathered}
E_{G}=\frac{G\left(\left.V_{\mathrm{y} 2}\right|_{\vartheta=0}\right)^{2}}{2} \rightarrow E_{G}=2 G L^{2} \dot{\theta}^{2} \operatorname{sen}^{2} \theta \\
E_{\mathrm{x}}=\int_{0}^{L} \frac{1}{2} m^{\prime}\left(V_{\mathrm{x}}\right)^{2} d \vartheta=\int_{0}^{L} \frac{1}{2} m^{\prime}(\vartheta \dot{\theta} \cos \theta)^{2} d \vartheta \rightarrow E_{\mathrm{x}}=\frac{m^{\prime}}{6} L^{3} \dot{\theta}^{2} \cos ^{2} \theta, \\
E_{\mathrm{y} 1}=\int_{0}^{L} \frac{1}{2} m^{\prime}\left(V_{\mathrm{y} 1}\right)^{2} d \vartheta=\int_{0}^{L} \frac{1}{2} m^{\prime}(\vartheta \dot{\theta} \operatorname{sen} \theta)^{2} d \vartheta \rightarrow E_{\mathrm{y} 1}=\frac{m^{\prime}}{6} L^{3} \dot{\theta}^{2} \operatorname{sen}^{2} \theta,
\end{gathered}
$$

e

$$
E_{\mathrm{y} 2}=\int_{0}^{L} \frac{1}{2} m^{\prime}\left(V_{\mathrm{y} 2}\right)^{2} d \vartheta=\int_{0}^{L} \frac{1}{2} m^{\prime}((2 L-\vartheta) \dot{\theta} \operatorname{sen} \theta)^{2} d \vartheta \rightarrow E_{\mathrm{y} 2}=\frac{7}{6} m^{\prime} L^{3} \dot{\theta}^{2} \operatorname{sen}^{2} \theta
$$

sendo $V_{x}$ a velocidade na direção horizontal, $V_{y 1}$ e $V_{y 2}$ as velocidades na direção vertical na barra para as barras inferiores e superiores, respectivamente. $m^{\prime}$ é a massa por comprimento da barra e $\vartheta$ a posição na barra em relação ao pólo de rotação, como mostrado na Figura 46. A energia total é obtida inserindo as eq. (133) a (136) na eq. (132)

$$
E_{\mathrm{t}}=\frac{1}{24} m \ell^{2} \dot{\theta}^{2}+\frac{1}{8} m \ell^{2} \operatorname{sen}^{2} \theta \dot{\theta}^{2}+\frac{1}{2} G \ell^{2} \operatorname{sen}^{2} \theta \dot{\theta}^{2}
$$

sendo as relações $m^{\prime}=m /(4 L)$ e $L=\ell / 2$ utilizadas.

Se um deslocamento virtual $\delta \theta$ for dado ao sistema, a soma do trabalho virtual feito pelas forças ativas será

$$
\delta W=-4 M_{1} \delta \theta-4 M_{2} \delta \theta
$$

sendo $M_{1}$ o momento fletor nos vínculos superior e inferior e $M_{2}$ o momento fletor nos vínculos centrais. A força generalizada correspondente à coordenada $\theta$ é dada por 


$$
Q=-4 M_{1}-4 M_{2}
$$

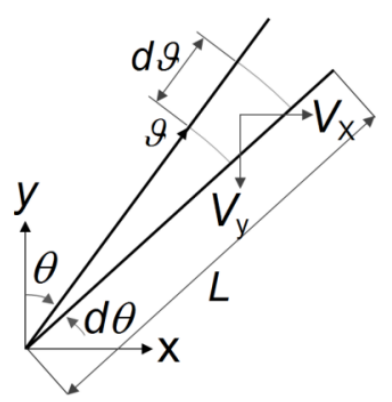

Figura 46 - Representação de parte da estrutura de Calladine.

A equação de Lagrange para o sistema conservativo com um grau de liberdade é dado por

$$
Q=\frac{\partial(\partial K / \partial \dot{\theta})}{\partial t}-\frac{\partial E_{\mathrm{t}}}{\partial \theta}
$$

Segundo a eq. (137)

$$
\frac{\partial E_{t}}{\partial \theta}=\left(\frac{m}{4}+G\right) \ell^{2} \operatorname{sen} \theta \cos \theta \dot{\theta}^{2}
$$

e

$$
\frac{d}{d t}\left(\frac{\partial E_{\mathrm{t}}}{\partial \dot{\theta}}\right)=\frac{1}{3} m \ell^{2} \ddot{\theta}+\left(\frac{m}{4}+G\right) \ell^{2}\left(\operatorname{sen}^{2} \theta \ddot{\theta}+2 \operatorname{sen} \theta \cos \theta \dot{\theta}^{2}\right) .
$$

A substituição das eq. (138), (140) e (141) na eq. (139) gera a equação que rege a segunda fase de movimento para a estrutura de Calladine,

$$
\begin{aligned}
& \frac{1}{3} m \ell^{2} \ddot{\theta}+\ell^{2}\left(\frac{m}{4}+G\right) \operatorname{sen}^{2} \theta \ddot{\theta}+2 \ell^{2}\left(\frac{m}{4}+G\right) \operatorname{sen} \theta \cos \theta \dot{\theta}^{2}-\ell^{2}\left(\frac{m}{4}+G\right) \operatorname{sen} \theta \cos \theta \dot{\theta}^{2} \\
& =-4 M_{1}-4 M_{2} \rightarrow \\
& \qquad \ddot{\theta}+\frac{\ell^{2}(m / 4+G) \operatorname{sen} \theta \cos \theta \dot{\theta}^{2}+4\left(M_{1}+M_{2}\right)}{\ell^{2}\left[m / 3+(m / 4+G) \operatorname{sen}^{2} \theta\right]}=0
\end{aligned}
$$

Os momentos $M_{1}$ e $M_{2}$ já foram calculados e são dados pelas eq. (32) e (33). As condições iniciais para a solução da eq. (142) são dadas pelas eq. (130) e (131). 
O instante final do fenômeno ocorre quando a energia cinética termina, $V=0$ na eq. (124)

$$
\begin{gathered}
V_{0}-\left(S \sigma_{\mathrm{d}} / G\right) \tau_{2}=0 \rightarrow \\
\tau_{2}=\frac{G V_{0}}{S \sigma_{\mathrm{d}}} .
\end{gathered}
$$




\section{APÊNDICE C - Resultados e cálculo dos fatores de transposição do modelo de Calladine com geometria distorcida.}

A Tabela 34 resume os cálculos dos fatores de transposição de escala para o modelo de Calladine com comprimento distorcido.

Tabela 34 - Cálculo dos fatores de transposição do modelo de Calladine com comprimento distorcido.

\begin{tabular}{|c|c|c|c|c|c|c|c|}
\hline \multicolumn{8}{|c|}{$\beta_{\llcorner} / \beta<1$} \\
\hline & $\beta$ & $\beta_{L}$ & $\beta_{L} / \beta$ & $\begin{array}{c}Y=\tau_{2} \\
(\mathrm{~ms})\end{array}$ & $\begin{array}{l}Y=A \\
\left(\mathrm{~m} / \mathrm{s}^{2}\right)\end{array}$ & $\begin{array}{c}Y=\dot{\varepsilon} \\
\left(\mathrm{s}^{-1}\right)\end{array}$ & $\begin{array}{l}Y=\sigma \\
(\mathrm{MPa})\end{array}$ \\
\hline modelo 1 & 0,1 & 0,050 & 0,50 & 0,08352 & 74137,65 & 1407,32 & 604,96 \\
\hline modelo 2 & 0,1 & 0,075 & 0,75 & 0,09232 & 76049,64 & 1958,88 & 620,57 \\
\hline$Y_{1} / Y_{2}$ & & & 0,6667 & 0,9047 & 0,9749 & 0,7184 & 0,9748 \\
\hline \multicolumn{3}{|c|}{$n_{\mathrm{i}}=\log \left(Y_{1} / Y_{2}\right) / \log \left(\beta_{L_{1}} / \beta_{L_{2}}\right)$} & & 0,2472 & 0,0628 & 0,8156 & 0,0628 \\
\hline & \multicolumn{2}{|c|}{$f_{2}=\left(\beta_{L} / \beta\right)^{n_{1}}$} & & 0,8425 & 0,9574 & 0,5682 & 0,9574 \\
\hline \multirow[t]{2}{*}{ modelo 1} & $f_{1}$ & & & 0,0912 & 12,0249 & 10,9658 & 1,2025 \\
\hline & $f_{1} f_{2}$ & & & 0,0768 & 11,5127 & 6,2306 & 1,1513 \\
\hline \multicolumn{8}{|c|}{$\beta_{L} / \beta>1$} \\
\hline & $\beta$ & $\beta_{L}$ & $\beta_{\llcorner} / \beta$ & $\tau_{2}(\mathrm{~ms})$ & $A\left(\mathrm{~m} / \mathrm{s}^{2}\right)$ & $\dot{\varepsilon}\left(\mathrm{s}^{-1}\right)$ & $\sigma(\mathrm{MPa})$ \\
\hline modelo 1 & 0,1 & 0,20 & 2,0 & 0,1424 & 75194,73 & 1691,39 & 613,59 \\
\hline modelo 2 & 0,1 & 0,15 & 1,5 & 0,1232 & 75722,33 & 1852,17 & 617,89 \\
\hline \multicolumn{3}{|c|}{ modelo 1 / modelo 2} & 1,3333 & 1,1558 & 0,9930 & 0,9132 & 0,9930 \\
\hline \multicolumn{3}{|c|}{$n_{\mathrm{i}}=\log \left(L_{\mathrm{m} 1} / L_{\mathrm{m} 2}\right) / \log \left(\beta_{\llcorner\mathrm{m} 1} / \beta_{\llcorner\mathrm{m} 2}\right)$} & & 0,5043 & $-0,0243$ & $-0,3156$ & $-0,0243$ \\
\hline \multicolumn{3}{|c|}{$f_{2}=\left(\beta_{L} / \beta\right)^{n_{1}}$} & & 1,4184 & 0,9833 & 0,8035 & 0,9833 \\
\hline \multirow[t]{2}{*}{ modelo 1} & $f_{1}$ & & & 0,0912 & 12,0249 & 10,9658 & 1,2025 \\
\hline & $f_{1} f_{2}$ & & & 0,1294 & 11,8241 & 8,8110 & 1,1824 \\
\hline
\end{tabular}


A Tabela 35 resume os cálculos dos fatores de transposição de escala para o modelo de Calladine com espessura distorcida.

Tabela 35 - Cálculo dos fatores de transposição do modelo de Calladine com espessura distorcida.

\begin{tabular}{|c|c|c|c|c|c|c|c|}
\hline \multicolumn{8}{|c|}{$\beta_{H} / \beta<1$} \\
\hline & $\beta$ & $\beta_{H}$ & $\beta_{H} / \beta$ & $\begin{array}{c}Y=\tau_{2} \\
(\mathrm{~ms})\end{array}$ & $\begin{array}{l}Y=A \\
\left(\mathrm{~m} / \mathrm{s}^{2}\right)\end{array}$ & $\begin{array}{c}Y=\dot{\varepsilon} \\
\left(s^{-1}\right)\end{array}$ & $\begin{array}{l}Y=\sigma \\
(\mathrm{MPa})\end{array}$ \\
\hline modelo 1 & 0,1 & 0,050 & 0,50 & 0,1318 & 37629,80 & 1710,44 & 614,12 \\
\hline modelo 2 & 0,1 & 0,075 & 0,75 & 0,1124 & 56978,69 & 1932,93 & 619,93 \\
\hline \multicolumn{3}{|l|}{$Y_{1} / Y_{2}$} & 0,6667 & 1,1726 & 0,6604 & 0,8849 & 0,9906 \\
\hline \multicolumn{3}{|c|}{$n_{\mathrm{i}}=\log \left(Y_{1} / Y_{2}\right) / \log \left(\beta_{H_{1}} / \beta_{H_{2}}\right)$} & & $-0,3932$ & 1,0232 & 0,3016 & 0,0232 \\
\hline & \multicolumn{2}{|c|}{$f_{2}=\left(\beta_{H} / \beta\right)^{n_{i}}$} & & 1,3133 & 0,4920 & 0,8114 & 0,9840 \\
\hline \multirow[t]{2}{*}{ modelo 1} & $f_{1}$ & & & 0,0912 & 12,0249 & 10,9658 & 1,2025 \\
\hline & $f_{1} f_{2}$ & & & 0,1198 & 5,9165 & 8,8972 & 1,1833 \\
\hline \multicolumn{8}{|c|}{$\beta_{H} / \beta>1$} \\
\hline & $\beta$ & $\beta_{H}$ & $\beta_{H} / \beta$ & $\tau_{2}(\mathrm{~ms})$ & $A\left(\mathrm{~m} / \mathrm{s}^{2}\right)$ & $\dot{\varepsilon}\left(\mathrm{s}^{-1}\right)$ & $\sigma(\mathrm{MPa})$ \\
\hline modelo 1 & 0,1 & 0,150 & 1,50 & 0,0901 & $1,1410 \mathrm{E} 5$ & 1964,77 & 620,71 \\
\hline modelo 2 & 0,1 & 0,125 & 1,25 & 0,0945 & 95351 & 2037,50 & 622,45 \\
\hline \multicolumn{3}{|c|}{ modelo 1 / modelo 2} & 1,20 & 0,9534 & 1,1966 & 0,9643 & 0,9972 \\
\hline \multicolumn{3}{|c|}{$n_{\mathrm{i}}=\log \left(H_{\mathrm{m} 1} / H_{\mathrm{m} 2}\right) / \log \left(\beta_{H \mathrm{~m} 1} / \beta_{H \mathrm{~m} 2}\right)$} & & $-0,2646$ & 0,9846 & $-0,1994$ & $-0,0154$ \\
\hline \multicolumn{3}{|c|}{$f_{2}=\left(\beta_{H} / \beta\right)^{n_{1}}$} & & 0,8983 & 1,4907 & 0,9224 & 0,9938 \\
\hline \multirow[t]{2}{*}{ modelo 1} & $f_{1}$ & & & 0,0912 & 12,0249 & 10,9658 & 1,2025 \\
\hline & $f_{1} f_{2}$ & & & 0,0819 & 17,9255 & 10,1143 & 1,1950 \\
\hline
\end{tabular}


A Tabela 36 resume os resultados do modelo de Calladine com comprimento distorcido após a aplicação dos fatores de transposição de escala calculados na Tabela 34.

Tabela 36 - Resultados da estrutura de Calladine: comparação do protótipo com o modelo com comprimento distorcido. Valores calculados no final do impacto.

\begin{tabular}{lcccccc}
\hline & $\beta$ & $\beta_{B}$ & $\tau_{2}(\mathrm{~ms})$ & $A\left(\mathrm{~m} / \mathrm{s}^{2}\right)$ & $\dot{\varepsilon}\left(\mathrm{s}^{-1}\right)$ & $\begin{array}{c}\sigma \\
(\mathrm{MPa})\end{array}$ \\
\hline $\begin{array}{l}\beta_{L} / \beta<1 \\
\text { protótipo }\end{array}$ & 1 & 1 & 1,1041 & 6340,26 & 184,57 & 517,37 \\
modelo corrigido & 0,10 & 0,05 & 1,0870 & 6439,60 & 225,87 & 525,47 \\
modelo não corrigido & 0,10 & 0,05 & 0,9238 & 7577,30 & 186,85 & 618,31 \\
\hline$\beta_{L} / \beta>1$ & & & & & & \\
protótipo & 1 & 1 & 1,1041 & 6340,26 & 184,57 & 517,37 \\
modelo corrigido & 0,10 & 0,20 & 1,1007 & 6359,50 & 191,96 & 518,93 \\
modelo não corrigido & 0,10 & 0,20 & 0,9403 & 7444,60 & 148,53 & 607,48 \\
\hline
\end{tabular}

A Tabela 37 resume os resultados do modelo de Calladine com espessura distorcida após a aplicação dos fatores de transposição de escala calculados na Tabela 35.

Tabela 37 - Resultados da estrutura de Calladine: comparação do protótipo com o modelo com espessura distorcida. Valores calculados no final do impacto.

\begin{tabular}{lcccccc}
\hline & $\beta$ & $\beta_{B}$ & $\tau_{2}(\mathrm{~ms})$ & $A\left(\mathrm{~m} / \mathrm{s}^{2}\right)$ & $\dot{\varepsilon}\left(\mathrm{s}^{-1}\right)$ & $\begin{array}{c}\sigma \\
(\mathrm{MPa})\end{array}$ \\
\hline$\beta_{H} / \beta<1$ & & & & & & \\
protótipo & 1 & 1 & 1,1041 & 6340,26 & 184,57 & 517,37 \\
modelo corrigido & 0,10 & 0,05 & 1,1001 & 6360,18 & 192,24 & 518,99 \\
modelo não corrigido & 0,10 & 0,05 & 1,8487 & 3786,51 & 185,47 & 617,96 \\
\hline$\beta_{H} / \beta>1$ & & & & & & \\
protótipo & 1 & 1 & 1,1041 & 6340,26 & 184,57 & 517,37 \\
modelo corrigido & 0,10 & 0,15 & 1,100 & 6365,28 & 194,26 & 519,41 \\
modelo não corrigido & 0,10 & 0,15 & 0,6554 & 10681,00 & 83,35 & 581,05 \\
\hline
\end{tabular}

